PABLO ANDRÉS SILVA ORTIZ

HIERARQUIZAÇÃO EXERGÉTICA E AMBIENTAL DE ROTAS DE PRODUÇÃO DE BIOETANOL 
PABLO ANDRÉS SILVA ORTIZ

HIERARQUIZAÇÃO EXERGÉTICA E AMBIENTAL DE ROTAS DE PRODUÇÃO DE BIOETANOL

Tese apresentada à Escola Politécnica da Universidade de São Paulo para obtenção do título de Doutor em Ciências. 
PABLO ANDRÉS SILVA ORTIZ

\section{HIERARQUIZAÇÃO EXERGÉTICA E AMBIENTAL DE ROTAS DE PRODUÇÃO DE BIOETANOL}

Tese apresentada à Escola Politécnica da Universidade de São Paulo para obtenção do título de Doutor em Ciências.

Área de Concentração:

Engenharia Mecânica de Energia e Fluidos

Orientador:

Prof. Dr. Silvio de Oliveira Júnior.

São Paulo

2016 
Este exemplar foi revisado e corrigido em relação à versão original, sob responsabilidade única do autor e com a anuência de seu orientador.

São Paulo, 1 de

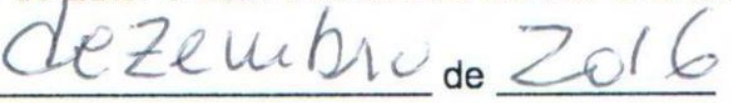

Assinatura do autor:

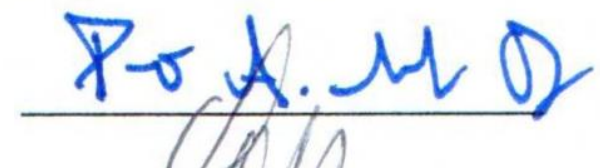

Assinatura do orientador:

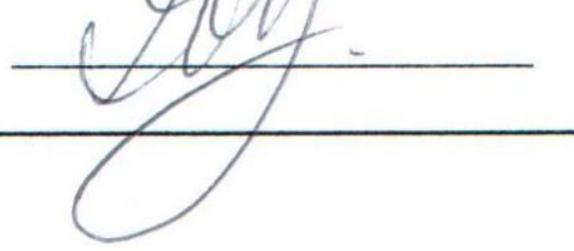

Catalogação-na-publicação

Silva Ortiz, Pablo Andrés

Hierarquização Exergética e Ambiental de Rotas de Produção de Bioetanol I P. A. Silva Ortiz, S. de Oliveira Júnior -- versão corr. -- São Paulo, 2016. 206 p.

Tese (Doutorado) - Escola Politécnica da Universidade de São Paulo. Departamento de Engenharia Mecânica.

1.Análise Exergética 2.Análise Exergo-Ambiental 3.Biorrefinarias 4.Biomassa Lignocelulósica 5.Exergia I.Universidade de São Paulo. Escola Politécnica. Departamento de Engenharia Mecânica II.t. III.de Oliveira Júnior, Silvio 


\section{AGRADECIMENTOS}

Ao Prof. Dr. Silvio de Oliveira Júnior, pela confiança depositada em mim para desenvolvimento desta pesquisa. Pela orientação e conselhos que fizeram com que este trabalho se concretizasse. Agradeço a paciência, a solidariedade, o comprometimento e abertura para expor minhas ideias ao longo dos anos.

À minha família e a minha namorada, pelo apoio incondicional, compreensão e carinho. Sendo sempre um porto seguro nos momentos de incerteza. Essa conquista também é de vocês!

Aos amigos e companheiros do Laboratório de Engenharia Térmica e Ambiental - LETE, com os quais eu tive o prazer de conviver e ainda ter a oportunidade de debater tópicos enfocados à Exergia. Aos professores e funcionários do Programa de Pós-Graduação em Engenharia Mecânica da Escola Politécnica da Universidade de São Paulo. Aos colegas e amigos com os quais compartilhei uma moradia em São Paulo. Muito obrigado de coração a todos.

Ao Prof. Dr. François Maréchal pela oportunidade e a equipe do IPESE-EPFL pelo apoio durante meu estágio no exterior. À família Gómez por ter-me recebido na sua residência durante minha permanência na Suíça.

Agradeço aos membros da banca examinadora, pela disponibilidade de participar e pelas valiosas contribuições.

À Coordenação de Aperfeiçoamento de Pessoal de Nível Superior (CAPES) pelo apoio financeiro durante os primeiros meses de meus estudos (Processo 159498/2011-2).

À Fundação de Amparo à Pesquisa do Estado de São Paulo (FAPESP) pelo apoio financeiro na forma de bolsa de doutorado, Bolsa no país (Processo 2012/23049-2) e Bolsa Estágio de Pesquisa no Exterior (Processo 2014/26286-0). 


\section{RESUMO}

$\mathrm{Na}$ atualidade, a geração de eletricidade e a produção de etanol de segunda geração a partir de materiais lignocelulósicos se apresentam como uma alternativa de desenvolvimento tecnológico no setor sucroenergético. Não obstante, a introdução de novos processos produtivos representa um verdadeiro desafio devido à complexidade e diversidade das rotas tecnológicas alternativas que podem ser avaliadas. Além disso, existem fatores econômicos e ambientais, que devem ser considerados durante o desenvolvimento e consolidação destas novas configurações. Nesse sentido, o presente trabalho tem como objetivo desenvolver uma metodologia para realizar a hierarquização exergética e exergo-ambiental de processos para obtenção de etanol e eletricidade a partir da cana-de-açúcar em distintas configurações de biorrefinarias. Para este fim, dados técnicos de operação foram adotados nas rotas tecnológicas envolvidas, bem como os aspectos ambientais da utilização destes sistemas. Os modelos propostos avaliaram as rotas Convencional (Caso 1), Bioquímica (Caso 2) e Termoquímica (Caso 3), utilizando programas de simulação e ferramentas matemáticas para simular estes processos. Ainda, a integração dos processos e diferentes usos para o bagaço excedente foram estudados, junto com diversos métodos de pré-tratamento visando à otimização e hierarquização destas rotas. O resultado final indicou configurações ótimas que permitiram a hierarquização em termos do índice exergético de renovabilidade dos processos de produção das rotas analisadas. Desse modo a rota convencional otimizada apresentou a máxima eficiência exergética dos processos e, por tanto, o menor custo exergético unitário médio das plataformas avaliadas. Ao passo que a rota bioquímica foi o sistema que promoveu um incremento de $28,58 \%$ e $82,87 \%$ na produção de etanol, quando comparado com o Caso 1 e o Caso 3, respectivamente. Além disso, a rota termoquímica apresentou a configuração com a maior taxa de geração de eletricidade excedente $(214,98 \mathrm{kWh} / \mathrm{TC})$. Em relação aos resultados do impacto ambiental das rotas tecnológicas, encontrou-se que a configuração mais sustentável foi a plataforma bioquímica, apresentando as menores taxas de emissões globais de $\mathrm{CO}_{2}\left(131,45 \mathrm{gCO}_{2} / \mathrm{MJ}\right.$ produtos).

Palavras-chave: Análise Exergética, Análise Exergo-Ambiental, Biorrefinarias, Bioetanol, Conversão da Biomassa Lignocelulósica, Exergia. 


\begin{abstract}
Currently, electricity generation and second-generation bioethanol production from lignocellulosic materials represent technological alternatives in the sugar-energy sector. Nevertheless, the introduction of new production processes represents a real challenge due to the complexity and diversity of the technological routes that can be evaluated. In addition, there are economic and environmental factors that must be considered during the development and consolidation of these new configurations. Accordingly, this project aims to develop a methodology to perform the exergy and exergo-environmental analysis, evaluation and ranking of processes in order to obtain ethanol and electricity from sugarcane in different biorefinery configurations. Hence, operating technical data of each technological route were adopted as well as the environmental aspects of using these systems. The proposed models assessed the Conventional (Case 1), Biochemical (Case 2) and Thermochemical (Case 3) routes using simulation programs and mathematical tools to simulate the ethanol production and electricity generation. Furthermore, the process integration and different uses for the excess bagasse were studied with various pretreatment methods aiming the optimizing and ranking of routes. The results indicated optimal settings that allowed the ranking in terms of the environmental exergy indicator "renewability" of the production processes for analyzed routes. In this way, the optimized conventional route presented the maximum exergy efficiency of the processes, therefore the lowest exergetic cost average of the evaluated platforms. While the biochemical route was the system that promoted an increase of $28.58 \%$ and $82.87 \%$ in the ethanol production, when compared to Case 1 and Case 3, respectively. In addition, the thermochemical route presented the configuration with the highest power generation rate exceeding $(214.98 \mathrm{kWh} / \mathrm{TC})$. Concerning, the environmental impact results, it was found that the most sustainable configuration was the biochemical platform, which presented the lowest overall $\mathrm{CO}_{2}$ emissions rates (131.45 $\mathrm{gCO}_{2} / \mathrm{MJ}$ products).
\end{abstract}

Keywords: Exergy Analysis, Exergo-Environmental Analysis, Biorefineries, Bioethanol, Lignocellulosic Biomass Conversion, Exergy. 


\section{LISTA DE ILUSTRAÇÕES}

Figura 1.1 - Comparativo de produção de etanol entre Brasil e USA. ......................................2

Figura 1.2 - Barreiras econômicas e tecnológicas na produção dos biocombustíveis................ 4

Figura 1.3 - Distribuição dos custos na produção do etanol.....................................................

Figura 1.4 - Rotas tecnológicas consideradas para produção de bioetanol e eletricidade........ 10

Figura 2.1 - Rendimento teórico da produção de etanol a partir da palha. .............................. 17

Figura 2.2 - Síntese das rotas tecnológicas para produção de bioenergia. …............................ 18

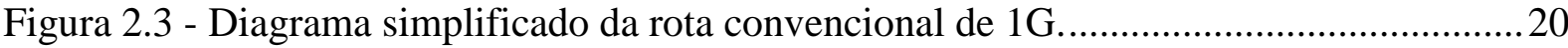

Figura 2.4 - Esquema simplificado das colunas de destilação...............................................25

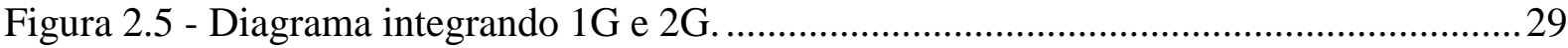

Figura 2.6 - Processos de produção de etanol a partir do bagaço da cana-de-açúcar................30

Figura 2.7 - Processo de pré-tratamento da biomassa............................................................ 31

Figura 2.8 - Categorização dos tipos de pré-tratamento da biomassa. .................................... 31

Figura 2.9 - Rotas de hidrólise e fermentação. .................................................................. 38

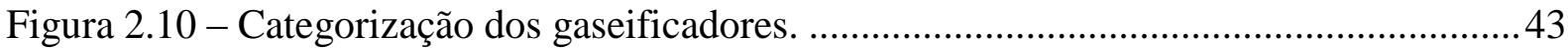

Figura 2.11 - Potência térmica por tipo de gaseificador. ….................................................... 44

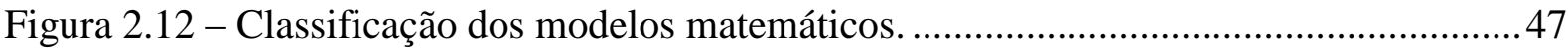

Figura 2.13 - Classificação dos métodos e catalisadores para limpeza do gás de síntese. ......49

Figura 2.14 - Efeito de conversão de Fischer-Tropsch na eficiência exergética global..........53

Figura 2.15 - Efeito da temperatura de gaseificação na eficiência exergética global..............53

Figura 2.16 - Efeito da temperatura de gaseificação na composição do gás de síntese............54

Figura 2.17 - Composição do gás em função à temperatura de operação................................55

Figura 2.18 - Comparação entre PCI e eficiência a frio do gás para madeira de pinho. .........56

Figura 2.19 - Índices de desempenho do processo de gaseificação do bagaço da cana. ..........56

Figura 2.20 - Parâmetros de operação do sistema BIGCC. ….................................................57

Figura 2.21 - Efeito da temperatura na eficiência de gaseificação do bagaço da cana.............58

Figura 2.22 - Efeito da razão de equivalência na eficiência de conversão de carbono.............58

Figura 2.23 - Distribuição da exergia para diversas matérias-primas.....................................59

Figura 2.24 - Comparação das matérias-primas em função da eficiência da gaseificação......59

Figura 2.25 - Efeitos da pressão de gaseificação e a vazão SB em termos do PCS e a eficiência exergética.

Figura 2.26 - Distribuição da exergia da gaseificação para diversas matérias-primas. 
Figura 2.27 - Eficiência global do sistema em função do teor de umidade. 61

Figura 3.1 - Representação esquemática para obtenção da exergia química padrão. 67

Figura 3.2 - Curvas compostas na análise Pinch. 70

Figura 3.3 - Eficiência exergética dos processos de produção de biocombustíveis. 73

Figura 3.4 - Custo em base exergética do açúcar e do álcool, em diversas configurações tecnológicas. 74

Figura 3.5 - Custo em base exergética da energia elétrica em decorrência da geração de eletricidade excedente 74

Figura 3.6 - Índice exergético de renovabilidade da usina em função do sistema de cogeração.

Figura 3.7 - Relação entre a eficiência exergética dos processos e o índice $\lambda$. 79

Figura 4.1 - Metodologia adotada para otimização das configurações. 83

Figura 4.2 - Configurações avaliadas. .86

Figura 4.3 - Esquema de simulação da rota convencional de $1 \mathrm{G}$. .92

Figura 4.4 - Esquema da unidade de preparo e extração. .93

Figura 4.5 - Sistema de evaporação - concentração do caldo.

Figura 4.6 - Sistema de cogeração com turbina de contrapressão. 98

Figura 4.7 - Sistema de cogeração com turbinas de contrapressão e condensação.

Figura 4.8 - Sistema de cogeração com turbina de extração-condensação.

Figura 4.9 - Metodologia de cálculo na estimativa dos processos de pré-tratamento. 103

Figura 4.10 - Esquema de simulação da rota tecnológica bioquímica de etanol 2G.

Figura 4.11 - Esquema de simulação da rota tecnológica 3. 106

Figura 4.12 - Esquema de um gaseificador de leito fluidizado circulante. 107

Figura 4.13 - Regressões lineares em função da composição da biomassa no gaseificador de leito arrastado. 109

Figura 4.14 - Esquema de um gaseificador de leito arrastado-EF.

Figura 4.15 - Condensados do sistema de evaporação do caldo.

Figura 4.16 - Condensados do sistema concetração do hidrolisado.

Figura 5.1 - Esquema geral considerado na análise exergética da Rota 1.

Figura 5.2 - Eficiência exergética por etapa da Rota 1.

Figura 5.3 - Irreversibilidades dos processos envolvidos na Rota 1

Figura 5.4 - Esquema geral do pré-tratamento de explosão a vapor-SE.

Figura 5.5 - Esquema geral do pré-tratamento Organosolv-ORG.

Figura 5.6 - Esquema geral do pré-tratamento de água quente pressurizada-LHW. 
Figura 5.7 - Esquema geral combinando pré-tratamentos de SE e LHW

Figura 5.8 - Porcentagem da exergia destruída nos processos de pré-tratamento.

Figura 5.9 - Esquema geral considerado na análise exergética da Rota 2.

Figura 5.10 - Eficiência exergética da Rota 2.

Figura 5.11 - Taxa de irreversibilidade da Rota 2. 141

Figura 5.12 - Esquema geral da simulação para a rota tecnológica de $2 \mathrm{G}$ termoquímica..... 142

Figura 5.13 - Preparo da mistura bagaço e palha da cana-CFB. 143

Figura 5.14 - Esquema geral do ciclo combinado. 144

Figura 5.15 - Esquema geral do sistema de limpeza do gás de síntese. 145

Figura 5.16 - Composição do syngas em termos da temperatura de operação-CBF. 146

Figura 5.17 - Composição do syngas em função da razão de equivalência -CFB 147

Figura 5.18 - Composição do syngas no gaseificador EF-Bagaço. 148

Figura 5.19 - Composição do syngas no gaseificador EF-Mistura. 149

Figura 5.20 - Eficiência exergética do gaseificador EF-Bagaço 150

Figura 5.21 - Irreversibilidades do processo de gaseificação EF-Bagaço. 151

Figura 5.22 - Eficiência exergética do gaseificador EF-Palha. 151

Figura 5.23 - Irreversibilidades do processo de gaseificação EF-Palha. 152

Figura 6.1 - MER - Rota 1. 156

Figura 6.2 - MER - Rota 2. 157

Figura 6.3 - MER - Rota 3. 158

Figura 6.4 - Análise global das rotas tecnológicas. 160

Figura 6.5 - Índice de renovabilidade das rotas. 162

Figura 6.6 - Comparação entre o índice 1 e a eficiência exergética global. 164

Figura 6.7 - Comparação entre o índice 2 e a eficiência exergética global. 165

Figura 6.8 - Indicadores de impacto ambiental. 167

Figura A.1 - MER - Explosão a vapor (SE). 189

Figura A.2 - MER - LHW. 190

Figura A.3 - MER - Pré-tratamento combinado entre SE e LHW. 191

Figura D.1 - Otimização multi-objetivo da rota 3-gaseificador CFB 201

Figura D.2 - Otimização multi-objetivo da rota 3-gaseificador EF. 202 


\section{LISTA DE TABELAS}

Tabela 1.1 - Produção anual de etanol no mundo.

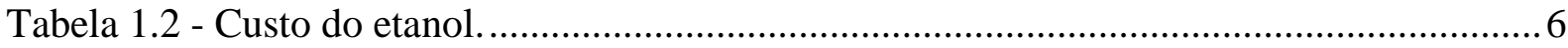

Tabela 1.3 - Cenários de produção de etanol........................................................................... 7

Tabela 1.4 - Resultados de casos de estudo para produção de eletricidade e/ou etanol 2G. .....8

Tabela 2.1 - Composição média da cana-de-açúcar. ................................................................ 13

Tabela 2.2 - Composição de diversos materiais lignocelulósicos. ............................................ 14

Tabela 2.3 - Composição típica do bagaço da cana.................................................................. 16

Tabela 2.4 - Tecnologias de cogeração estudadas no setor sucroalcooleiro. …........................2 27

Tabela 2.5 - Comparação dos processos de pré-tratamento da biomassa................................. 35

Tabela 2.6 - Vantagens e desvantagens dos métodos de pré-tratamento.................................. 36

Tabela 2.7 - Parâmetros de funcionamento dos principais tipos de gaseificadores................. 43

Tabela 3.1 - Valores típicos de $\varphi$ ou $\beta$ para alguns combustíveis industriais e substâncias

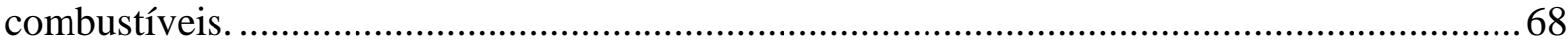

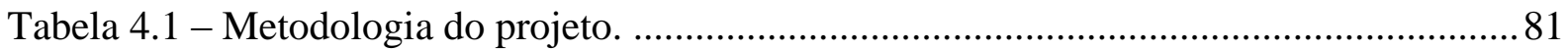

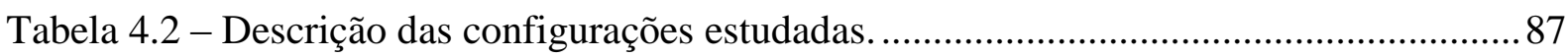

Tabela 4.3- Composição e exergia química padrão dos componentes utilizados na simulação.

Tabela 4.4 - Composição da cana-de-açúcar..........................................................................91

Tabela 4.5 - Parâmetros adotados na simulação da unidade de preparo e extração................. 93

Tabela 4.6 - Características técnicas selecionas nas operações de tratamento, concentração do

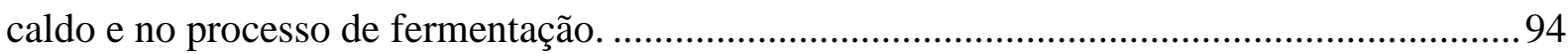

Tabela 4.7 -Condições operacionais aplicadas ao sistema de evaporação............................. 95

Tabela 4.8 - Reações consideradas no processo fermentativo................................................ 97

Tabela 4.9 - Principais parâmetros adotados no processo de cogeração. .................................99

Tabela 4.10 - Reações de combustão na fornalha da caldeira. ............................................. 100

Tabela 4.11 - Parâmetros considerados na simulação da unidade de destilação.................... 102

Tabela 4.12 - Características de operação selecionadas na etapa da desidratação via MEG. 103

Tabela 4.13 - Reações gerais do processo de gaseificação................................................... 107

Tabela 4.14 - Composição da biomassa avaliada no gaseificador EF................................. 109

Tabela 4.15 - Fluxos adotados na integração térmica - ROTA 1 ........................................ 113

Tabela 4.16 - Fluxos considerados na integração térmica - ROTA 2 ................................. 113 
Tabela 4.17 - Fluxos selecionados na integração térmica - ROTA 3 .................................. 114

Tabela 4.18 - Variáveis de dimensionamento dos equipamentos. ......................................117

Tabela 5.1 - Resultados da análise global da Rota 1 ......................................................... 124

Tabela 5.2 - Reações e taxas de conversão no método de explosão a vapor..........................129

Tabela 5.3 - Parâmetros do pré-tratamento de explosão a vapor-SE................................... 130

Tabela 5.4 - Parâmetros do pré-tratamento Organosolv-ORG. ............................................ 131

Tabela 5.5 - Parâmetros do pré-tratamento de água quente pressurizada-LHW ................... 132

Tabela 5.6 - Parâmetros do pré-tratamento combinado - SE e LHW...................................133

Tabela 5.7 - Comparação do rendimento nos processos de pré-tratamento simulados. .........134

Tabela 5.8 - Principais parâmetros na simulação dos processos de produção de etanol 2G. 136

Tabela 5.9 - Resultados da análise global da Rota 2 ...................................................... 138

Tabela 5.10 - Composição do gás sintético no processo CFB-Bagaço.................................. 147

Tabela 5.11 - Composição do gás sintético no processo CFB-Mistura................................ 148

Tabela 5.12 - Composição do gás sintético no processo EF-Bagaço. ......................................149

Tabela 5.13 - Composição do gás sintético no processo EF-Mistura...................................... 150

Tabela 5.14 - Análise do ciclo combinado operando com syngas-Processo CFB................. 152

Tabela 5.15 -Análise do ciclo combinado operando com syngas-Processo EF..................... 153

Tabela 5.16 -Resultados da análise exergética da Rota 3 ................................................. 154

Tabela 6.1 - Parcelas da exergia associada ao índice de renovabilidade............................... 163

Tabela 6.2 - Resultados de otimização das rotas tecnológicas avaliadas. ............................... 166

Tabela 6.3 - Resultados da hierarquização das rotas tecnológicas. ......................................... 168

Tabela A.1 - Parâmetros MER - Explosão a vapor (SE)..................................................... 190

Tabela A.2 - Parâmetros MER - Água quente pressurizada (LHW) .................................... 190

Tabela A.3 - Parâmetros MER - Pré-tratamento combinado entre SE e LHW....................... 192

Tabela B.1 - Parâmetros MER - Rota 1.............................................................................. 193

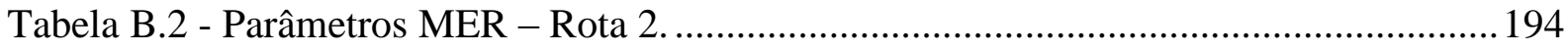

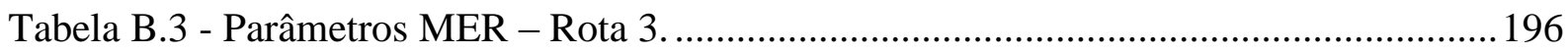

Tabela C.1 - Entradas e saídas do gaseificador EF - Bagaço da cana. .................................... 198

Tabela C.2 - Entradas e saídas do gaseificador EF - Palha da cana.....................................199

Tabela C.1 -Parâmetros de análise adotados na avaliação da Rota 2G-Termoquímica.........200

Tabela C.2 -Principais parâmetros utilizados na determinação dos custos de investimento. 201 


\section{LISTA DE ABREVIATURAS E SIGLAS}

$1 \mathrm{G}$

$2 \mathrm{G}$

BIG

BIGCC

BTL

CAPEX

$\mathrm{CFB}$

$\mathrm{EF}$

ER

F-T

IP

IEA

LHW

MILP

NREL

SE

SHF

$\mathrm{SSF}$

SSCF

ORG

OPEX

PIB

UNICA

TR

VC

${ }^{\circ} \mathrm{GL}$

$\mathrm{p} / \mathrm{p}$

$\mathrm{p} / \mathrm{v}$
Primeira Geração

Segunda Geração

Gaseificação de Biomassa Integrada

Ciclo Combinado com Gaseificação Integrada de Biomassa

Biomassa-para-Líquidos

Despesas de capital

Gaseificador de Leito Fluidizado Circulante

Leito Arrastado

Razão de Equivalência

Fischer-Tropsch

Integração de Processos

Agência Internacional de Energia

Água Quente Pressurizada e/ou Pré-Tratamento Hidrotérmico

Programação Linear Inteira Mista

Laboratório Nacional de Energias Renováveis dos Estados Unidos

Explosão a Vapor

Hidrólise e Fermentação Separadas

Sacarificação e Fermentação Simultâneas

Sacarificação e Cofermentação Simultâneas

Organosolv

Custo Operacional

Produto Interno Bruto

União da Indústria de Cana-de-Açúcar

Tempo de Residência

Volume de Controle

Teor alcoólico em volume a $15^{\circ} \mathrm{C}$

Porcentagem em Peso

Porcentagem Peso por Volume 


\section{LISTA DE SÍMBOLOS}

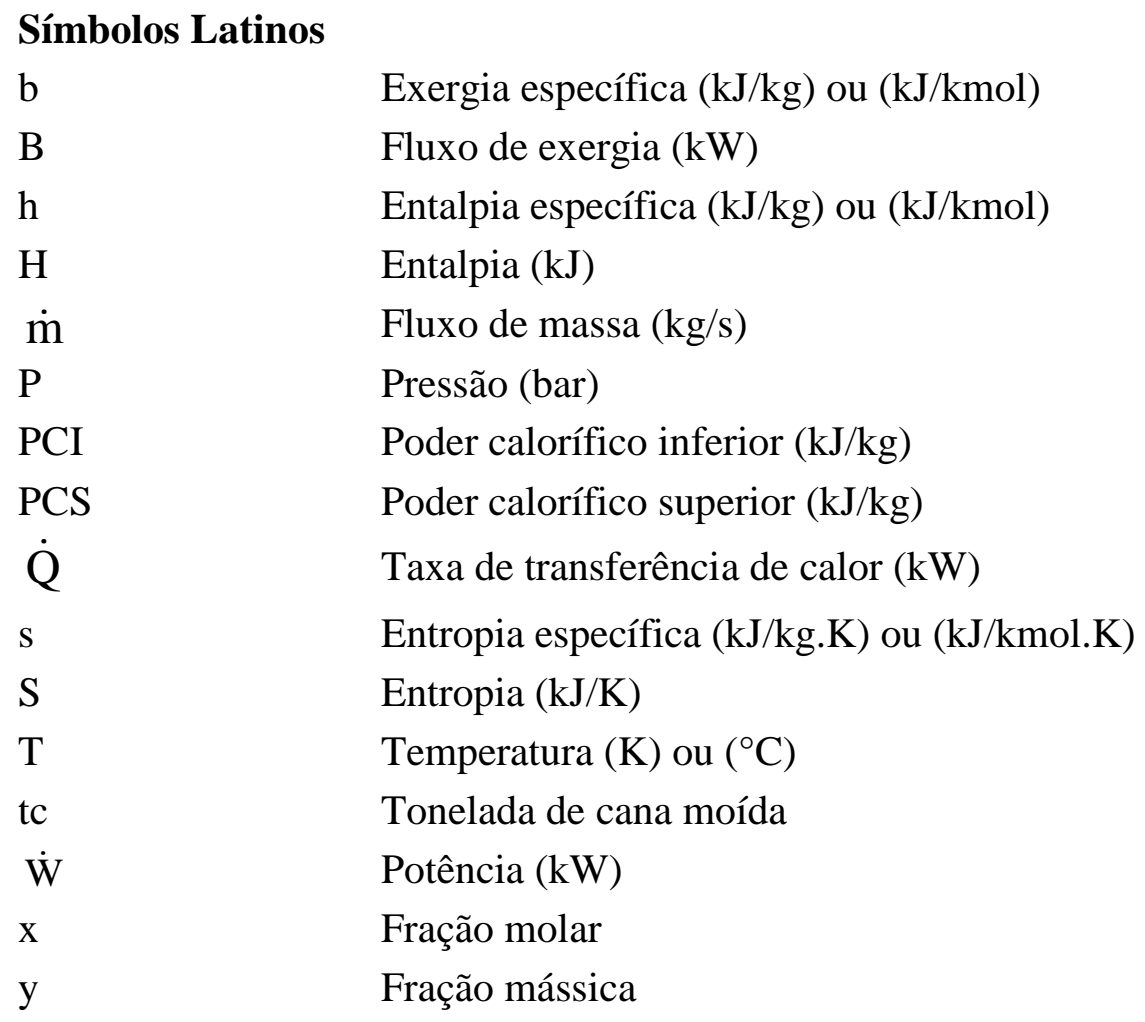

Símbolos Gregos

$\rho$

$\eta$

$\varphi$

$\Delta$

$\lambda$

\section{Subscritos}

0

comb

$\mathrm{e}$

en

ex

$\mathrm{t}$
Densidade específica $\left(\mathrm{kg} / \mathrm{m}^{3}\right)$

Eficiência / Rendimento

Coeficiente para cálculo da exergia química

Variação

Índice exergético de renovabilidade

\section{Referência}

Combustível

Entrada, energia, eletricidade, elétrico

Energético

Exergético

Térmico 


\section{SUMÁRIO}

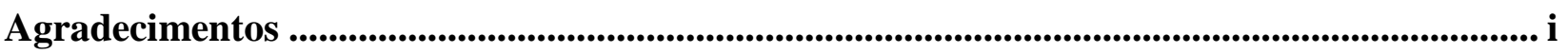

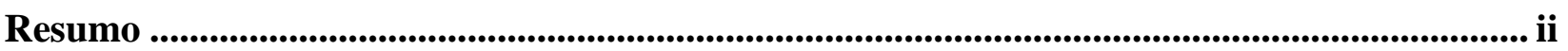

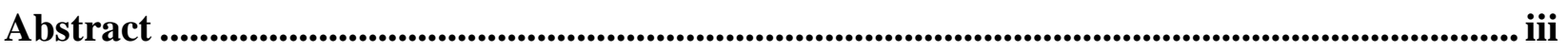

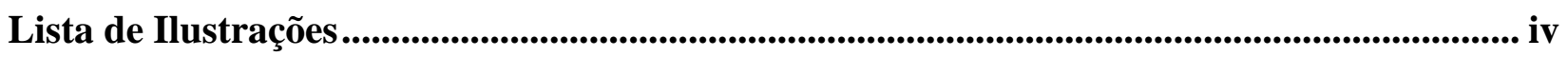

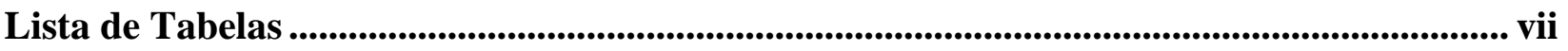

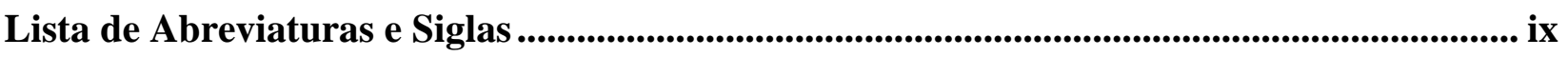

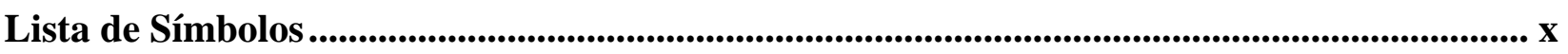

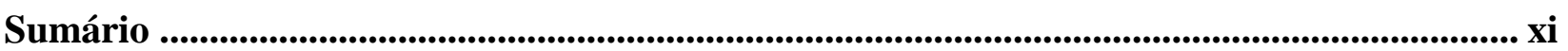

1. INTRODUÇÃ

1.1. O POTENCIAL DA CANA-DE-AÇÚCAR NA PRODUÇÃO DE BIOETANOL E

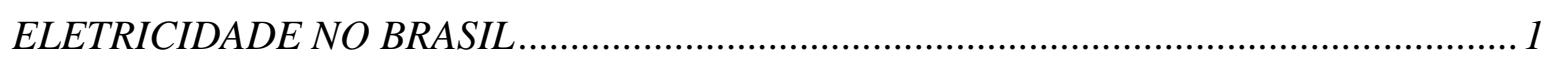

1.2. DESAFIOS E OPORTUNIDADES NA CADEIA PRODUTIVA DOS

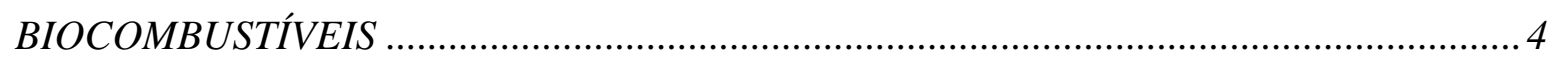

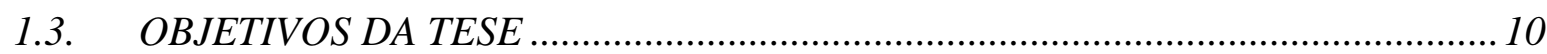

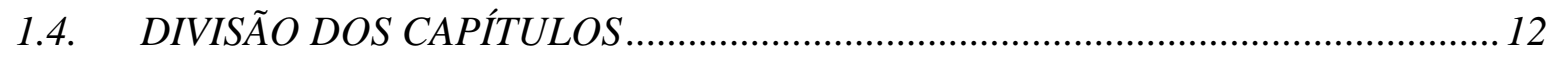

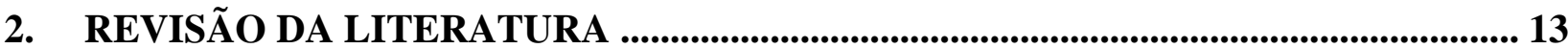

2.1. A CANA-DE-AÇÚCAR COMO INSUMO ENERGÉTICO.................................... 13

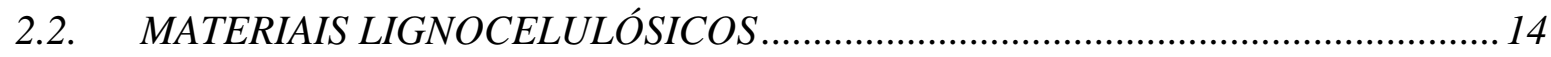

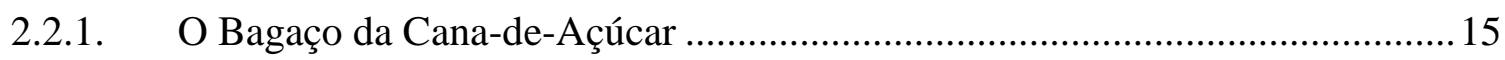

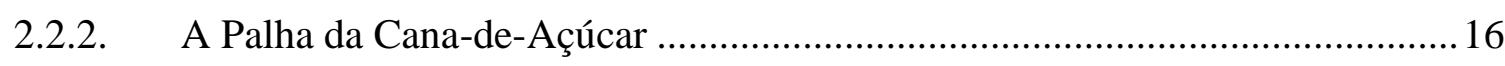

2.3. ROTAS TECNOLÓGICAS PARA PRODUÇÃO DE BIOETANOL E ELETRICIDADE A PARTIR DA CANA-DE-AÇÚCAR ................................................... 17

2.3.1. Rota de Conversão Convencional de Etanol 1G ............................................. 20

2.3.2. Rota de Conversão Bioquímica de Etanol 2G ...................................................... 28

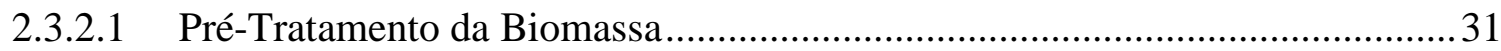


2.3.2.2 Hidrólise da Biomassa 37

2.3.3. Rota de Conversão Termoquímica de Etanol 2G .............................................. 39

2.4. SIMULAÇÃO E OTIMIZAÇÃO DE PROCESSOS DE CONVERSÃO DA BIOMASSA .51

2.4.1. Modelagem da Rota de Conversão Termoquímica ..........................................51

2.4.2. Modelagem da Rota de Conversão Bioquímica ............................................... 61

3. ANÁLISE TERMODINÂMICA, EXERGO-AMBIENTAL E OTIMIZAÇÃO DE CONFIGURAÇÕES PARA A PRODUÇÃO DE BIOETANOL E ELETRICIDADE

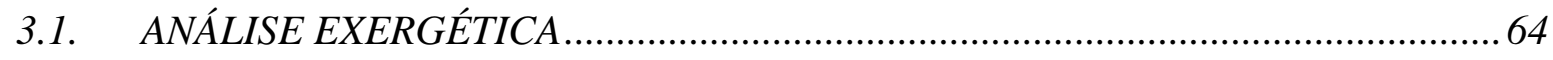

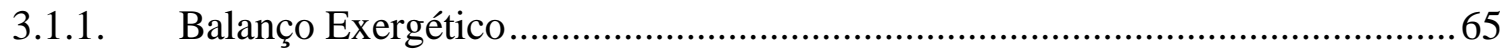

3.2. INTEGRAÇÃO ENERGÉTICA E OTIMIZAÇÃO DE PROCESSOS .......................69

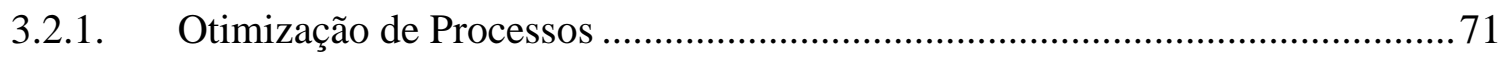

3.3. IMPACTOS AMBIENTAIS NA ANÁLISE DE SISTEMAS DE CONVERSÃO DE

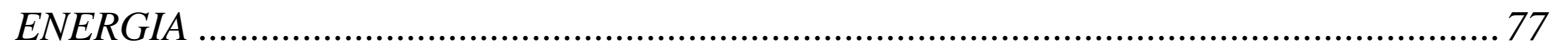

4. CONSTRUÇÃO DOS MODELOS PARA SIMULAÇÃO DE CONFIGURAÇÕES DE BIORREFINARIAS

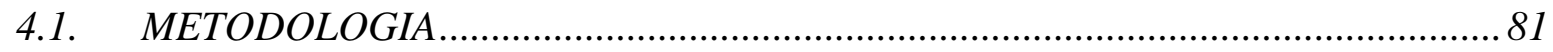

4.1.1. Configurações avaliadas para produção de etanol e eletricidade ...................... 86

4.2. DEFINIÇÃO DE FLUXOS, COMPONENTES, MÉTODOS E PROPRIEDADES.. 88

4.2.1. Definição dos modelos termodinâmicos............................................................ 90

4.2.2. Definição da composição da matéria-prima .................................................... 91

4.3. SIMULAÇÃO DAS ROTAS TECNOLÓGICAS PARA PRODUÇÃO DE

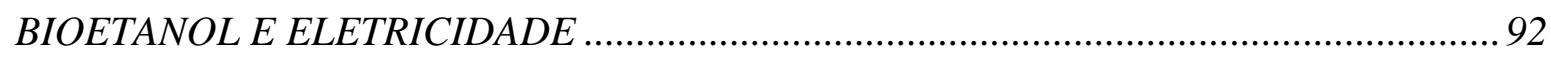

4.3.1. Rota de conversão convencional de etanol $1 \mathrm{G}$...............................................92

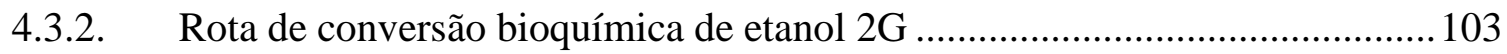

4.3.3. Rota de conversão termoquímica de etanol 2G ............................................. 106

4.4. FERRAMENTAS DE ANÁLISE UTILIZADAS NA AVALIAÇÃO DAS

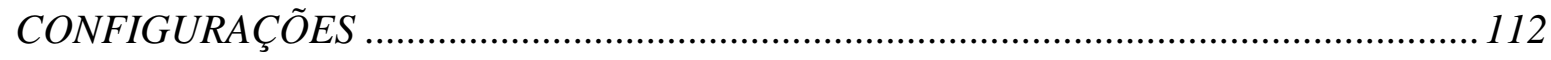




\section{ANÁLISE EXERGÉTICA DAS ROTAS TECNOLÓGICAS PARA PRODUÇÃO DE BIOETANOL E GERAÇÃO DE ELETRICIDADE}

5.1. CONCEITUAÇÃO DA ANÁLISE EXERGÉTICA NA PRODUÇÃO DE

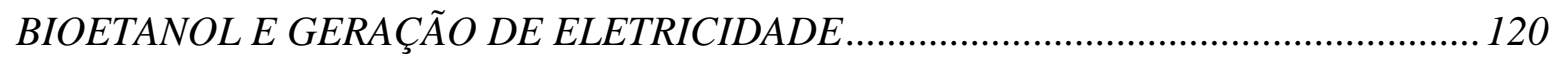

5.2. ANÁLISE EXERGÉTICA DA ROTA CONVENCIONAL DE ETANOL $1 G$........... 122 123

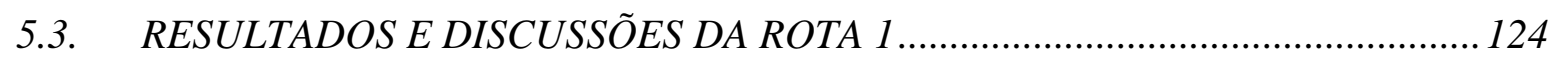

5.4. ANÁLISE EXERGÉTICA DA ROTA BIOQUÍMICA DE ETANOL 2G .................. 128

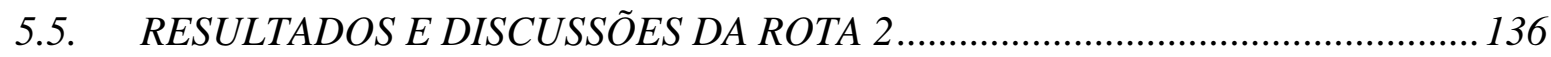

5.6. ANÁLISE EXERGÉTICA DA ROTA TERMOQUÍMICA DE ETANOL 2G ........... 142

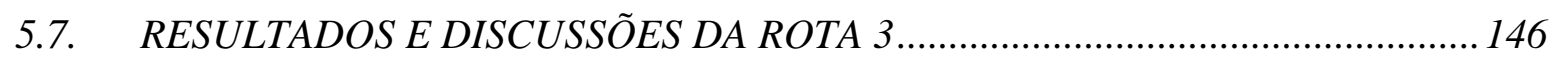

6. HIERARQUIZAÇÃO DAS ROTAS TECNOLÓGICAS AVALIADAS .................... 155

6.1. INTEGRAÇÃO DOS PROCESSOS NAS CONFIGURAÇÕES DE BIORREFINARIA 155

6.2. AVALIAÇÃO GLOBAL DAS CONFIGURAÇÕES ESTUDADAS ........................ 159

6.3. ANÁLISE E DISCUSSÃO DOS RESULTADOS DAS ROTAS OTIMIZADAS ....... 166

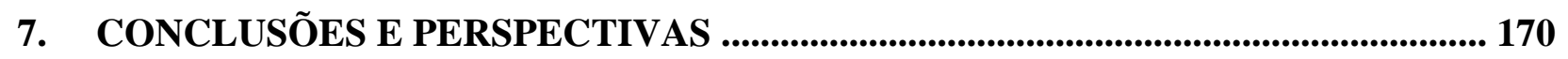

REFER $\hat{E} N C I A S$ BIBLIOGRÁFICAS .................................................................................. 172 APÊEDICES

APÊNDICE A. Máxima recuperação de energia para processos de pré-tratamento ......... 188

APÊNDICE B. Determinação do mínimo de energia requerida nas rotas tecnológicas..... 193

APÊNDICE C. Fluxos considerados na análise exergética do gaseificador EF.................... 197

APÊNDICE D. Otimização multi-objetivo: Plataforma Osmose............................................. 200

APÊNDICE E. Expressões de rendimento exergético...................................................... 203 


\section{INTRODUÇÃO}

\subsection{O POTENCIAL DA CANA-DE-AÇÚCAR NA PRODUÇÃO DE BIOETANOL E ELETRICIDADE NO BRASIL}

No Brasil, a produção de açúcar e etanol, a partir da cana-de-açúcar, representa uma das principais atividades produtivas. De acordo com o Procana, o setor sucroalcooleiro foi responsável por aproximadamente $2 \%$ do PIB nacional e por $31 \%$ do PIB da agricultura no Brasil em 2012 (BIOSEV, 2013).

Neste setor, a expectativa de crescimento no Brasil se diferencia por algumas vantagens competitivas, sendo a disponibilidade da matéria-prima a principal delas. Segundo o Ministério da Agricultura, Pecuária e Abastecimento (MAPA), o país é o maior produtor mundial de cana-de-açúcar, tendo processado 660,5 milhões de toneladas em 2015. Ainda, o processamento deste recurso gerou 162.588 toneladas de bagaço, equivalente ao $11 \%$ do consumo final por fonte da matriz energética no Brasil nesse ano (EMPRESA DE PESQUISA ENERGÉTICA, 2016).

Além disso, o Brasil foi o segundo maior produtor de etanol do mundo em 2014 com uma produção de 23.431.500 metros cúbicos $\left(\mathrm{m}^{3}\right)$ de etanol, conforme mostra a Tab. 1.1 (RENEWABLE FUELS ASSOCIATION, 2015). Deste total, 57,1\% referem-se ao etanol hidratado. Já a produção de etanol anidro, que é misturado à gasolina tipo $A$, registrou acréscimo de 1,9\% com relação ao 2013, totalizando $12.230 \mathrm{mil} \mathrm{m}^{3}$.

Tabela 1.1 - Produção anual de etanol no mundo.

\begin{tabular}{clccccc}
\multicolumn{2}{c}{ País / Região } & 2014 & 2013 & 2012 & 2011 & 2010 \\
\hline \hline & Estados Unidos & 54.131 .000 & 50.345 .980 & 50.035 .570 & 52.617 .060 & 50.084 .627 \\
Brasil & 23.431 .500 & 23.723 .180 & 21.111 .240 & 21.096 .034 & 26.198 .753 \\
União Europeia & 5.469 .920 & 5.189 .800 & 4.311 .584 & 4.538 .695 & 4.451 .630 \\
China & 2.403 .070 & 2.634 .647 & 2.100 .904 & 2.097 .600 & 2.048 .400 \\
Canadá & 1.930 .560 & 1.979 .770 & 1.699 .650 & 1.749 .800 & 1.348 .500 \\
\hline
\end{tabular}

Fonte: Adaptado de Renewable Fuels Association (2015). 
Assim, destacam-se as favoráveis condições ambientais e a grande extensão de terra disponível e propícia para a produção de cana-de-açúcar; aproximadamente 3,6\% da terra cultivável do Brasil, ou seja, 9,5 milhões de hectares são utilizados para a produção de cana o que permite a possibilidade de ampliação da área cultivada, além de expandir a sua produção (UNICA, 2015).

Além disso, o Brasil tem um dos menores custos de produção de cana-de-açúcar, devido a seus altos índices de produtividade ao longo dos ciclos. Estes fatos, associados ao incremento da demanda por fontes de energia limpas e renováveis, preveem o aumento da produção e exportação de etanol e a geração de eletricidade nos próximos anos no mercado nacional.

Na Fig. 1.1 é apresentada uma comparação entre a produção de etanol a partir do milho nos Estados Unidos (USA) e a partir de cana-de-açúcar no Brasil, para o período de 2000 a 2014.

Figura 1.1 - Comparativo de produção de etanol entre Brasil e USA.

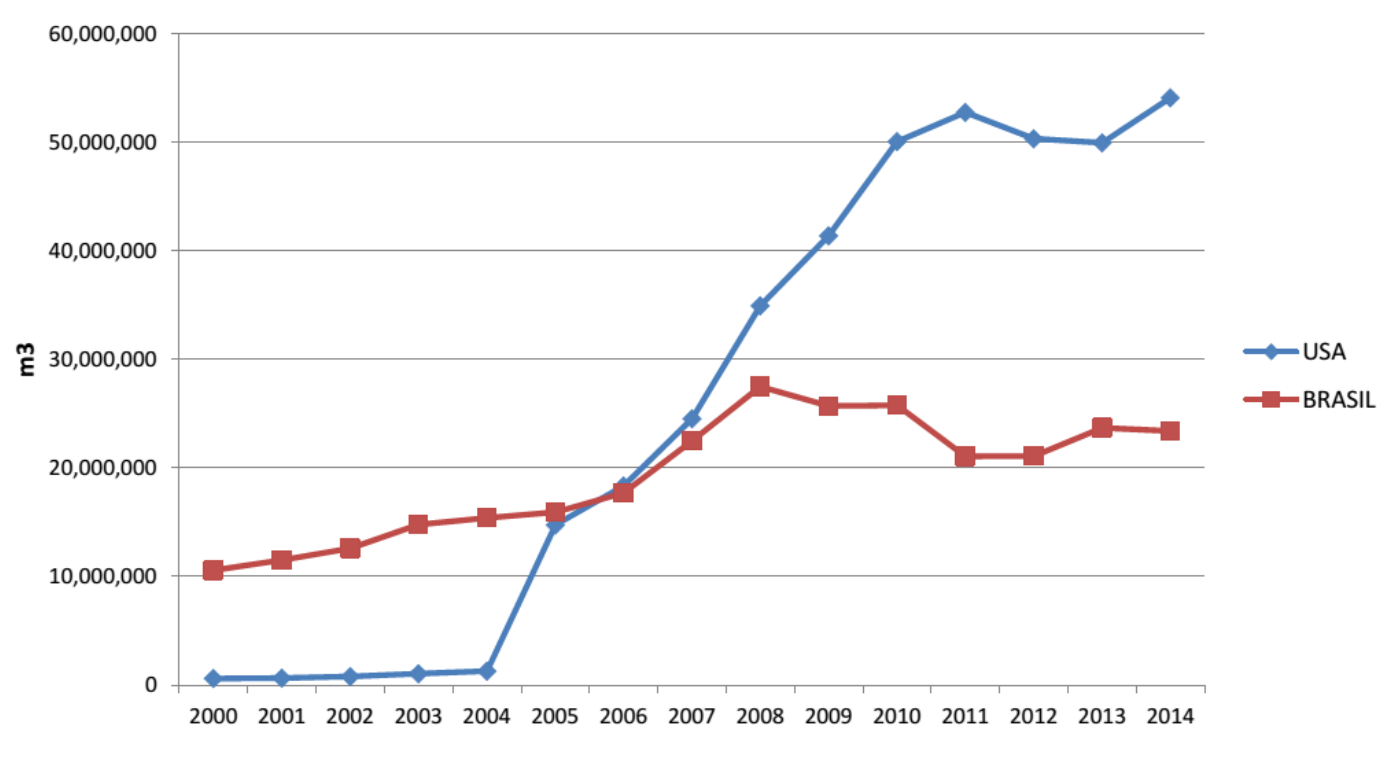

Fonte: Elaborado pelo autor.

Hoje em dia, o setor sucroalcooleiro brasileiro precisa da introdução de novas usinas e o melhoramento das existentes, foncado na produtividade dos processos de conversão, em função da geração de eletricidade ou na produção de etanol por hectare-ano de cana. Neste setor as unidades industriais dividem-se em usinas de açúcar, destilarias autônomas (voltadas à produção apenas de álcool) e usinas com destilaria anexa, que produzem açúcar e álcool. 
Em termos da eficiência de conversão dos processos produtivos destas unidades, tem-se que as irreversibilidades geradas em uma usina anexa encontram-se distribuídas em $68 \%$ no bloco de cogeração, $21 \%$ nos processos de produção de etanol, $4 \%$ no sistema de extração, $3 \%$ no tratamento do caldo e 4\% na produção do açúcar (PELLEGRINI, 2009). Ao passo que a destruição de exergia nos processos associados a uma destilaria autônoma representa 56\% no sistema de cogeração, seguido de $35 \%$ das irreversibilidades nos processos de produção de etanol, $5 \%$ do sistema de extração, $3 \%$ tratamento do caldo e $1 \%$ da etapa de pré-evaporação (PELLEGRINI et al. 2008).

Por outro lado, a partir da década de 1990 visando à modernização deste setor, no mercado de energia elétrica surgiu a possibilidade das usinas venderem seus excedentes de eletricidade. Assim, nesse novo cenário o bagaço (subproduto da cana) adquire um valor agregado no processo produtivo. A produção de bagaço é inerente a esse setor, com elevada produção e baixo custo do mesmo no Brasil (SATYANARAYANA; GUIMARÃES; WYPYCH, 2007). O valor da tonelada de bagaço depende de diversos fatores, como, a quantidade, a qualidade, a duração do fornecimento, a distância entre fornecedor-cliente, e a volatilidade da comercialização da energia elétrica, entre outras.

Nos anos de 2014 e 2015, a excelente remuneração da energia elétrica comercializada no mercado spot aumentou muito a demanda por biomassa de cana. Nesse período, em algumas localidades do estado de São Paulo, a média de preço da tonelada do bagaço para ser retirado na usina, chegou a $R \$ 150,00$. No entanto, nos primeiros meses de 2016, a baixa remuneração do mercado livre de energia, derrubou a demanda por bagaço, e consequentemente, seu preço, atingindo em média de $\mathrm{R} \$ 60,00$ a $\mathrm{R} \$ 25,00$ por tonelada (CANA ONLINE, 2016). Destacase que a geração de energia elétrica no Brasil atingiu 581,5 TWh, por meio de centrais de serviço público com $83,4 \%$ da geração total e autoprodutores com 16,6\% do total produzido em 2015 (EMPRESA DE PESQUISA ENERGÉTICA, 2016).

Neste contexto, a implementação de tecnologias avançadas de cogeração e a integração de processos (IP) na produção de biocombustíveis de primeira geração (1G) e segunda geração $(2 \mathrm{G})$, torna-se necessária para melhorar o desempenho dos processos. Assim, à luz desses desafios surge este projeto de pesquisa. 
Este trabalho abrange a avaliação exergética e exergo-ambiental de rotas tecnológicas que permitam o aproveitamento integral da cana-de-açúcar na produção de etanol e eletricidade para a valorização da sua cadeia produtiva por meio do conceito de biorrefinaria. Na Rota 1 visa-se realizar a avaliação de uma destilaria autônoma acoplada a um planta de cogeração. Já na Rota 2 será avaliado o processo de hidrólise da biomassa lignocelulósica dos resíduos da cana-de-açúcar, visando à obtenção de açúcares fermentescíveis para a produção de etanol. Finalmente, a Rota 3 tem como foco a geração de eletricidade utilizando o excedente de biomassa mediante a tecnologia da gaseificação.

\subsection{DESAFIOS E OPORTUNIDADES NA CADEIA PRODUTIVA DOS BIOCOMBUSTÍVEIS}

Os custos de produção em larga escala dos biocombustíveis e produtos procedentes do setor sucroalcooleiro dependem principalmente de dois fatores: $O$ custo da matéria-prima e o custo do processo de conversão. A partir destas premissas, uma série de barreiras econômicas e desafios tecnológicos devem ser superados para que a produção dos biocombustíveis atinja um nível de desenvolvimento similar ao alcançado pela indústria petroquímica. Na Fig. 1.2 são apresentados alguns dos aspectos-chave para o desenvolvimento na área dos biocombustíveis.

Figura 1.2 - Barreiras econômicas e tecnológicas na produção dos biocombustíveis.

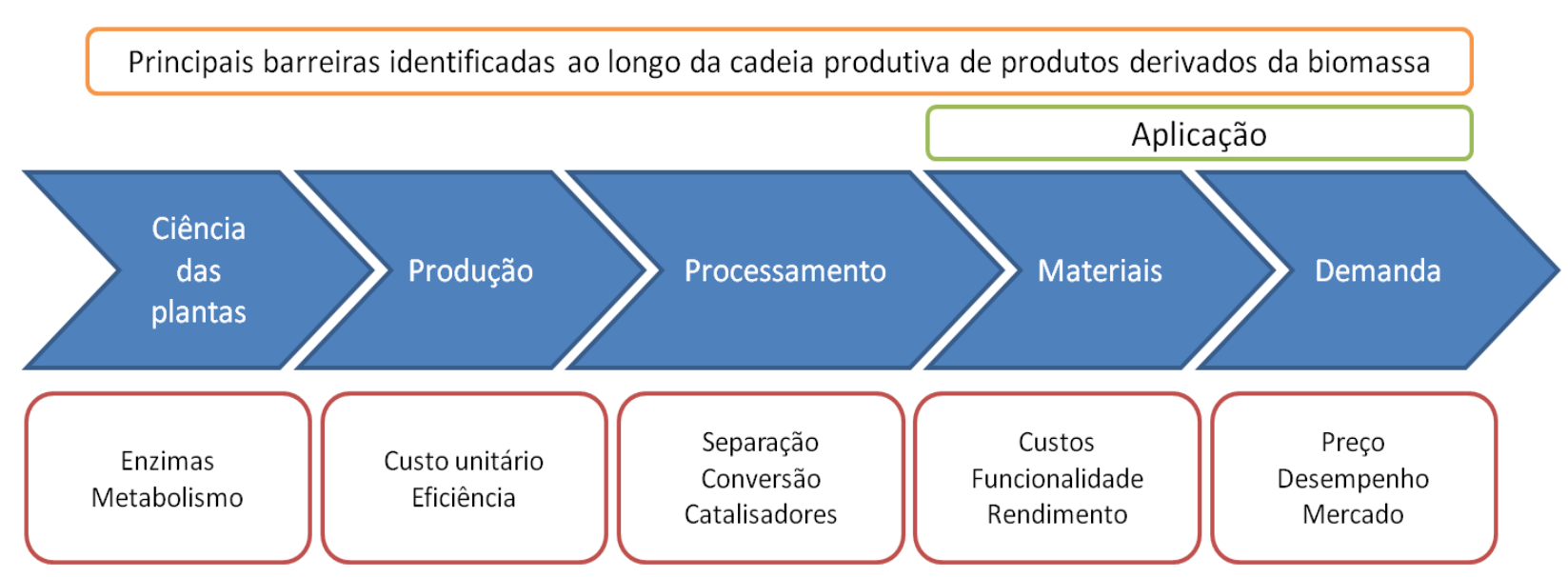

Fonte: Adaptado de U.S. DEPARTMENT OF ENERGY (1999). 
Em termos de oportunidades no cenário brasileiro, com o avanço nas tecnologias de aproveitamento da biomassa para liberação de açúcares simples e fermentáveis (pentoses e hexoses), o país poderá aumentar a produção de etanol, eletricidade e subprodutos, em decorrência da grande disponibilidade de resíduos agroindustriais, como o bagaço e a palha de cana, gerados ao longo da cadeia da cana-de-açúcar.

Além disso, diversos produtos químicos podem ser fabricados com base nos produtos das usinas sucroalcooleiras. Rotas biotecnológicas ou baseadas na síntese química dos açúcares podem ser usadas na produção de importantes building blocks, como ácido acrílico, butadieno e ácido adípico. Já as rotas baseadas no álcool podem ser usadas na produção do eteno, propeno, entre outros (BAIN COMPANY E GAS ENERGY, 2014). No futuro, espera-se que o biobutanol e o biodiesel sejam acrescentados a este portfólio de produtos.

Deve-se ressaltar que após um longo período de desenvolvimento tecnológico em nível mundial, voltado à produção de biocombustíveis, o etanol celulósico ou etanol de segunda geração (2G) já atingiu o estágio de plantas comerciais. No contexto brasileiro, atualmente o país tem uma capacidade instalada para produção de etanol de $2 \mathrm{G}$ de cerca de 140 milhões de litros por ano (safra), por meio das três primeiras plantas de produção do etanol celulósico, duas em escala comercial e outra demonstrativa (MILANEZ et al., 2015).

Apesar dos avanços atingidos na produção de etanol de $2 \mathrm{G}$ na conversão dos açúcares provenientes de biomassa, ainda há um grande desafio a ser superado no campo de desconstrução da biomassa lignocelulósica, ou seja, na conversão de polissacarídeos (celulose e hemicelulose) em monômeros (principalmente, glicose e xilose). Superar esse obstáculo é necessário para reduzir a competição por açúcares provenientes de fontes alimentícias, como do milho, beterraba, etc. (VAZ JÚNIOR, 2013).

É importante salientar que um dos principais gargalos tecnológicos que envolvem a produção de etanol lignocelulósico é o processo de pré-tratamento, foco deste projeto, que compreende a quebra das barreiras estruturais e composicionais dos materiais lignocelulósicos, facilitando a etapa posterior de hidrólise. 
Seguindo na linha de processo na produção de etanol $2 \mathrm{G}$ da cana-de-açúcar, outro desafio a partir de subprodutos lignocelulósicos (bagaço da cana) incide na decisão ou escolha do processo de hidrólise mais vantajoso para a obtenção dos monossacarídeos e no aumento dos rendimentos de açúcares fermentescíveis. Deste modo, surgem diversas oportunidades neste setor visando atingir a competitividade do etanol de $2 \mathrm{G}$ e acelerar sua evolução tecnológica nas etapas de produção de biomassa, avaliação dos custos, enzimas e equipamentos, de forma eficiente e economicamente viável.

No contexto brasileiro, Bonomi et al. (2016) realizaram uma avaliação técnico-econômica e ambiental do etanol $2 \mathrm{G}$ em termos das perspectivas de curto e longo prazo neste setor. Nesse estudo, o processo $2 \mathrm{G}$ inclui um pré-tratamento com explosão de vapor seguido por um processo de hidrólise e fermentação separado. No processo $1 \mathrm{G}$ e $2 \mathrm{G}$ integrado, o licor de glicose (C6) é fermentado juntamente com caldo da 1G usando a levedura convencional (Saccharomyces cerevisiae), enquanto o licor de pentoses (C5) é fermentado separadamente usando um micro-organismo geneticamente modificado. Destaca-se nos parâmetros adotados nos cenários de curto e longo prazo, a conversão de hemicelulose em monómeros e oligômeros de $60 \%$ a 80 \% na etapa de pré-tratamento, ao passo que no processo de hidrólise enzimática o uso de teores de sólidos é $15 \%$ a $25 \%$ e a conversão de celulose em glicose de $60 \%$ a $80 \%$, respectivamente.

Assim, na Tab. 1.2 apresenta-se o custo do etanol para as configurações avaliadas de $1 \mathrm{G}$ e $2 \mathrm{G}$ integrada (1G2G). Sendo, curto prazo (ST), longo prazo (LT) e cana energia (EC), enquanto que na Fig. 1.3 comparam-se em termos percentuais os parâmetros considerados no custo de produção de etanol dos diferentes cenários.

Tabela 1.2 - Custo do etanol.

\begin{tabular}{|c|c|c|c|c|}
\hline Parâmetros & $1 G$ & $1 G 2 G-S T$ & $1 G 2 G-L T$ & $1 G 2 G-E C$ \\
\hline Biomassa & 676,2 & 644 & 579,6 & 466,9 \\
\hline Custo do capital & 305,9 & 370,3 & 257,6 & 338,1 \\
\hline Enzima & 0 & 80,5 & 64,4 & 161 \\
\hline Manutenção & 161 & 112,7 & 96,6 & 96,6 \\
\hline Mão de obra & 8,05 & 8,05 & 8,05 & 12,88 \\
\hline Outros & 8,05 & 8,05 & 12,88 & 12,88 \\
\hline Custo do etanol $\left(R \$ / m^{3}\right)$ & 1159,2 & 1223,6 & 1019,13 & 1088,36 \\
\hline
\end{tabular}

Fonte: Adaptado de Bonomi et al. (2016). 
Figura 1.3 - Distribuição dos custos na produção do etanol.

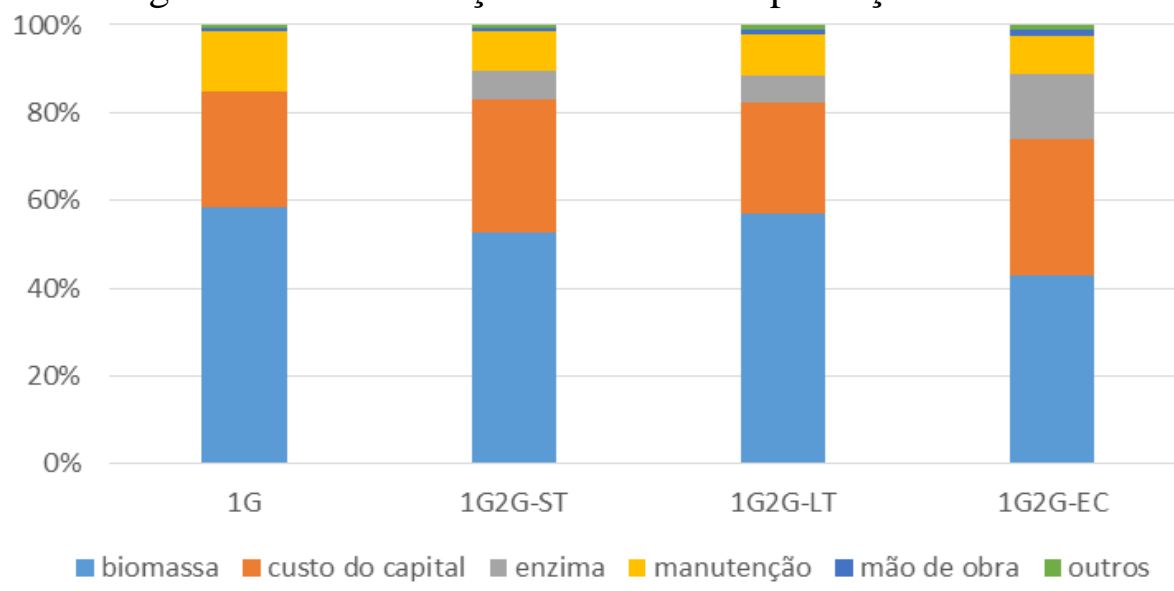

Fonte: Adaptado de Bonomi et al. (2016).

O estudo conduzido por Bonomi et al. (2016) foi baseado nos cenários de curto e longo prazo apresentados pelo BNDES na avaliação técnico-econômica de configurações de plantas de etanol de $1 \mathrm{G}, 1 \mathrm{G} 2 \mathrm{G}$ integrados e $2 \mathrm{G}$ independentes, conforme apresentado na Tab. 1.3 (MILANEZ et al., 2015). Ainda nesta tabela, apresenta-se o rendimento exergético de cada cenário calculado a partir da exergia dos produtos entre a exergia dos insumos.

Tabela 1.3 - Cenários de produção de etanol.

\begin{tabular}{|c|c|c|c|c|c|c|c|c|}
\hline \multicolumn{3}{|l|}{ Cenários } & $\begin{array}{c}\text { Fluxo } \\
\text { Mássico }\end{array}$ & $\begin{array}{c}\text { Fluxo } \\
\text { Mássico }\end{array}$ & Etanol & Eletricidade & Eletricidade & $\begin{array}{l}\text { Rendimento } \\
\text { Exergético }\end{array}$ \\
\hline & & & [TC/ano] & {$[T / h]$} & {$[l / T C]$} & {$[k W h / T C]$} & {$[k W]$} & {$[\%]$} \\
\hline Caso base & $\mathrm{CC}$ & 0 & $2,000,000$ & 416,67 & 53,6 & 11,5 & 4,792 & 25,31 \\
\hline \multirow{3}{*}{$1 G$} & CC PA & 1 & $4,250,000$ & 885,42 & 84,9 & 174,3 & 154,328 & 43,48 \\
\hline & $\begin{array}{l}\text { CC CE } \\
\text { PA }\end{array}$ & 2 & $6,060,000$ & 1262,50 & 76,6 & 201,5 & 254,394 & 39,94 \\
\hline & $\begin{array}{l}\text { CC CE } \\
\text { PA }\end{array}$ & 3 & $8,560,000$ & 1783,33 & 68,8 & 216,7 & 386,448 & 19,73 \\
\hline \multirow{5}{*}{$\begin{array}{l}\text { 1G2G } \\
\text { Integrado }\end{array}$} & CC PA & 4 & $4,250,000$ & 885,42 & 108 & 68,6 & 60,740 & 44,85 \\
\hline & $\begin{array}{l}\text { CC CE } \\
\text { PA }\end{array}$ & $5 \mathrm{~A}$ & $6,060,000$ & 1262,50 & 117 & 70,4 & 88,880 & 30,51 \\
\hline & $\begin{array}{l}\text { CC CE } \\
\text { PA }\end{array}$ & $5 \mathrm{~B}$ & $6,060,000$ & 1262,50 & 122 & 66,6 & 84,083 & 36,21 \\
\hline & $\begin{array}{l}\text { CC CE } \\
\text { PA }\end{array}$ & $6 \mathrm{~A}$ & $8,560,000$ & 1783,33 & 121 & 68,0 & 121,267 & 23,49 \\
\hline & $\begin{array}{l}\text { CC CE } \\
\text { PA }\end{array}$ & $6 \mathrm{~B}$ & $8,560,000$ & 1783,33 & 125 & 69,6 & 124,120 & 30,11 \\
\hline \multirow{5}{*}{$\begin{array}{l}2 G \\
\text { Indep. }\end{array}$} & MLC & 7 & 420,000 & 87,50 & 22,9 & 36,8 & 3,220 & 5,11 \\
\hline & $\mathrm{CE}$ & $8 \mathrm{~A}$ & $4,380,000$ & 912,50 & 94 & 69,6 & 63,510 & 34,65 \\
\hline & CE & $8 \mathrm{~B}$ & $4,380,000$ & 912,50 & 100 & 61,1 & 55,754 & 36,29 \\
\hline & $\mathrm{CE}$ & $9 \mathrm{~A}$ & $6,780,000$ & 1412,50 & 99,1 & 70,3 & 99,299 & 36,37 \\
\hline & $\mathrm{CE}$ & $9 \mathrm{~B}$ & $6,780,000$ & 1412,50 & 103 & 65,1 & 91,954 & 37,22 \\
\hline
\end{tabular}

Fonte: Adaptado de Milanez et al. (2015). 
Sendo,

CE Cana-energia, composta por palha e colmos,

CC Cana-de-açúcar convencional,

PA Palha,

MLC Material lignocelulósico.

Neste resumo das configurações estudadas pelo BNDES o período de safra considerado foi 200 dias de operação e a entressafra 130 dias. O caso-base (Cenário 0) representa a média atual do setor sucroenergético, isto é, uma usina $1 \mathrm{G}$ anexa com capacidade de processamento na faixa de 2 milhões de toneladas na safra, com tecnologia básica e sem integração energética (Milanez et al. 2015).

Nesse estudo, o potencial de melhoria de eficiência do etanol $2 \mathrm{G}$ foi avaliado por meio de duas rotas tecnológicas (rotas A e B). A rota A refere-se a um processo de produção com fermentação separada de C5 (açúcares com cinco carbonos, xilose). Enquanto que a rota B envolve um processo com co-fermentação dos açúcares C5 e C6 (açúcares com seis carbonos, glicose).

Nesta mesma linha, Albarelli (2013) propõe diversas configurações tecnológicas para produção de eletricidade e/ou etanol 2G. Sendo avaliado o processo convencional, destilaria autônoma (D) e produção conjunta de açúcar e etanol (PC). Na Tab. 1.4 são mostrados os resultados destas configurações.

Tabela 1.4 - Resultados de casos de estudo para produção de eletricidade e/ou etanol 2G.

\begin{tabular}{|c|c|c|c|c|c|c|c|c|c|c|c|c|c|c|c|c|c|}
\hline \multirow{2}{*}{ PRODUTOS } & \multirow{2}{*}{ [Unidades] } & \multirow{2}{*}{$D$} & \multirow{2}{*}{$P C$} & CASO I & \multicolumn{3}{|c|}{$\mathrm{CASO}_{2}$} & \multirow{2}{*}{$\begin{array}{c}\text { CASO } 3 \\
\text { D3 }\end{array}$} & \multirow{2}{*}{$\begin{array}{c}\text { CASO } 4 \\
D 4\end{array}$} & \multirow{2}{*}{$\begin{array}{c}\text { CASO 5 } \\
D 5\end{array}$} & \multicolumn{2}{|c|}{ CASO 6} & \multicolumn{2}{|c|}{ CASO 7} & \multicolumn{3}{|c|}{ CASO 8} \\
\hline & & & & DI & $D 2 A$ & $D 2 B$ & $P C 2 B$ & & & & D6A & D6B & $D 7 A$ & $D 7 B$ & $D 8 A$ & $D 8 B$ & $P C 8 B$ \\
\hline ETANOL & {$[\mathrm{L} / \mathrm{TC}]$} & 81,9 & 43,3 & 81,9 & 81,9 & 81,9 & 43,3 & 93,6 & 97,1 & 84,8 & 86,9 & 94,7 & 86,3 & 95,7 & 88,5 & 96,7 & 57 \\
\hline ETANOL & {$[\mathrm{kW}]$} & 240241 & 127014 & 240241 & 240241 & 240241 & 127014 & 274561 & 284827 & 248747 & 254907 & 277787 & 253147 & 280721 & 259601 & 283654 & 167200 \\
\hline ELETRICIDADE & {$[\mathrm{KWh} / \mathrm{TC}]$} & 50,1 & 55,8 & 80,7 & 128 & 172,5 & 179,6 & 87 & 71 & & 136 & 117 & 136 & 109 & 140 & 122 & 130 \\
\hline ELETRICIDADE & {$[\mathrm{kW}]$} & 25050 & 27900 & 40350 & 64000 & 86250 & 89800 & 43500 & 35500 & 0 & 68000 & 58500 & 68000 & 54500 & 70000 & 61000 & 65000 \\
\hline AÇÚCAR & {$[\mathrm{KG} / \mathrm{TC}]$} & -- & 65 & -- & -- & -- & 65 & -- & -- & -- & -. & -- & -- & .- & -- & -. & 65 \\
\hline$A C C U ́ C A R$ & {$[k W]$} & - & 157797 & -- & - & - & 157797 & -- & - & - & -. & - & - & -. & - & - & 157797 \\
\hline $\begin{array}{r}\text { Rendimento } \\
\text { Exergético }\end{array}$ & [\%] & 37,58 & 44,29 & 39,75 & 43,11 & 46,25 & 53,07 & 45,06 & 45,37 & 35,24 & 45,74 & 47,63 & 45,49 & 47,49 & 46,69 & 48,82 & 55,24 \\
\hline
\end{tabular}

Fonte: Adaptado de Albarelli (2013).

De forma similar à comparação anterior foi determinado o rendimento exergético de cada cenário por meio da exergia dos produtos (etanol e eletricidade) entre a exergia dos insumos (cana de açúcar e produtos químicos). 
As simulações destas configurações estão focadas na rota bioquímica usando diversos prétratamentos (tecnologias de explosão a vapor, explosão a vapor catalisada e hidrotérmico), e a hidrólise enzimática da biomassa.

Nota-se que nestes casos de estudo a rota A considera menores quantidades da palha na cogeração e/ou menores rendimentos de hidrólise e fermentação. Já a rota B refere-se aos casos que consideraram maior quantidade da palha na cogeração e/ou maiores rendimentos de hidrólise e fermentação. 


\subsection{OBJETIVOS DA TESE}

\section{Objetivo Geral}

O objetivo desta tese de doutorado é desenvolver uma metodologia para realizar a análise, avaliação e hierarquização exergética e exergo-ambiental de processos para obtenção de etanol e eletricidade a partir da cana-de-açúcar em distintas configurações de biorrefinarias (Fig. 1.4). Com base nesta metodologia visa-se obter configurações ótimas, permitindo assim quantificar o desempenho exergético, econômico e ambiental (em termos da renovabilidade dos processos de produção) para as seguintes rotas propostas.

- ROTA 1-Convencional: ETANOL (1G) E ELETRICIDADE;

- ROTA 2-Bioquímica: ETANOL (2G) E ELETRICIDADE;

- ROTA 3-Termoquímica: ETANOL (2G), GÁS DE SÍNTESE E ELETRICIDADE.

Figura 1.4 - Rotas tecnológicas consideradas para produção de bioetanol e eletricidade.

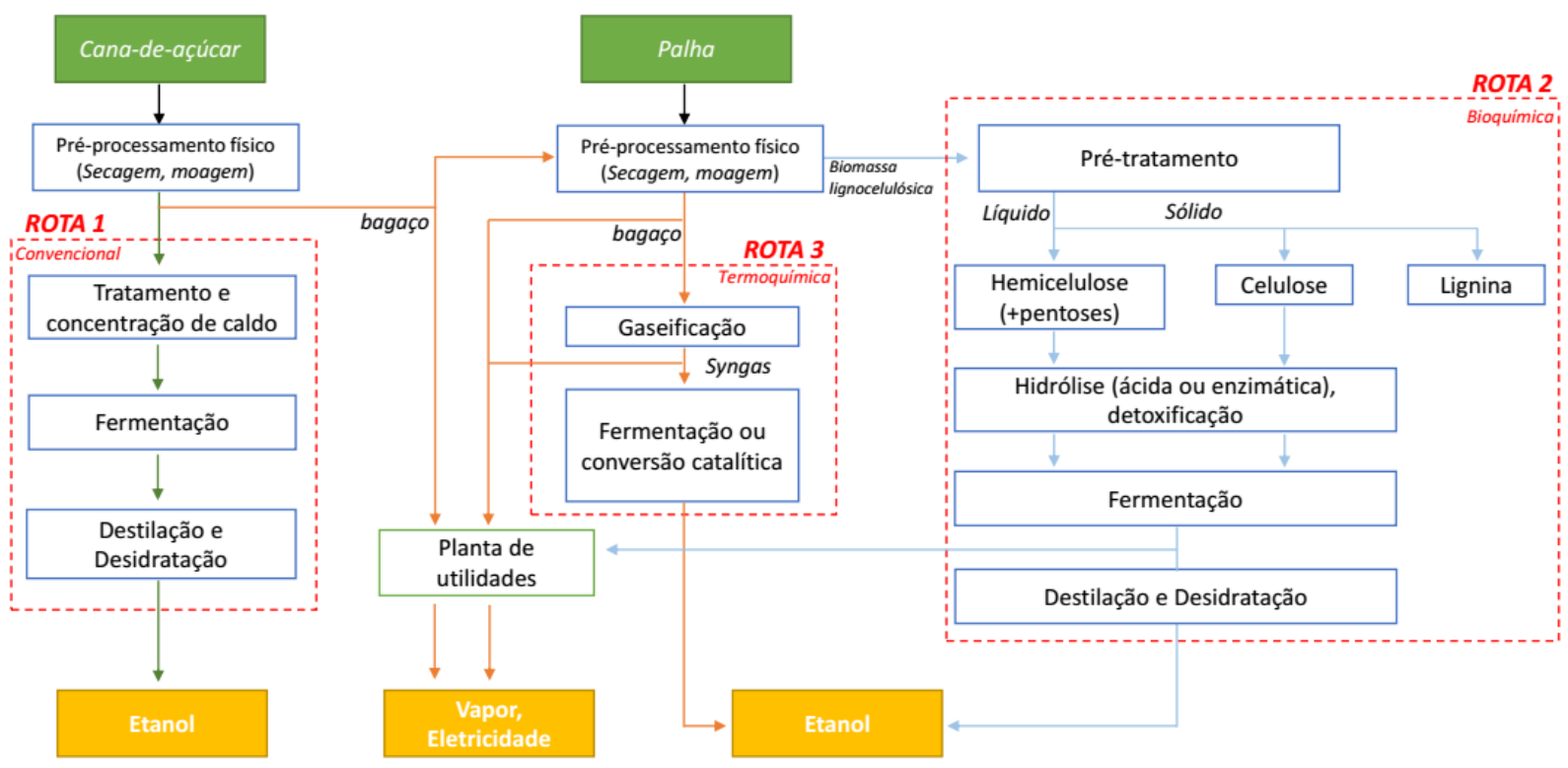

Fonte: Elaborado pelo autor. 


\section{Objetivos Específicos}

As configurações ótimas das rotas tecnológicas propostas são resultado de uma metodologia baseada na avaliação exergética e exergo-ambiental dos processos de conversão de energia. Nesse contexto foram estabelecidos os seguintes objetivos específicos:

1. Caracterizar os processos de conversão de energia em cada configuração analisada em termos dos resíduos/rejeitos e os dados de consumo e produção mais representativos desses processos.

2. Aplicar modelos termodinâmicos para a simulação dos processos de conversão de energia das rotas propostas.

3. Comparar os desempenhos exergéticos das rotas avaliando alternativas para minimizar a geração de entropia (irreversibilidades) com o intuito de melhorar a qualidade dos produtos obtidos.

4. Definir indicadores exergo-ambientais apropriados para hierarquizar as configurações estudadas de biorrefinarias em determinados cenários de produção de bioetanol e eletricidade (Índice de $\mathrm{CO}_{2}$ equivalente em base exergética). 


\subsection{DIVISÃO DOS CAPÍTULOS}

O texto ora apresentado está dividido em sete (7) capítulos e seis (6) apêndices.

O Cap. 1 apresenta uma breve discussão sobre o panorama da produção de bioetanol e eletricidade no contexto brasileiro. Ainda, expõe o objetivo geral e os objetivos específicos desta tese. Por último, mostra alguns desafios e oportunidades do setor sucroalcooleiro.

O Cap. 2 expressa uma visão geral das rotas tecnológicas para conversão da biomassa. Além disso, apresenta uma revisão do estado da arte dos principais processos e etapas na cadeia produtiva do etanol a partir da cana-de-açúcar.

O Cap. 3 descreve os conceitos envolvidos na análise exergética e exergo-ambiental nos processos de conversão de energia aplicados aos sistemas térmicos. Ainda, este capítulo exibe uma resenha sobre a integração energética de processos e do impacto ambiental de sistemas focados na produção de bioetanol e eletricidade.

O Cap. 4 exibe a metodologia definida para a construção dos modelos (estudos de caso) para simulação das configurações de Biorrefinarias, junto com a definição das variáveis e os componentes empregados na simulação.

O Cap. 5 traz a descrição dos processos empregados na simulação das rotas tecnológicas para produção de bioetanol e eletricidade. Assim, os principais parâmetros dos modelos desenvolvidos são apresentados objetivando à aplicação da análise exergética destas configurações.

O Cap. 6 ilustra os parâmetros de performance empregados na integração térmica dos processos. Além disso, exibe os critérios adotados na avaliação global das configurações visando obter a hierarquização das rotas tecnológicas.

Finalmente, o Cap. 7 apresenta as conclusões deste trabalho e sugestões para trabalhos futuros. Ainda as informações complementares são sintetizadas nos apêndices deste documento. 


\section{REVISÃO DA LITERATURA}

\subsection{A CANA-DE-AÇÚCAR COMO INSUMO ENERGÉTICO}

A cana-de-açúcar produz o colmo industrializável, que representa de $80 \%$ a $85 \%$ da biomassa total, o restante se constitui de folhas e ponteiros (topo da planta). Uma parte destas folhas e ponteiros é queimada quando a cana é colhida com queima prévia, ou deixada no campo quando colhida mecanicamente.

Na composição química da cana-de-açúcar apresentada na Tab. 2.1, os açúcares referem-se à Sacarose $(12,5 \%)$, Glicose $(0,9 \%)$ e Levulose $(0,6 \%)$. Além disso, os principais compostos das fibras são Celulose (5,5\%), Lignina (2,0\%) e Pentosana (2,0\%). Enquanto, a porcentagem das cinzas refere-se principalmente a Dióxido de Silício $\left(\mathrm{SiO}_{2}\right)$ e Óxido de Potássio $\left(\mathrm{K}_{2} \mathrm{O}\right)$, (Camargo, 1990).

Tabela 2.1 - Composição média da cana-de-açúcar.

\begin{tabular}{|l|c|}
\hline Componente & Teor médio $(\% \mathbf{p} / \mathbf{p})$ \\
\hline Água & 74,5 \\
\hline Açúcares & 14,0 \\
\hline Fibras & 10,0 \\
\hline Cinzas & 0,50 \\
\hline Matérias nitrogenadas & 0,40 \\
\hline Gorduras e ceras & 0,20 \\
\hline Substâncias pépticas, gomas e muscilagem & 0,20 \\
\hline Ácidos combinados & 0,12 \\
\hline Ácidos livres & 0,80 \\
\hline
\end{tabular}

Fonte: Reproduzido de Camargo (1990).

No Brasil, a produtividade média da cana-de-açúcar é 85 toneladas por hectare, sendo que para cada tonelada de cana processada são gerados cerca de $140 \mathrm{~kg}$ de bagaço em base seca e $140 \mathrm{~kg}$ de palha, ou seja, 12 toneladas de bagaço e 12 toneladas de palha (SANTOS et al., 2012). 


\subsection{MATERIAIS LIGNOCELULÓSICOS}

A maior parte da biomassa com alto teor de celulose empregada como matéria-prima na produção de etanol é gerada como resíduo nos processos produtivos dos setores agrícola, industrial e florestal.

Destacam-se os resíduos gerados na indústria do papel e celulose, açúcar e álcool (bagaço e palha) e a fração orgânica dos resíduos domésticos. Muitos destes resíduos não têm valor econômico no mercado ou possuem baixo custo de aquisição, e geralmente são associados a problemas ambientais quando considerado seu tratamento e eliminação.

A biomassa lignocelulósica está composta basicamente de polímeros de carboidratos (celulose e hemicelulose), lignina e uma pequena parte constituída por ácidos, sais e minerais. Na Tab. 2.2 é apresentada a composição de diversos materiais lignocelulósicos em base seca (LORA; VENTURINI, 2012).

Tabela 2.2 - Composição de diversos materiais lignocelulósicos.

\begin{tabular}{|l|c|c|c|c|}
\hline Compostos & $\begin{array}{c}\text { Bagaço da } \\
\text { cana }\end{array}$ & $\begin{array}{c}\text { Palha de } \\
\text { trigo }\end{array}$ & $\begin{array}{c}\text { Palha de } \\
\text { arroz }\end{array}$ & Eucalipto \\
\hline Celulose & 38,1 & 36,6 & 41,0 & 49,50 \\
\hline Glicose (C6) & 23,3 & 19,2 & 14,8 & 10,73 \\
\hline Hemicelulose & 2,5 & 2,4 & 4,5 & 0,31 \\
\hline Xilose (C5) & 1,1 & 2,4 & 0,4 & 0,76 \\
\hline Arabinose (C5) & $\mathrm{ND}$ & 0,8 & 1,8 & 1,27 \\
\hline Galactose (C6) & $\mathbf{1 8 , 4}$ & $\mathbf{1 4 , 5}$ & $\mathbf{9 , 9}$ & $\mathbf{2 7 , 7 1}$ \\
\hline Manose (C6) & 2,8 & 9,6 & 12,4 & 1,26 \\
\hline Lignina & 3,0 & 3,0 & ND & ND \\
\hline Cinzas & $\mathbf{1 9 , 2 6}$ & $\mathbf{1 7 , 1}$ & $\mathbf{1 5 , 4}$ & $\mathbf{1 9 , 5 0}$ \\
\hline Proteínas & & & & \\
\hline $\begin{array}{l}\text { Poder calorifico } \\
\text { GJ }\end{array}$ &
\end{tabular}

ND: Não disponível

Fonte: Reproduzido de Lora e Venturini (2012). 
A celulose e a hemicelulose são polissacarídeos que podem ser utilizados na produção de bioetanol por meio de processos de pré-tratamento e hidrólise, que permitem a obtenção de açúcares fermentescíveis (HAMELINCK; HOOIJDONK; FAAIJ, 2005).

Por outro lado, o licor obtido no pré-tratamento pode ser diluído no caldo da cana, diminuindo desta forma o impacto de inibidores da fermentação eventualmente formados nesta etapa, tais como fenólicos, ácido acético, furfural, 5-hidroximetilfurfural e iões metálicos (IBRAHEEM; NDIMBA, 2013).

Contudo, o uso de biomassas lignocelulósicas como matéria-prima para produção de etanol nos últimos anos tem despertado grande interesse na comunidade acadêmica e industrial. No cenário brasileiro, espera-se no curto prazo ter uma estimativa fidedigna da produção do etanol celulósico em escala demonstrativa e comercial.

$\mathrm{Na}$ atualidade pesquisas nessa área, ainda são necessárias para promover a viabilização técnica e econômica da tecnologia de pré-tratamento e hidrólise na introdução do etanol $2 \mathrm{G}$. Merece destaque o estudo conduzido por Milanez et al. (2015) apresentado no capítulo anterior, que considerou diferentes configurações e processos integrados nesta rota tecnológica, utilizando tanto o caldo quanto o bagaço, a palha e a cana energia como insumos.

\subsubsection{O Bagaço da Cana-de-Açúcar}

O bagaço de cana é definido como o resíduo fibroso obtido após a moagem no processo de extração do caldo. Este material fibroso é composto de água e pequenas quantidades de sólidos solúveis. A composição do bagaço varia em função da eficiência do sistema de extração de caldo, a variedade da cana, região de cultivo, maturidade, entre outros. Na Tab. 2.3 apresenta-se a composição típica da fibra do bagaço da cana-de-açúcar, para cada g/100g de substância seca (REIN, 2007). 
Tabela 2.3 - Composição típica do bagaço da cana.

\begin{tabular}{|l|c|}
\hline Componente & (\%) \\
\hline Celulose & 40 \\
\hline Hemicelulose & 33 \\
\hline Lignina & 22 \\
\hline Cinzas / Outros & 5 \\
\hline
\end{tabular}

Fonte: Reproduzido de Rein (2007).

\subsubsection{A Palha da Cana-de-Açúcar}

Quanto à palha, um programa visando a sua eliminação gradativa da queima já vem sendo implantado no Brasil. O estado de São Paulo é um exemplo deste programa, que deve ocorrer de forma semelhante em outros estados do país, aumentando dessa forma, a disponibilidade de palha. Assim, a fração excedente será transportada para a usina e utilizada como matériaprima na produção de etanol ou geração de eletricidade.

É importante ressaltar que é recomendável deixar uma fração da palha no campo, de forma a contribuir para o controle de doenças das culturas e evitar o crescimento de outras espécies, além de formar uma camada protetora do solo. Estima-se que cerca de $50 \%$ a $60 \%$ da palha deveria ser deixada no campo (HASSUANI; LEAL; MACEDO, 2005), mas ainda não existe um consenso sobre esta alternativa. Em contrapartida alguns pesquisadores afirmam que só uma fração reduzida deve permanecer no campo, entre $10 \%$ e $20 \%$ para aumentar assim a palha excedente visando à obtenção dos produtos citados anteriormente e aumentado a produtividade.

A palha da cana-de-açúcar sendo toda a parte aérea da planta menos os colmos industrializáveis representa $15 \%$ do peso dos colmos da cana madura, ou $12 \%$ quando seca. Em termos energéticos a palha representa 1/3 da energia potencial da cana. Sua composição é basicamente celulose, hemicelulose e lignina, na proporção aproximada de 40\%, 30\% e 25\%, respectivamente (SANTOS et al. 2012). O potencial da palha de cana-de-açúcar para produção de etanol em função dos rendimentos de conversão é ilustrado na Fig. 2.1. Nota-se que, quando considerada toda a conversão de glicose em etanol, o aproveitamento integral da cana-de-açúcar (colmos, palha e bagaço) pode aumentar significativamente a produção de etanol por hectare, passando dos atuais $7000 \mathrm{~L}$ para aproximadamente $14000 \mathrm{~L}$, sem necessidade de expansão da área cultivada (SANTOS et al. 2012). 
Figura 2.1 - Rendimento teórico da produção de etanol a partir da palha.

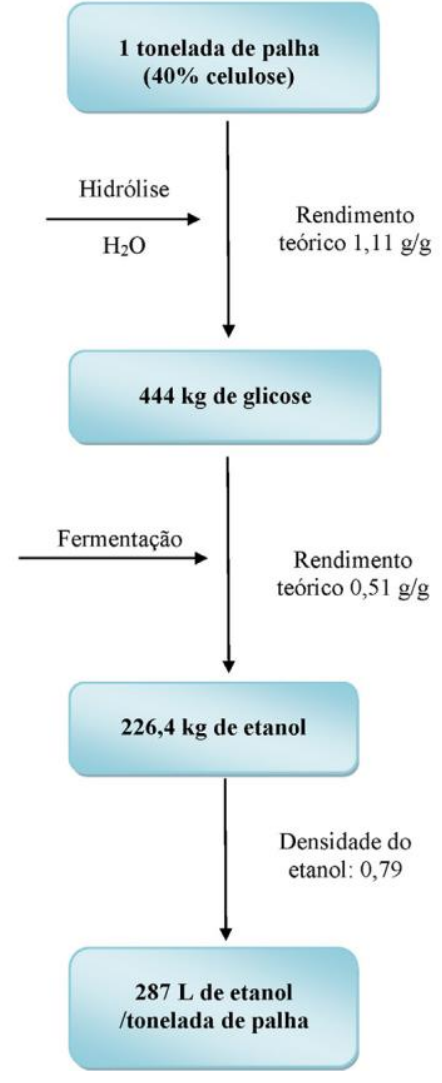

Fonte: Reproduzido de Santos et al. (2012).

\subsection{ROTAS TECNOLÓGICAS PARA PRODUÇÃO DE BIOETANOL E ELETRICIDADE A PARTIR DA CANA-DE-AÇÚCAR}

Baseado na grande disponibilidade de biomassa lignocelulósica processada na indústria da cana-de-açúcar, bem como em outras atividades agroindustriais, esta representa uma matériaprima eficaz para ser aproveitada. Nesse sentido, e à procura de novas perspectivas para sistemas de bioenergia, há um crescente interesse na utilização simultânea da biomassa lignocelulósica para produção de biocombustíveis e geração de eletricidade.

Na Fig. 2.2 é apresentada uma síntese das diversas rotas de conversão que podem ser aplicadas para transformar a biomassa em biocombustíveis e calor útil (DAMARTZIS; ZABANIOTOU, 2011). Destacam-se neste esquema, as denominadas rotas, também chamadas de plataformas termoquímicas e bioquímicas. 
Figura 2.2 - Síntese das rotas tecnológicas para produção de bioenergia.

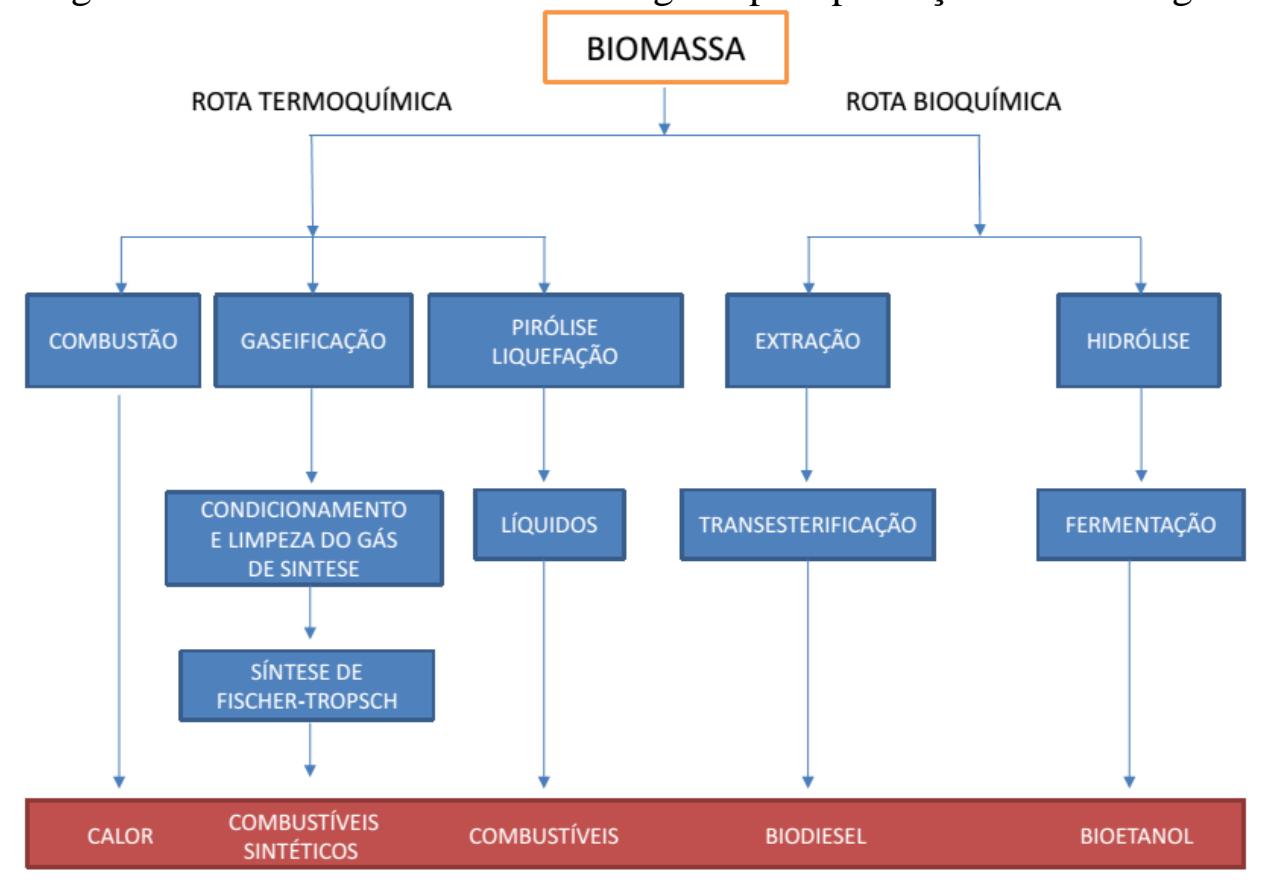

Fonte: Adaptado de Damartzis e Zabaniotou (2011).

A rota termoquímica envolve basicamente as tecnologias de Combustão, Gaseificação, Pirólise e Liquefação. Estas duas últimas tecnologias, junto com a Torrefação, processo de pré-carbonização ou pré-tratamento, que se desenvolve justamente na fase endotérmica da pirólise, entre $250^{\circ} \mathrm{C}$ e $300^{\circ} \mathrm{C}$; se caracterizam por resolver problemas relacionados à logística com o adensamento da biomassa e a viabilização de seu transporte, gerando assim, um produto que pode ser utilizado diretamente como combustível.

Enquanto, na pirólise rápida a biomassa é aquecida $\left(450^{\circ} \mathrm{C}-600^{\circ} \mathrm{C}\right)$ em curto intervalo de tempo na ausência de ar para obter um tipo de óleo combustível pesado, conhecido como bioóleo ou óleo de pirólise, este posteriormente é refinado em vários combustíveis ou usado de maneira direta. Alternativamente o bio-óleo e seu resíduo podem ser tratados como uma matéria-prima para produção de combustível BTL “biomassa-para-líquidos" (DAMARTZIS; ZABANIOTOU, 2011).

Do mesmo modo, no processo de gaseificação da biomassa é gerado o gás de síntese (syngas) principalmente constituído de $\mathrm{CO}$ e $\mathrm{H}_{2}$, que é empregado na produção de bio-produtos e de energia. Desta forma, novas tecnologias são agregadas na cadeia produtiva, por exemplo, síntese Fischer-Tropsch (F-T) para produção de hidrocarbonetos, reação catalítica ou fermentação para a produção de álcoois. 
Assim, a biomassa é convertida termoquimicamente produzindo um portfólio de produtos de alto valor agregado. Uma opção promissora dentro desse conceito é a coprodução de substâncias químicas, tais como misturas de álcoois e gás natural sintético (SNG). Essa opção se baseia na gaseificação da biomassa a baixas temperaturas, limpeza avançada dos gases, separação e melhoramento do produto intermediário (LUQUE; SPEIGHT, 2015).

Em contrapartida, a rota bioquímica compreende a fermentação dos açúcares contidos nas plantas ou obtidos a partir da lignocelulose. Existem várias alternativas para liberação de açúcares da biomassa lignocelulósica. O processo se inicia pelo pré-tratamento, que busca expor a celulose e a hemicelulose ao ataque de enzimas ou micro-organismos para liberação dos açúcares e posterior fermentação.

As estratégias de desenvolvimento podem variar desde a hidrólise dos açúcares C6 (hexose), e fermentação separada dos açúcares C5 (pentoses) e C6; hidrólise e fermentação conjunta dos açúcares C6; fermentação conjunta dos açúcares C5 e C6, etc. Os produtos obtidos podem variar de combustíveis (etanol, hidrocarbonetos) a bioprodutos (propanodiol, ácido succínico, ácido lático, etc.). Adicionalmente, óleos obtidos a partir de algas e óleos vegetais são classificados nesta plataforma. Assim, após a extração dos óleos através da transesterificação (diferentes processos e catalisadores) é possível obter glicerina e biodiesel.

No entanto, outras tecnologias são desenvolvidas, tais como metátese de olefinas, por meio da qual o óleo pode ser convertido em combustíveis de maior valor (gasolina de aviação) e mesmo alfa-olefinas e ácidos graxos.

Nesse contexto, prevê-se um aumento na produção de bioetanol a partir de sua conversão pela rota termoquímica ou por meio da rota bioquímica (hidrólise enzimática). Nota-se, que cada uma das rotas abrange diversas variedades de tecnologias, as quais podem levar a diferentes produtos. A seguir, será apresentada uma resenha destas rotas tecnológicas. 


\subsubsection{Rota de Conversão Convencional de Etanol 1G}

A etapa industrial do processamento da cana-de-açúcar a partir da rota convencional (destilaria autônoma) pode ser dividida em cinco grandes volumes de controle: Sistema de Extração, Planta de Tratamento de Caldo, Pré-evaporação, Produção de Álcool e Sistema de Cogeração, conforme ilustrado na Fig. 2.3 para o modelo de produção integrada de álcool e eletricidade (PELLEGRINI et al. 2008).

Figura 2.3 - Diagrama simplificado da rota convencional de $1 \mathrm{G}$.

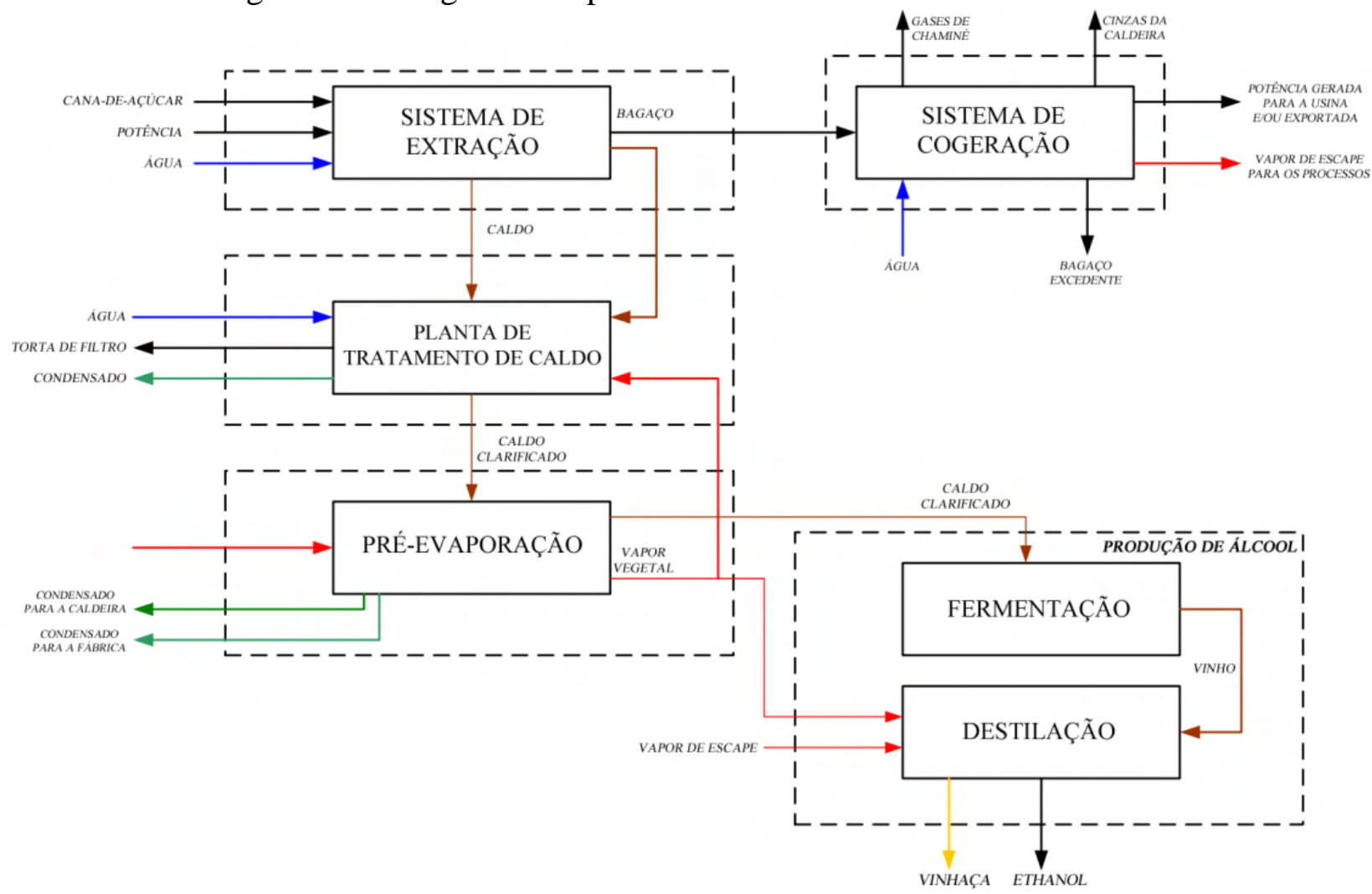

Fonte: Adaptado de Pellegrini et al. (2008).

\section{Sistema de Extração}

Esta fase é composta pelas etapas de limpeza, preparo e extração. Inicialmente, na cana-deaçúcar é feita a limpeza a seco a fim de retirar as impurezas trazidas do campo, principalmente a terra que é carregada juntamente com a cana durante o corte. O preparo da cana é realizado por meio de picadores e desfibradores, equipamentos responsáveis pela abertura das fibras, servindo como um 'pré-tratamento' que facilita a etapa de extração, onde ocorre a separação do caldo e do bagaço. 
A extração de açúcares é basicamente um processo de separação de materiais que tem como objetivo recuperar a máxima quantidade de caldo. O caldo, que é constituído por uma solução de sacarose e água, é direcionado à etapa de tratamento, enquanto o bagaço é usado como combustível no sistema de cogeração. O consumo de água na etapa de alimentação, preparo e extração é 2,615 m³/tc (ELIA NETO, 2009).

A extração do caldo é efetuada de duas maneiras: moagem e difusão, sendo a tecnologia de moagem a mais comum em usinas brasileiras. Em termos exergéticos, a moenda consome $14,4 \mathrm{kWh}_{\mathrm{ex}} / \mathrm{tc}$, enquanto o difusor consome entre 18,7 e $24,6 \mathrm{kWh}_{\mathrm{ex}} / \mathrm{tc}$, porém obtém uma maior eficiência de extração. Ainda, o uso do vapor de baixa pressão do difusor implica uma geração de eletricidade adicional em relação à moenda. Portanto, a decisão entre um ou outro sistema deve ser feita considerando o impacto do equipamento na usina como um todo (PELLEGRINI, 2009).

Neste sentido, destaca-se um estudo que avaliou diferentes possibilidades de diminuir o consumo de vapor através da análise de custo exergético. O caso base foi uma planta tradicional de produção de etanol, para a qual o custo unitário exergético de etanol e da eletricidade foram determinados. Adicionalmente, duas propostas foram avaliadas: a utilização do difusor como sistema de extração e o uso da tecnologia Pinch para realizar uma integração energética entre os sistemas de destilação e extração (MODESTO; ZEMP; NEBRA, 2009).

Os resultados da eficiência exergética, geração de irreversibilidade e custo exergético unitário dos produtos para os três casos foram analisados e comparados. Os resultados mostram a viabilidade do uso de difusores e recuperação de calor para reduzir o consumo de vapor em usinas de produção de etanol. 


\section{Tratamento de Caldo}

Os principais objetivos do tratamento de caldo (clarificação) são obter um pH onde as perdas por inversão de sacarose sejam mínimas durante os processos subsequentes, e a remoção de material insolúvel e substâncias dissolvidas indesejáveis (PELLEGRINI, 2009). O caldo misto começa a ser purificado pela remoção, através de peneiramento, dos materiais em suspensão como areia, terra, pedaços de cana, bagaço, etc (CAMARGO, 1990). Em seguida, a etapa da sulfitação, na qual o caldo entra em contato com dióxido de enxofre $\left(\mathrm{SO}_{2}\right)$, baixando o pH do mesmo para valores entre 3,8 a 4,3 (ENSINAS, 2008).

Posteriormente, se realiza a fase de calagem, com a adição ao caldo de hidróxido de cálcio $\mathrm{Ca}(\mathrm{OH})_{2}$, denominado "leite de cal", que é em seguida aquecido em duas etapas: até $70^{\circ} \mathrm{C}$, para a adição dos agentes alcalinizantes e posteriormente e até $105^{\circ} \mathrm{C}$, antes de ser enviado para o processo de flasheamento, onde os gases dissolvidos são eliminados, ao passo que a adição de ácido fosfórico, cal ou outros produtos fosfatados ao caldo em tratamento, antes da decantação, constitui uma prática bastante difundida nas usinas (CAMARGO, 1990).

Na decantação, o caldo misto é posto em repouso para que haja remoção das impurezas tanto por floculação quanto por sedimentação, visando principalmente à precipitação/coagulação dos coloides e a produção do caldo o mais clarificado possível. Durante este processo, a matéria-prima em suspensão e os coloides são separados do caldo claro. O lodo decantado sofre tratamento e é levado à filtração, onde o caldo é separado do precipitado (CAMARGO, 1990).

Nas usinas uma prática comum é a adição do leite de cal ao lodo antes de filtração, uma vez que a cal melhora as características físicas do lodo. Nota-se que temperatura do lodo acima de $80^{\circ} \mathrm{C}$ beneficia esta fase devido à redução do caldo que o impregna (CAMARGO, 1990).

Como subproduto neste processo tem-se a torta de filtro, utilizada como insumo na produção de adubo orgânico. Esta torta contém aproximadamente $2 \%$ de sacarose e $70 \%$ de umidade. O consumo de água na lavagem do filtro é de 50 m³/tc (PELLEGRINI, 2009). 
De acordo com Dias (2011), o caldo é concentrado em evaporadores, com o objetivo de obter a concentração de açúcares adequada para o processo fermentativo. Diferentes arranjos de evaporadores podem ser empregados, em simples ou múltiplo efeito, sendo os de simples efeito mais comuns na indústria brasileira. Evaporadores múltiplo efeito com quatro ou cinco estágios operando de forma co-corrente também são encontrados. Nesses equipamentos o caldo, que apresenta inicialmente concentração de 14 - $16^{\circ}$ Brix é concentrado a 55 - $65^{\circ}$ Brix nos evaporadores. Dias (2008) apresenta os aspectos mais importantes do tratamento do caldo em maiores detalhes.

\section{Produção de Álcool: Fermentação e Destilação}

No processo de fermentação se produz o álcool a partir da conversão do açúcar presente na cana. Para atingir este objetivo existe a necessidade de preparar o mosto de fermentação para que este esteja nas condições ideais de concentração, pureza e temperatura.

O mosto é um composto basicamente formado por sacarose e água. Sofre um processo de fermentação alcoólica com leveduras que convertem a sacarose em etanol, emitindo dióxido de carbono em reação exotérmica.

Embora o processo seja complexo, para fins práticos pode ser representado por meio da etapa da sacarificação, que consiste no desdobramento de substâncias não diretamente fermentescíveis em outras diretamente fermentescíveis (CAMARGO, 1990), conforme a Eq. (2.1).

$$
\begin{aligned}
& \mathrm{C}_{12} \mathrm{H}_{22} \mathrm{O}_{11}+\mathrm{H}_{2} \mathrm{O} \rightarrow \\
& \begin{array}{l}
\text { (sacarose) } \\
\text { (glicose e frutose) }
\end{array}
\end{aligned}
$$

As hexoses (glicose e frutose) geradas são convertidas a etanol e dióxido de carbono, segundo a Eq. (2.2). Esta equação foi descrita primeiramente por Gay-Lussac em 1810 (GLAZER; NIKAIDO, 2007) apud DIAS (2011).

$$
\mathrm{C}_{6} \mathrm{H}_{12} \mathrm{O}_{6} \rightarrow 2 \mathrm{C}_{2} \mathrm{H}_{5} \mathrm{OH}+2 \mathrm{CO}_{2}
$$


A partir desta reação é possível calcular a eficiência estequiométrica da produção de etanol por meio da Eq. (2.3), conhecida como o coeficiente de Gay-Lussac (DIAS, 2011).

$$
\eta=\frac{92 \mathrm{~g} \text { etanol }}{180 \mathrm{~g} \text { glicose }}=0,511 \mathrm{~g} \text { etanol } / \mathrm{g} \text { glicose }
$$

O sistema de fermentação por batelada alimentada Melle-Boinot é comumente utilizado nas usinas brasileiras, por ser mais difundido nas destilarias, tendo como característica principal a recuperação de leveduras por meio da centrifugação do vinho. O "leite de levedura" resultante da centrifugação é recuperado com adição de ácido sulfúrico e água, retornando posteriormente à dorna de fermentação. O caldo enviado às dornas varia entre 16 até $20^{\circ}$ Brix, dependendo da origem do mosto.

No interior das dornas, os açúcares são transformados em etanol. Para isto ocorrer, é necessário manter a temperatura da dorna entre $32^{\circ} \mathrm{C}$ e $35^{\circ} \mathrm{C}$, para que sejam atingidos maiores rendimentos de fermentação, uma vez que temperaturas altas inibem a ação das leveduras, reduzindo a produção de álcool (CAMARGO, 1990).

Após a fermentação, o vinho é enviado às centrífugas para a recuperação do fermento. Assim, o leite de levedura retorna às cubas para o tratamento e a fase leve da centrifugação é enviada para as colunas de destilação. O teor alcoólico do vinho produzido é $9^{\circ} \mathrm{GL}$ e o rendimento estequiométrico da fermentação é cerca de 91\% (PELLEGRINI, 2009).

O álcool contido no vinho resultante da fermentação é separado da água no processo de destilação, composto por uma primeira etapa de aquecimento do vinho para que seja atingida a temperatura ideal de operação da coluna de destilação. Desta forma, o vinho é enviado à Coluna A (Fig. 2.6), na qual a mistura água-etanol, chamada flegma (graduação alcoólica em torno de $50^{\circ} \mathrm{GL}$ ), é separada da vinhaça (fundo) e do álcool de 2 a (topo).

A flegma produzida segue para a Coluna B (retificação), onde será concentrada e purificada. Nesta fase, a concentração da mistura atinge $96^{\circ} \mathrm{GL}$. A flegmaça, efluente proveniente do conjunto de retificação, é misturada à vinhaça e destinada à agricultura. A energia necessária para operação dessas colunas é fornecida por vapor de baixa pressão (na faixa de $98 \mathrm{kPa} 245$ $\mathrm{kPa}$ ) através da troca direta ou indireta (MARTINS; FONTES; GOMES, 2009). 
Na Fig. 2.4 é ilustrada uma configuração simplificada das colunas de destilação para produção de álcool, normalmente empregada nas usinas do Brasil (DIAS, 2011).

Figura 2.4 - Esquema simplificado das colunas de destilação.

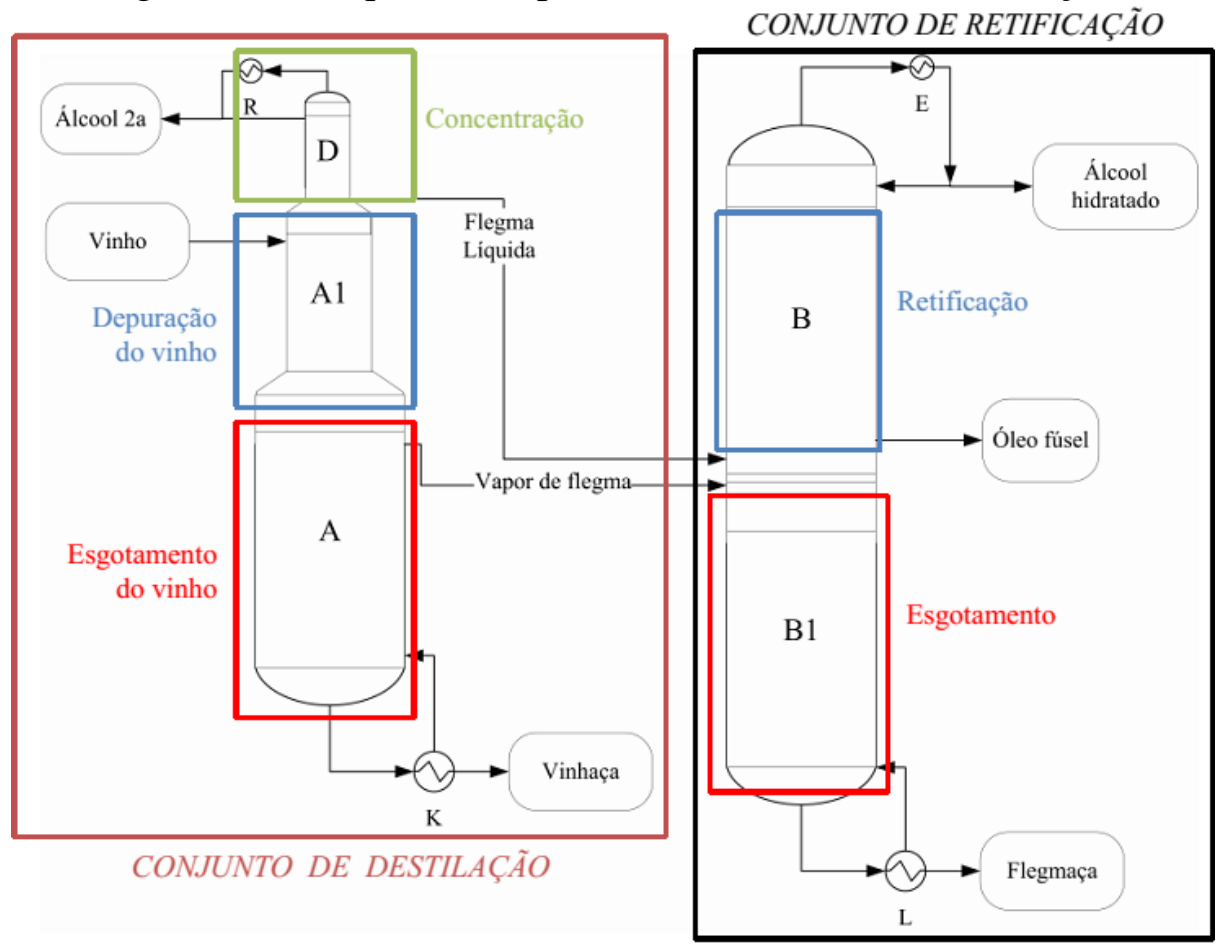

Fonte: Adaptado de Dias (2011).

As quantidades de vinhaça e flegmaça formada variam entre 9 e $15 \mathrm{~L} / \mathrm{L}$ de álcool, dependendo do tipo da troca com o vapor. A fim de se obter álcool anidro (AEAC). É ainda necessária a etapa de desidratação do álcool hidratado (AEHC), seja através de uma coluna operando com ciclohexano (destilação extrativa) ou em peneiras moleculares (adsorventes sintéticos). A concentração final do álcool anidro atinge 99,7º GL (PELLEGRINI, 2009).

\section{Desidratação}

Seguindo na linha da cadeia produtiva de etanol encontra-se a etapa de desidratação, onde o etanol hidratado é convertido em etanol anidro. Diferentes tecnologias estão disponíveis, sendo comumente adotadas configurações que empregam agentes desidratantes, como a destilação azeotrópica via ciclohexano $\left(\mathrm{C}_{6} \mathrm{H}_{12}\right)$ e a destilação extrativa via monoetilenoglicol (MEG). 
O processo de destilação extrativa começou a ser utilizado industrialmente em 2001 e no curto espaço de quatro safras tornou-se responsável por aproximadamente $25 \%$ da produção nacional de etanol anidro, enquanto que a destilação azeotrópica responde por todo o resto, quase $70 \%$ do total de etanol anidro produzido no Brasil (CORTEZ; LORA; GÓMEZ, 2008).

A destilação extrativa via MEG apresenta um custo inicial de investimento maior, cerca de $40 \%$ a $50 \%$ a mais, quando comparado com uma planta operando com ciclohexano. Sua principal vantagem está no menor consumo de vapor, variando na faixa de 0,7 a $0,8 \mathrm{~kg}$ de vapor/litro de etanol produzido, ao passo que na etapa de desidratação via destilação azeotrópica, o consumo de vapor de aquecimento vai de 1,5 a 1,6 kg vapor/litro de etanol anidro produzido, que representa aproximadamente $35 \%$ do consumo total de vapor na produção do etanol anidro nas plantas operando no Brasil (CORTEZ; LORA; GÓMEZ, 2008).

De acordo com Meirelles (2006), devido à semelhança entre os processos, é possível fazer a conversão de um sistema existente de desidratação via destilação azeotrópica $\left(\mathrm{C}_{6} \mathrm{H}_{12}\right)$ para um processo de destilação extrativa (MEG). Dita substituição tecnológica resultaria na duplicação da capacidade produtiva deste processo.

\section{Cogeração no Setor Sucroalcooleiro}

Ao longo dos anos a indústria sucroalcooleira do Brasil tem direcionado esforços para aumentar a eficiência energética das usinas, alcançando a autoprodução da energia necessária, tanto térmica quanto elétrica para sua operação.

Sobressai o avanço obtido nas caldeiras utilizadas na agroindústria canavieira, que até a década de 1980 se baseava na eliminação do bagaço, resíduo considerado como indesejável, e portanto, essas possuíam uma concepção de baixa eficiência e baixo custo (CAMARGO, 1990). 
No entanto, com a possibilidade de geração de eletricidade excedente para venda à rede, surgem alterações no processo e a introdução de tecnologias que permitam reduzir o consumo específico global de energia da planta, visando o uso racional da energia nestes sistemas, trazendo novos desafios e oportunidades para o setor sucroalcooleiro.

Por exemplo, espera-se que em curto prazo parte da palha da cana seja recuperada do campo, o que permitiria a extensão da geração de energia nas usinas durante a entressafra. Na Tab. 2.4 são ilustradas as principais tecnologias estudadas, assim com seus valores típicos de operação.

Tabela 2.4 - Tecnologias de cogeração estudadas no setor sucroalcooleiro.

\begin{tabular}{|c|c|c|c|}
\hline TECNOLOGIAS & $\begin{array}{l}T \text { de geração } \\
\text { do vapor }\left({ }^{\circ} \mathrm{C}\right)\end{array}$ & $\begin{array}{c}\text { P de geração } \\
\text { do vapor (bar) }\end{array}$ & Referência \\
\hline $\begin{array}{l}\text { CICLO RANKINE COM } \\
\text { TURBINAS DE } \\
\text { CONTRAPRESSÃO }\end{array}$ & $280-320$ & 22 & $\begin{array}{l}\text { (PELLEGRINI, 2009) } \\
\text { (ENSINAS; ARNAO; NEBRA, 2010) }\end{array}$ \\
\hline $\begin{array}{l}\text { CICLO RANKINE COM } \\
\text { TURBINAS DE EXTRAÇÃO- } \\
\text { CONDENSAÇÃO }\end{array}$ & $\begin{array}{l}480-520 \\
420-520\end{array}$ & $\begin{array}{c}60 \\
40-120\end{array}$ & $\begin{array}{l}\text { (PELLEGRINI, 2009) } \\
\text { (ENSINAS; ARNAO; NEBRA, 2010) } \\
\text { (ESCOBAR, 2010) }\end{array}$ \\
\hline $\begin{array}{l}\text { TURBINAS A GÁS ** } \\
\text { SISTEMAS COM GASEIFICAÇÃO } \\
\text { E CICLOS COMBINADOS }\end{array}$ & $\begin{array}{l}\text { Atmosférico I: } 400 \\
\text { Atmosférico II: } 510 \\
\text { Pressurizado: } 510\end{array}$ & $\begin{array}{l}42 \\
80 \\
80\end{array}$ & (PELLEGRINI, 2009) \\
\hline SUPERCRÍTICOS & $\begin{array}{l}\text { Décadas de } 60 \text { e } 70, \\
540-560 \\
\\
\text { Década de } 90 \\
\text { USC* } 600\end{array}$ & $\begin{array}{l}250 \\
290\end{array}$ & (PELLEGRINI, 2009) \\
\hline $\begin{array}{l}\text { Fonte: Elaborado pelo autor } \\
\text { exclusivamente com turbinas a } \\
\text { injeção de vapor (BIG-STIG " } S\end{array}$ & $\begin{array}{l}\text { * Ultra-Supercríticas } \\
\text { ás (BIG-GT “Biomass } \\
\text { am Injected Gas Turbin }\end{array}$ & $\begin{array}{l}\text { (USC “Ultra-Su } \\
\text { Integrated Gasific } \\
\text { ?), e finalmente s }\end{array}$ & $\begin{array}{l}\text { ercritical Plants") ** Sistemas } \\
\text { tion"), passando por sistemas com } \\
\text { stemas com ciclo combinado (BIG- }\end{array}$ \\
\hline
\end{tabular}

No Brasil, os sistemas de cogeração mais utilizados baseiam-se na utilização do ciclo Rankine com turbinas de contrapressão. Além disso, são constantes os investimentos em sistemas de geração a alta pressão (60 a 90 bar) com turbinas de extração-condensação (SEABRA; MACEDO, 2010). 
Outros aspetos de interesse no setor sucroalcooleiro é o uso e reuso de água e geração de efluentes. O uso médio da água em uma usina com destilaria anexa com uma produção de cana dividida em $50 \%$ para açúcar e $50 \%$ para o etanol é de $22 \mathrm{~m}^{3} / \mathrm{t}$ cana. Já o uso da água em uma destilaria autônoma para a produção de etanol se situa em $15 \mathrm{~m}^{3} / \mathrm{t}$ cana (ELIA NETO, 2009).

Nesse contexto, estudos visando à minimização da captação de água tornam-se necessários para viabilizar a implementação de novos projetos neste setor. Diferentes propostas estão sendo analisadas a fim de minimizar o uso de água nos processos convencionais de produção de etanol $1 \mathrm{G}$ e nos processos integrando configurações de $1 \mathrm{G}$ e $2 \mathrm{G}$.

Merecem destaque neste item os estudos de Chavez-Rodriguez et al. (2013) sobre o uso e recirculação da água em função das correntes de açúcar e etanol nas usinas brasileiras. Além disso, Mosqueira-Salazar et al. (2013), avaliaram a redução do uso de água e aplicaram a análise exergética na produção integrada de etanol de 1G-2G a partir da cana-de-açúcar.

\subsubsection{Rota de Conversão Bioquímica de Etanol 2G}

Atualmente o setor sucroalcooleiro tem como desafio a proposição e implementação de diferentes configurações de processo visando o aproveitamento integral da cana, principalmente do bagaço e da palha, subprodutos inerentes à produção de bioetanol.

Essas biomassas lignocelulósicas (bagaço e palha) representam as matérias-primas na produção de etanol 2G. Desse modo, os processos bioquímicos estão caracterizados pelas etapas de pré-tratamento e hidrólise da biomassa, permitindo assim a obtenção de açúcares fermentescíveis por meio dos polímeros de carboidratos celulose e hemicelulose, presentes na estrutura do bagaço e da palha. O interesse no desenvolvimento destes processos deve-se à possibilidade de conversão da biomassa em produtos específicos sob condições brandas de temperatura, pH e pressão (VAZ JÚNIOR, 2013).

Nesse cenário, é essencial otimizar o processo de produção de etanol $1 \mathrm{G}$ visando a obtenção de maiores frações de bagaço excedente, de forma a disponibilizá-lo em maiores quantidades na produção de etanol 2G. É importante salientar que operações na produção de etanol $1 \mathrm{G}$ e 
$2 \mathrm{G}$ podem ser compartilhadas, tais como fermentação, destilação e cogeração, o que promove uma redução nos custos de equipamentos. Na Fig. 2.5 apresenta-se uma configuração integrada da $1 \mathrm{G}$ e $2 \mathrm{G}$ visando à produção de etanol e geração de eletricidade (DIAS et al., 2013a).

Figura 2.5 - Diagrama integrando $1 \mathrm{G}$ e $2 \mathrm{G}$.

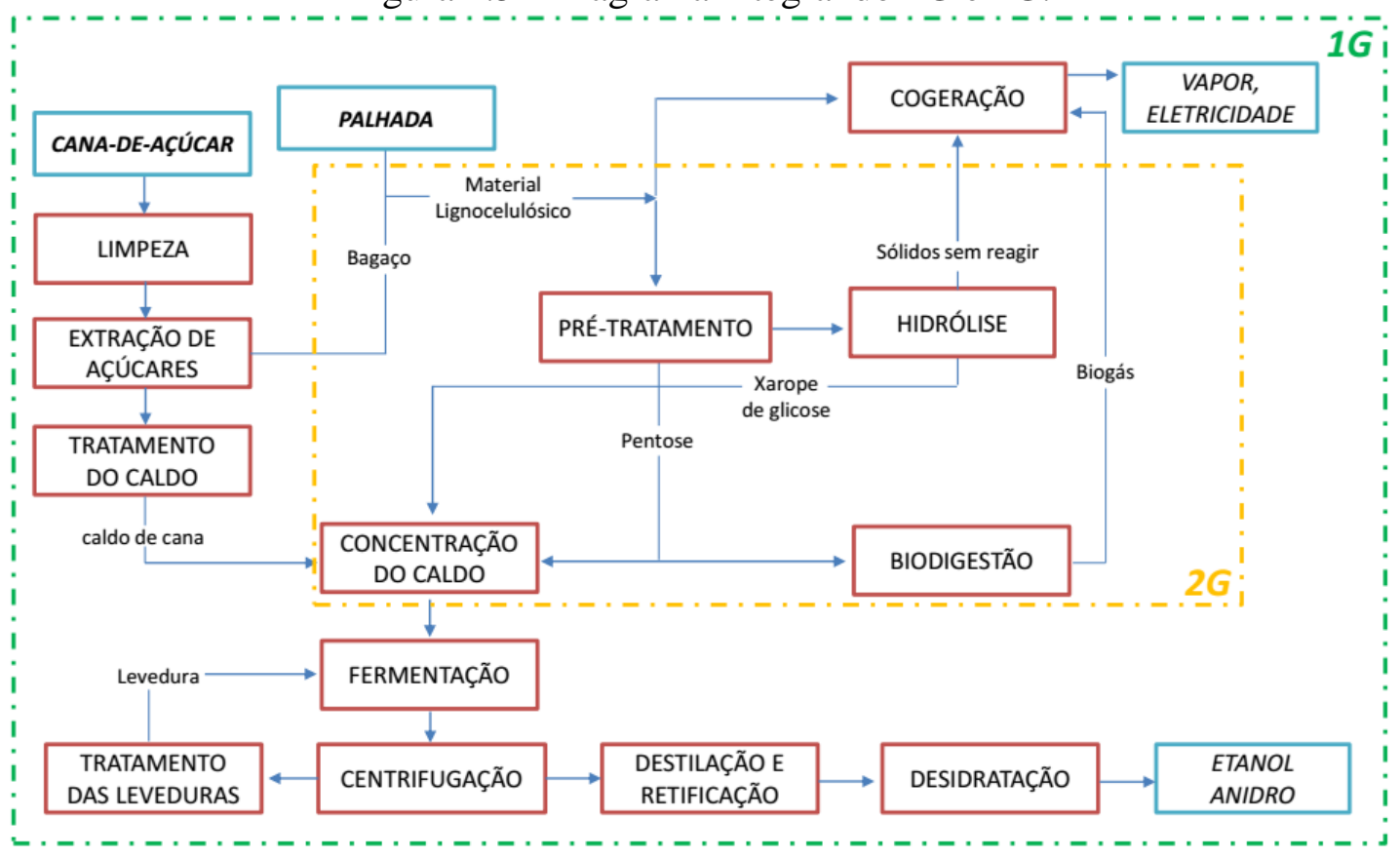

Fonte: Adaptado de Dias et al. (2013a).

Analogamente, um esquema global visando à produção de etanol a partir do bagaço da canade-açúcar (Rota 2), baseado em diversos processos de pré-tratamento e hidrólise da biomassa é ilustrado na Fig. 2.6. Nota-se na seção de hidrólise, a classificação das tecnologias de hidrólise e fermentação, sendo estas, de maneira simultânea (SSF), hidrólise e fermentação separadas (SHF), por meio de um processo simultâneo de sacarificação e cofermentação (SSCF) ou por meio de cofermentação $(C F)$. 
Figura 2.6 - Processos de produção de etanol a partir do bagaço da cana-de-açúcar.

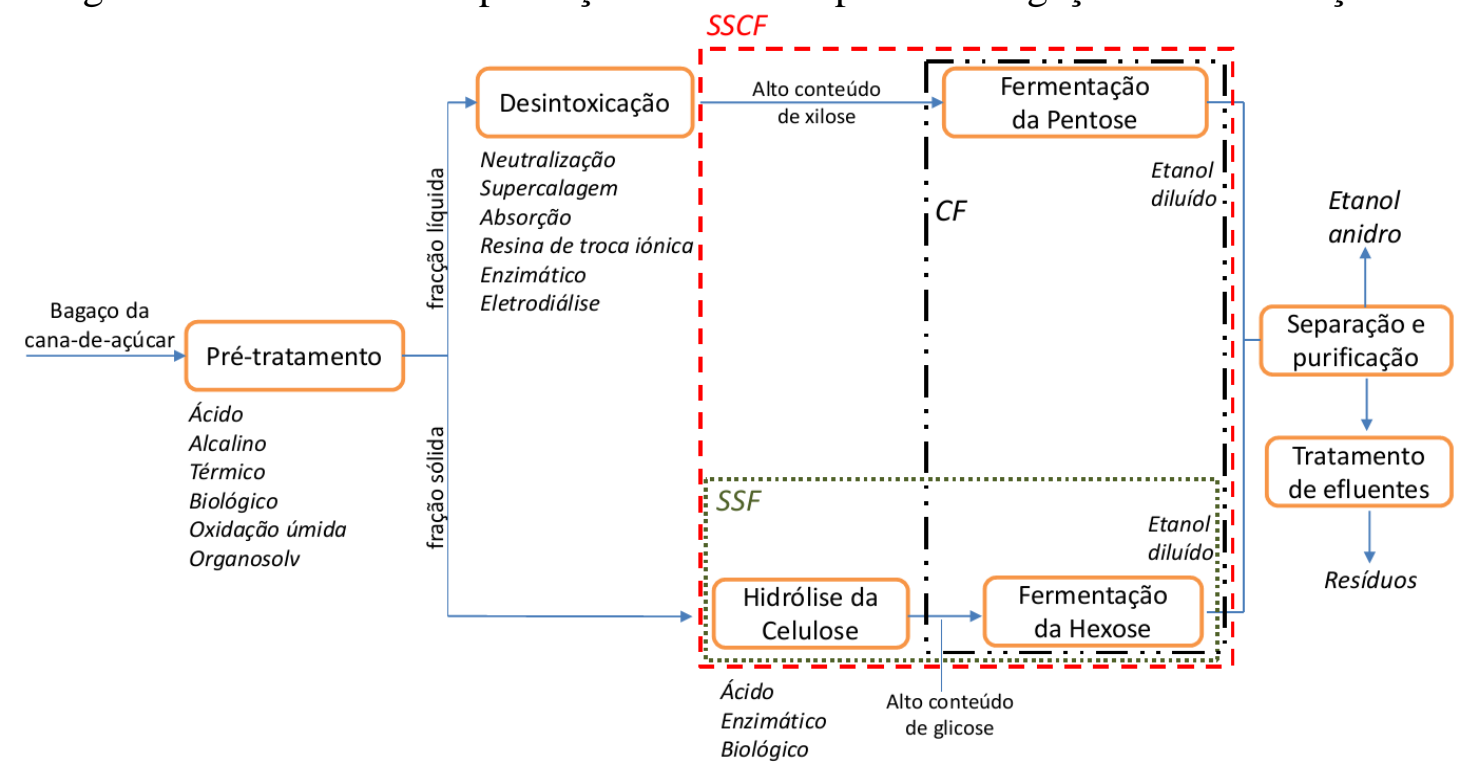

Fonte: Adaptado de Cardona; Quintero e Paz (2010).

No processo SSF a glicose é convertida continuamente em bioetanol. Recentemente, a configuração SSF tornou-se vantajosa para a fermentação simultânea de pentose (C5) e hexose (C6) através do processo SSCF. Assim, o processo da hidrólise enzimática libera continuamente açúcares C6, o que incrementa a taxa de glicólise de modo que a fermentação dos açúcares C5 torna-se mais rápida, atingindo maiores rendimentos de produção (BALAT; BALAT; OZ, 2008).

Cardona; Quintero; Paz, (2010) apresentam uma resenha do estado-da-arte e as perspectivas da produção de bioetanol do bagaço, focado na transformação atual e no potencial de açúcares, através da hidrólise e considerando tecnologias de pré-tratamento, métodos de desintoxicação, transformação biológica e os processos de hidrólise e fermentação.

No decorrer desta seção será apresentada a descrição dos principais métodos de prétratamento e hidrólise da biomassa lignocelulósica. 


\subsubsection{Pré-Tratamento da Biomassa}

$\mathrm{Na}$ produção de etanol a partir da biomassa, o pré-tratamento faz referência às ações realizadas visando deixar mais exposta a fibra de celulose previamente à sua sacarificação por meio de tratamentos físicos, físico-químicos, químicos ou biológicos. Na Fig. 2.7 é apresentado um diagrama simplificado do processo de pré-tratamento da biomassa lignocelulósica.

Figura 2.7 - Processo de pré-tratamento da biomassa.

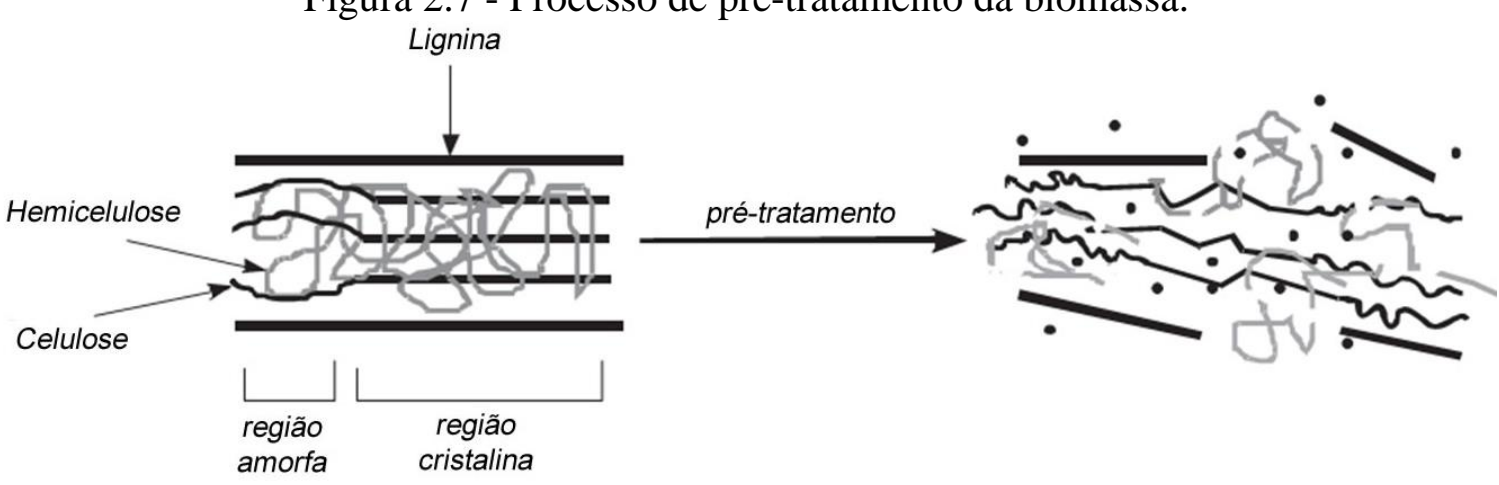

Fonte: Adaptado de Kumar et al. (2009).

Os principais objetivos do pré-tratamento são: reduzir o grau de cristalinidade da celulose, dissociar o complexo lignina-celulose e aumentar a área superficial da biomassa, de forma que a eficiência na etapa da hidrólise seja aumentada (RABELO et al. 2011).

Ressalta-se que a celulose da biomassa é resistente ao ataque enzimático. Por isto, faz-se necessária uma etapa de pré-tratamento. Esta etapa deve facilitar a conversão das frações celulósicas e hemicelulósicas da biomassa em açúcares fermentáveis. Cada tipo de biomassa requer um pré-tratamento particular para minimizar a degradação do substrato, e maximizar o rendimento de açúcar fermentável (SUN; CHENG, 2002). Nesse sentido, na Fig. 2.8 são sintetizados os principais métodos de pré-tratamento aplicados à biomassa.

Figura 2.8 - Categorização dos tipos de pré-tratamento da biomassa.

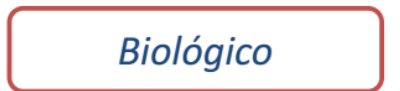

- Micro-organismos (e.g. Fungos White-,Brown-, Soft-Rot, Actinomicetos)

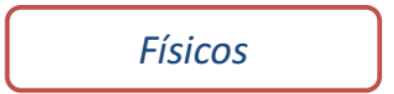

- Cominuição mecânica (e.g. Picagem, Moagem) - Extrusão (e.g. Raios Gama, Micro-ondas)

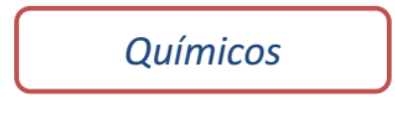

- Ácida "Líquidos iônicos - Alcalina - Oxidativo - Organosolv "Ozonólise

\section{Físico-químicos}

- Explosão a vapor

- Explosão/expansão com amônia

- Água quente pressurizada (Processo hidrotérmico)

Fonte: Elaborado pelo autor. 
Os pré-tratamentos biológicos inseridos no esquema anterior estão caracterizados pelo uso de fungos para solubilizar a lignina. Assim, a biodeslignificação e a degradação biológica da lignina são realizadas utilizando micro-organismos. Estes processos têm baixos rendimentos de produção e longos tempos de reação; devido à intoxicação dos micro-organismos pelos derivados da lignina. Porém, a baixa taxa de hidrólise impede a sua implementação (HAMELINCK; HOOIJDONK; FAAIJ, 2005).

A seguir é feita uma descrição de alguns dos métodos de pré-tratamento mais estudados objetivando sua aplicação na indústria sucroalcooleira.

\section{Método de Explosão a Vapor}

O pré-tratamento de explosão a vapor, também conhecido como auto-hidrólise é um dos métodos mais empregados nos materiais lignocelulósicos. Este método se caracteriza pela rápida despressurização e resfriamento da biomassa no final do pré-tratamento, o qual causa a “explosão” da água contida na biomassa.

O processo causa a degradação da hemicelulose e a transformação da lignina, devido à alta temperatura utilizada, mas incrementa o potencial de hidrólise da celulose. Fatores como tempo de residência, tamanho de partícula e o teor de umidade afetam este método (KUMAR et al. 2009).

Além disso, a adição de $\mathrm{H}_{2} \mathrm{SO}_{4}, \mathrm{SO}_{2}$ ou $\mathrm{CO}_{2}$ neste tipo de pré-tratamento pode melhorar efetivamente a hidrólise enzimática diminuindo a formação de inibidores e conduzindo a uma remoção mais completa de hemicelulose (PRASAD; SINGH e JOSHI, 2007). Diferentes trabalhos envolvendo o pré-tratamento do bagaço da cana por meio deste método são encontrados na literatura, Carrasco et al. (2010), Martín et al. (2002) e Martín et al. (2007).

\section{Método de Água Quente Pressurizada}

Neste tipo de pré-tratamento hidrotérmico, também chamado de LHW por suas siglas em Inglês (Liquid Hot Water), a água quente pressurizada é utilizada visando solubilizar, principalmente, a hemicelulose, fazer a celulose mais acessível ao ataque enzimático e evitar a formação de inibidores. 
De acordo com Mosier et al. (2005), a biomassa pré-tratada com este tipo de método resulta em 40 a $60 \%$ da biomassa total dissolvida no processo, sendo $4-22 \%$ da celulose, $35-60 \%$ da lignina e quase toda a hemicelulose removida durante um tempo de 15 minutos e temperaturas de 200 a $230^{\circ} \mathrm{C}$. Nesta referência também se indica que para evitar a formação de inibidores, o pH deve ser mantido entre 4 e 7. Mantendo o pH nestes limites, a formação de monossacarídeos é minimizada. No caso particular do bagaço da cana-de-açúcar a temperatura de operação encontra-se na faixa de 200 a $280{ }^{\circ} \mathrm{C}$ (PANDEY et al., 2014)

\section{Método Organosolv}

No processo Organosolv utiliza-se uma mistura de solvente orgânico associado à água com um ácido, o que promove um aumento da solubilidade da lignina. A fração hemicelulósica pode ser retirada previamente à deslignificação, por meio de uma etapa de pré-hidrólise, o que permite um melhor aproveitamento da hemicelulose e evita sua degradação na etapa de deslignificação.

Os solventes orgânicos empregados neste método incluem Metanol, Etanol, Acetona, Etilenoglicol e Álcool Tetrahidrofurfuril (ZHENG; PAN; ZHANG, 2009). Ácidos orgânicos como oxálico, acetilsalicílico ou salicílico também poder ser utilizados como catalisadores.

\section{Método de Explosão com Amônia}

$\mathrm{O}$ processo de explosão/expansão com amônia $\left(\mathrm{NH}_{3}\right)$, também conhecido como AFEX por suas siglas em Inglês (Ammonia Fiber Explosion/Expansion), é um pré-tratamento físicoquímico no qual o material lignocelulósico entra em contato com amônia concentrada sob temperaturas moderadas, aumentando a acessibilidade da celulose ao ataque enzimático sem remover a lignina ou hemicelulose da biomassa. Além disso, neste método a amônia deve ser recirculada visando obter baixos custos no processo (ZHENG; PAN; ZHANG, 2009).

\section{Método Ácido}

Neste tipo de pré-tratamento a lignina solubiliza rapidamente e precipita em meios ácidos. A solubilização da hemicelulose e a precipitação da lignina resultante é função do ácido (forte ou diluído) empregado no processo (HENDRIKS; ZEEMAN, 2009). 
Geralmente, utiliza-se ácido sulfúrico como agente, embora outros ácidos (e.g. nítrico, clorídrico e fosfórico) possam ser utilizados. Neste processo a mistura (solução do ácido e biomassa) pode ser aquecida indiretamente no reator, ou diretamente por injeção de vapor (LORA; VENTURINI, 2012). De acordo com Prasad; Singh e Joshi (2007), o pré-tratamento ácido precisa de condições menos severas para atingir altos rendimentos de conversão de xilana para xilose, parâmetro necessário para garantir a viabilidade econômica do processo, uma vez que a xilana representa aproximadamente um terço dos carboidratos totais da biomassa.

\section{Método Alcalino}

Os processos de pré-tratamento com bases utilizam temperaturas e pressões mais baixas quando comparados com outros métodos. Os álcalis (bases) mais comuns usados como agentes neste tipo de pré-tratamento são Hidróxido de sódio $(\mathrm{NaOH})$, Hidróxido de cálcio $\mathrm{Ca}(\mathrm{OH})_{2}$, Amônia $\left(\mathrm{NH}_{3}\right)$ e Uréia $\left(\mathrm{NH}_{2}\right)_{2} \mathrm{CO}$.

Ao contrário dos métodos ácidos, tem-se a limitação que algumas bases são convertidas em sais irrecuperáveis ou incorporadas como sais na biomassa por meio das reações de prétratamento (RABELO, 2010).

Finalmente, uma comparação dos processos de pré-tratamento da biomassa em termos das condições de operação empregadas em cada método é ilustrada na Tab. 2.5. Já uma breve descrição das vantagens e desvantagens destes métodos é apresentada na Tab. 2.6. 


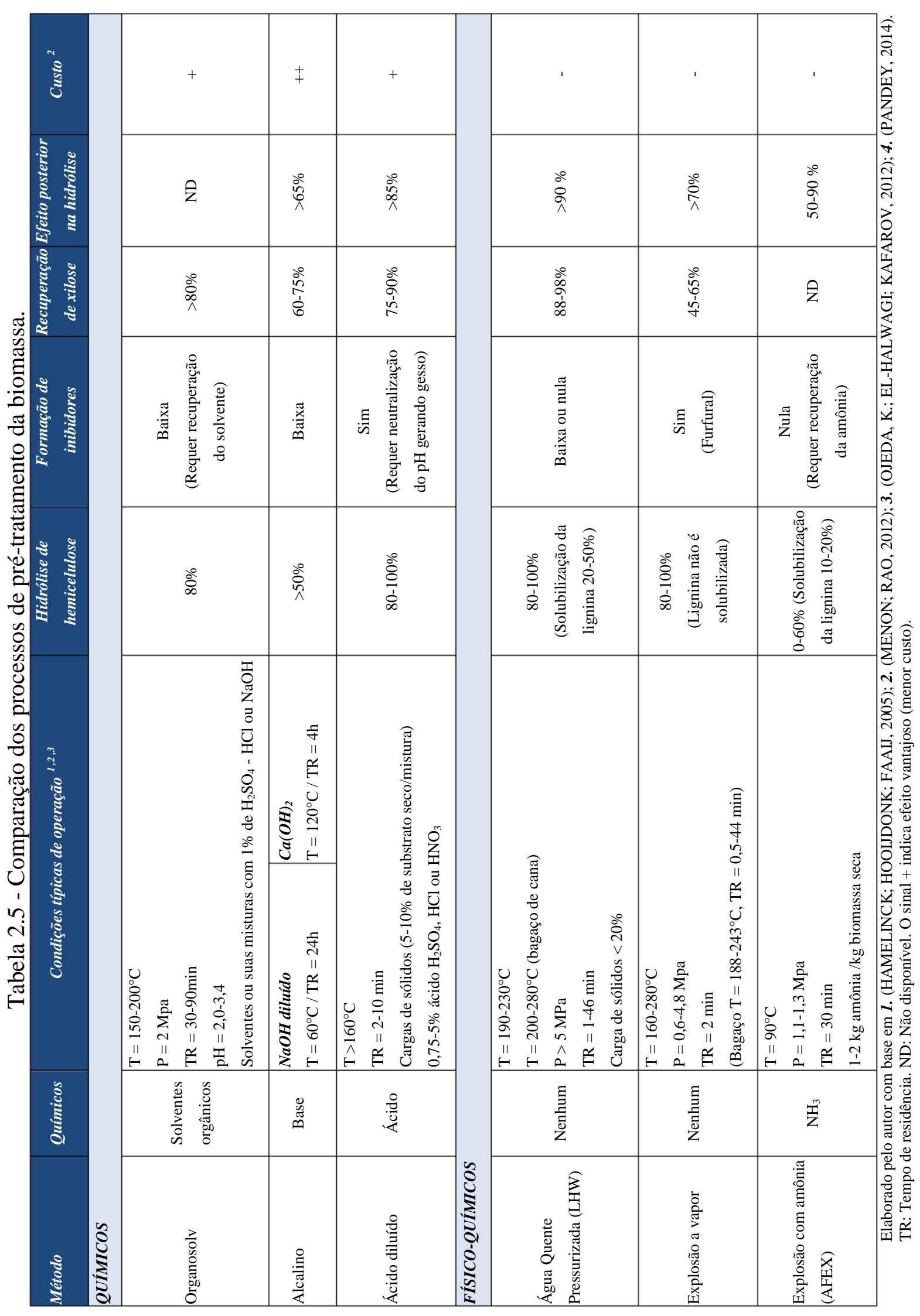




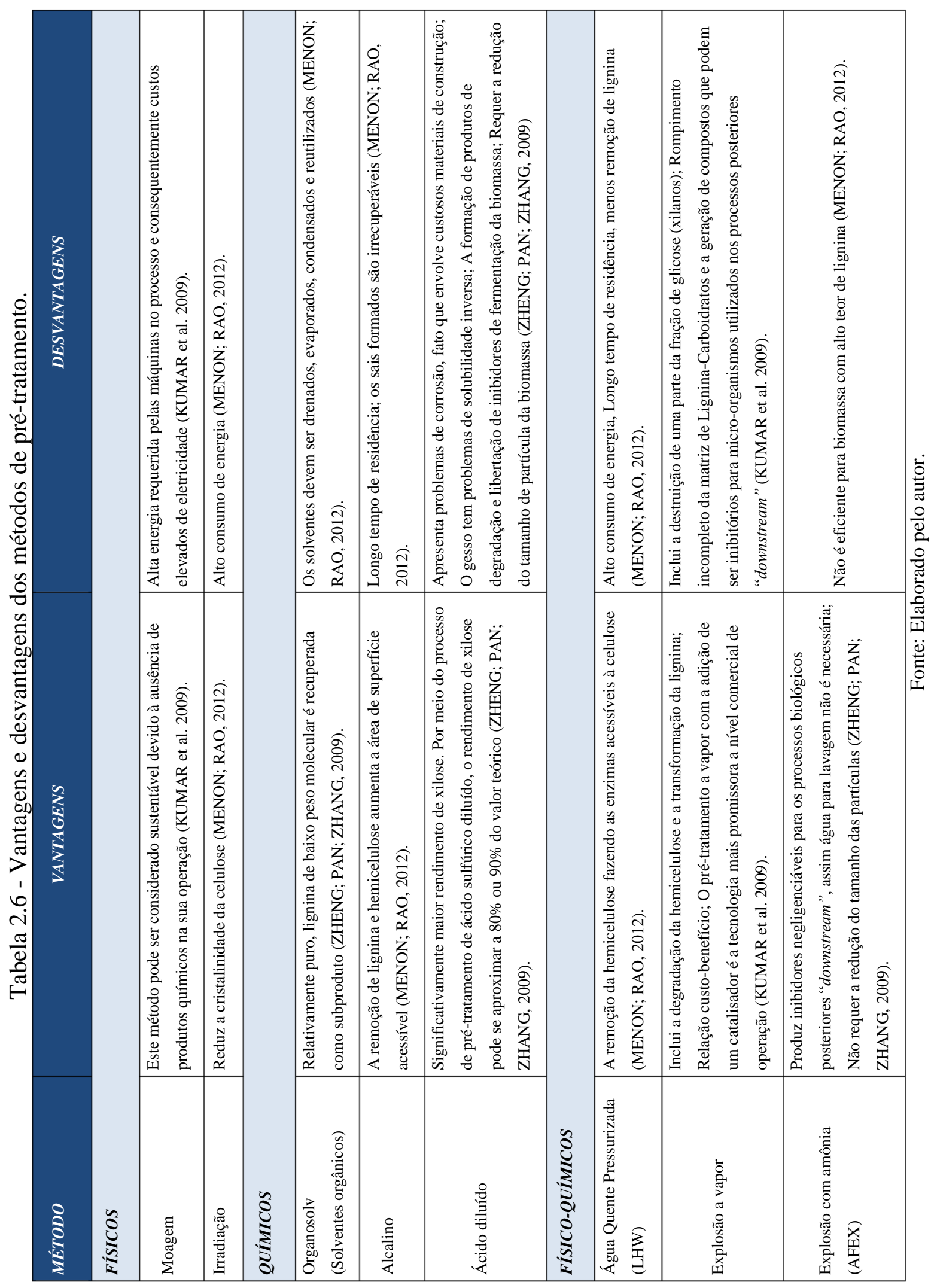




\subsubsection{Hidrólise da Biomassa}

No processo de hidrólise da celulose obtém-se glicose, composto facilmente fermentescível por meio de micro-organismos comumente empregados na indústria. A hidrólise da hemicelulose, no entanto, gera pentoses e compostos que ainda não possuem tecnologia de fermentação a etanol em nível comercial. Destaca-se ainda que o processo da hidrólise pode ser conduzido mediante métodos químicos ou enzimáticos.

A hidrólise química (ácida) ocorre em altas temperaturas e em reatores pressurizados, e os ácidos mais comumente utilizados são o sulfúrico e o clorídrico. Neste tipo de hidrólise, se as condições de reação (temperatura e concentração de ácido) não forem muito bem controladas, ocorrerá degradação dos produtos finais (açúcares e lignina), causando inibição ao metabolismo da fermentação posterior. Além disso, os rendimentos de açúcares obtidos são muito baixos sendo necessários reatores de alto custo e resistentes à corrosão (RABELO et al. 2011).

Entretanto, a hidrólise enzimática desses materiais é conduzida por meio do complexo de enzimas da celulase. Este processo ocorre a baixas temperaturas e à pressão atmosférica, além de ser menos poluente quando comparado à hidrólise ácida. Um dos grandes desafios desta tecnologia está relacionado à redução dos custos de produção destes complexos enzimáticos.

Geralmente, o processo de hidrólise enzimática apresenta vantagens associadas à obtenção de rendimentos superiores a $0,85 \mathrm{~g}$ glicose/g celulose, sob temperaturas de $40-50{ }^{\circ} \mathrm{C}$ e pressão atmosférica (RABELO et al. 2011). Aspectos operacionais relacionados à elevada duração do processo (48-72h), desativação catalítica por inibição da atividade enzimática, bem como do elevado custo das enzimas, têm acarretado incertezas quanto à viabilidade econômica do processo de hidrólise enzimática no contexto da produção de bioetanol a partir de biomassas lignocelulósicas (MACEDO, 2008).

Na Fig. 2.9 são ilustradas esquematicamente as rotas tecnológicas de hidrólise e fermentação. Cada uma dessas alternativas de conversão para o aproveitamento dos açúcares apresenta vantagens e desvantagens que vêm sendo avaliadas por diversos grupos de pesquisa, sem haver ainda um consenso. 
Figura 2.9 - Rotas de hidrólise e fermentação.

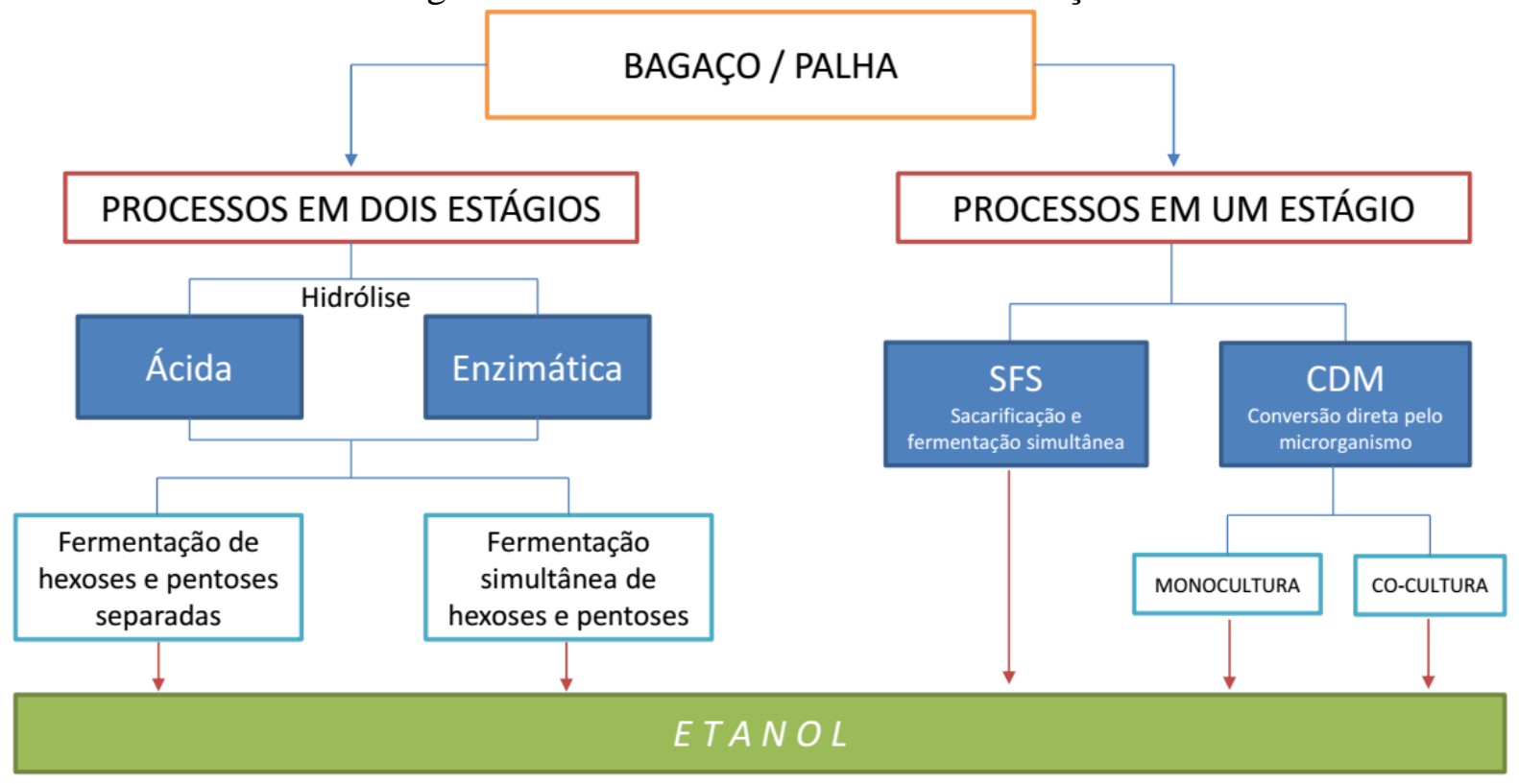

Fonte: Adaptado de Rabelo et al. (2011).

Nos processos em dois estágios, primeiramente é realizada a hidrólise (por via ácida ou enzimática) e, posteriormente, a fermentação dos açúcares, quando se pode ter a fermentação das pentoses, seguida da fermentação das hexoses ou a fermentação simultânea de hexoses e pentoses. Já nos processos em um estágio, a hidrólise e a fermentação são realizadas conjuntamente.

No processo de sacarificação e fermentação simultânea (SFS), empregam-se celulases de um micro-organismo celulolítico (em geral fungos Trichoderma) junto com um micro-organismo produtor de etanol. Por outro lado, na conversão direta via micro-organismos (CDM) estes produzem as enzimas e realizam a fermentação. Pode-se empregar a monocultura, na qual um único micro-organismo hidrolisa a celulose e fermenta os açúcares a etanol ou a co-cultura, onde um micro-organismo realiza a hidrólise e outro a fermentação (RABELO et al. 2011). 


\subsubsection{Rota de Conversão Termoquímica de Etanol 2G}

Sob a denominação de processos termoquímicos de conversão de biomassa encontram-se várias tecnologias que conduzem a produtos primários e secundários diferentes. A principal característica destes processos é o fato de usarem altas temperaturas para que ocorram as reações químicas.

A gaseificação da biomassa consiste na sua conversão em um gás combustível denominado gás de síntese ou syngas, permitindo o uso de motores e turbinas em aplicações de geração, o que constitui um potencial técnico para o acréscimo da eficiência na conversão. Assim, a partir de sistemas de gaseificação da biomassa e catalisadores também é possível obter hidrocarbonetos com características similares aos combustíveis líquidos comerciais.

No entanto, estas opções de conversão ainda apresentam desafios tecnológicos para sua implementação e desenvolvimento, embora a biomassa seja acessível a um custo reduzido. Neste sentido a descrição das variáveis e fatores identificados como os mais representativos no desempenho do sistema de gaseificação de acordo com Lora e Venturini (2012), são:

- A razão de equivalência (comumente conhecida como fator de ar);

- O tipo de agente de gaseificação (ar, oxigênio, vapor);

- O tempo de residência, o qual é limitado pela velocidade de fluidização quando o processo é realizado em reatores de leito fluidizado;

- As características da biomassa em termos da sua composição físico-química e o conteúdo energético;

- A utilização de catalisadores.

Isto considerando que a gaseificação é um processo de oxidação parcial que é determinado pelas quantidades de ar e combustível introduzidas no reator, sendo estas as principais variáveis envolvidas no processo. Ainda, os diferentes tipos de gaseificadores (reatores) onde o processo é desenvolvido, e suas características de projeto, adicionam outros fatores que igualmente exercem influência na eficiência do processo de transformação termoquímica. 
É interessante notar que nesta pesquisa será adotado um gaseificador de leito fluidizado-CFB e um gaseificador de leito arrastado-EF. Assim, as variáveis de maior importância sobre a gaseificação de biomassa neste tipo de equipamentos são apresentadas a seguir de acordo com alguns dos parâmetros estabelecidos em Lora e Venturini (2012).

1. Fator de ar: Esta variável corresponde ao valor da relação ar-combustível real utilizada durante o processo, dividida pela relação ar-combustível teórica (estequiométrica), conforme ilustrado na Eq. (2.4). Portanto, o fator de ar define a quantidade de combustível queimado (combustão completa) com relação á quantidade gaseificada (oxidação parcial e/ou redução).

$$
F . A=\frac{\left(R_{A} / C\right)_{\text {real }}}{\left(R_{A / C}\right)_{e s t}}
$$

Onde:

$\left(R_{A} / C\right)_{\text {est }}$ : Relação ar-combustível estequiométrica

$\left.\left(R_{A}\right)_{C}\right)_{\text {real }}$ : Relação ar - combustível real

A relação ar - combustível estequiométrica $\left(\mathrm{m}^{3}\right)$ a condições normais de pressão e temperatura por quilograma $(\mathrm{kg})$ de biomassa pode ser expressa em função dos dados da análise elementar do combustível (em base úmida), como se mostra na Eq. (2.5).

$$
\left(R_{A}\right)_{\text {est }}=0,0889 \cdot(C+0,375 \cdot S)+0,265 \cdot H-0,0333 \cdot O
$$

Os fatores de ar convencionais na gaseificação da biomassa em leito fluidizado estão na faixa de 0,2 e 0,4; o que representa que, para cada kg de combustível precisa-se de 20 a 40\% da quantidade de ar estequiométrica necessária para combustão.

2. Temperatura: Esta propriedade deve estar condicionada às quantidades de ar e combustível que participam na reação (fator de ar). Além disso, a composição elementar e as características imediatas (voláteis e carbono fixo principalmente) do combustível a ser gaseificado têm um efeito considerável sobre esta variável. 
Deve-se garantir que durante o processo a temperatura tenha o valor adequado para que o carbono presente no combustível seja transformado por completo e não se acumule nas cinzas, acarretando uma irreversibilidade no sistema.

3. Capacidade de produção de gás: Este parâmetro expressa a vazão de gás gerado por unidade de massa de combustível alimentado ao sistema. Note-se que a produção de gás tem uma relação diretamente proporcional com o fator de ar e com o tempo de residência dos gases na zona de redução. Valores típicos de produção de gás em reatores do tipo leito fluidizado estão na faixa de 1,8 e $2,5 \mathrm{Nm}^{3} / \mathrm{kg}$ de biomassa.

4. Composição e poder calorífico do gás produzido: $O$ gás produzido na gaseificação de biomassa é composto por $\mathrm{CO}_{2}, \mathrm{CO}, \mathrm{CH}_{4}, \mathrm{H}_{2} \mathrm{O}, \mathrm{H}_{2}, \mathrm{~N}_{2}, \mathrm{O}_{2}$ e poucas quantidades de alcatrão. Além disso, as concentrações de $\mathrm{CO}, \mathrm{H}_{2}$ e $\mathrm{CH}_{4}$ estão condicionadas ao desenvolvimento das reações envolvidas na gaseificação. Dessa forma o agente de gaseificação (ar, oxigênio, vapor) utilizado tem uma influência considerável na composição e no poder calorífico do gás produzido (syngas).

5. Eficiência da gaseificação: Este parâmetro pode ser determinado por duas vias: $a$ quente e a frio. Segundo Kumar; Sharma e Bhandari (2014) a eficiência a quente do gás é calculada a partir da Eq. (2.6).

$$
\eta_{\text {quente }}=\left(\frac{E Q}{E B S+E S}\right) \cdot E G S \cdot 100 \%
$$

Onde:

$E Q$ - Energia química do syngas seco por unidade de volume $\left(\mathrm{MJ} / \mathrm{Nm}^{3}\right)$

$E B S$ - Energia da biomassa seca $(\mathrm{MJ} / \mathrm{kg})$

$E S$ - Energia sensível do agente de gaseificação (MJ/kg)

$E G S$ - Eficiência do gás seco por $\mathrm{kg}$ de biomassa seca $\left(\mathrm{Nm}^{3} / \mathrm{kg}\right)$

De acordo com Pellegrini e Oliveira Jr, (2007), a eficiência a frio do gás é determinada por meio da Eq. (2.7).

$$
\eta_{\text {frio }}=\frac{(\dot{m} \cdot P C I)_{\text {gás produzido }}}{(\dot{m} \cdot P C I)_{\text {biomassa }}}
$$


Além dos fatores descritos, outra variável a ser levada em consideração é o efeito da composição das cinzas na transformação termoquímica, por causa do caráter catalítico dos minerais presentes neste processo. Segundo Kirubakaran et al. (2009), a existência de traços de metais nas cinzas resulta em alterações da temperatura de decomposição térmica da celulosa da biomassa.

Ainda, merece destaque a expressão da razão de vapor para biomassa (Steam to biomass ratio-SB) calculada por meio da Eq. (2.8).

$$
S B=\frac{\text { fluxodevapor }(\mathrm{kg} / \mathrm{h})}{\text { fluxodebiomassa }(\mathrm{kg} / \mathrm{h})}
$$

Finalmente, as características próprias do combustível tais como a granulometria e umidade tem efeitos igualmente importantes no processo de gaseificação. Neste sentido, a umidade pode afetar consideravelmente a composição do gás combustível dada à redução da temperatura no interior do gaseificador por causa da energia requerida para a vaporização da água presente no combustível.

\section{Tipos de gaseificadores}

O gaseificador ou reator é o equipamento no qual acontece a conversão termoquímica da biomassa em syngas. A classificação dos tipos de gaseificadores baseia-se no movimento relativo do fluxo da biomassa e do agente de gaseificação.

De um modo geral, os gaseificadores são classificados em quatro tipo de reatores: Leito fixo ou de leito móvel (gases que fluem em contracorrente, co-corrente ou fluxo cruzado), Leito fluidizado (a biomassa é mantida em suspensão por um fluxo ascendente de gás de gaseificação), Leito arrastado (biomassa e ar movimentam-se na direção co-corrente relativa ao fluxo e as reações ocorrem em uma nuvem densa de partículas muito finas com pressões elevadas), Plasma (a fração orgânica da matéria-prima sólida é convertida em syngas de elevado valor calórico).

Na Fig. 2.10 é ilustrada uma representação esquemática da classificação dos tipos de gaseificadores. 
Figura 2.10 - Categorização dos gaseificadores.
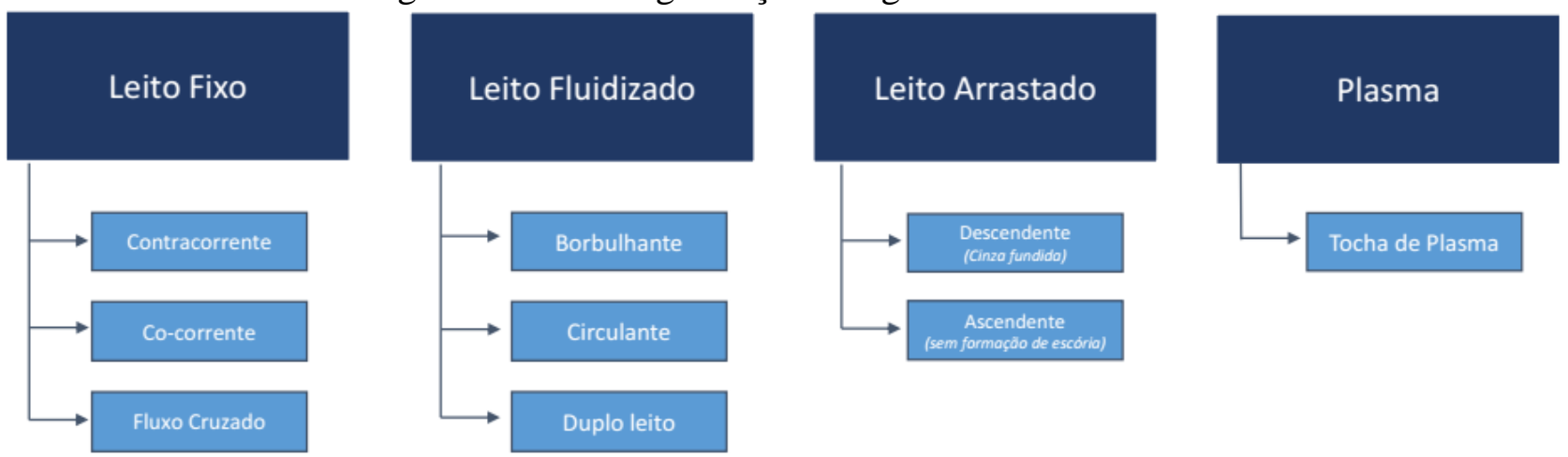

Fonte: Elaborado pelo autor.

Destaca-se que os gaseificadores e o gás resultante nos processos de gaseificação possuem características específicas dependendo da tecnologia adotada. Porém, a aplicação do produto final, as condições de operação e a qualidade requerida do gás, são fatores determinantes na seleção do tipo de gaseificador. Deste modo, a Tab. 2.7 sintetiza os principais parâmetros operacionais para diversos tipos de gaseificadores.

Tabela 2.7 - Parâmetros de funcionamento dos principais tipos de gaseificadores.

\begin{tabular}{|lcccc|}
\hline Características técnicas & Leito Fixo & Leito Fluidizado & $\begin{array}{c}\text { Fluxo de } \\
\text { arraste }\end{array}$ & Plasma \\
\hline $\mathrm{T}\left({ }^{\circ} \mathrm{C}\right)$ & $700-1200$ & $<900$ & $1200-1500$ & $>1500$ \\
\hline $\begin{array}{l}\text { Alcatrão } \\
\left(\mathrm{g} / \mathrm{Nm}^{3}\right)\end{array}$ & $\begin{array}{l}\text { Intermediário } \\
\text { Contracorrente: } 30-150 \\
\text { Co-corrente: } 0,015-3 \\
\text { Fluxo cruzado: } 0,01-0,1\end{array}$ & $\begin{array}{l}\text { Intermediário } \\
\text { Borbulhante: } 0,1-1 \\
\text { Circulante: } 1-30\end{array}$ & Isento & Isento \\
\hline $\begin{array}{l}\text { Escala } \\
(\mathrm{MW}\end{array}$ & $<10$ & $10-100$ & $>100$ & 50 \\
\hline Alimentação da biomassa $(\mathrm{mm})$ & $<5-150$ & $<20$ & $<1$ & Irrelevante \\
\hline Teor de umidade $(\%)$ & $5-60$ & $20-30$ & $15-35$ & Irrelevante \\
\hline Tempo de residência & 60-120 min & $20-30$ min & $<10 \mathrm{~s}$ & $2-4 \mathrm{~s}$ \\
\hline Eficiência a quente $(\%)$ & $\begin{array}{l}\text { Contracorrente: } 90-95 \\
\text { Co-corrente: } 85-90\end{array}$ & $\begin{array}{l}\text { Borbulhante: } 89 \\
\text { Circulante: } 89\end{array}$ & 80 & $80-95$ \\
\hline
\end{tabular}

Fonte: Elaborado pelo autor com base em Stevens (2001); Ruiz et al. (2013); Abdollahi-Neisiani et al. (2013).

Ainda é interessante notar dentre os parâmetros de funcionamento dos gaseificadores a potência térmica fornecida segundo o tipo de gaseificador. Na Fig. 2.11 apresentam-se as faixas de operação para cada reator (JIN; LARSON; CELIK, 2009). 
Figura 2.11 - Potência térmica por tipo de gaseificador.

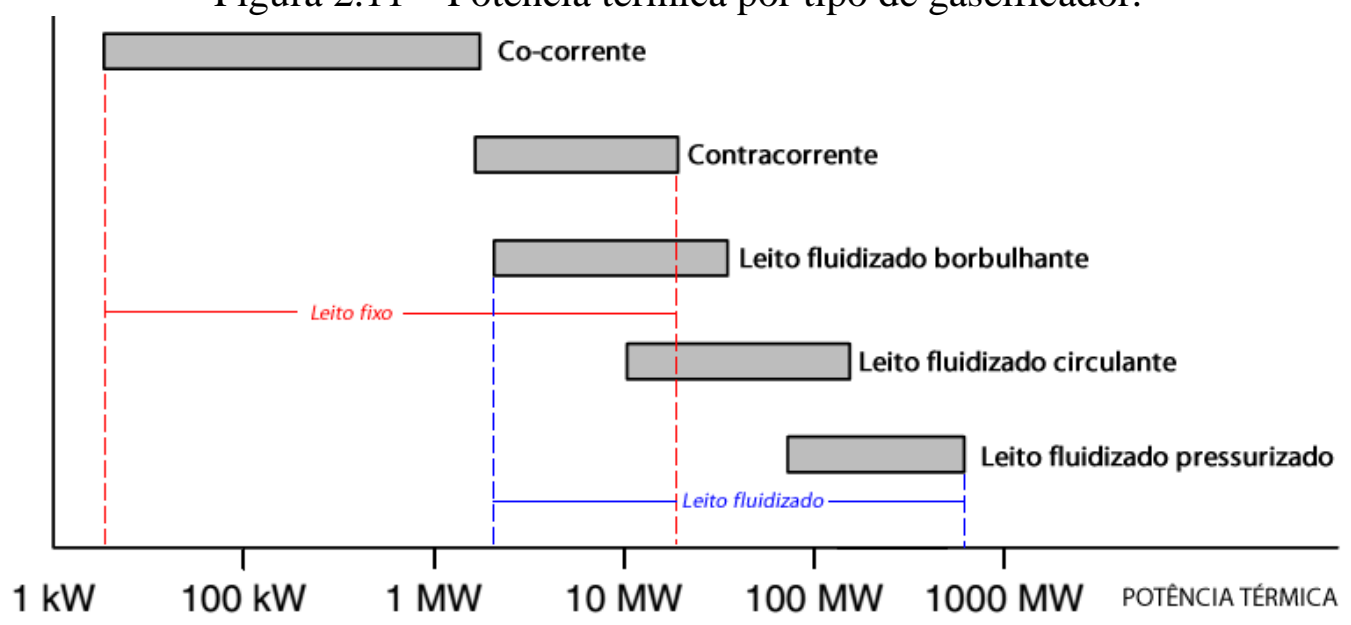

Fonte: Adaptado de Jin; Larson e Celik, (2009).

Como mencionado os gaseificadores do tipo leito fluidizado-CFB e leito arrastado-EF serão adotados na simulação da rota 3 desta pesquisa, pois estes equipamentos encontram-se na faixa de potência requerida para sua avaliação. Nesse sentido, algumas considerações adicionais destas tecnologias são apresentadas a seguir.

O tipo de gaseificador CFB (circulating fluidized bed) consiste em uma câmara de reação que contém partículas inertes suportadas por uma placa distribuidora e mantidas em suspensão por um fluido que atravessa o reator em sentido ascendente. Neste tipo de reator não se apresentam zonas diferenciadas de reação. Os reatores de leito fluidizado têm um leito isotérmico que opera usualmente em temperaturas na faixa de $700-900{ }^{\circ} \mathrm{C}$ (BELGIORNO et al., 2003).

Os principais tipos de gaseificadores de leito fluidizado são do tipo borbulhante e circulante e podem ser atmosféricos ou pressurizados. Por um lado, gaseificadores de leito fluidizado borbulhante são típicos de aplicações de escala mediana. Por outro lado, os gaseificadores de leito fluidizado circulante são de fácil escalonamento e típicos de grandes capacidades, tanto para aplicações de gaseificação como de combustão. Estes sistemas encontram-se entre 6 e 7 no nível de maturidade tecnológica no TRL (Technology Readiness Level), classificação que denota a demostração dos sistemas em ambiente operacional. 
Nota-se que um gaseificador operando em condição de leito fluidizado utilizando biomassa como insumo apresentam vantagens consideráveis, dentre as quais se destacam a alta taxa de conversão de carbono em gás energético devido às elevadas eficiências dos mecanismos de transferência de calor e massa, além da uniformidade da temperatura ao longo do reator.

A modelagem deste tipo de reator é complexa. Vale a pena destacar nesta área os trabalhos do Prof. Márcio de Souza-Santos do Departamento de Engenharia Mecânica da UNICAMP por meio do desenvolvimento do simulador CeSFaMB-Comprehensive simulator of Bubbling and Circulating Fluidized Bed and Moving Downdraft and Updraft Bed Equipments (DE SOUZA-SANTOS; BENINCA, 2014; DE SOUZA-SANTOS; BERNAL e RODRIGUEZTORRES, 2015).

Constata-se que os gaseificadores de leito arrastado foram inicialmente desenvolvidos para aplicações de gaseificação de coque de petróleo e carvão mineral em plantas IGCC de grande capacidade. Geralmente, neste equipamento se utilizam o combustível na forma de gás, pó ou em estado líquido (lama, slurry em inglês), exigindo a adequação da biomassa a uma granulometria muito fina ou inclusive a estado líquido por meio de uma pirólise previa (LORA; VENTURINI, 2012).

Neste tipo de tecnologia, o combustível é usualmente transportado por uma mistura de oxigênio com vapor de água, e gaseificado a temperatura superiores de $1200^{\circ} \mathrm{C}$ e pressão acima de 20 bar. O processo de gaseificação ocorre durante o transporte pneumático dos materiais que compõem a mistura, que pode ser tanto em sentido ascendente (quando o combustível é fornecido pelos extremos laterais do reator) como em sentido descendente (quando o combustível é fornecido pelo topo do reator). A cinza é removida em estado líquido e o alcatrão é completamente craqueado garantindo a produção de um syngas de alto poder calorífico e sem hidrocarbonetos pesados (OLOFSSON; NORDIN; SÖDERLIND, 2005).

A maior dificuldade na utilização deste tipo de equipamento com biomassa está no alto custo da trituração da mesma até a granulometria requerida, como consequência à baixa densidade da biomassa e alto consumo de energia. As soluções propostas são a torrefação antes da moenda ou a conversão da biomassa em bio-óleo e/ou coque (a partir da pirólise) a fim de garantir a granulometria exigida de partículas ou gotas na entrada do gaseificador (LORA; VENTURINI, 2012). 
Um gaseificador de leito de arrastado ou leito de fluxo de arraste bem-sucedido operando com biomassa é conhecido como processo Choren. Mediante esta tecnologia obtêm-se a produção de um gás livre de alcatrões e cinzas devido da alta temperatura de operação do reator. $\mathrm{O}$ fato desse sistema utilizar oxigênio como agente oxidante garante um syngas com alto poder calorífico. O processo de gaseificação Carbo-V® da CHOREN é composto por 3 etapas, sendo a pré-gasificação da biomassa a $400-500^{\circ} \mathrm{C}$, seguida da combustão do gás de pirólise e o alcatrão (temperaturas de 1300 a $1500^{\circ} \mathrm{C}$ ). Finalmente, o produto de combustão quente flui para uma terceira câmara, onde o char é gaseificado. Posteriormente, o gás produzido é processado na síntese de Fischer-Tropsch ou outras aplicações (BASU, 2013).

A seguir uma breve discussão será feita sobre os modelos matemáticos empregados na modelagem de sistemas de gaseificação.

\section{Modelos matemáticos}

Modelos matemáticos podem ser utilizados para explicar, prever ou simular o comportamento do processo e para analisar os efeitos de diferentes variáveis sobre o seu desempenho global (MIKULANDRIC et al. 2013).

Atualmente, especial atenção é dada à modelagem dos processos de gaseificação da biomassa, o que pode contribuir para concepção de projetos de plantas mais eficientes, a previsão de emissão e controle, visando otimizar este processo.

Porém, a modelagem matemática e simulação do processo de gaseificação fornecem informações quantitativas (diagnóstico) sobre o desempenho do gaseificador, o efeito da matéria-prima, parâmetros de projeto e condições de operação. No entanto, para agregar valor a este tipo de informações precisam-se validar através da reprodução de dados experimentais.

Desta forma, os modelos matemáticos aplicados a projetos de gaseificador ou destinados para avaliar a rota global da gaseificação podem ser classificados em: Equilíbrio termodinâmico, Cinético, Redes neurais artificiais e Dinâmica de fluidos computacional (CFD), conforme sintetizado na Fig. 2.12. 
Figura 2.12 - Classificação dos modelos matemáticos.

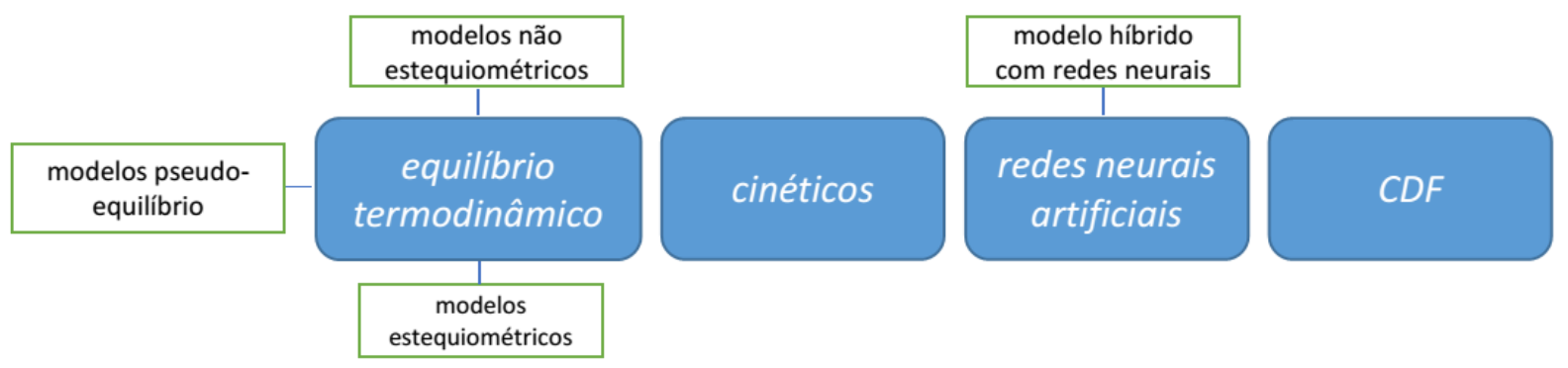

Fonte: Elaborado pelo autor.

É interessante notar que o modelo de equilíbrio termodinâmico prevê o máximo rendimento quando os reagentes estão em contato por um tempo infinito, sem considerar o tipo e tamanho do reator. De fato, os produtos saem do reator antes de atingir o equilíbrio, por essa razão, o modelo de equilíbrio apenas fornece um rendimento ideal. Existem dois tipos de abordagens nestes modelos.

O primeiro é a estequiométrica (constante de equilíbrio) e o segundo representado por modelos não estequiométricos (método minimização da energia livre de Gibbs). No modelo estequiométrico são consideradas todas as reações químicas e as espécies envolvidas no processo através de um mecanismo de reação. No entanto, quando adotado o modelo não estequiométrico não é necessário nenhum conhecimento do mecanismo de reação. Este se baseia na minimização da energia total de Gibbs a partir da composição de entrada do combustível de alimentação. Merece destaque o modelo desenvolvido por Pellegrini e Oliveira Jr (2007) aplicando este conceito para a gaseificação do bagaço da cana.

Do mesmo modo, os modelos cinéticos são usados para descrever os mecanismos cinéticos do processo de gaseificação de biomassa através das reações químicas e os fenômenos de transferência entre fases.

Para aplicações práticas, o uso do modelo cinético é mais realista. No entanto, a temperaturas mais elevadas (> $1500 \mathrm{~K}$ ), o uso do modelo de equilíbrio é mais eficaz (ABDOLLAHINEISIANI et al., 2013), enquanto os modelos de redes neurais artificiais representam uma abordagem de modelagem matemática pura, que correlaciona os dados de entrada e saída para formar um modelo de predição matemática. 


\section{Processos de limpeza e condicionamento do syngas}

Atualmente pesquisas referentes ao tópico de limpeza e condicionamento para o gás de síntese proveniente da gaseificação de biomassa, estão focalizadas na remoção do material particulado e dos alcatrões gerados neste processo de transformação termoquímica.

O alcatrão é definido como uma mistura complexa de hidrocarbonetos condensáveis que, por suas características químicas e físicas, não são admissíveis em aplicações diretas em máquinas térmicas (motores alternativos de combustão interna e/ou turbinas a gás).

Como mencionado, a natureza e o teor das impurezas presentes no syngas dependem das características do processo de gaseificação (principalmente do tipo de reator) e do tipo de biomassa utilizada (biomassas com alto teor de voláteis podem favorecer uma maior formação de alcatrão). Assim, os processos de limpeza e condicionamento devem ser implementados para adequar as características e qualidade do gás de síntese à sua utilização prevista.

Em geral, a tolerância na presença de alcatrões no gás produzido depende da utilização posterior do syngas. Por exemplo, quando a produção de gás tem como único fim a geração de calor por combustão direta, a limpeza não é necessária (FERNANDES, 2014).

Neste ponto é interessante notar que ainda não há consenso acerca da definição da composição exata para a simulação do alcatrão nos sistemas de gaseificação da biomassa. Segundo Devi; Ptasinski e Janssen (2003), o alcatrão é definido como todo aquele poluente orgânico com peso molecular maior do que o benzeno $\mathrm{C}_{6} \mathrm{H}_{6}(78 \mathrm{~g} / \mathrm{mol})$.

Entretanto, Jin; Larson e Celik (2009), adotaram o alcatrão (como ácido abiético, $\mathrm{C}_{20} \mathrm{H}_{30} \mathrm{O}_{2}$ ) sendo de $1 \%(\mathrm{p} / \mathrm{p})$ da biomassa seca. Já Camacho-Ardila et al. (2014) simularam rigurosamente a produção de alcatrão a partir das reações envolvidas nos principais compostos da biomassa, Celulose: hidroximetilfurfural, levoglucosan, hidroxiacetaldeído, ácido acético e acetona; Hemicelulose: xilose, ácido acético e furfural seguido por metanol. Finalmente, a Lignina: fenol, 2,3-dihidro-benzofurano e propanedial. 
Do mesmo modo, Camacho-Ardila et al. (2012) modelaram o alcatrão como sendo naftalina $\left(\mathrm{C}_{10} \mathrm{H}_{8}\right)$ na análise de um gaseificador de leito fluidizado circulante utilizando o método de minimização da energia livre de Gibbs, para predizer a composição do gás produzido a partir do bagaço da cana-de-açúcar.

Srinivas et al. (2013) apresentaram uma revisão detalhada das opções da modelagem de alcatrão no processo de gaseificação da biomassa através do simulador Aspen Plus ${ }^{\circledR}$. Ainda, expuseram os desafios na modelagem da produção do alcatrão. Desta forma, as características de desempenho de três métodos sugeridos nesta área são ilustradas: Oxidação parcial não catalisada, Reforma catalítica a vapor, e Absorção.

A seleção do sistema de limpeza dos gases depende de diversos fatores, tais como: a eficiência de remoção, o custo de operação e manutenção, o custo de investimento, o espaço disponível e as características do gás produzido (temperatura e pressão), entre outros. Cabe salientar que existem duas rotas tecnológicas para o condicionamento dos gases: limpeza úmida a baixa temperatura e limpeza a seco a alta temperatura. Assim, na Fig. 2.13 apresenta-se uma classificação dos métodos de limpeza, catalisadores e filtros utilizados em dependência do tipo de impureza que se pretende remover e da temperatura do gás (LORA; VENTURINI, 2012).

Figura 2.13 - Classificação dos métodos e catalisadores para limpeza do gás de síntese.

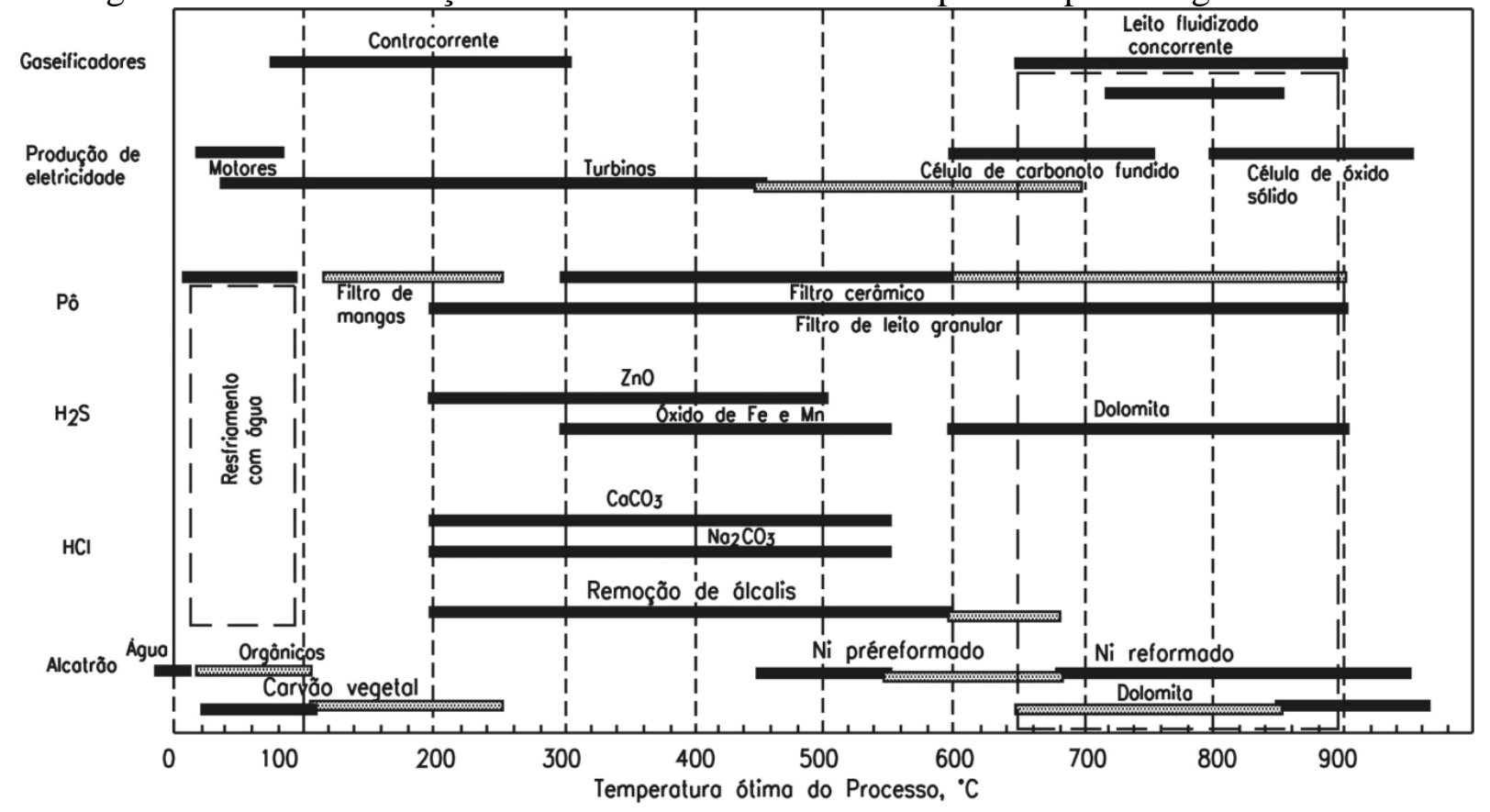

Fonte: Reproduzido de Lora e Venturini, (2012). 


\section{Turbinas a gás para operar com gás de síntese}

Diversos desafios devem ser superados na utilização do gás de síntese nas turbinas a gás (TG). Merecem destaque as seguintes considerações:

- Materiais, Componentes e Revestimentos: Para suportar altas temperaturas;

- Desempenho e Monitoramento: Visando aprimorar as etapas de controle e otimização;

- Flexibilidade do combustível: O fato de adotar combustíveis alternativos na TG implica maior quantidade de insumos devido a seu baixo poder calorífico;

- Queima suplementar: Arranjos combinando a utilização de misturas de gás natural e syngas.

Neste ponto é interessante notar as revisões das atuais barreiras tecnológicas apresentadas por Gupta; Rehman e Sarviya (2010) e Ruiz et al. (2013) sobre o uso dos biocombustíveis em turbina a gás e da gaseificação de biomassa para geração de eletricidade, respectivamente.

No que diz respeito à simulação destes equipamentos, diferentes pesquisas têm sido conduzidas utilizando como referência turbinas comerciais dos principais fornecedores deste mercado.

Nesse sentido, Kam; Morey e Tiffany (2009) propuseram um modelo em Aspen Plus ${ }^{\circledR}$ do processo de produção de etanol baseado na integração do sistema de cogeração da biomassa. Os autores modelaram a turbina a gás com base nas especificações da ALSTOM. Nesta abordagem foi considerada na entrada do ar a compressão a partir de um processo adiabático com uma eficiência isentrópica de $85 \%$ e uma perda mecânica de 3\%. Ainda, foi adotada uma razão de pressão de 10:1 na turbina e uma temperatura de combustão de $1070{ }^{\circ} \mathrm{C}$. Já no processo de expansão foi assumida uma eficiência isentrópica de $90 \%$ com perdas mecânicas de $2 \%$.

Chacartegui et al. (2012) expuseram considerações e parâmetros técnicos da turbina a gás 9FB da General Electric (GE) para operar com syngas. Do mesmo modo, Jin; Larson e Celik (2009) avaliaram o desempenho da turbina a gás 7FB da GE através da análise técnicoeconômica de sistemas de geração de energia elétrica baseados na gaseificação da biomassa. 


\subsection{SIMULAÇÃO E OTIMIZAÇÃO DE PROCESSOS DE CONVERSÃO DA BIOMASSA}

Recentemente, pesquisadores vêm trabalhando na avaliação global das rotas de conversão da biomassa a partir da determinação dos fluxos de massa e energia, aplicação de indicadores econômicos e ambientais e via integração e otimização de processos. A seguir será apresentada uma revisão de algumas aplicações nestas rotas via análise exergética/otimização (projeto conceitual) visando identificar os focos de perdas de energia e introduzir melhorias nos projetos.

\subsubsection{Modelagem da Rota de Conversão Termoquímica}

Na rota termoquímica diversas configurações de ciclo combinado com gaseificação integrada de biomassa têm sido desenvolvidas de forma intensiva ao longo da última década visando sistemas energéticos sustentáveis.

Sendo digno de notar os estudos conduzidos por Damartzis e Zabaniotou (2011), onde se expõe uma revisão dos processos de conversão termoquímica da biomassa para biocombustíveis de $2 \mathrm{G}$ por meio de um projeto de processo integrado. Merecem destaque as abordagens da modelagem de sistemas de gaseificação, reforma a vapor e a síntese F-T.

Saidur et al. (2012) descreveram algumas considerações gerais das tecnologias de conversão termoquímica da biomassa baseado na análise exergética dos processos. Além disso, mostraram indicadores e correlações para determinar a eficiência exergética das rotas de conversão.

Sues; Juraščík e Ptasinski (2010) reportaram os resultados obtidos na análise exergética para a produção de biocombustíveis a partir de diversos resíduos. As rotas de produção definidas abrangem as etapas de pré-tratamento da gaseificação, a limpeza do gás, reações shift águagás, reatores catalíticos, a separação final do gás e o seu melhoramento. Também foi proposta uma rota que, a partir de uma turbina a gás e turbinas a vapor, produz calor e eletricidade utilizando o gás não convertido e a remoção de calor, respectivamente. 
Nesse contexto, Dutta et al. 2012 apresentaram uma análise técnico-econômica visando à produção comercial de etanol e álcoois a custos competitivos pela conversão da biomassa lignocelulósica em syngas via gaseificação indireta, seguido pela conversão do syngas em um líquido por meio de catalisadores pré-comerciais. Os principais processos incluem a gaseificação com vapor indireto, a limpeza do gás e a síntese catalítica de álcoois mistos, e os processos auxiliares incluem alimentação e secagem, separação de álcool, geração de vapor e eletricidade. Além disso, foi realizada uma análise de fluxo de caixa e uma estimativa de custos dos equipamentos.

Seguindo esta linha de pesquisa, Taillon e Blanchard (2013) apresentaram a análise exergética detalhada de três centrais de cogeração. A primeira, uma planta de gaseificação acoplada com motores a gasolina (5,5 MWe, $11 \mathrm{MWt}$ ). A segunda, uma planta operando em ciclo combinado com gaseificação integrada (15,6 MWe, 7,8 MWt). Por último, uma planta de combustão (22,5 MWe, $45 \mathrm{MWt}$ ). Estes autores também calcularam a destruição de exergia (em termos das correntes de entrada/saída e mudanças na composição química) e o balanço de entropia do processo. Os resultados mostraram que a planta de gaseificação fornece um benefício superior de 4-5\% na eficiência exergética em relação à planta de combustão e que $50 \%$ do total da exergia destruída ocorreu a partir das reações de oxidação da biomassa.

Prins; Ptasinski e Janssen (2004) apresentaram a análise exergética de um ciclo combinado com gaseificação integrada de biomassa e do processo Fischer-Tropsch $(\mathrm{F}-\mathrm{T})$. O processo empregou serragem como matéria-prima e combinou um gaseificador atmosférico com um reator F-T. Ainda utilizou um ciclo Rankine para a geração de eletricidade a partir do gás de síntese.

Merece destaque que a eficiência exergética global do sistema foi 36,4\% e que as maiores irreversibilidades ocorreram no processo de gaseificação da biomassa e na planta de utilidades. Finalmente, os autores propuseram algumas modificações para melhorar os processos, atingindo uma eficiência exergética de 46,2\%. Na Fig. 2.14 mostra-se o efeito da conversão de monóxido de carbono no reator de $\mathrm{F}-\mathrm{T}$ para a razão de produção de combustíveis líquidos e geração de eletricidade em termos da eficiência exergética global do sistema. Por fim, o efeito da temperatura de gaseificação na eficiência exergética em decorrência do teor de umidade da biomassa é ilustrado na Fig. 2.15. 
Figura 2.14 - Efeito de conversão de Fischer-Tropsch na eficiência exergética global.

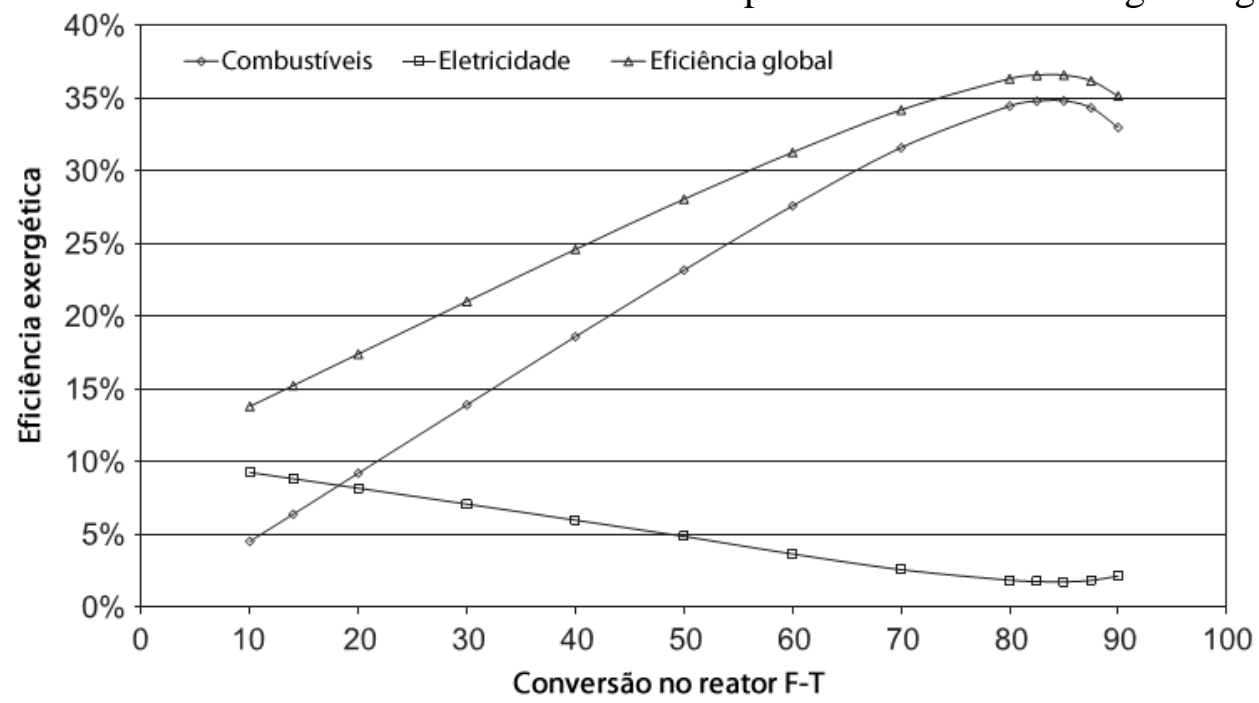

Fonte: Adaptado de Prins et al. (2004).

Figura 2.15 - Efeito da temperatura de gaseificação na eficiência exergética global.

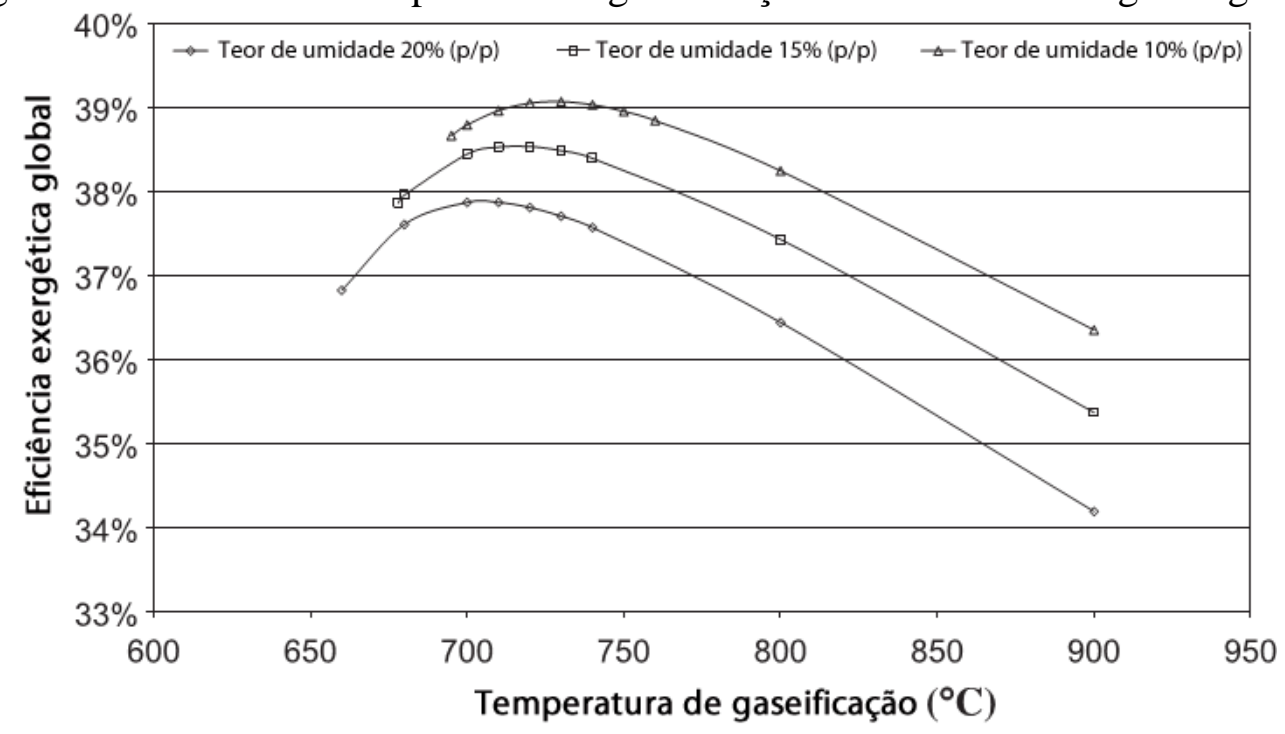

Fonte: Adaptado de Prins et al. (2004).

Do mesmo modo, Piekarczyk et al. (2013) analisaram os biocombustíveis de 2G como sendo combustíveis Fischer-Tropsch ou gás natural sintético, produzidos a partir de biomassas lignocelulósicas. Esses autores também compararam a eficiência termodinâmica do sistema aplicando tanto a análise exergética como um parâmetro para determinar o custo termoecológico de produção. 
Van der Heijden e Ptasinski (2012) apresentaram uma análise exergética avaliando a produção de etanol por meio da rota termoquímica. Esta configuração combina a gaseificação indireta da biomassa (i.e. o processo não ocorre com a ajuda de um agente oxidante precisando de uma fonte de energia externa) e utiliza vapor de água como agente de gaseificação e madeira como matéria-prima, com a posterior conversão do gás de síntese produzido em etanol.

Esta rota envolve várias etapas no processo de conversão, incluindo: secagem e gaseificação da biomassa, limpeza do syngas, reforma, condicionamento, compressão e síntese de etanol. Dentre os resultados obtidos merece destaque a análise de sensibilidade em termos da temperatura de operação do gaseificador. Na Fig. 2.16 apresenta-se a composição do syngas a diferentes temperaturas de gaseificação.

Figura 2.16 - Efeito da temperatura de gaseificação na composição do gás de síntese.

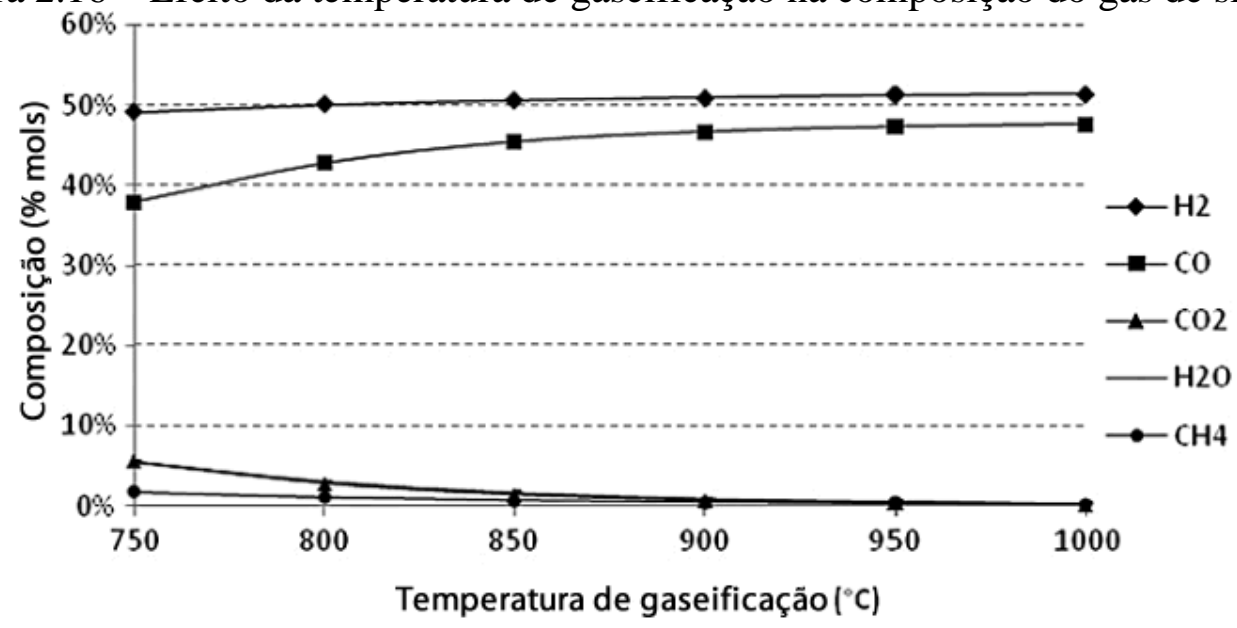

Fonte: Adaptado de Van der Heijden e Ptasinski (2012).

Damartzis et al. (2012) desenvolveram um modelo matemático para avaliar uma planta de cogeração com gaseificação de leito fluidizado borbulhante, acoplado a um motor de combustão interna (ICE), utilizando biomassa lignocelulósica como insumo energético. $\mathrm{O}$ modelo foi desenvolvido no simulador Aspen Plus ${ }^{\circledR}$ baseado nos balanços de massa e energia e a cinética das reações representando as diferentes etapas do processo da gaseificação (secagem, pirólise, oxidação e limpeza do gás).

Na Fig. 2.17 é apresentada a comparação dos resultados experimentais e simulados em função composição do syngas (v/v) à temperatura de operação. Sendo os símbolos $\left(\square: \mathrm{CO}, \circ: \mathrm{H}_{2}\right.$, $\left.\Delta: \mathrm{CO}_{2}, \diamond: \mathrm{CH}_{4}\right)$ a representação das métricas experimentais e as linhas as simuladas. 
Figura 2.17 - Composição do gás em função à temperatura de operação.

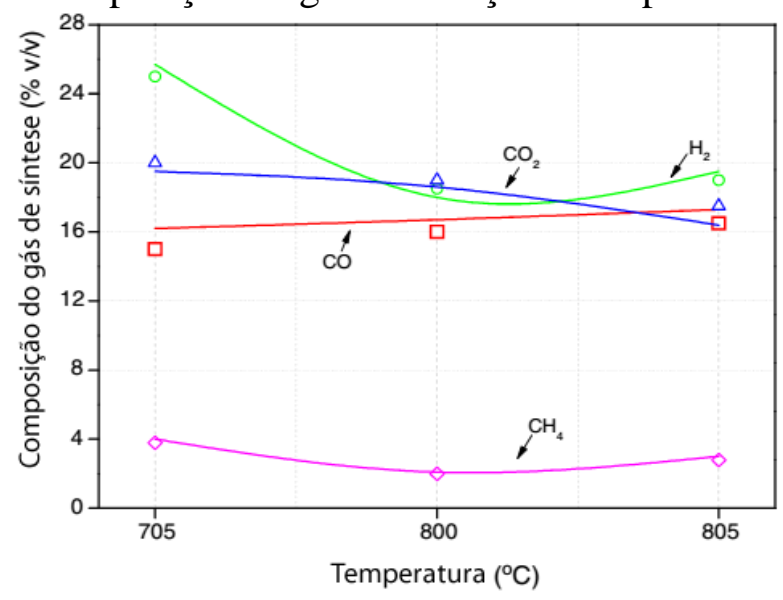

Fonte: Adaptado de Damartzis et al. (2012).

Neste ponto, merece destaque a ampla revisão da literatura em termos da simulação do processo de gaseificação da biomassa apresentada por Puig-Arnavat; Bruno e Coronas, (2010). Igualmente, vale salientar que o gaseificador é um dos equipamentos menos eficientes em toda a cadeia de produção de energia a partir da biomassa, sendo o responsável pela maior taxa de exergia destruída nesses sistemas. Portanto, a análise da eficiência do gaseificador pode contribuir substancialmente para a melhoria do desempenho global do sistema.

Nesse sentido, diversas simulações consideraram o equilíbrio termodinâmico através da minimização da energia livre de Gibbs na avaliação de gaseificadores. Por exemplo, Paviet; Chazarenc e Tazerout (2009) desenvolveram um modelo de equilíbrio para um gaseificador concorrente baseado em dados experimentais da gaseificação de madeira. Os modelos termoquímicos assumiram que os reagentes atingiram o equilíbrio químico. A partir desta abordagem foi possível predizer a composição final do syngas produzido, cuja composição molar em base seca foi $\mathrm{H}_{2}=13 \%, \mathrm{CO}=16 \%, \mathrm{CO}_{2}=12 \%, \mathrm{~N}_{2}=58 \%$ quando considerada uma temperatura de gaseificação de $1300 \mathrm{~K}$.

Do mesmo modo, Melgar et al. (2007) apresentaram um modelo de equilíbrio químico para gaseificação da biomassa, por meio da minimização da energia livre de Gibbs, em que foi analisada a influência da relação de gaseificação combustível/ar e a umidade na temperatura de equilíbrio (caso adiabático). Na Fig. 2.18 estão sintetizados os resultados obtidos da comparação entre PCI e a eficiência a frio do gás para madeira de pinho com $18 \%$ de umidade. 
Figura 2.18 - Comparação entre PCI e eficiência a frio do gás para madeira de pinho.

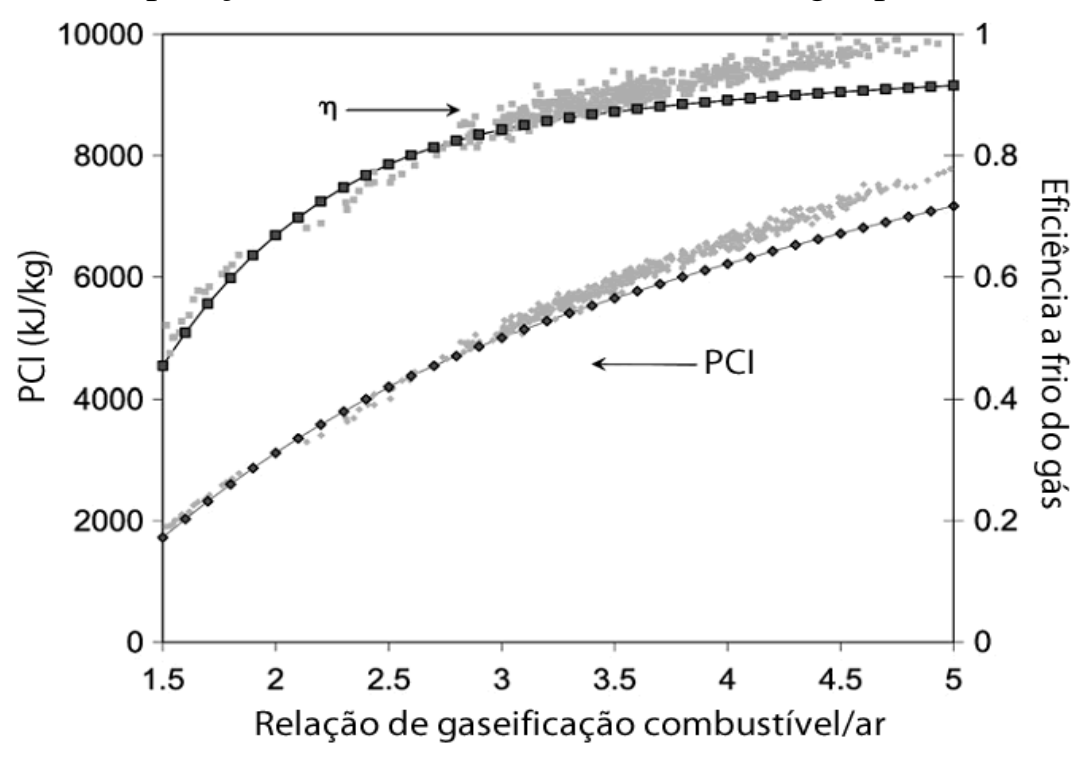

Fonte: Adaptado de Melgar et al. (2007).

Neste cenário, Pellegrini e Oliveira Jr (2007) apresentaram um modelo baseado em considerações de equilíbrio químico para o caso particular do processo de gaseificação do bagaço da cana. A análise exergética foi conduzida por meio de quatro indicadores de eficiência, cujos resultados são mostrados na Fig. 2.19.

Figura 2.19 - Índices de desempenho do processo de gaseificação do bagaço da cana.

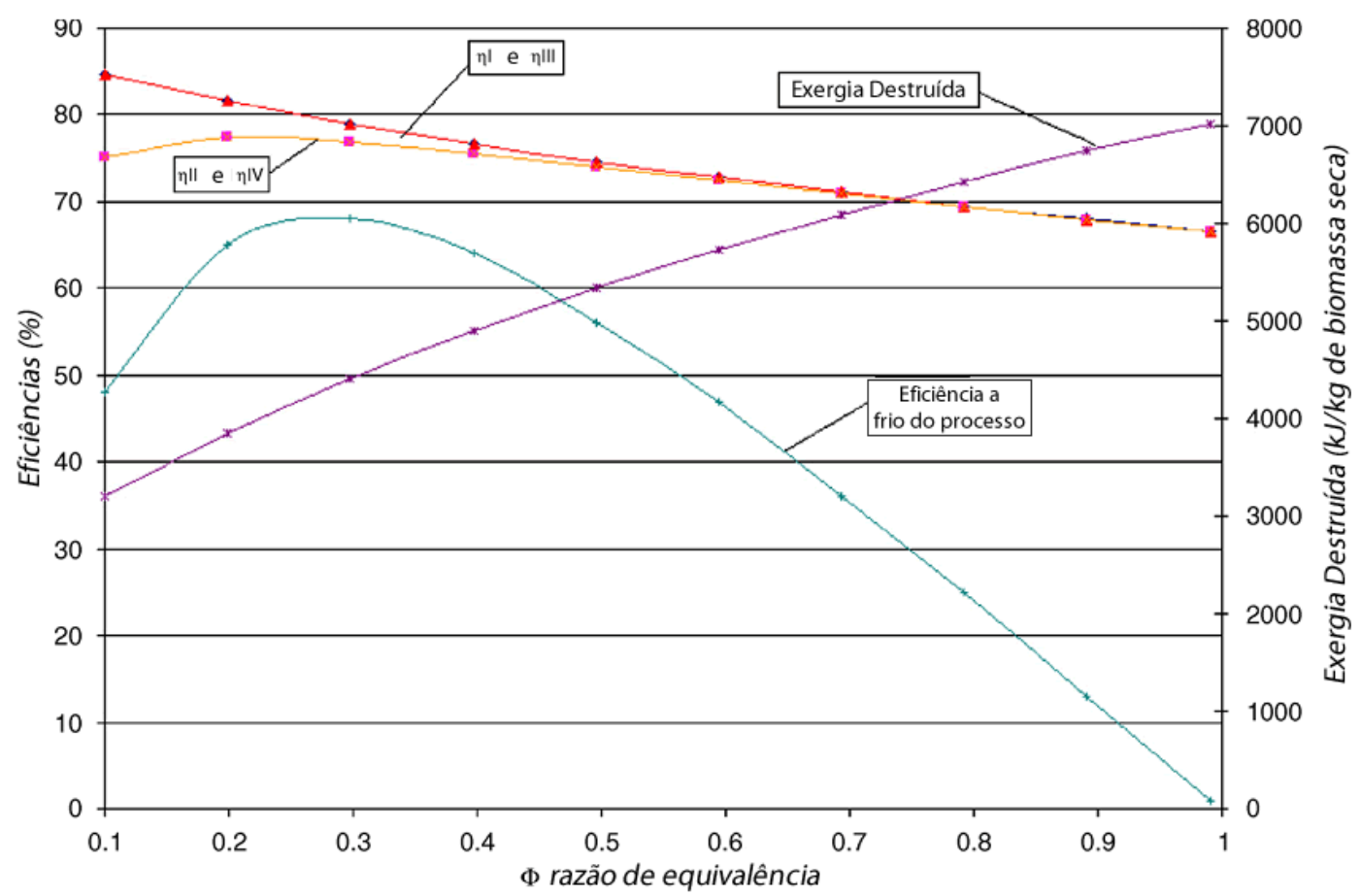

Fonte: Adaptado de Pellegrini e Oliveira Jr (2007). 
O modelo consiste na minimização da energia livre de Gibbs do gás produzido, a partir da determinação de balanços de massa, energia e exergia do sistema. Nesta análise, uma fórmula molecular reduzida do bagaço foi adotada como sendo $\mathrm{CH}_{1.61} \mathrm{O}_{0.7}$. Ainda os autores realizaram uma análise de sensibilidade para determinar pontos ótimos de operação de um sistema BIGCC levando em consideração diferentes razões de pressão, consumo e qualidades de vapor, e a potência líquida produzida, conforme ilustrado na Fig. 2.20.

Figura 2.20 - Parâmetros de operação do sistema BIGCC.

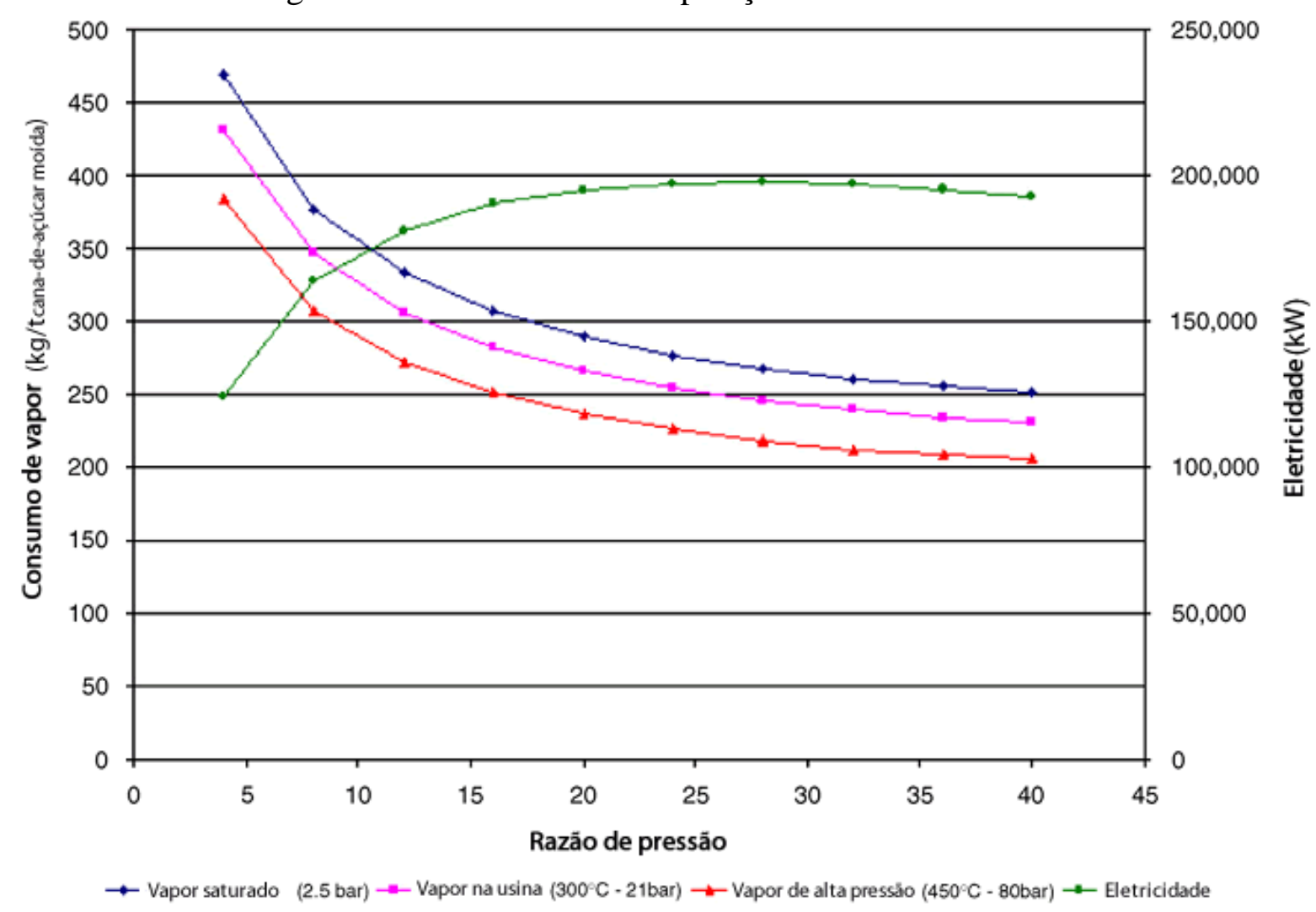

Fonte: Adaptado de Pellegrini e Oliveira Jr (2007).

Semelhantemente, Kasembe; John e Mhilu (2012) desenvolveram um modelo de equilíbrio químico para um gaseificador incorporando à análise exergética. $\mathrm{O}$ processo da gaseificação é avaliado à pressão atmosférica de 1 bar, considerando temperaturas de operação entre $800 \mathrm{a}$ $1400 \mathrm{~K}$ para o bagaço da cana-de-açúcar. Neste caso, o bagaço foi representado pela fórmula $\mathrm{CH}_{1.42} \mathrm{O}_{0.65} \mathrm{~N}_{0.0026}$. Na Fig. 2.21 apresenta-se o efeito da temperatura na eficiência para uma razão de equivalência de 0,4 em função da exergia química e física do reator. 
Figura 2.21 - Efeito da temperatura na eficiência de gaseificação do bagaço da cana.

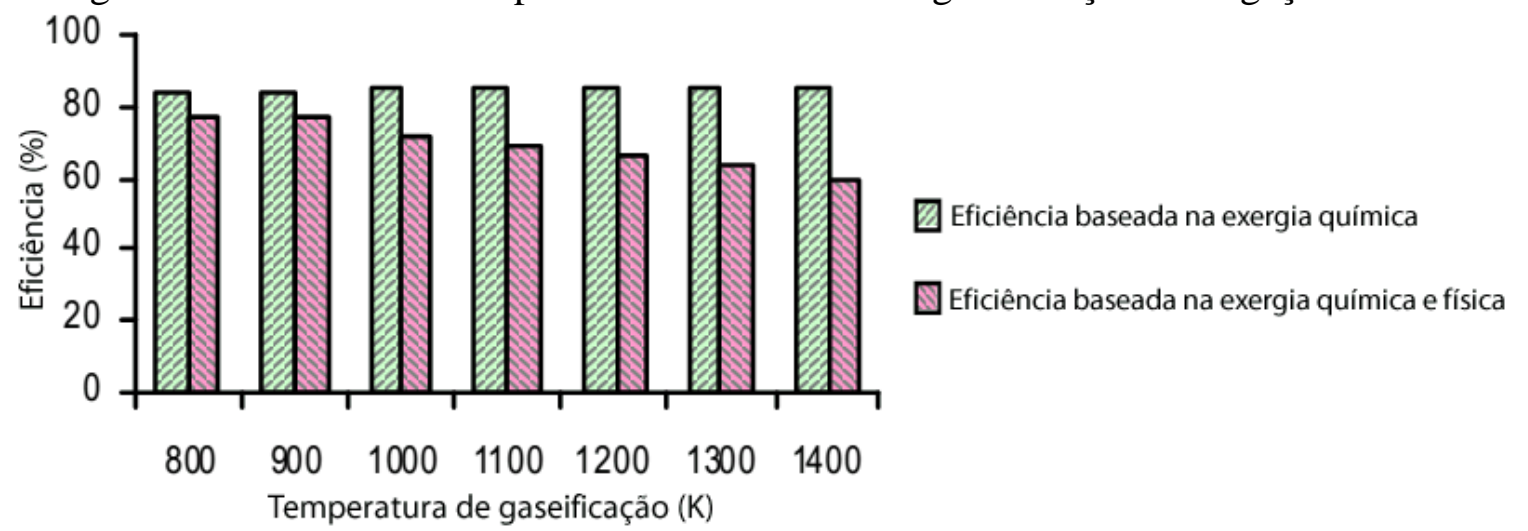

Fonte: Adaptado de Kasembe et al. (2012).

Nikoo e Mahinpey (2008) desenvolveram um modelo para avaliar o desempenho de um gaseificador de leito fluidizado atmosférico considerando aspectos relacionados à cinética de reações e fatores hidrodinâmicos utilizando sub-rotinas de Fortran na interface do programa Aspen Plus ${ }^{\circledR}$ para simular o processo da gaseificação. Assim, na Fig. 2.22 é apresentada a razão de equivalência em decorrência à eficiência de conversão de carbono quando adotada uma taxa de alimentação de biomassa: $0,512 \mathrm{~kg} / \mathrm{h}$; temperatura: $800^{\circ} \mathrm{C}$; fluxo mássico de vapor: $0,8 \mathrm{~kg} / \mathrm{h}$.

Figura 2.22 - Efeito da razão de equivalência na eficiência de conversão de carbono.

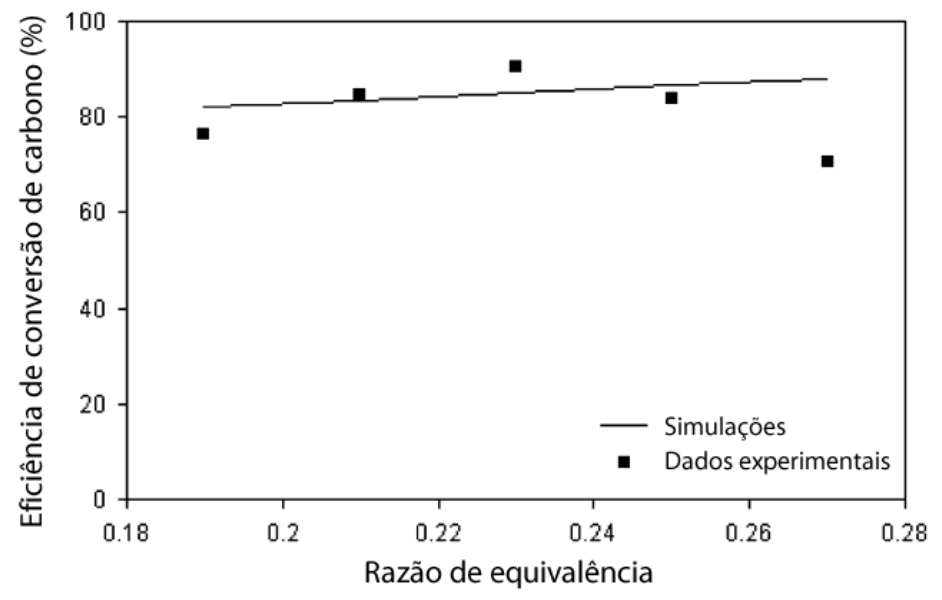

Fonte: Adaptado de Nikoo e Mahinpey (2008).

Entretanto, Blanco; Velásquez e Chejne (2013) a partir de uma avaliação energética, exergética e termoeconômica analisaram o potencial de três tipos de biomassas (bagaço de cana, resíduos de palmeira e cascas de arroz) como substitutos do carvão mineral no processo de gaseificação. Os resultados apresentaram rendimentos do processo variando de $40 \%$ a $50 \%$ e rendimentos exergéticos entre 2 e $3 \%$. 
O processo de gaseificação do carvão mineral apresenta uma maior taxa de destruição de exergia, quando comparado com as biomassas, embora seu gás de síntese tenha a exergia química mais elevada, devido a que a gaseificação do carvão requer uma maior quantia de oxigênio. Na Fig. 2.23 mostra-se a distribuição da exergia para os diferentes insumos. Ao passo que a Fig. 2.24 ilustra os rendimentos exergéticos do processo de gaseificação em função destas matérias-primas.

Figura 2.23 - Distribuição da exergia para diversas matérias-primas.

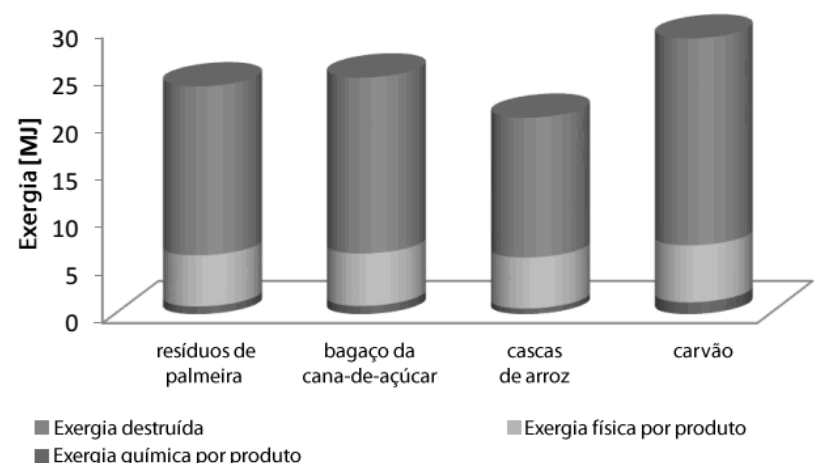

Fonte: Adaptado de Blanco et al. (2013).
Figura 2.24 - Comparação das matérias-primas em função da eficiência da gaseificação.

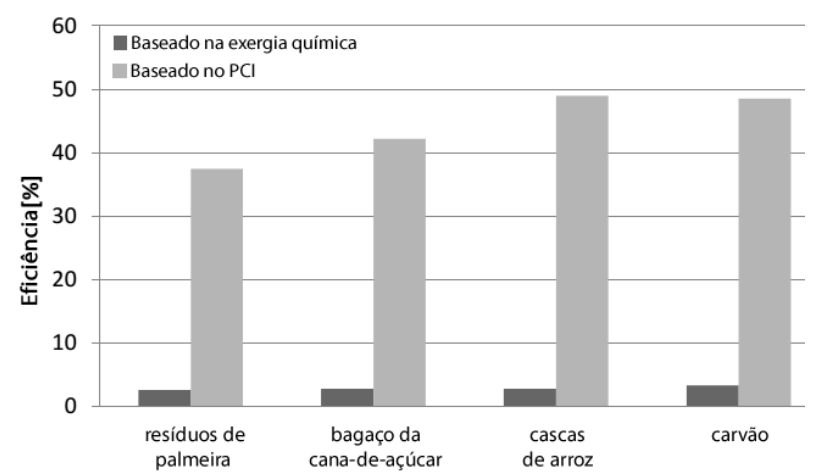

Song et al. (2013) propuseram uma avaliação termodinâmica da gaseificação de biomassa via vapor para um sistema interligado de reatores de leito fluidizado baseados no poder calorifico superior (PCS). Os resultados fornecem o rendimento em termos da vazão de vapor/biomassa e do PCS do gás de síntese a seco, como também a eficiência exergética do processo.

Na Fig. 2.25 apresentam-se os efeitos da pressão de gaseificação e a vazão de vapor/biomassa (SB) em decorrência do PCS e a eficiência exergética quando considerada uma temperatura de gaseificação de $700^{\circ} \mathrm{C}$. Onde os termos (-) e (+) na eficiência exergética representam a configuração sem recuperação de calor e com recuperação de calor, respectivamente. Já os símbolos designam as pressões de operação do sistema, sendo, a: 1 bar, o: 10 bar, $\mathbf{\Delta}$ : 20 bar. 
Figura 2.25 - Efeitos da pressão de gaseificação e a vazão SB em termos do PCS e a eficiência exergética.
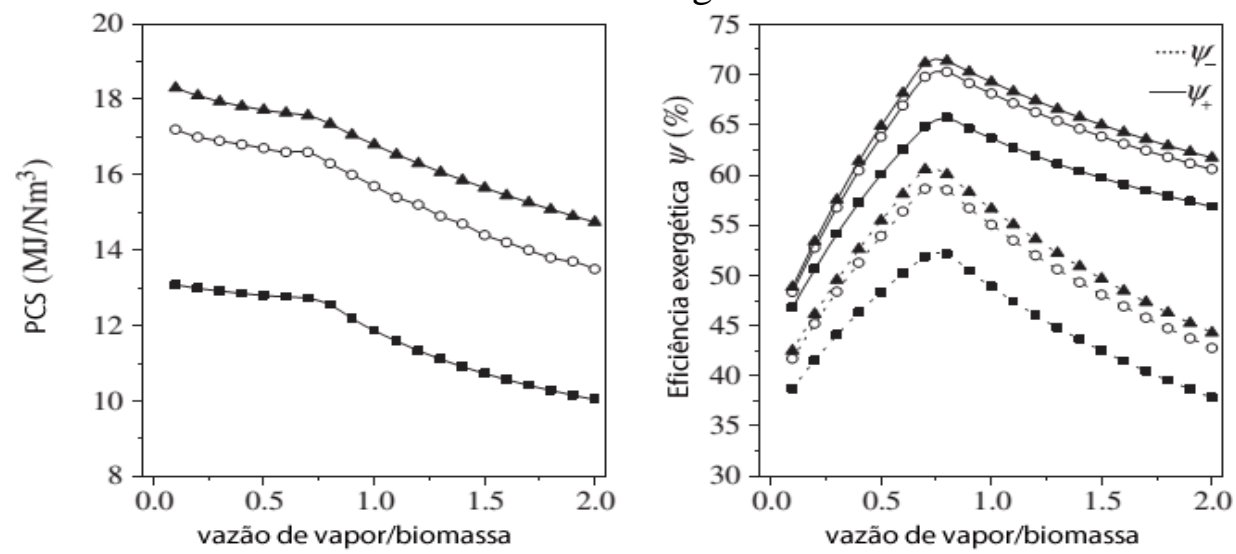

Fonte: Adaptado de Song et al. (2013).

Por fim, Ptasinski; Prins e Pierik (2007) compararam a eficiência da gaseificação de diferentes tipos de biomassas (madeira, palha, capim, lodo e adubo) comparativos à gaseificação de carvão. Esses autores também avaliaram a eficiência exergética para um gaseificador idealizado operando no equilíbrio químico, onde são desprezados o teor de cinzas e as perdas de calor. Assim, as eficiências do processo são avaliadas através de um indicador denominado de 'ponto-limite de carbono', pelas suas siglas em Inglês CBP, sendo este o ponto no qual é adicionada a quantidade do ar suficiente para evitar a formação de carbono e atingir a gaseificação completa.

A Fig. 2.26 apresenta a distribuição da exergia no processo da gaseificação de diferentes recursos energéticos em função da exergia química e física e das irreversibilidades associadas ao projeto.

Figura 2.26 - Distribuição da exergia da gaseificação para diversas matérias-primas.

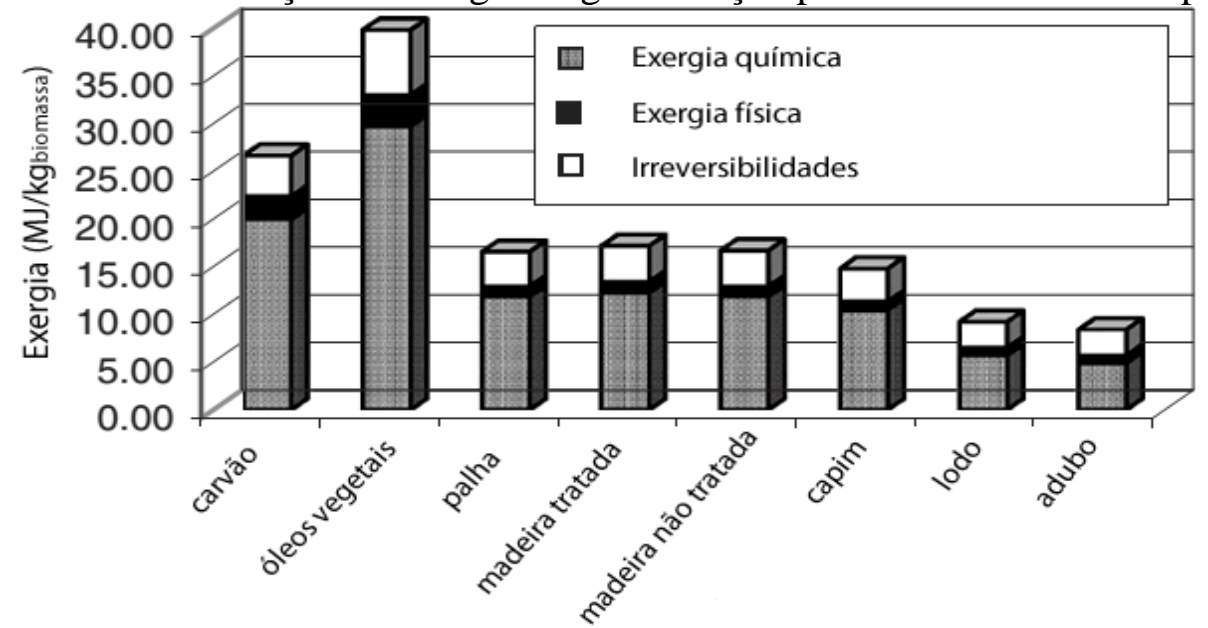

Fonte: Adaptado de Ptasinski; Prins e Pierik (2007). 
É interessante notar que a eficiência global do sistema é função do teor de umidade, conforme apresentado na Fig. 2.27. Deste modo, apresenta-se uma possibilidade de melhoria na eficiência de gaseificação por secagem utilizando a entalpia do gás produzido.

Figura 2.27 - Eficiência global do sistema em função do teor de umidade.

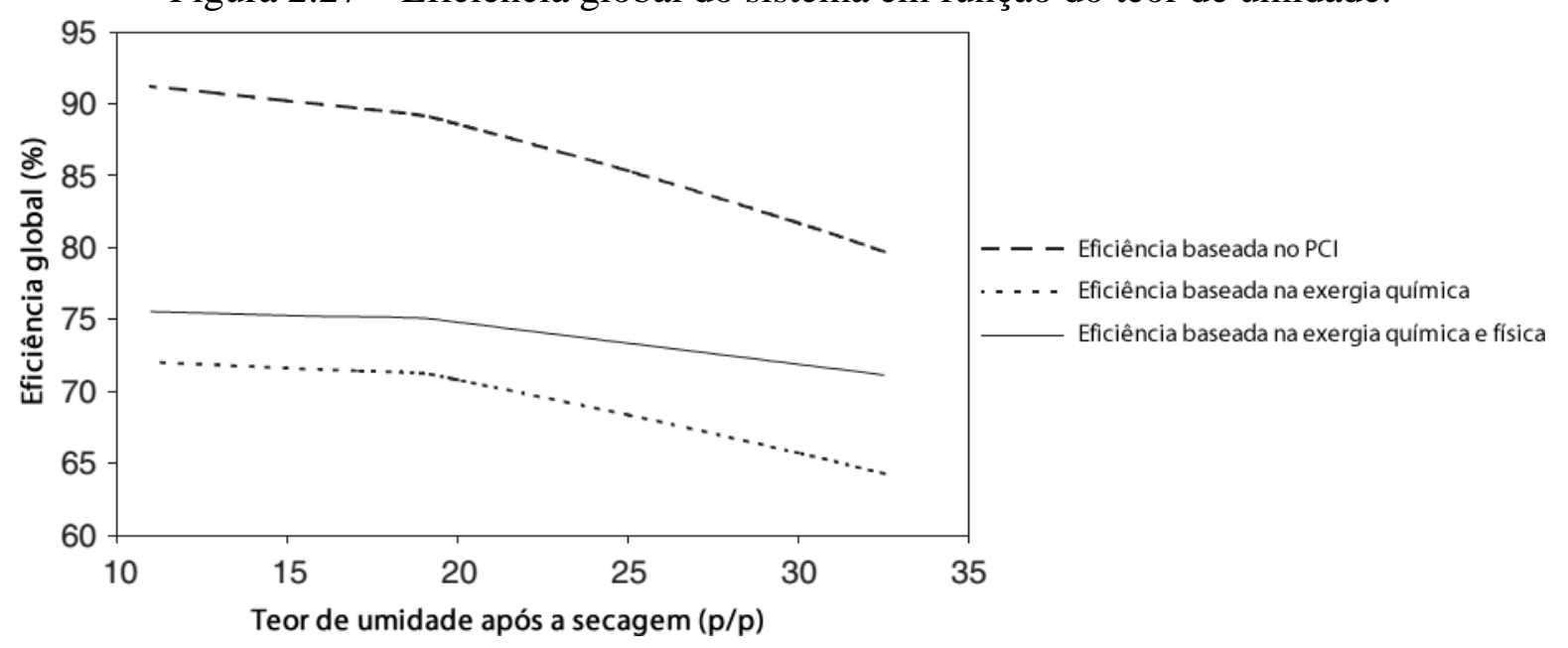

Fonte: Adaptado de Ptasinski; Prins e Pierik (2007).

\subsubsection{Modelagem da Rota de Conversão Bioquímica}

Igualmente, merece destaque a avaliação global da rota bioquímica onde diversas configurações têm sido avaliadas de forma intensiva visando sistemas energéticos sustentáveis.

Por exemplo, o Laboratório Nacional de Ciência e Tecnologia do Bioetanol (CTBE) realizou diversas simulações sobre o potencial de melhoria da eficiência do processo de produção de etanol 2G em diferentes cenários tecnológicos, utilizando a ferramenta Biorrefinaria Virtual de Cana-de-Açúcar (BVC).

A BVC é uma plataforma de simulação computacional que possibilita avaliar tecnicamente, nos três pilares da sustentabilidade (econômico, ambiental e social), diferentes rotas e tecnologias integradas na cadeia produtiva da cana-de-açúcar e de outras biomassas. Assim, a partir da BVC foram definidos e simulados cenários de plantas de produção de etanol $1 \mathrm{G}, 1 \mathrm{G}$ e $2 \mathrm{G}$ integradas, e $2 \mathrm{G}$ independente. Neste ponto, vale salientar os resultados obtidos na simulação detalhada destas rotas apresentadas em Bonomi et al., (2012), Dias et al., (2013a), Dias et al., (2012) e Dias et al., (2013b). 
Do mesmo modo, Albarelli; Ensinas e Silva (2014) avaliaram uma configuração de biorrefinaria de etanol $1 \mathrm{G}$ produzido a partir do caldo de cana e etanol $2 \mathrm{G}$ empregando a fração fina do bagaço composta por células do parênquima (P-fração). Além disso, foram analisadas as tecnologias de pré-tratamento de água quente pressurizada e explosão a vapor. Os resultados indicaram que após a integração térmica e da água, os processos avaliados foram autossuficientes na demanda de energia, sendo capaz de suprir eletricidade excedente para a rede e apresentar consumos de água dentro do limite ambiental do estado de São Paulo.

Também, na avalição da rota bioquímica se destacam os trabalhos de simulação desenvolvidos pelo grupo do Centro de Pesquisa para o Desenvolvimento Sustentável em Indústria e Energia da Universidade Industrial de Santander na Colômbia, utilizando como matéria-prima o bagaço da cana-de-açúcar.

Nesse sentido, Ojeda e Kafarov (2009). avaliaram a eficiência exergética do processo de hidrólise enzimática em dois tipos de reatores na produção de etanol a partir da palha no programa ASPEN HYSYS ${ }^{\circledR}$, atingindo eficiências na faixa de $64,3 \%$ a $72,1 \%$, em virtude das irreversibilidades associadas aos resíduos e efeitos inibitórios durante a etapa de hidrólise.

Posteriormente, Ojeda; Sánchez e Kafarov (2011) analisaram três configurações para produção de etanol $2 \mathrm{G}$. Os resultados mostraram que a maior eficiência exergética do processo foi obtida quando utilizado o pré-tratamento de explosão a vapor, a sacarificação e fermentação simultânea (SSF), e desidratação, alcançando 79,58\%. Enquanto, o menor rendimento $(73,98 \%)$ ocorreu no arranjo utilizando o pré-tratamento com ácido diluído, processo SSF e desidratação.

Da mesma forma, Ojeda et al. (2011a) estudaram a análise exergética e o ciclo de vida da produção de bioetanol considerando quatro métodos diferentes de pré-tratamento acoplado a um processo SSCF. Os principais resultados mostraram que o pré-tratamento com explosão a vapor catalisada com ácido ( 90\%) representa a melhor opção. Enquanto, o pré-tratamento Organosolv apresentou a maior acessibilidade ao ataque enzimático atingindo a melhor eficiência exergética $(\sim 60 \%)$ na etapa da hidrólise. 
Finalmente, Ojeda et al. (2011b) avaliaram via análise exergética três cenários de produção de etanol $2 \mathrm{G}$ a partir do bagaço pré-tratado com ácido diluído, considerando as tecnologias de SHF, SSF e SSFC, sendo a última a mais eficiente do ponto de vista exergético, em razão da ausência de inibidores gerados nas outras configurações. 


\section{ANÁLISE TERMODINÂMICA, EXERGO-AMBIENTAL E OTIMIZAÇÃO DE CONFIGURAÇÕES PARA A PRODUÇÃO DE BIOETANOL E ELETRICIDADE}

Nesta seção é feita uma breve descrição dos conceitos envolvidos na análise exergética aplicados na avaliação de sistemas térmicos. Parte do texto ilustrado neste documento é um resumo do seminário "EXERGIA: Conceituação e Aplicação" (SILVA; FLÓREZ-ORREGO, 2013).

Ainda, no decorrer deste capítulo será apresentada uma resenha da integração energética de processos e os impactos ambientais na análise de configurações industrais focadas na produção de bioetanol e eletricidade. Finalmente, serão ilustradas algumas aplicações referentes à análise exergo-ambiental e à otimização de sistemas térmicos afins às rotas tecnológicas propostas nesta pesquisa.

\subsection{ANÁLISE EXERGÉTICA}

A necessidade de diferenciar a energia do conceito de qualidade da energia e sua possibilidade de ser convertida em outras formas da mesma, especialmente na realização de trabalho, levou à definição do termo exergia. De acordo com Kotas (1985), a análise exergética proporciona um modo de avaliar a magnitude das irreversibilidades, em relação à exergia fornecida em uma planta ou determinado componente.

A análise exergética refere-se à utilização conjunta da 1a Lei (Conservação de energia) e da 2a Lei da Termodinâmica (Princípio do aumento da entropia), a qual proporciona o grau de degradação da energia. Assim, esta análise aplicada a plantas de conversão de energia permite identificar as maiores fontes de geração de irreversibilidade devido às ineficiências do processo e, a partir do diagnóstico, é possível indicar, as possibilidades de melhorias que podem ser obtidas a partir de um balanço exergético para um volume de controle definido. 


\subsubsection{Balanço Exergético}

A exergia não é uma propriedade conservativa. No entanto, isso não impede que possa ser realizado o balanço dessa propriedade para um sistema (sist.) e/ou volume de controle (VC) que sofre qualquer tipo de interação. Nesse sentido, o balanço exergético ou balanço de exergia para um sistema que evolui desde um estado 1 até um estado 2 é escrito de acordo com a Eq. (3.1):

$$
B_{1-2}^{Q}-B_{1-2}^{W}-B_{\text {dest }}=\Delta B_{\text {sist }, 1-2}^{P}+\Delta B_{\text {sist }, 1-2}^{K}+\Delta B_{\text {sist }, 1-2}^{P H}+\Delta B_{\text {sist }, 1-2}^{C H}
$$

Sendo $B^{W}, B^{Q}$ as parcelas da exergia associadas à interação de tipo trabalho e calor, respectivamente. Além disso, nesta expressão são ilustrados os quatro componentes da exergia total, sendo, $B^{K}$ exergia cinética, $B^{P}$ exergia potencial, $B^{P H}$ exergia física e $B^{C H}$ exergia química. Onde o termo $B_{\text {dest }}$ representa a exergia destruída ou a taxa de destruição da exergia do particular processo. Analogamente, o balanço de exergia para um $V C$ que evolui desde um estado 1 até um estado 2 pode ser determinada pela Eq. (3.2):

$$
B_{1-2}^{M}+B_{1-2}^{Q}-B_{1-2}^{W}-B_{d e s t}=\Delta B_{V C, 1-2}^{P H}+\Delta B_{V C, 1-2}^{K}+\Delta B_{V C, 1-2}^{P}+\Delta B_{V C, 1-2}^{C H}
$$

Onde o termo $B^{M}$ é a exergia associada à transferência da massa. A Eq. (3.3) concebe a expressão anterior por extenso:

$$
\begin{aligned}
\sum_{e} m \cdot b-\sum_{s} m & \cdot b+\int\left(1-\frac{T_{O}}{T}\right) \delta Q-\left(W-P_{O} \Delta V\right)-B_{\text {dest }} \\
= & \Delta U_{V C, 1-2}+P_{O} \Delta V_{V C, 1-2}-T_{O} \Delta S_{V C, 1-2}+\Delta\left(m \frac{v^{2}}{2}\right)_{V C}+\Delta(m g z)_{V C}+\Delta B_{V C, 1-2}^{C H}
\end{aligned}
$$

Sendo $b$ a exergia da massa que entra ou sai do $V C$, dada pela Eq.(3.4):

$$
b=\left(h-h_{O}\right)-T_{O}\left(s-s_{O}\right)+1 / 2\left(m v^{2}\right)+m g z+b^{C H}
$$

As parcelas correspondentes às exergias cinética e potencial da massa que atravessa o sist./VC, podem ser geralmente desprezadas em relação à parcela da exergia física ou química. 
Destaca-se que quando o sistema/volume de controle não sofre nenhuma deformação, o termo $P_{O} \Delta V$ é nulo e assim todo o trabalho desenvolvido pelo (ou exercido sobre) o sist./VC é o mesmo trabalho útil. Além disso, se o sist./VC em questão não apresenta variações das propriedades termodinâmicas com o tempo em qualquer ponto (regime permanente), a Eq. (3.3) pode ser representada em termos de taxas de variação, como:

$$
\dot{B}_{\text {dest }}=\sum_{e} \dot{m} \cdot b-\sum_{s} \dot{m} \cdot b+\int\left(1-\frac{T_{0}}{T}\right) \frac{\delta Q}{d t}-\dot{W}_{u t i l}
$$

Como ilustrado na Eq. (3.5), o termo $\dot{B}_{\text {dest }}$ é o resultado da degradação de energia e é diretamente proporcional à taxa de geração de entropia. Este termo representa a possibilidade "perdida" de gerar trabalho útil ou irreversibilidade "máximo trabalho perdido".

Por outro lado, merece ser destacado, que na avaliação dos processos implícitos na operação das plantas, indicadores de conversão como a eficiência exergética são utilizados, conforme apresentado na análise das pesquisas de KAMATE; GANGAVATI (2009); PELLEGRINI; OLIVEIRA JR (2011) e SAIDUR et al. (2012).

Assim, por meio da definição geral de eficiência dada pela relação entre o efeito útil e o insumo consumido, pode-se chegar às expressões da eficiência energética, $\eta_{\mathrm{en}}$ (Eq. 3.6) e eficiência exergética, $\eta_{\mathrm{ex}}$ (Eq. 3.7) de plantas de cogeração:

$$
\begin{gathered}
\eta_{\mathrm{en}}=\frac{\dot{\mathrm{W}}+\dot{\mathrm{Q}}}{\dot{\mathrm{Q}}_{\mathrm{comb}}} \\
\eta_{\mathrm{ex}}=\frac{\dot{\mathrm{W}}+\dot{\mathrm{B}}_{\mathrm{Q}}}{\dot{\mathrm{B}}_{\mathrm{comb}}}
\end{gathered}
$$

$\mathrm{Na}$ Eq. (3.7) o termo $\dot{\mathrm{B}}_{\mathrm{Q}}$ representa a exergia transferida a um processo para fins de aquecimento ou refrigeração. Vários trabalhos baseados na análise exergética são encontrados na literatura citando três formas de eficiência exergética adequadas para avaliar o desempenho de processos de conversão de energia, em processos químicos (PQ), processos térmicos (PT), e processos puramente dissipativos (PD), entre esses se destacam SZARGUT; MORRIS; STEWARD (1988); KOTAS (1985); BEJAN; TSATSARONIS; MORAN (1996). 


\section{Exergia química padrão de substâncias complexas e combustiveis industriais}

Na Fig. 3.1 é representada esquematicamente a metodologia aplicada para o cálculo da exergia química de qualquer substância (OLIVEIRA JÚNIOR, 2013).

Figura 3.1 - Representação esquemática para obtenção da exergia química padrão.

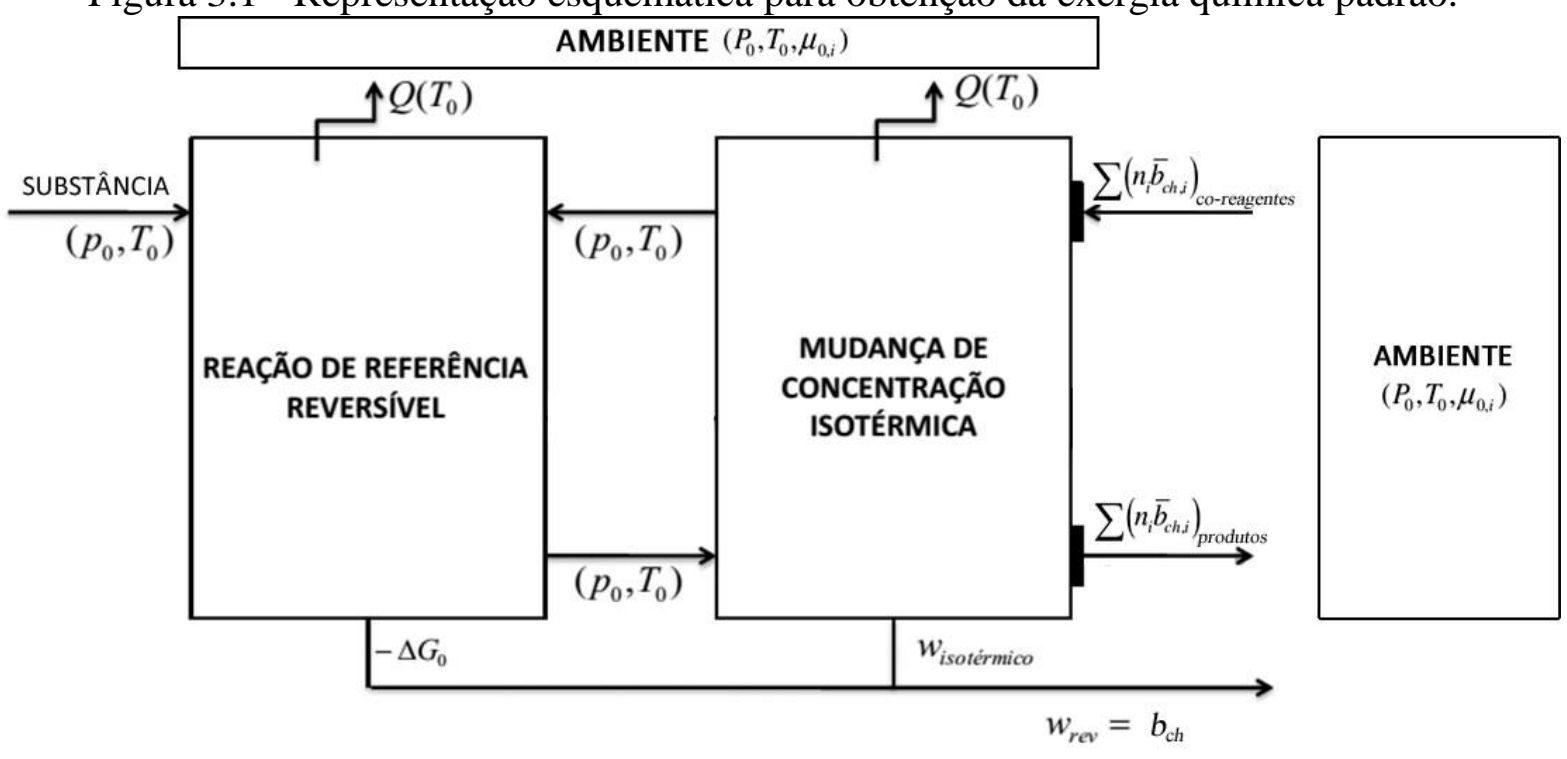

Fonte: Adaptado de Oliveira Júnior (2013).

A exergia química padrão de uma substância que não se encontra presente no ambiente pode ser calculada considerando-se uma reação ideal dessa substância com as substâncias de referência presentes no ambiente, para as quais a exergia química é conhecida. No entanto, os combustíveis sólidos e líquidos são constituídos por diferentes componentes químicos dos quais geralmente se desconhece sua composição exata. Para esses casos SZARGUT; MORRIS; STEWARD (1988), estabeleceram que a relação entre a exergia química e o poder calorífico inferior do combustível (PCI), chamada de $\varphi$ ou $\beta$, é a mesma que para qualquer substância pura com as mesmas relações atômicas $H / C, O / C, N / C$, e em alguns casos $S / C($ KOTAS, 1985).

De acordo com Szargut et al. (1988), para combustíveis fósseis sólidos compostos por substâncias orgânicas secas com $\mathrm{C}, \mathrm{H}, \mathrm{O}$ e $\mathrm{N}$ em sua composição química, e com $O / C \leq 0,5$ tem-se a correlação da Eq. (3.8).

$\beta=1,0437+0,0140(H / C)+0,0968(O / C)+0,0467(N / C)$ 
Para madeira $\left(\frac{O}{C} \leq 2,67\right)$, tem-se a Eq. (3.9):

$$
\beta=\frac{1,0412+0,2160(H / C)-0,2499(O / C)(1+0,7884(H / C))+0,0450(N / C)}{1-0,3035(O / C)}
$$

Quando o combustível contém umidade ou enxofre, a exergia química determina-se de acordo com a expressão da Eq. (3.10), a partir da relação $\varphi$ ou $\beta$ entre a exergia química e o (PCI):

$$
\begin{aligned}
\bar{b}_{F}^{C H}=[P C I+ & \left.w \cdot h_{l v}\right]_{\text {agua }} \cdot \varphi_{\text {seco }}+\left[\bar{b}^{C H}-P C I\right]_{\text {enxofre }} \cdot s \\
& =[P C I+w \cdot 2442]_{\text {agua }} \cdot \varphi_{\text {seco }}+9417 \cdot s \quad[\mathrm{~kJ} / \mathrm{kg}]
\end{aligned}
$$

Enquanto, para substâncias líquidas como derivados do petróleo é utilizada a correlação da Eq. (3.11). Por fim, na Tab. 3.1 ilustram-se os valores típicos de $\varphi$ para alguns combustíveis industriais e para outras substâncias combustíveis.

$$
\beta=1,0401+0,1728(H / C)+0,0432(O / C)+0,2169(S / C)(1-2,0628(H / C))
$$

Tabela 3.1 - Valores típicos de $\varphi$ ou $\beta$ para alguns combustíveis industriais e substâncias combustíveis.

\begin{tabular}{|l|c|}
\hline COMBUSTÍVEL & $\varphi=\frac{\bar{b}^{C H}}{P C I}$ \\
\hline Coque & 1,05 \\
\hline Carvão - diferentes tipos & $1,06-1,10$ \\
\hline Madeira & $1,15-1,30$ \\
\hline Óleos Combustíveis e Petróleo & $1,04-1,08$ \\
\hline Gás Natural & $1,04 \pm 0,5 \%$ \\
\hline Gás de Carvão & $1,00 \pm 1 \%$ \\
\hline Hidrogênio & 0,985 \\
\hline Monóxido de Carbono & 0,973 \\
\hline Enxofre (rômbico) & 2,017 \\
\hline
\end{tabular}

Fonte: Adaptado de Kotas (1985). 


\subsection{INTEGRAÇÃO ENERGÉTICA E OTIMIZAÇÃO DE PROCESSOS}

A integração de processos (IP) na indústria tornou-se uma ferramenta fundamental para o projeto e planejamento de suas atividades, proporcionando informações sobre a redução de custos operacionais e de investimento. Algumas das aplicações da IP são:

- Integração entre o processo e a planta de utilidades;

- Projetos de equipamentos como reatores, separadores e redes de trocadores de calor;

- Planejamento da operação de processos;

- Minimização da geração de efluentes aquosos e de consumo de água nos processos;

- Minimização de geração de resíduos e redução das emissões.

Por outro lado, a minimização do consumo de recursos naturais em processos industriais integrados provém não só o melhor aproveitamento da energia, mas também do consumo de matérias-primas e água, com análises que incluem integração térmica e de massa, além de gestão dos resíduos (ENSINAS; ARNAO; NEBRA, 2010).

Neste contexto, a aplicação de técnicas de IP permite o aprimoramento do uso da energia. Assim, análises conduzidas com base em conceitos de exergia e/ou termoeconomia representam ferramentas que possibilitam uma avaliação global de um sistema e orientam a proposição de alternativas de melhoria nos processos.

A integração do processo também pode ser realizada por meio do estudo do calor envolvido e da combinação dos fluxos de energia no sistema, possibilitando o uso de correntes de temperatura mais alta que necessitam ser resfriadas para fornecer calor à outra parte do mesmo processo. A análise Pinch pode ser usada como um mecanismo para calcular os requisitos de energia mínima de um dado processo (ALBARELLI, 2013).

A análise Pinch é um método para analisar e melhorar a eficiência energética no projeto de processos e operação de sistemas térmicos. A técnica foi introduzida pela primeira vez em 1979 pelo pesquisador Linhoff e seus colegas de trabalho para analisar os fluxos de energia no processo de redes de trocadores de calor. Esta análise se baseia na Primeira e Segunda Lei da Termodinâmica, indicando que o calor só pode fluir a partir de temperaturas mais elevadas (fontes) a temperaturas mais baixas (AL-MAYYAHI; HOADLEY; RANGAIAH, 2013). 
Nesta análise, as correntes de fluxo de calor são combinadas em grupos de fluxos quentes e frios formando as curvas compostas. Um conjunto simples de ferramentas gráficas, Curvas Compostas (CC) e Grande Curva Composta (GCC) são usadas para demonstrar os limites termodinâmicos da integração de calor, a qual pode ser conseguida ao maximizar o processo de recuperação de calor e minimizar o consumo de energia externa, como apresentado na Fig. 3.2, sendo Qhmin o consumo mínimo de utilidade quente e Qcmin o consumo mínimo de utilidade fria nesta figura. O ponto de maior aproximação entre essas curvas é a temperatura Pinch (ponto de estrangulamento térmico), sendo este o melhor ponto para iniciar os estudos de design (KEMP, 2007).

Figura 3.2 - Curvas compostas na análise Pinch.

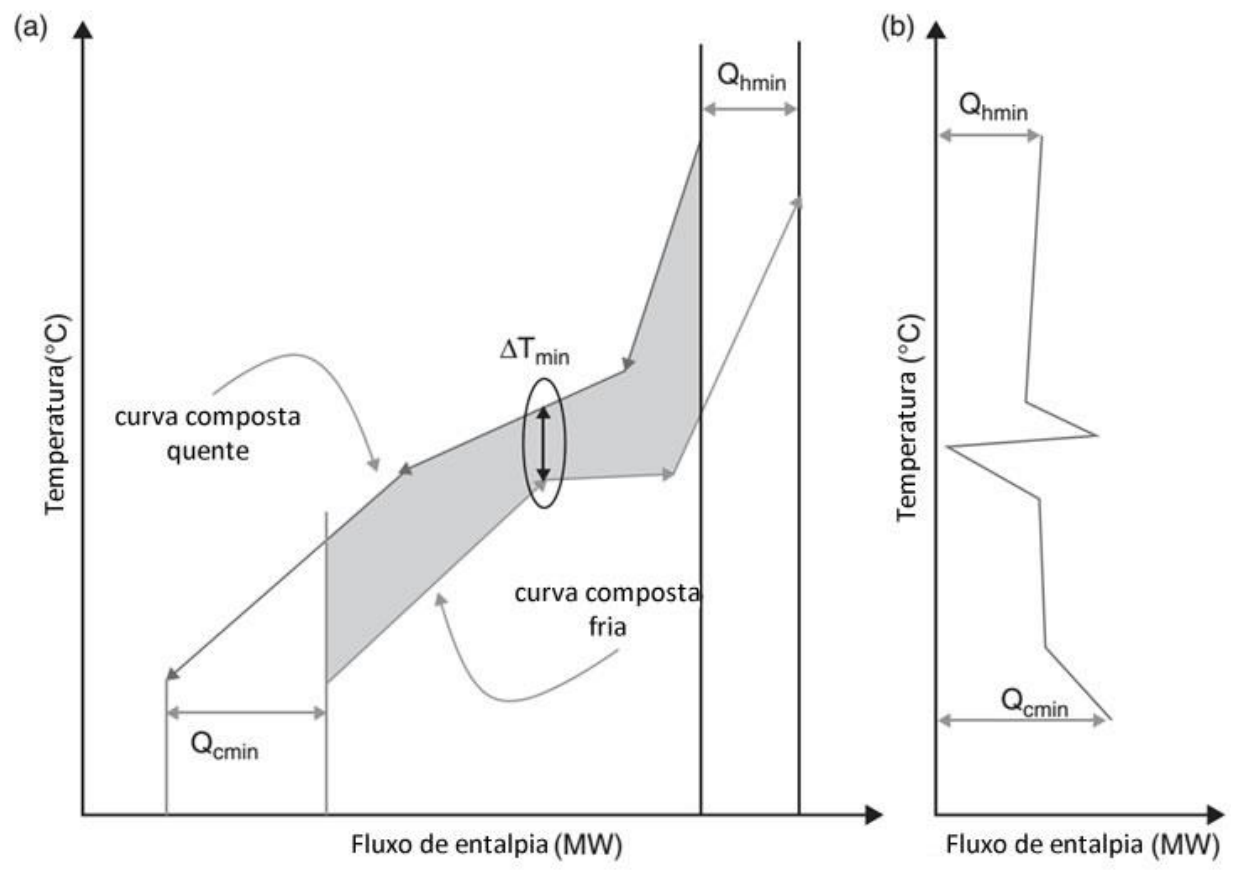

Fonte: Adaptado de Al-Mayyahi et al. (2005).

Esta etapa é chamada de meta de consumo mínimo de utilidades ou máxima recuperação de energia (MER, Minimum Energy Requirement), fase onde são determinadas as quantidades mínimas de utilidade quente e de utilidade fria uma vez conhecidos os requerimentos de aquecimento e resfriamento das correntes do processo. 


\subsubsection{Otimização de Processos}

As técnicas de otimização buscam obter a melhor solução para um problema em termos de máximos e mínimos de grandezas mensuráveis em seus domínios. Assim, na otimização de processos é necessário definir a função objetivo, o modelo do processo e as restrições da configuração a ser avaliada.

$\mathrm{Na}$ formulação de um problema de otimização a função objetivo representa lucro, custo, energia, produção, etc., em termos das variáveis de decisão do processo ou sistema em análise. O modelo do processo e as restrições descrevem as inter-relações entre estas variáveis.

Deste modo, o objetivo da otimização de um sistema energético é encontrar a estrutura e os valores ótimos dos parâmetros do sistema que minimizam o custo final dos produtos, considerando as restrições impostas pela confiabilidade, rendimento, disponibilidade, manutenção, operabilidade e impacto ambiental (TSATSARONIS, 1993).

$\mathrm{Na}$ área da engenharia as aplicações mais comuns das técnicas de otimização são o dimensionamento e otimização de processos, a integração mássica e energética, a estimação de parâmetros e otimização de sistemas técnico-econômicos. De acordo com Secchi (2015), não existe um único método que possa ser aplicado eficientemente para todos os problemas. $\mathrm{O}$ método escolhido para um caso particular depende das características da função objetivo, da natureza das restrições e do número de variáveis do problema. Contudo, os seguintes passos devem ser observados na formulação e solução de um problema de otimização:

1. Análise do processo e suas variáveis;

2. Determinação do critério para otimização e especificação da função objetivo em termos das variáveis do processo;

3. Desenvolvimento do modelo relacionando as suas variáveis através de restrições de igualdade e desigualdade. Cálculo do grau de liberdade do sistema;

4. Quando a formulação do problema é de dimensão elevada, procura-se particionar o problema em partes menores ou simplificar a função objetivo e o modelo;

5. Aplicação de técnicas apropriadas de otimização;

6. Analisar a solução obtida frente a variações nos parâmetros do modelo e hipóteses (análise de sensibilidade). 
Por exemplo, uma das vertentes do processo de otimização é a otimização termodinâmica, a qual utiliza a seguinte metodologia para determinar os critérios de desempenho dos sistemas (SIENIUTYCZ, 2003):

a. Energia mecânica ou elétrica (trabalho), gerado ou consumido,

b. Perdas de energia mecânica ou exergia, e produção de entropia,

c. Parâmetros de estado termodinâmico na etapa final do processo (constituindo os critérios de otimização físico-químicos), por exemplo, a concentração final de um produto valioso em um reator químico.

\section{Avaliação de configurações para produção de bioetanol e eletricidade}

Dentre os trabalhos desenvolvidos visando à integração energética de usinas produtoras de açúcar, etanol e eletricidade a partir da cana-de-açúcar, destacam-se:

Velásquez (2009) avaliou diversas rotas de produção de biocombustíveis por meio da análise exergética e exergo-ambiental. Sendo estas rotas, a hidrólise ácida do amido de polpa da banana, a hidrólise enzimática do material lignocelulósico de resíduo do cultivo da banana; a produção combinada de açúcar e etanol mediante a moagem da cana-de-açúcar, assim como a extração e transesterificação do óleo da palmeira do dendê para a produção de biodiesel, conforme ilustrado na Fig. 3.3.

Destaca-se dentre os resultados obtidos nesta análise, a determinação da eficiência exergética para o processo produtivo de biocombustíveis a partir de diversos insumos. Os valores da eficiência exergética reportados para as plantas de utilidades de cada rota: Banana 7,2\%, Polpa 10,8\%, Pedúnculo 4,3\%, Cana-de-açúcar 13,9\% e Palmeira-do-dendê 14,3\% (VELÁSQUEZ, 2009).

Do mesmo modo, os valores da eficiência exergética global das usinas de produção de biocombustíveis nessas configurações foram: Banana 24,5\%, Polpa 35,1\%, Pedúnculo 12,2\%, Cana-de-açúcar 45,5\% e Palmeira-do-dendê 74,7\% (VELÁSQUEZ, 2009). 
Figura 3.3 - Eficiência exergética dos processos de produção de biocombustíveis.
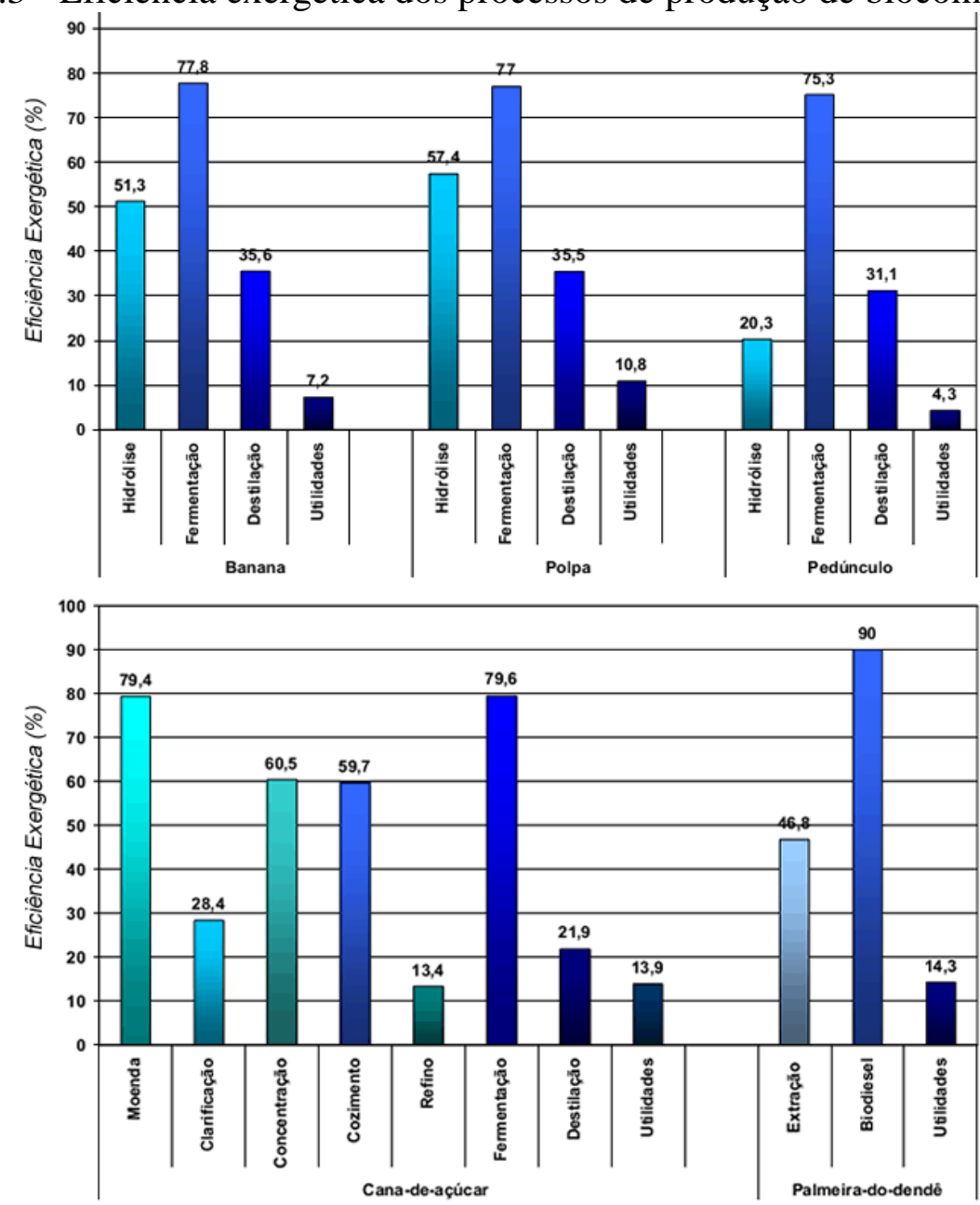

Fonte: Adaptado de Velásquez (2009).

Neste ponto, Pellegrini (2009) apresenta configurações otimizadas para geração conjunta de energia eletromecânica e calor em usinas sucroalcooleiras, avaliando o impacto destas nos custos exergéticos de produção de açúcar, álcool e eletricidade. As propostas incluem a elevação dos parâmetros de geração de vapor nas caldeiras, maior integração térmica dos processos, eletrificação dos acionamentos mecânicos e uso de tecnologias avançadas de cogeração, considerando sistemas com vapor supercrítico e ciclos combinados de gaseificação de biomassa.

Alguns dos principais resultados deste estudo são apresentados graficamente, por meio da Fig. 3.4 e Fig. 3.5, em função do custo em base exergética de açúcar, álcool e eletricidade para cada configuração tecnológica avaliada (PELLEGRINI, 2009). 
Figura 3.4 - Custo em base exergética do açúcar e do álcool, em diversas configurações tecnológicas.

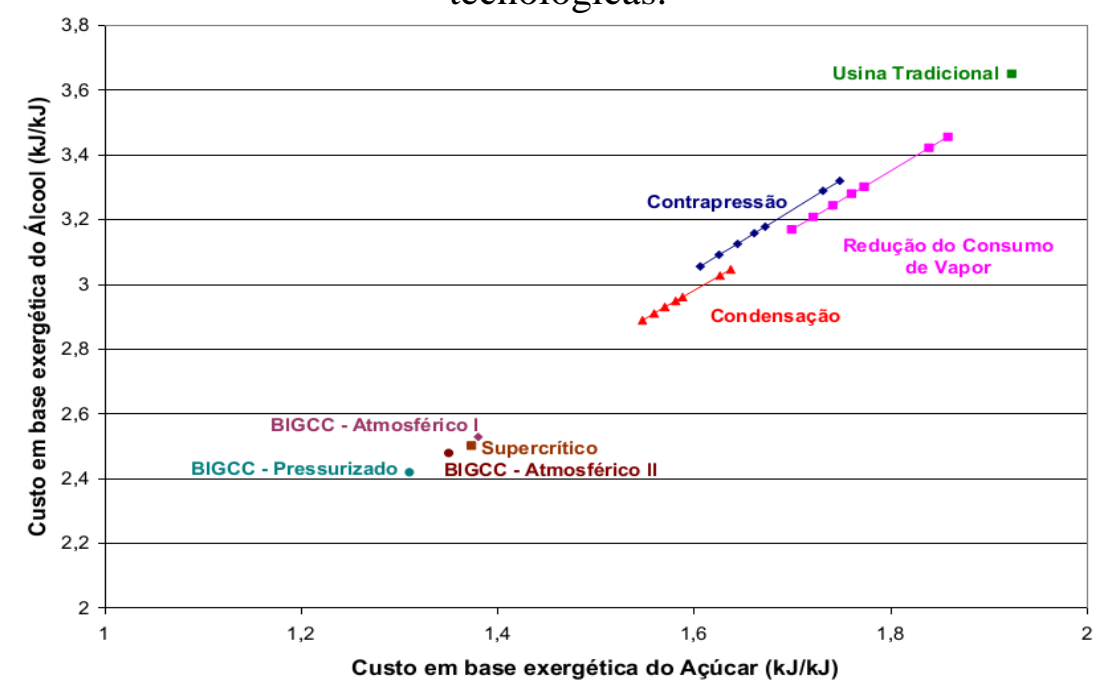

Fonte: Reproduzido de Pellegrini (2009).

Figura 3.5 - Custo em base exergética da energia elétrica em decorrência da geração de eletricidade excedente.

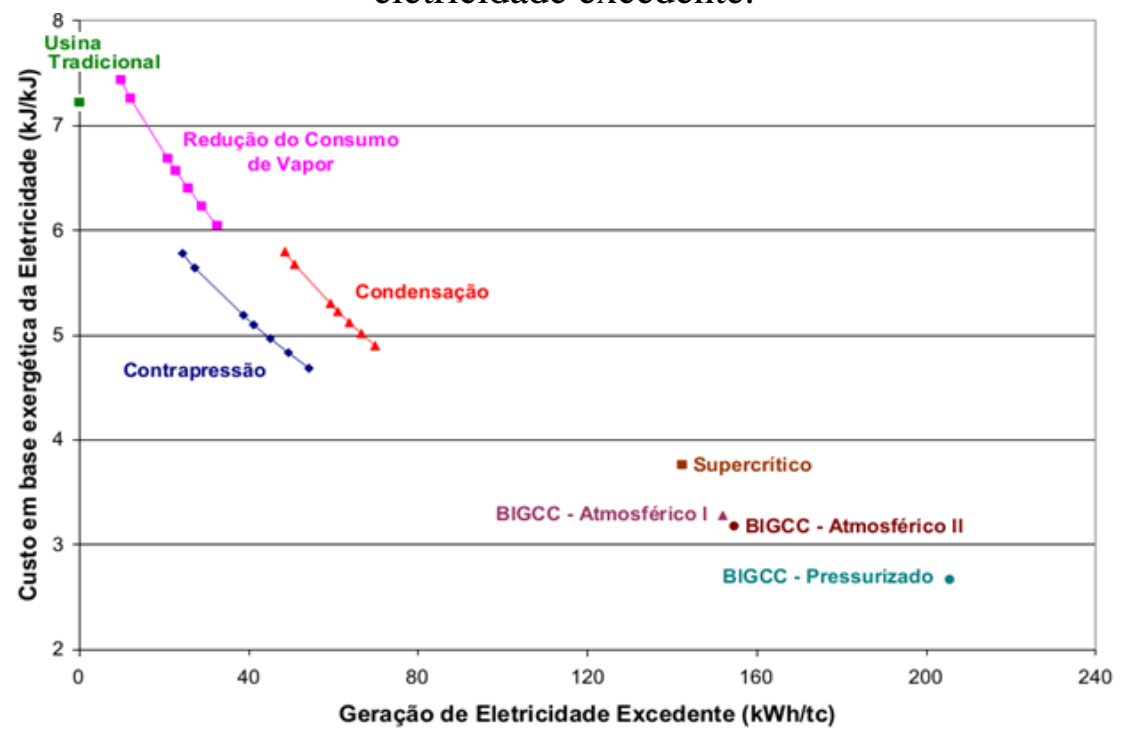

Fonte: Reproduzido de Pellegrini (2009).

Neste sentido, Pellegrini e Oliveira Jr (2011) mostraram o potencial do setor sucroalcooleiro brasileiro como um fornecedor de eletricidade, por meio de uma abordagem de otimização exergética de sistemas de cogeração em usinas de cana. Assim, uma análise exergética foi realizada para os processos de produção de açúcar e etanol com base em dados fornecidos para uma unidade real. Ademais, os autores conduziram uma discussão sobre a renovabilidade dos processos empregando-se um índice baseado no conceito de processo reversível. Concluise desse estudo que a geração de eletricidade excedente melhora o desempenho exergoambiental da usina. 
Escobar (2010) propôs uma análise termodinâmica integrada de uma planta de cogeração acoplada a um sistema de destilação, em uma destilaria autônoma. Nesse trabalho, foi realizada a avaliação simultânea de dois sistemas, utilizando como ferramenta de análise uma metodologia exergo-econômica. Os resultados das alternativas consideradas foram aplicados em uma destilaria convencional operando com baixos parâmetros de vapor $\left(2,1 \mathrm{MPa}, 300^{\circ} \mathrm{C}\right)$ e tecnologia de destilação atmosférica.

Ensinas (2008) expôs um método de integração térmica para a produção de açúcar e etanol, visando obter uma redução da demanda das utilidades quentes e frias. Um procedimento de otimização termoeconômica foi aplicado para avaliar a redução de custo no projeto de integração da planta, que incluiu uma rede de trocadores de calor e um sistema de evaporação. Além disso, foi realizada uma análise exergética, avaliando as melhorias obtidas com a integração, mostrando que a geração de entropia no processo pode ser minimizada com a redução do consumo de energia e com o aumento da eficiência do sistema de cogeração.

Neste sentido, Palacios-Bereche (2011) realizou um estudo com a finalidade de modelar o processo de produção de etanol via hidrólise enzimática, inserido no processo convencional das usinas sucroalcooleiras, utilizando como ferramenta de análise o simulador Aspen Plus ${ }^{\circledR}$. Adicionalmente, neste projeto foi avaliado o potencial de produção de etanol considerando a integração térmica das correntes do processo, por meio do método Pinch. Os resultados desta análise para o processo convencional apresentaram um incremento na produção de etanol de 9,7\%. Entretanto, quando aplicado o método de integração térmica utilizando membranas para a concentração do licor de glicose obtido no processo da hidrólise, foi atingindo um incremento de $22,4 \%$ na produção de etanol.

Por fim, Dias (2011) realizou um estudo para determinar as melhores condições para a inserção de diferentes tecnologias de produção de etanol $2 \mathrm{G}$ no Brasil, a partir das frações lignocelulósicas da cana-de-açúcar, o que possibilitou o aumento da produção sem expansão da área cultivada. Além disso, as tecnologias foram comparadas com diferentes prétratamentos e condições de hidrólise enzimática. Os resultados mostraram que a otimização no consumo de energia do processo de $1 \mathrm{G}$ e o uso de parte da palha são essenciais para aumentar significativamente a produção de etanol. Contudo, o teor de sólidos utilizado nas reações de hidrólise apresenta um grande impacto na produção total de etanol. Assim, ganhos 
podem ser obtidos ao se integrar a produção de etanol $2 \mathrm{G}$ e geração de eletricidade em uma destilaria autônoma convencional.

Na atualidade, pesquisadores vêm desenvolvendo trabalhos focados na avaliação das rotas de conversão da biomassa para produção de biocombustíveis, a partir da aplicação de métodos de análise termoeconômicos, seguidos por uma otimização multi-objetivo dos sistemas visando introduzir configurações otimizadas nesses projetos.

Em seus estudos, Albarelli et al. (2015b) avaliaram uma biorrefinaria de cana produzindo etanol através da fermentação do caldo, metanol a partir da gaseificação de resíduos lignocelulósicos de cana e a síntese de combustíveis líquidos. Nesta análise duas tecnologias de gaseificação foram comparadas, leito arrastado e leito fluidizado circulante. A otimização multi-objetivo foi conduzida mediante um algoritmo genético. Os resultados mostraram que a eficiência energética das biorrefinarias aumenta significativamente com a integração de uma planta de produção de metanol em uma destilaria de etanol convencional.

Destaca-se ainda a abordagem da simulação da tecnologia de fluido supercrítico, particularmente a gaseificação com água supercrítica (SCWG), para agregar valor aos resíduos de uma biorrefinaria de cana. Neste sentido Albarelli et al. (2015a) avaliaram uma configuração SCWG a partir de ferramentas de processos de engenharia, tais como integração térmica, análise de ciclo de vida, avaliação econômica e otimização multi-objetivo. Os resultados mostraram as soluções otimizadas do processo SCWG e o aumento da eficiência global em termos da fixação de carbono e energia. O processo SCWG diminuiu as emissões de $\mathrm{CO}_{2}$ equivalentes e levando a um processo termicamente autossuficiente.

Gassner e Maréchal (2013) investigaram configurações otimizadas da conversão termoquímica dos resíduos com o objetivo de aumentar o rendimento total a partir da produção combinada de vários combustíveis e eletricidade. Os autores compararam diferentes tecnologias para o processamento termoquímico e a recuperação de calor e energia. O estudo mostrou que o rendimento de combustível pode ser mais do dobro, atingindo eficiências totais de energia e exergia de até $72 \%$ e $78 \%$, respectivamente. 


\subsection{IMPACTOS AMBIENTAIS NA ANÁLISE DE SISTEMAS DE CONVERSÃO DE ENERGIA}

A análise da literatura indica que existe uma relação qualitativa entre exergia e desenvolvimento sustentável, assim mesmo entre exergia e sustentabilidade de processos ou sistemas Jorgensen e Norsnielsen (2007); Velásquez (2009); Kanoglu; Dincer e Rosen (2007). Observou-se, ainda a relação entre exergia e gestão, sendo vários os indicadores propostos que usam a exergia como base na ponderação da sustentabilidade.

De acordo com Krahl (2009), a contabilização da exergia permite determinar as características de um sistema e o efeito que sua operação pode exercer no meio ambiente usando um denominador comum. Portanto, a exergia auxilia na tomada de decisões relacionadas a planejamento energético e a desenvolvimento sustentável a partir de:

- Análise de sistemas energéticos, combinando a $1^{\mathrm{a}}$ Lei com a $2^{\mathrm{a}}$ Lei da Termodinâmica;

- Quantificação das perdas de energia e energia residual de modo que pode prover informações importantes para o uso mais eficiente de recursos;

- Determinação do impacto da utilização de energia no meio ambiente.

Nesta pesquisa, a discussão exergo-ambiental a respeito da renovabilidade das rotas para a produção de álcool e eletricidade será conduzida por meio do índice exergético de renovabilidade $(\lambda)$ culminando na proposta apresentada por Velásquez et al. (2013).

O índice leva em consideração a relação entre a exergia dos produtos/subprodutos e as exergias não-renováveis (fóssil) utilizadas, a exergia destruída (irreversibilidades total do processo), a exergia de desativação e a exergia das emissões/resíduos, conforme apresentado na Eq. (3.12):

$$
\lambda=\frac{\Sigma B_{\text {produtos/subprodutos }}}{B_{\text {fóssil }}+B_{\text {destruída }}+B_{\text {desativaçãoo }}+\Sigma B_{\text {emissões/resíduos }}}
$$


De acordo com Pellegrini (2009), a análise dos processos a partir desse índice permite quantificá-los como:

- Ambientalmente desfavoráveis: $0 \leq \lambda<1$;

- Interna e externamente reversíveis, com uso apenas de insumos não-renováveis: $\lambda=1$;

- Ambientalmente favoráveis: $\lambda>1$;

- Interna e externamente reversíveis, com uso apenas de insumos renováveis: $\lambda \rightarrow \infty$

Destaca-se o significado do índice de renovabilidade ser maior que 1 . Isso quer dizer que a exergia dos produtos poderia ser usada para "restaurar" o meio ambiente às condições anteriores à ocorrência do processo e ainda obter um fluxo positivo de exergia para outro uso. Este autor apresentara os resultados do $\lambda$ para as diferentes configurações de plantas de utilidades estudadas na produção combinada de açúcar, álcool e eletricidade, conforme ilustrado na Fig. 3.6.

Figura 3.6 - Índice exergético de renovabilidade da usina em função do sistema de cogeração.

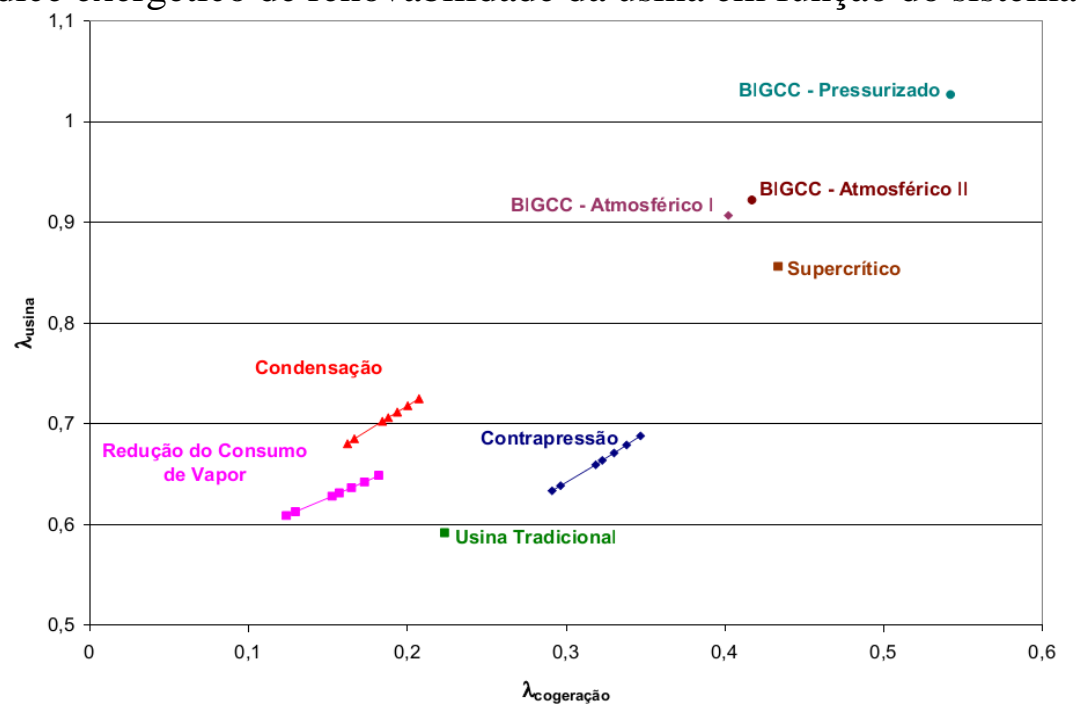

Fonte: Reproduzido de Pellegrini (2009).

Observa-se também nesse estudo que o índice para a usina como um todo é superior ao índice do sistema de cogeração. Isto ocorre devido às irreversibilidades do sistema de cogeração representarem em média $68 \%$ das irreversibilidades totais de uma usina, sendo seus produtos a energia-eletromecânica e o calor utilizado nos processos de produção de açúcar e álcool, além da eletricidade excedente vendida para a rede. Porém, esses produtos equivalem a apenas $18 \%$ da exergia do açúcar e do álcool para uma usina tradicional, e $42 \%$ para o sistema BIGCC pressurizado (PELLEGRINI, 2009). 
Além disso, Pellegrini (2009) conduziu uma avaliação comparativa das configurações propostas, onde se nota que o aumento da eficiência do sistema de cogeração (maior geração de eletricidade excedente) e uma melhor integração térmica dos processos da usina (redução do consumo de vapor) melhoram o desempenho ambiental da usina. Desta maneira, aumentam a exergia dos produtos (numerador do $\lambda$ ) enquanto diminuem as exergias destruídas e perdidas (denominador do $\lambda$ ), de acordo com a Eq. (3.12).

Por outro lado, Velásquez (2009) aplicou o índice $\lambda$ na avaliação da produção de biocombustíveis para diversas matérias-primas. Para todos os insumos analisados, excetuando o uso do óleo da palmeira-do-dendê, nenhum processo foi considerado renovável porque o valor do indicador obtido resultou menor que um $(\lambda<1)$. Note-se que para todos os casos estudados por dito autor, há uma estreita relação entre o indicador de renovabilidade e a eficiência exergética global. Constata-se que quanto maior eficiência exergética global, maior é o valor do indicador, como ilustrado na Fig. 3.7.

Figura 3.7 - Relação entre a eficiência exergética dos processos e o índice $\lambda$.

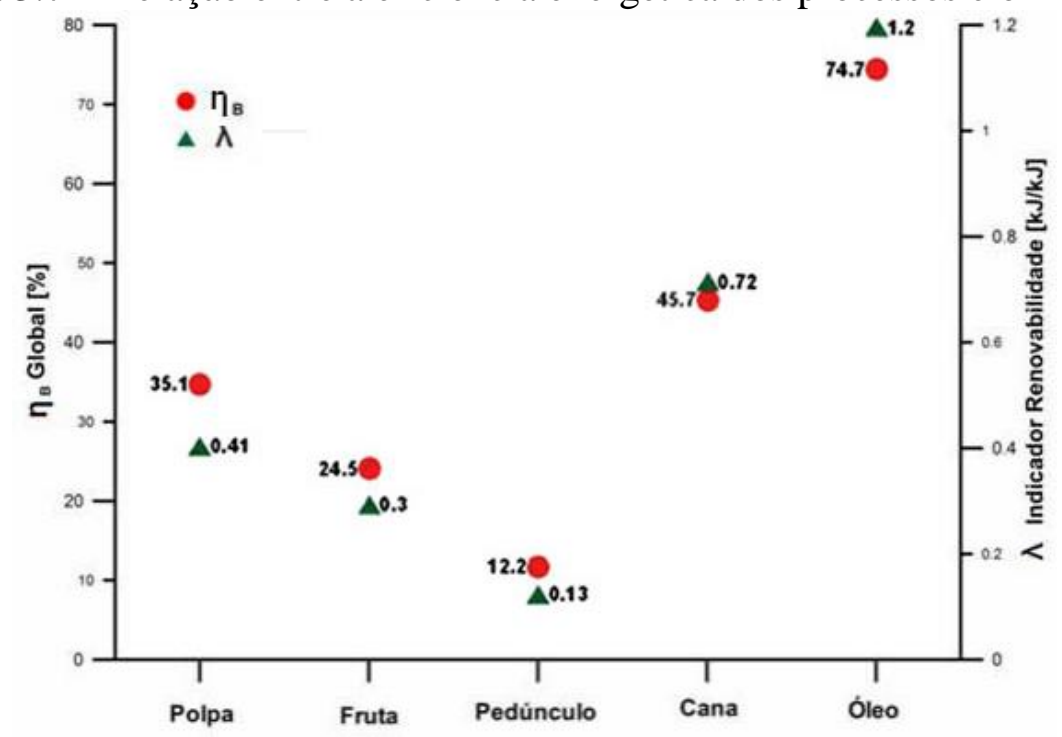

Fonte: Reproduzido de Velásquez (2009).

É importante ressaltar que o índice guarda forte relação com o volume de controle $(V C)$ considerado, devido ao número de processos de conversão de energia sendo envolvidos. Assim, quanto maior for o $V C$ adotado, menor será o valor do índice $\lambda$ em função do aumento das irreversibilidades e da possibilidade do aporte de insumos não renováveis (fósseis) ao processo. Por esse motivo, ao comparar sistemas diferentes é importante garantir a compatibilidade dos volumes de controle a fim de evitar distorções nas análises. 
À luz deste item, conclui-se que a exergia pode ser utilizada como um indicador ambiental para determinar a medida de desvio do equilíbrio dos sistemas, avaliar as mudanças e quantificar as irreversibilidades do meio ambiente por causa dos processos (JORGENSEN; NORSNIELSEN, 2007). 


\section{CONSTRUÇÃo dOS MODELOS PARA SIMULAÇÃo DE CONFIGURAÇÕES DE BIORREFINARIAS}

Os modelos considerados na análise e avaliação de cada rota tecnológica deste projeto serão apresentados no decorrer do capítulo. Além disso, nesta seção são ilustradas as ferramentas de análise e metodologias adotadas na simulação dos processos.

\subsection{METODOLOGIA}

Com o objetivo de definir as configurações ótimas das rotas tecnológicas propostas faz-se necessária uma análise prévia de uma usina convencional do setor sucroalcooleiro, a fim de estabelecer as condições de contorno para a operação dos sistemas. Tais condições possibilitaram a integração e modelagem matemática em cada rota segundo os critérios adotados. Nesse sentido, a avaliação exergética e exergo-ambiental dos processos foi conduzida por meio das etapas apresentadas na Tab. 4.1.

Tabela 4.1 - Metodologia do projeto.

\begin{tabular}{|c|l|}
\hline ETAPA & \multicolumn{1}{c|}{ ATIVIDADE } \\
\hline $\mathbf{1}$ & $\begin{array}{l}\text { Caracterização dos processos de conversão de energia em cada } \\
\text { configuração de biorrefinaria analisada e definição de um fluxograma } \\
\text { básico (planta síntese). }\end{array}$ \\
\hline $\mathbf{2}$ & $\begin{array}{l}\text { Análise termodinâmica realizada por meio de modelos matemáticos, } \\
\text { balanços de massa, energia e exergia em cada etapa dos processos } \\
\text { produtivos. }\end{array}$ \\
\hline $\mathbf{3}$ & $\begin{array}{l}\text { Aplicação de indicadores exergo-ambientais que permitirão quantificar } \\
\text { e comparar o desempenho exergético e ambiental dos processos. }\end{array}$ \\
\hline $\mathbf{4}$ & $\begin{array}{l}\text { Comparação dos desempenhos e avaliação dos produtos obtidos nas } \\
\text { rotas. }\end{array}$ \\
\hline $\mathbf{5}$ & $\begin{array}{l}\text { Proposição de alterações nas configurações de biorrefinarias analisadas } \\
\text { visando reduzir os custos de produção e aumento do desempenho } \\
\text { exergético e ambiental. }\end{array}$ \\
\hline $\mathbf{6}$ & $\begin{array}{l}\text { Hierarquização das configurações e condições de operação de } \\
\text { biorrefinarias para cenários de produção de etanol e eletricidade por } \\
\text { meio dos indicadores propostos na etapa 4. }\end{array}$ \\
\hline
\end{tabular}

Fonte: Elaborado pelo autor. 
Inicialmente realizou-se uma revisão do estado-da-arte sobre os aspectos gerais das biorrefinarias, visando obter a caracterização dos resíduos e os dados de consumo e produção mais representativos dos processos (Etapa 1).

Posteriormente, foi realizada a simulação dos processos químicos intrínsecos nas rotas tecnológicas a partir do simulador Aspen Plus ${ }^{\circledR}$ (Aspentech, 2013). Nesta fase, buscou-se suporte nas ferramentas computacionais $\operatorname{Vali}^{\circledR}$ (Belsim, 2014) e EES ${ }^{\circledR}$ (Klein, 2015), que permitem considerar balanços de massa, energia e exergia, bem como realizar procedimentos de otimização (Etapas 2, 3, e 4).

Uma vez realizadas estas etapas foi conduzida a integração dos processos com a finalidade de obter a configuração otimizada de uma biorrefinaria. Desta forma, a configuração 'ótima' foi avaliada energética, exergética e ambientalmente, sendo determinados os seus produtos e custos monetários em base exergética (Etapas 5 e 6).

Merece ser destacado que na avaliação das rotas tecnológicas de produção de etanol e eletricidade foi adotada a metodologia de otimização desenvolvida pelo Laboratório de Processos Industriais e Engenharia de Sistemas de Energia (IPESE) da Escola Politécnica Federal de Lausana (EPFL).

Neste sentido, com o intuito de encontrar as melhores configurações para cada rota, foram estabelecidas as condições de contorno/operação, funções objetivo e as variáveis mais representativas dos sistemas. A partir desses parâmetros realizou-se a integração e modelagem matemática das rotas avaliadas, de acordo com a metodologia apresentada na Fig. 4.1.

Deste modo, os modelos propostos para a simulação dos cenários base das rotas tecnológicas foram otimizados mediante a plataforma OSMOSE, ferramenta concebida pelo IPESE que envolve a análise termoeconômica e ambiental à luz da integração térmica e energética dos processos (BOLLIGER, 2010). 
Figura 4.1 - Metodologia adotada para otimização das configurações.

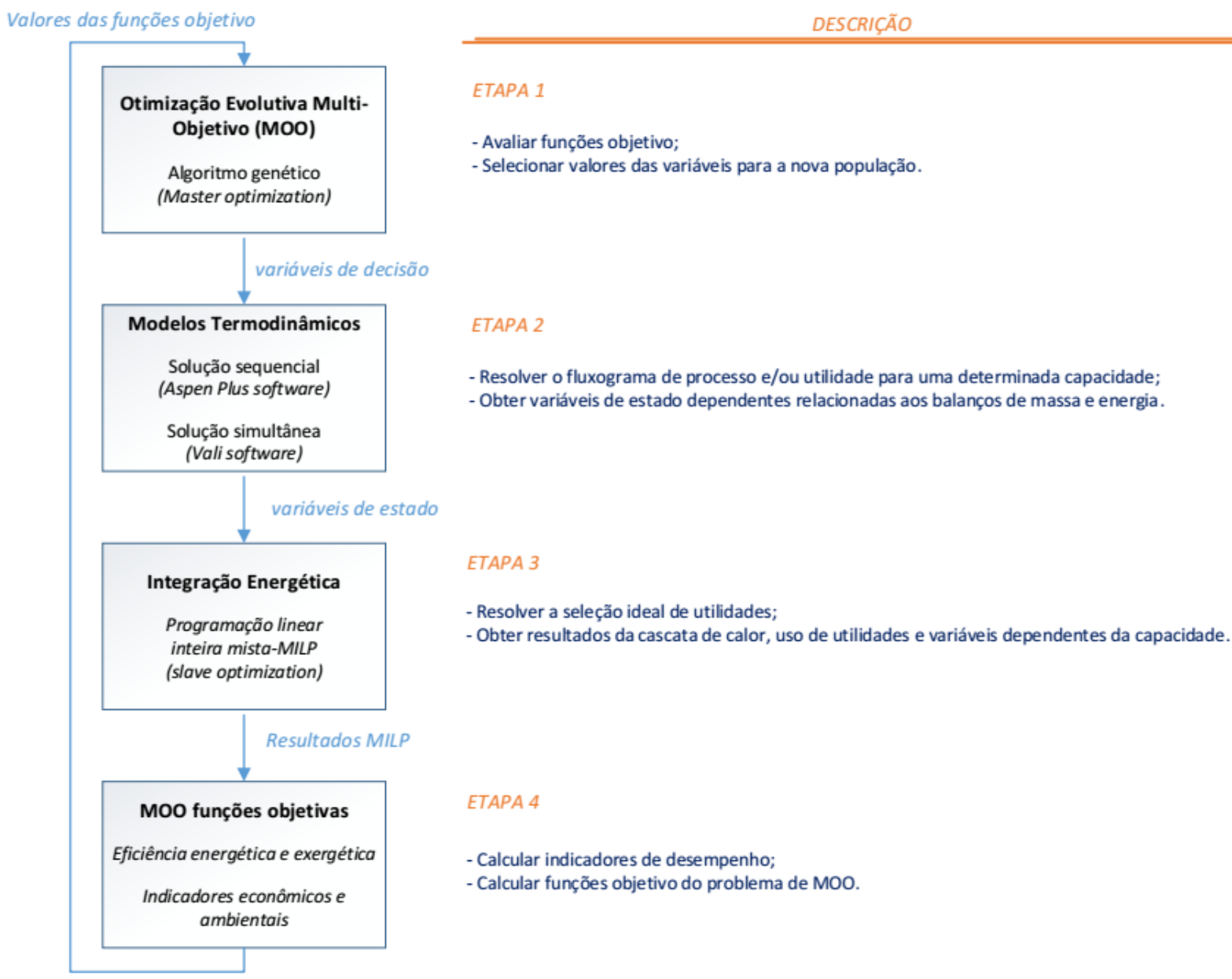

Fonte: Adaptado de Mian et al. (2015).

Os modelos das rotas tecnológicas propostas, foram desenvolvidos utilizando os programas Aspen Plus ${ }^{\circledR}$ e Vali $^{\circledR}$, sendo este último aplicado no caso da configuração do gaseificador de leito arrastado envolvendo a rota 3 desta pesquisa. Em seguida, a integração de processos através da plataforma OSMOSE, permitiu conduzir a avaliação termoeconômica e a otimização multi-objetivo. A versão de OSMOSE utilizada é escrita na linguagem de programação Lua. A Fig. 4.1 mostra a metodologia que foi implementada no OSMOSE para a avaliação e otimização de sistemas energéticos (MIAN; ENSINAS; MARECHAL, 2015).

Esta metodologia permite gerar sistematicamente conjuntos de configurações ideais e parâmetros de funcionamento a partir de uma concepção geral do processo para executar simultaneamente a otimização dos processos do ponto de vista termodinâmico, econômico e ambiental utilizando técnicas de otimização multi-objetivo. 
Vale destacar que as usinas sucroalcooleiras Brasileiras foram o foco deste estudo, razão pela qual os parâmetros do processo típicos do setor (dados de literatura) foram adotados nas simulações. Nesse sentido, a metodologia empregada na resolução de problemas para a avaliação das configurações desta pesquisa foi realizada nas seguintes etapas:

1. Avaliação dos balanços de massa e energia dos processos modelados no Aspen Plus ${ }^{\circledR}$ e $\mathrm{Vali}^{\circledR}$. Estes modelos determinaram a taxa de conversão das espécies e foram utilizados para definir os balanços dos sistemas;

2. Desenvolvimento da integração energética dos sistemas com base no método de Análise Pinch. Deste modo, o potencial de recuperação dos fluxos de calor entre correntes quentes e frias do processo é alcançado na resolução do problema de cascata de calor. A integração ótima da utilidade é obtida quando a produção combinada de combustível, energia e calor são maximizados, o que minimiza o custo operacional através da resolução do problema de cascata de calor usando a técnica da programação linear inteira mista-MILP desenvolvida por MARECHAL; KALITVENTZEFF (1996). O problema de MILP é resolvido usando o software GLPK e glpsol solver incorporado na plataforma OSMOSE (ALBARELLI et al., 2015b);

3. Aplicação da avaliação econômica. O modelo econômico consiste na determinação do custo total do investimento. As principais unidades de processo são dimensionadas e seu custo de aquisição é calculado usando correlações da literatura proposta em Turton (2009) e Ulrich; Vasudevan (2003);

4. Execução da otimização multi-objetivo (MOO). Esta etapa foi conduzida no nível mestre considerando um subproblema de operação (escravo), descrito nas anteriores fases. Esta abordagem permite superar a complexidade do problema de projeto, enquadrando-se na categoria de problemas de programação não linear inteira mista MILP (GASSNER; MARÉCHAL, 2009). MOO foi realizado usando o algoritmo evolutivo desenvolvido por Molyneaux (2002) e incorporado na plataforma OSMOSE. Duas funções objetivos foram consideradas no problema de otimização: $a$ maximização da eficiência exergética e a minimização do custo de investimento. 
Com relação à avaliação econômica é importante ressaltar que o intervalo de incerteza para uma estimativa deste tipo de análise pode ser $\pm 30 \%$ a 50 aproximadamente (PETERS; TIMMERHAUS, 2001), uma vez que as estimativas do valor futuro podem ser incorretas, até certo ponto, em função das bases de dados dos fornecedores de equipamentos, parâmetros de custos de aquisição, vida útil prevista, taxa de produção, operação em diferentes níveis de capacidade, localização geográfica da planta, inflação, etc.

Destaca-se ainda que idealmente, em uma avaliação econômica os custos dos equipamentos comerciais ou dados fornecidos pelos fabricantes das tecnologias emergentes devem ser usados para uma análise precisa. No entanto, os fabricantes publicam apenas poucas informações e dificilmente dados específicos dos equipamentos estão disponíveis. Portanto, os custos de investimento são avaliados usando correlações de custos. Estas estimativas se baseiam no dimensionamento e tipo de material de construção, que dependem da produtividade do processo, determinada pelas variáveis de decisão e condições de funcionamento do equipamento.

Por fim, deve-se ressaltar que, nesta pesquisa, a metodologia de otimização multi-objetivo foi aplicada unicamente a Rota Termoquímica $2 \mathrm{G}$, envolvendo a conversão da biomassa por meio de gaseificadores do tipo Leito Fluidizado Circulante (CFB) e Leito Arrastado (EF) na sua análise global. 


\subsubsection{Configurações avaliadas para produção de etanol e eletricidade}

Nesta seção apresenta-se uma síntese das configurações adotadas na simulação das rotas de produção de etanol e geração de eletricidade. Inicialmente, a visão geral dos processos envolvidos nas análises é oferecida na Fig. 4.2. Além disso, com o intuito de facilitar a sua identificação, a Tab. 4.2 expõe uma breve descrição das tecnologias e as ferramentas computacionais das configurações estudadas.

Figura 4.2 - Configurações avaliadas.

\section{G}

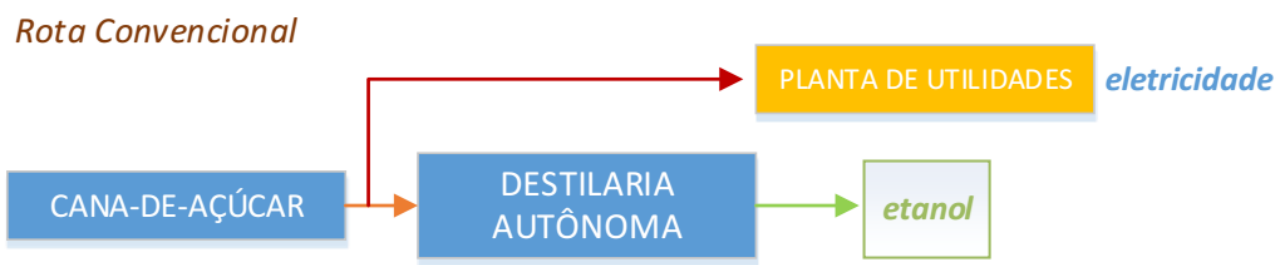

\section{G}

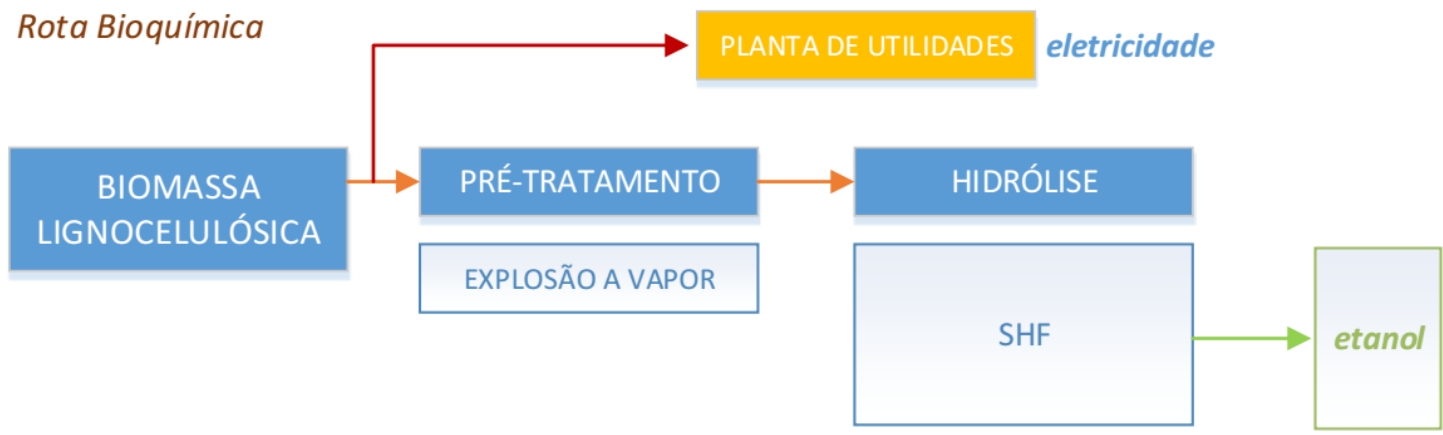

\section{G}

Rota Termoquímica

eletricidade

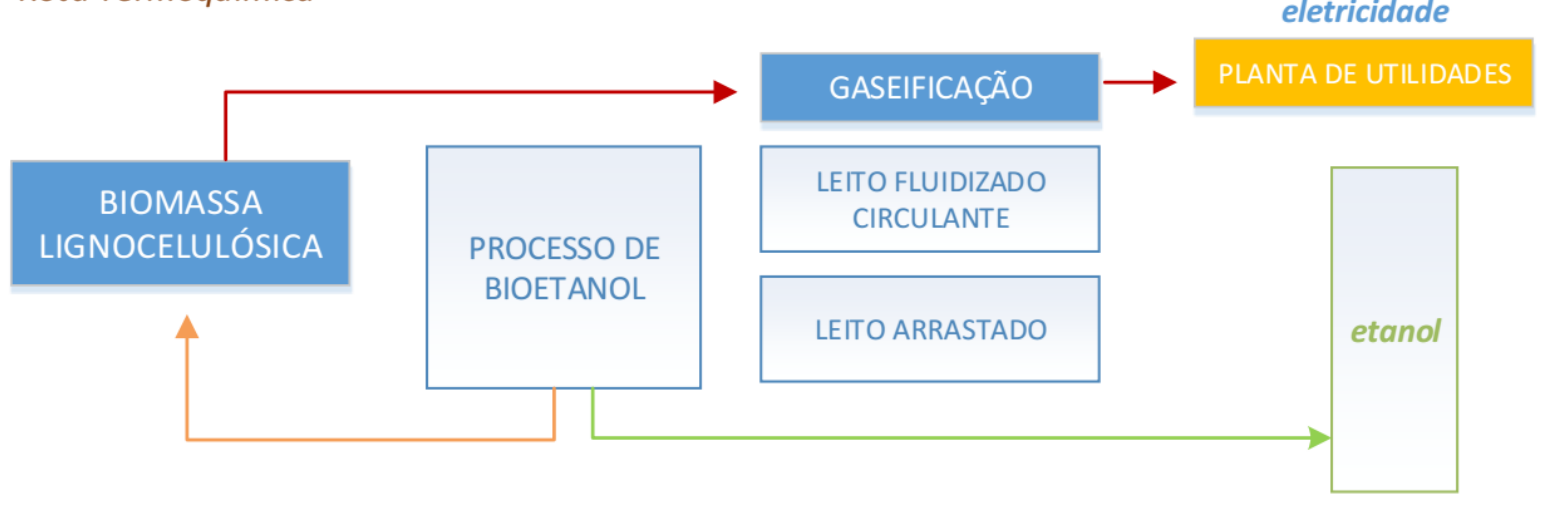

Fonte: Elaborado pelo autor. 
Tabela 4.2 - Descrição das configurações estudadas.

\begin{tabular}{|c|c|c|c|c|}
\hline & Estudo de & & Descrição da Configuração & \\
\hline ROTA 1 & Caso 1 & $\begin{array}{l}\text { Cenário base } \\
\text { Aspen Plus }{ }^{\circledR}\end{array}$ & Destilaria Autônoma & $\begin{array}{l}\text { Integração } \\
\text { Térmica }\end{array}$ \\
\hline ROTA 2 & Caso 2 & $\begin{array}{l}\text { Cenário base } \\
\text { Aspen Plus }\end{array}$ & $\begin{array}{l}\text { Rota Bioquímica } 2 \mathrm{G}-\mathrm{SHF} \\
\text { Explosão a vapor (SE) }\end{array}$ & $\begin{array}{l}\text { Integração } \\
\text { Térmica }\end{array}$ \\
\hline \multirow{6}{*}{ ROTA 3} & Caso 3 & $\begin{array}{l}\text { Cenário base } \\
\text { Aspen Plus }\end{array}$ & $\begin{array}{l}\text { Rota Termoquímica } 2 \mathrm{G} \\
\text { CFB }\end{array}$ & $\begin{array}{l}\text { Integração } \\
\text { Térmica }\end{array}$ \\
\hline & Caso 4 & Aspen Plus ${ }^{\circledR}$ & $\begin{array}{l}\text { Rota Termoquímica } 2 \mathrm{G} \\
E F\end{array}$ & \\
\hline & Caso 5 & Aspen Plus ${ }^{\circledR}$ & $\begin{array}{l}\text { Rota Termoquímica } 2 \mathrm{G} \\
\text { Gaseificador -CFB (Bagaço) }\end{array}$ & \\
\hline & Caso 6 & Aspen Plus ${ }^{\circledR}$ & $\begin{array}{l}\text { Rota Termoquímica 2G } \\
\text { Gaseificador -CFB (Palha) }\end{array}$ & \\
\hline & Caso 7 & Vali ${ }^{\circledast}$ & $\begin{array}{l}\text { Rota Termoquímica 2G } \\
\text { Gaseificador-EF (Bagaço) }\end{array}$ & \\
\hline & Caso 8 & Vali $^{\circledR}$ & $\begin{array}{l}\text { Rota Termoquímica 2G } \\
\text { Gaseificador -EF (Palha) }\end{array}$ & \\
\hline
\end{tabular}

Fonte: Elaborado pelo autor.

Nota-se da Tab. 4.2 que os modelos dos cenários base (Caso 1, Caso 2 e Caso 3) foram otimizados, via integração térmica mediante a plataforma OSMOSE. Desse modo, a determinação do mínimo de energia requerida (MER) nas rotas tecnológicas é apresentada no Apêndice B. Analogamente, os resultados da aplicação do MER para diferentes tipos de prétratamento da biomassa são reportados no Apêndice A.

Ainda a otimização multi-objetivo da rota termoquímica (Caso 3 e Caso 4) foi conduzida nesta plataforma com o auxílio do programa Matlab. Para tal, uma população inicial de 100 casos foi adotada com um número máximo de 1000 iterações. Assim, a população final representada nas curvas de Pareto compõe-se de cerca de 70 pontos para ambas as funções objetivo, eficiência exergética e custo de investimento, de acordo com os resultados a serem apresentados no Apêndice D.

Por fim, os balanços de massa e energia obtidos na avaliação do projeto do gaseificador de leito arrastado-EF, caso 7 e caso 8, são reportados no Apêndice C. 


\subsection{DEFINIÇÃO DE FLUXOS, COMPONENTES, MÉTODOS E PROPRIEDADES}

Conforme apresentado na metodologia, as simulações das operações envolvidas na produção de bioetanol e eletricidade foram realizadas principalmente por meio do simulador Aspen Plus $^{\circledR}$, ferramenta computacional amplamente utilizada na indústria de processos químicos. Este simulador permite prever o comportamento de um processo a partir dos balanços de massa e energia, relações de equilíbrio e reações químicas. A seguir será apresentado o procedimento da simulação adotado de Palacios-bereche (2011).

Neste simulador é necessário definir a natureza dos fluxos que participam no processo. Desta forma, foi selecionado o tipo MIXCISLD, que permite duas possíveis subcorrentes: CISOLID e MIXED. Assim, CISOLID (Conventional Inert Solid) é utilizada para componentes dos fluxos convencionais que aparecem na fase sólida, mas que não participam no equilíbrio de fases. Por sua vez, a MIXED é utilizada para definir componentes convencionais dos fluxos que atingem o equilíbrio de fases. Na base de dados deste simulador não estão disponíveis os componentes do bagaço, como sendo Celulose, Hemicelulose e Lignina. Por esta razão, estes componentes foram criados como correntes do tipo sólido levando em consideração as propriedades e parâmetros indicados pelo NREL no relatório, 'Development of an Aspen Plus physical property database for biofuels components' (WOOLEY; PUTSCHE, 1996).

Na Tab. 4.3 são ilustrados os componentes especificados do simulador na modelagem das rotas tecnológicas propostas. Adicionalmente, os açúcares redutores são considerados como dextrose/glicose $\left(\mathrm{C}_{6} \mathrm{H}_{12} \mathrm{O}_{6}\right)$, enquanto os minerais são representados pelo óxido de potássio $\left(\mathrm{K}_{2} \mathrm{O}\right)$, uma vez que este componente está em maior proporção na cana-de-açúcar (CHEN, 1993).

Para adicionar outros componentes não sacarídeos as substâncias $\mathrm{KCl}$ e $\mathrm{C}_{6} \mathrm{H}_{6} \mathrm{O}_{6}$ são definidas. Assim, o cloreto de potássio representa os sais e o ácido aconítico descreve os ácidos orgânicos, respectivamente. Estes componentes foram adotados, já que eles estão em maior proporção no caldo de cana. Outros componentes não sacarídeos como as proteínas, amidos, polissacaríeos solúveis, ceras e fosfolípedeos não foram considerados (PALACIOSBERECHE, 2011). 
Destaca-se ainda a definição do óxido de silício $\left(\mathrm{SiO}_{2}\right)$ para representar o componente "Terra" (DIAS, 2011). Além disso, o componente levedura $\left(\mathrm{CH}_{1.8} \mathrm{O}_{0.9} \mathrm{~N}_{0.145}\right)$ foi adicionado no simulador levando em conta as especificações reportadas em Eisjberg (2006).

Tabela 4.3- Composição e exergia química padrão dos componentes utilizados na simulação.

\begin{tabular}{|c|c|c|c|c|}
\hline FÓRMULA & COMPONENTE & FLUXO & TIPO & $\begin{array}{c}b^{C H} \text { especifica } \\
k J / k m o l\end{array}$ \\
\hline $\mathrm{C}_{6} \mathrm{H}_{10} \mathrm{O}_{5}$ & Celulose & CELULOSE & Sólido & 3.404 .400 \\
\hline $\mathrm{C}_{5} \mathrm{H}_{8} \mathrm{O}_{4}$ & Hemicelulose & HEMICELU & Sólido & 2.826 .640 \\
\hline $\mathrm{C}_{7,3} \mathrm{H}_{13,9} \mathrm{O}_{1,3}$ & Lignina & LIGNINA & Sólido & 3.449 .500 \\
\hline $\mathrm{CA}_{3}\left(\mathrm{PO}_{4}\right)_{2}$ & Fosfato de cálcio & CA3(PO4)2 & Sólido & 19.400 \\
\hline $\mathrm{CH}_{1,8} \mathrm{O}_{0,9} \mathrm{~N}_{0,1}$ & Levedura & LEVEDURA & Sólido & 147.600 \\
\hline $\mathrm{SIO}_{2}$ & Óxido de silício (Terra) & $\mathrm{SIO} 2$ & Sólido & 1.900 \\
\hline $\mathrm{CH}_{1,57} \mathrm{~N}_{0,29} \mathrm{O}_{0,31} \mathrm{~S}_{0,007}$ & Cellulase & ENZYME & Sólido & 145.600 \\
\hline $\mathrm{SO}_{2}$ & Dióxido de enxofre & $\mathrm{O} 2 \mathrm{~S}$ & Convencional & 313.400 \\
\hline $\mathrm{CO}_{2}$ & Dióxido de carbono & $\mathrm{CO} 2$ & Convencional & 19.870 \\
\hline $\mathrm{C}_{2} \mathrm{H}_{6} \mathrm{O}$ & Etanol & ETHANOL & Convencional & 1.250 .900 \\
\hline $\mathrm{C}_{6} \mathrm{H}_{12} \mathrm{O}_{6}$ & Dextrose (Glicose) & DEXTROSE & Convencional & 2.793 .200 \\
\hline $\mathrm{C}_{2} \mathrm{H}_{4} \mathrm{O}_{2}$ & Ácido acético & $\mathrm{C} 2 \mathrm{H} 4 \mathrm{O}-01$ & Convencional & 908.000 \\
\hline $\mathrm{C}_{3} \mathrm{H}_{8} \mathrm{O}_{3}$ & Glicerol & $\mathrm{C} 3 \mathrm{H} 8 \mathrm{O} 3$ & Convencional & 1.705 .600 \\
\hline $\mathrm{C}_{5} \mathrm{H}_{10} \mathrm{O}_{5}$ & Xilose & XYLOSE & Convencional & 1.835 .300 \\
\hline $\mathrm{C}_{5} \mathrm{H}_{4} \mathrm{O}_{2}$ & Furfural & FURFURAL & Convencional & 2.338 .700 \\
\hline $\mathrm{C}_{5} \mathrm{H}_{12} \mathrm{O}$ & Álcool isoamílico & $\mathrm{C} 5 \mathrm{H} 12-01$ & Convencional & 3.311 .700 \\
\hline $\mathrm{C}_{4} \mathrm{H}_{6} \mathrm{O}$ & Ácido succinico & C4H6O-01 & Convencional & 1.609 .400 \\
\hline $\mathrm{C}_{6} \mathrm{H}_{6} \mathrm{O}_{6}$ & Ácido aconítico & C6H6O6 & Convencional & 3.128 .500 \\
\hline $\mathrm{C}_{2} \mathrm{H}_{6} \mathrm{O}_{2}$ & Etilenoglicol (MEG) & $\mathrm{C} 2 \mathrm{H} 6 \mathrm{O} 2$ & Convencional & 1.208 .056 \\
\hline $\mathrm{C}_{12} \mathrm{H}_{22} \mathrm{O}_{11}$ & Sacarose & SUCROSE & Convencional & 3.311 .700 \\
\hline $\mathrm{CA}(\mathrm{OH})_{2}$ & Hidróxido de cálcio & $\mathrm{CA}(\mathrm{OH}) 2$ & Convencional & 53.700 \\
\hline CAO & Óxido de cálcio & $\mathrm{CAO}$ & Convencional & 110.200 \\
\hline $\mathrm{CO}$ & Monóxido de carbono & $\mathrm{CO}$ & Convencional & 275.100 \\
\hline $\mathrm{K}_{2} \mathrm{O}$ & Óxido de potássio & $\mathrm{K} 2 \mathrm{O}$ & Convencional & 413.100 \\
\hline KCL & Cloreto de potássio & $\mathrm{KCL}$ & Convencional & 19.600 \\
\hline NO & Óxido de nitrogênio & NO & Convencional & 88.900 \\
\hline $\mathrm{N}_{2}$ & Nitrogênio & $\mathrm{N} 2$ & Convencional & 720 \\
\hline $\mathrm{O}_{2}$ & Oxigênio & $\mathrm{O} 2$ & Convencional & 3.970 \\
\hline $\mathrm{H}_{2}$ & Hidrogênio & $\mathrm{H} 2$ & Convencional & 331.300 \\
\hline $\mathrm{H}_{2} \mathrm{O}$ & Água & WATER & Convencional & 900 \\
\hline $\mathrm{H}_{2} \mathrm{SO}_{4}$ & Ácido sulfúrico & $\mathrm{H} 2 \mathrm{SO} 4$ & Convencional & 108.600 \\
\hline $\mathrm{NH}_{3}$ & Amônia & NH3 & Convencional & 337.900 \\
\hline
\end{tabular}

Fonte: Elaborado pelo autor. 


\subsubsection{Definição dos modelos termodinâmicos}

Os processos são simulados em regime permanente e estão divididos por blocos de hierarquia em função da rota tecnológica analisada. $\mathrm{O}$ estado de referência escolhido na determinação das propriedades termodinâmicas é $25^{\circ} \mathrm{C}$ e 1 atm. Para calcular entalpias, entropias e energia livre de Gibbs, o Aspen Plus ${ }^{\circledR}$ utiliza o dado de energia padrão de formação (DHFORM) e a energia livre de Gibbs de formação (DGFORM). No caso das substâncias sólidas, determinam-se por meio do calor padrão de formação de sólidos (DHSFRM) e energia livre de Gibbs para sólidos (DGSFRM).

O modelo termodinâmico adotado na simulação da rota convencional foi o NRTL (NonRandom Two-Liquid), já na rota bioquímica foi considerado o modelo UNIQUAC, que envolve a equação de Estado de Redlich-Kwong. Ao passo que na rota termoquímica, o método PR-BM (equação de Estado de Peng-Robinson com função Boston-Mathias) foi escolhido para cálculos envolvendo gases.

No sistema de cogeração, foi utilizado o método RKS-BM (Redlich-Kwong-Soave com função Boston-Mathias), por ser adequado para gases de alta temperatura (ASPENTECH, 2014). Para os fluxos de vapor foram utilizadas tabelas de vapor (STEAMNBS), uma vez que representam com precisão a água pura e o vapor para uma ampla variedade de temperaturas e pressões. 


\subsubsection{Definição da composição da matéria-prima}

Na simulação dos processos foi utilizada a cana-de-açúcar como insumo energético. Desse modo, a composição adotada no Aspen Plus ${ }^{\circledR}$ em função da porcentagem mássica inserida nas subcorrentes CISOLID e MIXED deste simulador é apresentada na Tab. 4.4.

Tabela 4.4 - Composição da cana-de-açúcar.

\begin{tabular}{|c|l|c|c|c|c|}
\hline \multirow{2}{*}{ Fórmula } & \multirow{2}{*}{ Componente } & \multicolumn{3}{|c|}{$\mathrm{g} / \mathrm{mol}$} & \multicolumn{3}{|c|}{$\%$ em massa } \\
\cline { 3 - 6 } & & Massa Molar & CANA & CISOLID & MIXED \\
\hline $\mathrm{C}_{6} \mathrm{H}_{10} \mathrm{O}_{5}$ & Celulose & 162,14 & 5,95 & 43,46 & \\
\hline $\mathrm{C}_{5} \mathrm{H}_{8} \mathrm{O}_{4}$ & Hemicelulose & 132,12 & 3,52 & 25,71 & \\
\hline $\mathrm{C}_{7,3} \mathrm{H}_{13,9} \mathrm{O}_{1,3}$ & Lignina & 122,49 & 3,19 & 23,30 & \\
\hline $\mathrm{C}_{12} \mathrm{H}_{22} \mathrm{O}_{11}$ & Sacarose & 342,29 & 13,92 & & 16,13 \\
\hline $\mathrm{C}_{6} \mathrm{H}_{12} \mathrm{O}_{6}$ & Dextrose & 180,16 & 0,60 & & 0,70 \\
\hline $\mathrm{K}_{2} \mathrm{O}$ & Minerais & 94,2 & 0,20 & & 0,23 \\
\hline $\mathrm{KCl}$ & Cloreto de potássio & 74,55 & 1,17 & & 1,36 \\
\hline $\mathrm{C}_{6} \mathrm{H}_{6} \mathrm{O}_{6}$ & Ácido aconítico & 174,1 & 0,6 & & 0,70 \\
\hline $\mathrm{H}_{2} \mathrm{O}$ & Água & 18,015 & 69,82 & & 80,89 \\
\hline $\mathrm{SiO}_{2}$ & Terra & 60,08 & 1,03 & 7,52 & \\
\hline
\end{tabular}

Fonte: Adaptado de Dias (2011), Palacios-Bereche (2011). 


\subsection{SIMULAÇÃO DAS ROTAS TECNOLÓGICAS PARA PRODUÇÃO DE BIOETANOL E ELETRICIDADE}

\subsubsection{Rota de conversão convencional de etanol 1G}

O esquema incorporado no simulador Aspen Plus ${ }^{\circledR}$ para o desenvolvimento da Rota 1 pode ser visto na Fig. 4.3. Este esquema simplificado representa uma destilaria convencional de $1 \mathrm{G}$, caracterizado por cinco (5) VC (blocos de hierarquia) que descrevem as operações envolvidas neste processo: Preparo e Extração (EXT), Tratamento, Concentração $e$ Fermentação (ALCOOL), Sistema de Cogeração (COGERA), Destilação e Retificação (DEST-RET) e Desidratação (DESIDRA). O resumo dos parâmetros obtidos na literatura e adotados nas operações acima citadas é ilustrado da Tab. 4.5 à Tab. 4.12, (Dias 2008, Palacios-Bereche 2011, Bonomi et al., 2012).

Figura 4.3 - Esquema de simulação da rota convencional de 1G.

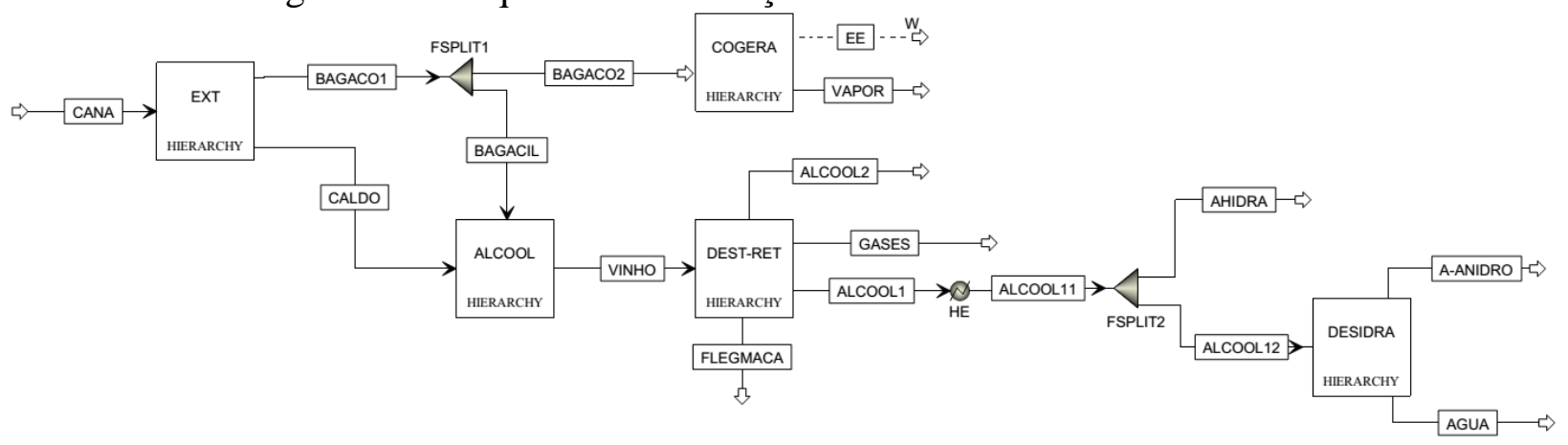

Fonte: Elaborado pelo autor.

\section{Unidade de Preparo e Extração}

O fluxograma adotado no simulador Aspen Plus ${ }^{\circledR}$ para o bloco Preparo e Extração (EXT) é ilustrado na Fig. 4.4. Nesta unidade são representadas as operações de limpeza da cana, extração e tratamento físico do caldo por meio de blocos separadores. Primeiramente, a cana passa por uma etapa de limpeza a seco para retirada dos contaminantes trazidos juntamente com a matéria-prima durante a colheita. 
Em seguida, a cana passa à extração, etapa onde o caldo é separado do bagaço. A extração do caldo é realizada com o auxílio de água de embebição (H2O-EMB) a $50^{\circ} \mathrm{C}$. Na simulação, foi adotado que esta operação tem eficiência de $97 \%$ em relação à extração de sacarose e dextrose (REIN, 2007).

Finalmente, o caldo extraído passa por um tratamento físico realizado por peneiras para separação do bagacilho, considerando que $82 \%$ do residual de fibras e solo são removidos, ocorrendo perda de 2,1\% dos outros componentes (PALACIOS-BERECHE, 2011).

Figura 4.4 - Esquema da unidade de preparo e extração.

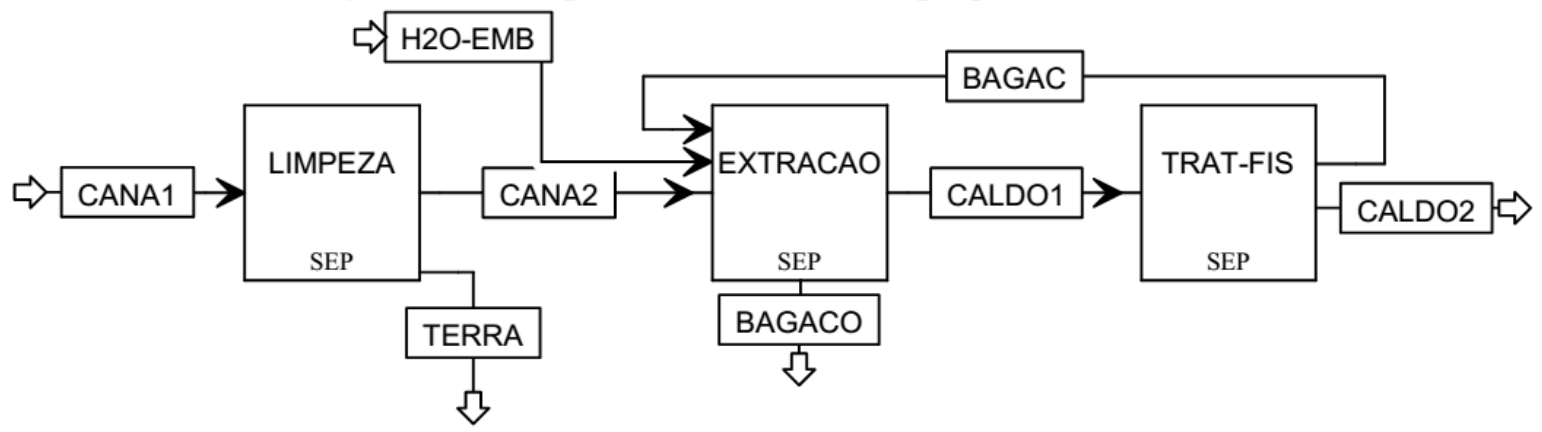

Fonte: Elaborado pelo autor.

Neste bloco algumas variáveis são inseridas como Design Specs. Por exemplo, a vazão de água de embebição (H2O-EMB), é calculada automaticamente pelo simulador em função da vazão da cana e das especificações fornecidas na Tab. 4.5, resultando em consumo de 300 $\mathrm{kg} / \mathrm{TC}$.

Tabela 4.5 - Parâmetros adotados na simulação da unidade de preparo e extração.

\begin{tabular}{|l|c|c|}
\hline Especificações técnicas & Valores & Unidades $^{1}$ \\
\hline Remoção de terra na lavagem $^{1}$ & 90 & $\%$ \\
\hline Perdas de açúcares na lavagem $^{1}$ & 0,8 & $\mathrm{~kg} / \mathrm{tc}$ \\
\hline Eficiência de extração $^{2}$ & 97 & $\%$ \\
\hline Remoção na etapa de tratamento físico $^{3}$ & 82 & $\%$ \\
\hline
\end{tabular}

tc: tonelada de cana.

1 (Bonomi et al., 2012);

2 (Rein, 2007);

3 (Palacios-Bereche, 2011). 


\section{Tratamento, Concentração e Fermentação}

Neste bloco são reproduzidas as operações de tratamento e concentração do caldo, bem como a fermentação e tratamento do mosto. Os principais parâmetros de simulação adotados nestas etapas são ilustrados na Tab. 4.6.

Tabela 4.6 - Características técnicas selecionas nas operações de tratamento, concentração do caldo e no processo de fermentação.

\begin{tabular}{|c|c|c|}
\hline Parâmetros & Valores & Unidades \\
\hline \multicolumn{3}{|l|}{ Tratamento e concentração do caldo $^{1}$} \\
\hline Pressão de descarga da bomba (tratamento) & 2,5 & bar \\
\hline Água para lavagem da torta de filtro & 0,03 & $\mathrm{~m}^{3} / \mathrm{tc}$ \\
\hline Consumo de $\mathrm{CaO}$ & 0,5 & $\mathrm{~kg} / \mathrm{tc}$ \\
\hline Umidade do lodo & 83 & $\%$ \\
\hline Umidade da torta de filtro & 70 & $\%$ \\
\hline Vazão da corrente de bagacilho & 5 & $\mathrm{~kg} / \mathrm{tc}$ \\
\hline Brix do xarope & 65 & $\%$ \\
\hline Pressão de descarga da bomba (mosto) & 6 & bar \\
\hline Temperatura na saída da esterilização & 130 & ${ }^{\circ} \mathrm{C}$ \\
\hline Temperatura na saída do resfriamento & 32 & ${ }^{\circ} \mathrm{C}$ \\
\hline Número de efeitos no sistema de evaporação de múltiplo efeito & 5 & \\
\hline \multicolumn{3}{|l|}{ Processo de fermentação } \\
\hline Temperatura de fermentação ${ }^{1}$ & 33 & ${ }^{\circ} \mathrm{C}$ \\
\hline Umidade das células de levedura $^{2}$ & 67 & $(\%)$ \\
\hline Quantidade de $\mathrm{H}_{2} \mathrm{SO}_{4}$ adicionada no tratamento da levedura ${ }^{1}$ & 5 & $\mathrm{~kg} / \mathrm{m}^{3}$ \\
\hline Teor alcoólico do vinho alimentado nas colunas de destilação & 8,5 & ${ }^{\circ} \mathrm{GL}$ \\
\hline
\end{tabular}

Posteriormente ao tratamento do caldo, este é concentrado em um sistema de evaporação que remove parte da água até atingir uma concentração de sólidos solúveis apropriada para o processo de fermentação (o teor varia entre 18 a 19 Brix), Palacios-Bereche (2011).

Desse modo, na simulação foi considerado um sistema de evaporação de múltiplo efeito (5 efeitos) para a concentração do caldo, baseado na abordagem de Dias (2008) e PalaciosBereche (2011). Este número de efeitos foi adotado nesta pesquisa levando-se em conta a experiência de usinas anexas. Apesar de estar sendo simulada uma destilaria autônoma, a incorporação de um sistema de evaporação com estas características permite uma redução no consumo de vapor de escape deste processo. 
De acordo com Ensinas (2008), os maiores consumos do vapor em uma usina convencional estão localizados no sistema de evaporação e na coluna de destilação, com 74\% e 16\% do total, respectivamente. As características do sistema de evaporação de múltiplo efeito adotado na simulação são apresentadas na Tab. 4.7. Por outro lado, o diagrama deste processo é ilustrado na Fig. 4.5.

Tabela 4.7 -Condições operacionais aplicadas ao sistema de evaporação.

\begin{tabular}{|l|c|c|}
\hline Parâmetros & Valor & Unidades \\
\hline Pressão de operação do $1^{\circ}$ efeito & 1,69 & bar \\
\hline Pressão de operação do $2^{\circ}$ efeitor & 1,31 & bar \\
\hline Pressão de operação do $3^{\circ}$ efeito & 0,93 & bar \\
\hline Pressão de operação do $4^{\circ}$ efeito & 0,54 & bar \\
\hline Pressão de operação do $5^{\circ}$ efeito & 0,16 & bar \\
\hline
\end{tabular}




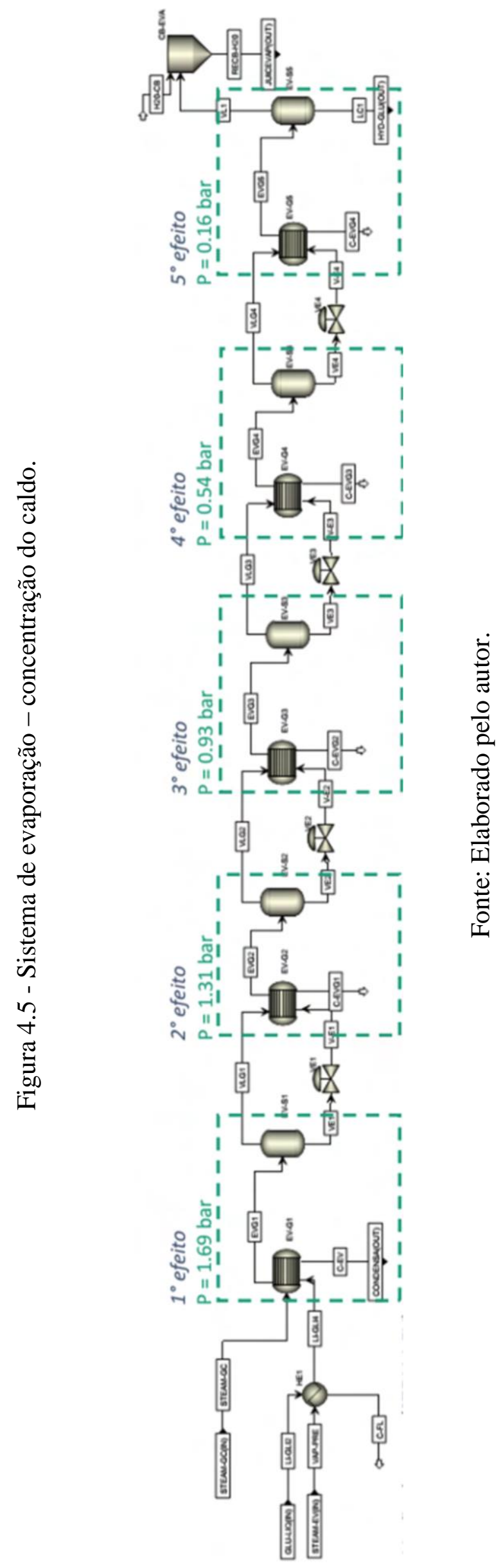


A etapa de fermentação representa uma parte fundamental na cadeia de produção de etanol, onde açúcares presentes no caldo são convertidos a etanol e outros subprodutos através de um processo fermentativo.

Na simulação deste processo foram adotadas duas reações principais: 1) a conversão de sacarose em glicose e frutose (Eq. 4.1) e 2) a conversão de glicose e frutose em etanol (Eq. 4.2) com cinco reações secundárias de formação de subprodutos (Eqs. 4.3 a 4.7), de acordo com reações ilustradas em Eisjberg (2006).

Durante a fermentação ocorre também o crescimento da levedura (Eq. 4.7). A Tab. 4.8 apresenta as reações consideradas na simulação do processo de fermentação junto aos valores de conversão adotados para produção de etanol e subprodutos reportados por Dias (2011).

Tabela 4.8 - Reações consideradas no processo fermentativo.

\begin{tabular}{|l|c|c|}
\hline Reação & Equação & $\begin{array}{c}\text { Conversão } \\
\text { (\%) }\end{array}$ \\
\hline $\begin{array}{l}\text { Formação de glicose e frutose } \\
\mathrm{C}_{12} \mathrm{H}_{22} \mathrm{O}_{11}+\mathrm{H}_{2} \mathrm{O} \rightarrow 2 \mathrm{C}_{6} \mathrm{H}_{12} \mathrm{O}_{6}\end{array}$ & $(4.1)$ & - \\
\hline $\begin{array}{l}\text { Produção de etanol } \\
\mathrm{C}_{6} \mathrm{H}_{12} \mathrm{O}_{6} \rightarrow 2 \mathrm{C}_{2} \mathrm{H}_{5} \mathrm{OH}+\mathrm{CO}_{2}\end{array}$ & $(4.2)$ & 90,48 \\
\hline $\begin{array}{l}\text { Produção de glicerol } \\
\mathrm{C}_{6} \mathrm{H}_{12} \mathrm{O}_{6}+4 \mathrm{H}^{+}+4 \mathrm{e}^{-} \rightarrow 2 \mathrm{C}_{3} \mathrm{H}_{8} \mathrm{O}_{3}\end{array}$ & $(4.3)$ & 2,67 \\
\hline $\begin{array}{l}\text { Produção de ácido succínico } \\
\mathrm{C}_{6} \mathrm{H}_{12} \mathrm{O}_{6}+2 \mathrm{H}_{2} \mathrm{O} \rightarrow \mathrm{C}_{4} \mathrm{H}_{6} \mathrm{O}_{4}+2 \mathrm{CO}_{2}+10 \mathrm{H}^{+}+10 \mathrm{e}^{-}\end{array}$ & $(4.4)$ & 0,29 \\
\hline $\begin{array}{l}\text { Produção de ácido acético } \\
\mathrm{C}_{6} \mathrm{H}_{12} \mathrm{O}_{6}+2 \mathrm{H}_{2} \mathrm{O} \rightarrow 2 \mathrm{C}_{2} \mathrm{H}_{4} \mathrm{O}_{2}+2 \mathrm{CO}_{2}+8 \mathrm{H}^{+}+8 \mathrm{e}^{-}\end{array}$ & $(4.5)$ & 1,19 \\
\hline $\begin{array}{l}\text { Produção de álcool isoamilílico } \\
\mathrm{C}_{6} \mathrm{H}_{12} \mathrm{O}_{6} \rightarrow 0,795 \mathrm{C}_{5} \mathrm{H}_{12} \mathrm{O}+2,025 \mathrm{CO}_{2}+1,155 \mathrm{H}_{2} \mathrm{O}+0,15 \mathrm{H}^{+}+0,15 \mathrm{e}^{-}\end{array}$ & $(4.6)$ & 0,00031 \\
\hline $\begin{array}{l}\text { Crescimento da levedura } \\
0,1485 \mathrm{C}_{6} \mathrm{H}_{12} \mathrm{O}_{6}+0,145 \mathrm{NH}_{4}^{+}+0,1087 \mathrm{CO}_{2} \rightarrow \mathrm{CH}_{1,8} \mathrm{O}_{0,9} \mathrm{~N}_{0,145}+0,2087\end{array}$ & $(4.7)$ & 1,37 \\
\hline $\mathrm{H}_{2} \mathrm{O}+0,145 \mathrm{H}^{+}$ & & \\
\hline
\end{tabular}




\section{Sistema de Cogeração}

$\mathrm{Na}$ atualidade, as usinas do setor sucroalcooleiro estão baseadas no ciclo Rankine. A partir desta configuração, o vapor gerado nas caldeiras é expandido em turbinas, gerando eletricidade e produzindo vapor de escape para atender à demanda térmica do processo, conforme ilustrado na Fig. 4.6.

Figura 4.6 - Sistema de cogeração com turbina de contrapressão.

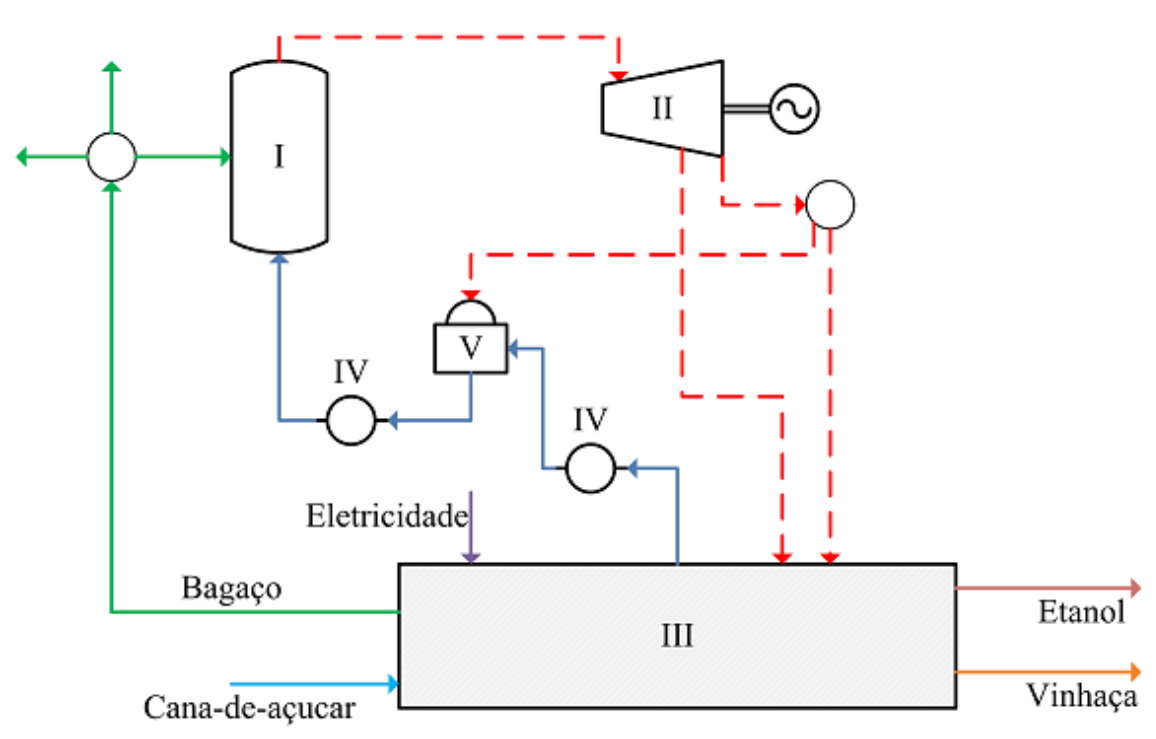

\begin{tabular}{|ll|}
\hline I & Caldeira \\
II & Turbogerador \\
III & Processo \\
IV & Bombas \\
V & Desaerador \\
\hline \hline-- & Vapor \\
\hline & Condensados \\
& Cana-de-açúcar \\
& Bagaço \\
& Etanol \\
& Vinhaça \\
\hline
\end{tabular}

Fonte: Reproduzido de Dias et al. (2011).

Destaca-se ainda que quando todo o material lignocelulósico é queimado, o excedente de vapor gerado é condensado e empregado em turbinas de extração e condensação como mostrado na Fig. 4.7. Os principais parâmetros de simulação adotados na análise do sistema de cogeração, bloco COGERA, são apresentados na Tab. 4.9. 
Figura 4.7 - Sistema de cogeração com turbinas de contrapressão e condensação.

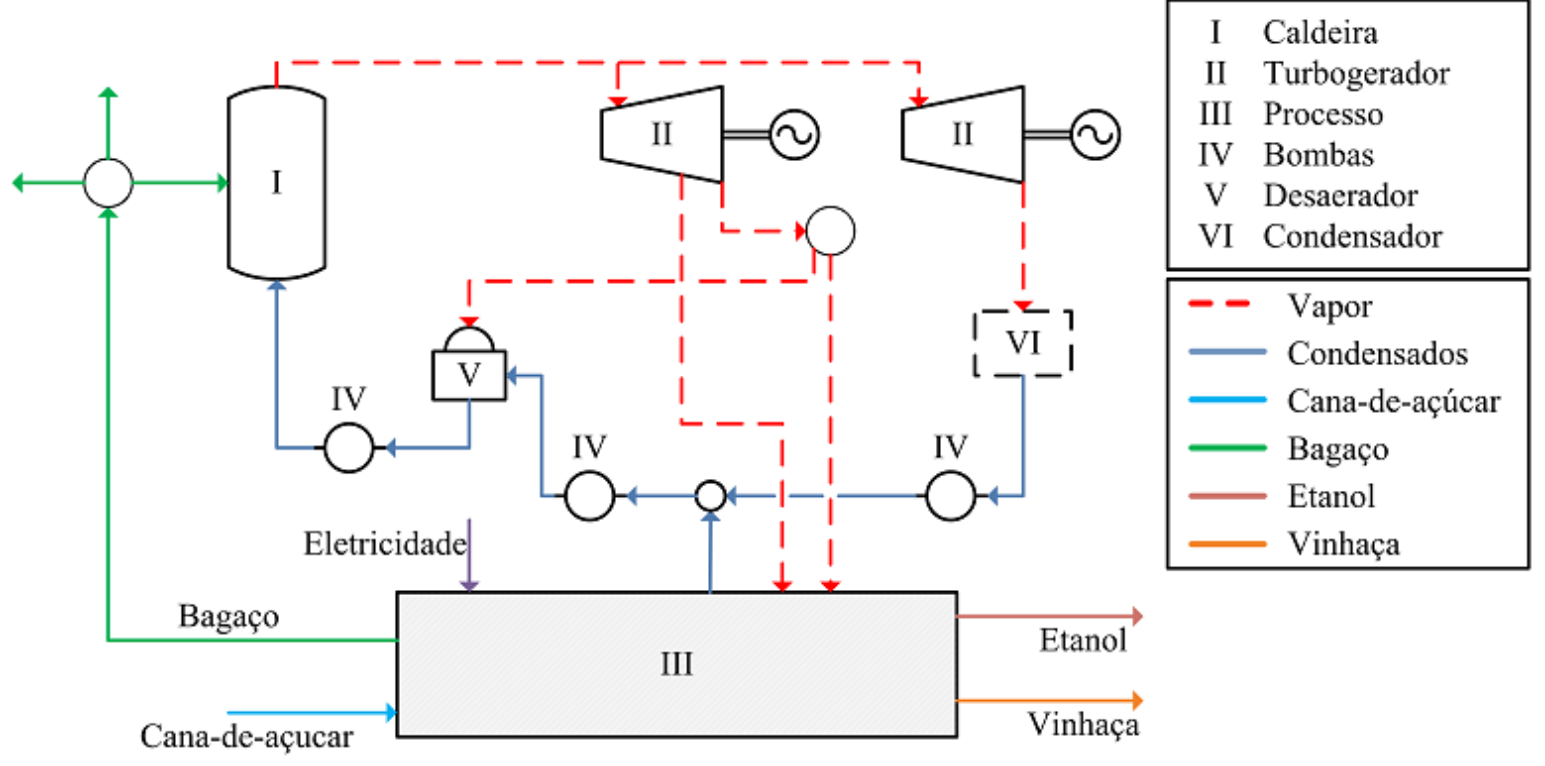

Fonte: Reproduzido de Dias et al. (2011).

Tabela 4.9 - Principais parâmetros adotados no processo de cogeração.

\begin{tabular}{|l|c|c|}
\hline Parâmetros $^{I}$ & Valores & Unidades \\
\hline Eficiência da caldeira (base PCI) & 85 & $\%$ \\
\hline Pressão de vapor gerado na caldeira & 67 & bar \\
\hline Temperatura de vapor gerado na na caldeira & 480 & ${ }^{\circ} \mathrm{C}$ \\
\hline Eficiência isentrópica das turbinas de geração elétrica & 80 & $\%$ \\
\hline Eficiência isentrópica das bombas & 70 & $\%$ \\
\hline Pressão desaerador & 1,65 & $\mathrm{bar}$ \\
\hline Pressão do vapor de process & 2,5 & $\mathrm{bar}$ \\
\hline Pressão do vapor de processo & 6 & $\mathrm{bar}$ \\
\hline Consumo de potência mecânica da usina & 16 & $\mathrm{kWh} / \mathrm{tc}$ \\
\hline Demanda de eletricidade da usina & 12 & $\mathrm{kWh} / \mathrm{tc}$ \\
\hline Perdas de vapor & 5 & $\% \mathrm{massa}$ \\
\hline (Palacios-Bereche, 2011). & &
\end{tabular}

Nesta etapa, um reator estequiométrico foi adotado no simulador para representar a fornalha da caldeira de geração de vapor, levando em consideração as reações de combustão indicadas pelo NREL (WOOLEY; PUTSCHE, 1996). Além disso, foram incluídas as reações de combustão de sacarose (Eq. 4.11), glicose (Eq. 4.12) e ácidos orgânicos (Eq. 4.13), conforme apresentado na Tab. 4.10. 
Tabela 4.10 - Reações de combustão na fornalha da caldeira.

\begin{tabular}{|l|l|c|l|}
\hline \multicolumn{1}{|c|}{ Composto } & \multicolumn{1}{|c|}{ Reação de combustão } & \multicolumn{1}{c|}{ Equação } & \multicolumn{1}{c|}{ Referência } \\
\hline Celulose & $\mathrm{C}_{6} \mathrm{H}_{10} \mathrm{O}_{5}+6 \mathrm{O}_{2} \rightarrow 5 \mathrm{H}_{2} \mathrm{O}+6 \mathrm{CO}_{2}$ & $(4.8)$ & Wooley e Putshe, 1996 \\
\hline Hemicelulose & $\mathrm{C}_{5} \mathrm{H}_{8} \mathrm{O}_{4}+5 \mathrm{O}_{2} \rightarrow 4 \mathrm{H}_{2} \mathrm{O}+5 \mathrm{CO}_{2}$ & $(4.9)$ & Wooley e Putshe, 1996 \\
\hline Lignina & $\mathrm{C}_{7,3} \mathrm{H}_{13,9} \mathrm{O}_{1,3}+10,125 \mathrm{O}_{2} \rightarrow 6,95 \mathrm{H}_{2} \mathrm{O}+7,3 \mathrm{CO}_{2}$ & $(4.10)$ & Wooley e Putshe, 1996 \\
\hline Sacarose & $\mathrm{C}_{12} \mathrm{H}_{22} \mathrm{O}_{11}+12 \mathrm{O}_{2} \rightarrow 11 \mathrm{H}_{2} \mathrm{O}+12 \mathrm{CO}_{2}$ & $(4.11)$ & Dias, 2011 \\
\hline Glicose & $\mathrm{C}_{6} \mathrm{H}_{12} \mathrm{O}_{6}+6 \mathrm{O}_{2} \rightarrow 6 \mathrm{H}_{2} \mathrm{O}+6 \mathrm{CO}_{2}$ & $(4.12)$ & Dias, 2011 \\
\hline Ácidos & Ácidos $+4,5 \mathrm{O}_{2} \rightarrow 3 \mathrm{H}_{2} \mathrm{O}+6 \mathrm{CO}_{2}$ & $(4.13)$ & Dias, 2011 \\
\hline
\end{tabular}

Fonte: Elaborado pelo autor.

O ciclo com turbina de extração-condensação foi considerado no simulador Aspen Plus ${ }^{\circledR}$ baseado na configuração proposta por Palacios-Bereche (2011), conforme apresentado na Fig. 4.8. O nível de pressão e temperatura do vapor gerado foi adotado em 67 bar e $480{ }^{\circ} \mathrm{C}$. A finalidade é acompanhar a tecnologia que está sendo introduzida nas usinas sucroalcooleiras do Brasil.

Neste estudo, o fluxo mássico de bagaço disponível para a caldeira foi determinado a partir do fluxo de bagaço resultante do sistema de extração, descontando 5\% do bagaço para autoconsumo (operações de parada e posta em marcha) e ainda subtraindo o fluxo mássico de bagacilho para filtros de $5 \mathrm{~kg} / \mathrm{tc}$. 


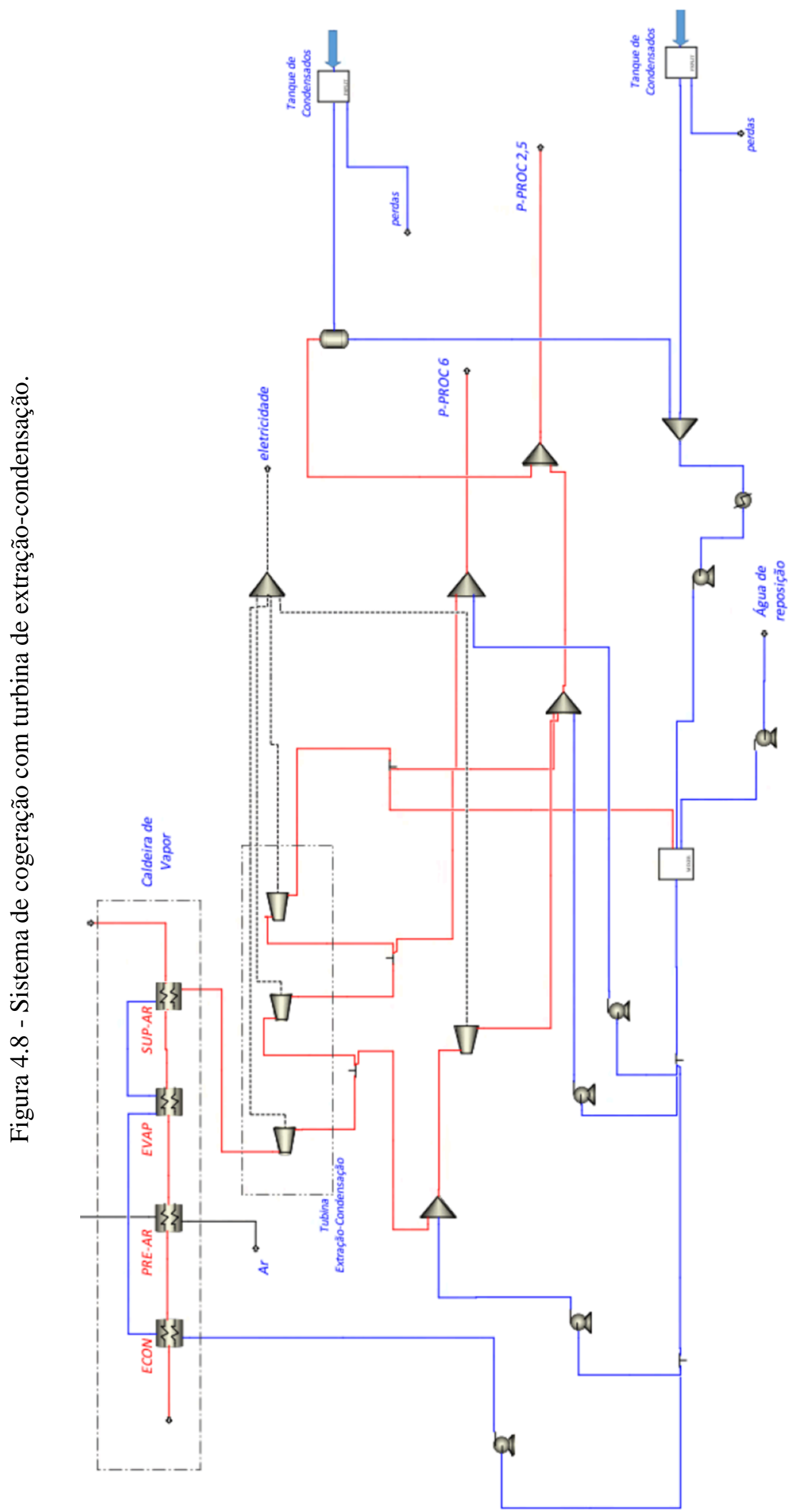

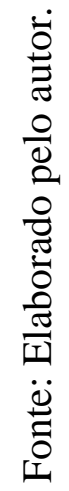




\section{Unidade de Destilação e Desidratação}

Na etapa de destilação, o vinho é pré-aquecido no condensador da coluna B antes de ser alimentado no topo da coluna A1, e o etanol hidratado (AEHC) é produzido na coluna B. Nota-se que as colunas A e B utilizam refervedores de aquecimento indireto, que operam com vapor de escape ou vegetal.

Para a simulação desta etapa foram tomados como referência os parâmetros de operação reportados por Dias (2008) e Palacios-Bereche (2011). Assim, as principais características técnicas das colunas de destilação são apresentadas na Tab. 4.11.

Tabela 4.11 - Parâmetros considerados na simulação da unidade de destilação.

\begin{tabular}{|c|c|c|}
\hline Características de operação ${ }^{1,2}$ & Valores & Unidades \\
\hline \multicolumn{3}{|l|}{ Coluna de destilação A } \\
\hline Número de estágios & 19 & \\
\hline Pressão no primeiro estágio & 139,3 & $\mathrm{kPa}$ \\
\hline Queda de pressão & 13,2 & $\mathrm{kPa}$ \\
\hline Posição de retirada da flegma vapor & \multicolumn{2}{|c|}{$2^{\circ}$ estágio } \\
\hline \multicolumn{3}{|l|}{ Coluna de destilação Al } \\
\hline Número de pratos - Coluna A1 & 8 & \\
\hline Pressão no primeiro estágio & 136,3 & $\mathrm{kPa}$ \\
\hline Queda de pressão & 0,4 & $\mathrm{kPa}$ \\
\hline \multicolumn{3}{|l|}{ Coluna de destilação $B-B 1$} \\
\hline Número de pratos - Coluna B, B1 & 45 & \\
\hline Pressão no topo da coluna B-B1 & 116 & $\mathrm{kPa}$ \\
\hline Teor alcoólico da flegma (vapor e líquido) & 0,02 & $\%$ (massa) \\
\hline Teor de etanol no AEHC & 93 & $\%$ (massa) \\
\hline
\end{tabular}

${ }^{1}$ Dias (2008), ${ }^{2}$ Palacios-Bereche (2011).

Na simulação da etapa de desidratação, considerou-se a desidratação realizada pela destilação extrativa, utilizando monoetilenoglicol-MEG $\left(\mathrm{C}_{2} \mathrm{H}_{6} \mathrm{O}_{2}\right)$. Nesse sentido, foram utilizadas informações apresentadas na literatura por Meirelles (2006), Dias (2008) e Palacios-Bereche (2011). Deste modo, os parâmetros adotados neste processo podem ser vistos na Tab. 4.12. 
Tabela 4.12 - Características de operação selecionadas na etapa da desidratação via MEG.

\begin{tabular}{|l|c|c|}
\hline Parâmetros & Valores & Unidades \\
\hline Número de estágios da coluna extrativa & 35 & \\
\hline Pressão no topo da coluna extrativa & 1,013 & bar \\
\hline Razão de refluxo da coluna extrativa & 0,99 & \\
\hline Posição de alimentação do solvente na coluna extrativa & \multicolumn{2}{|c|}{$3^{\circ}$ estágio } \\
\hline Posição de alimentação do VAEHC na coluna extrativa & \multicolumn{2}{|c|}{$24^{\circ}$ estágio } \\
\hline Posição de alimentação da solução na coluna recuperativa & \multicolumn{2}{|c|}{$6^{\circ}$ estágio } \\
\hline Número de estágios da coluna recuperativa & 10 & \\
\hline Pressão no primeiro da coluna recuperativa & 0,2 & ${ }^{\text {bar }}$ \\
\hline Temperatura do solvente na saída do resfriador & 90 & ${ }^{\circ} \mathrm{C}$ \\
\hline Conteúdo de etanol no AEAC & 99,35 & $\%$ (massa) \\
\hline
\end{tabular}

${ }^{1}$ Palacios-Bereche (2011), ${ }^{2}$ Dias (2008), ${ }^{3}$ Meirelles (2006).

\subsubsection{Rota de conversão bioquímica de etanol $2 G$}

Nesta rota foram escolhidos e avaliados quatro (4) métodos de pré-tratamento, sendo estes, Explosão a Vapor (EV), Organosolv, Água Quente Pressurizada/Hidrotérmico (LHW) e a combinação dos processos $E V+L H W$, utilizando o bagaço de cana-de-açúcar obtido no processo de extração como insumo.

A metodologia de cálculo aplicada para avaliar os métodos de pré-tratamento da biomassa lignocelulósica é descrita na Fig. 4.9. Os esquemas de cada configuração junto com as reações e taxas de conversão dos casos estudados serão apresentados no próximo capítulo.

Figura 4.9 - Metodologia de cálculo na estimativa dos processos de pré-tratamento.

\begin{tabular}{|c|c|c|c|c|}
\hline Recursos & Transformação & Condições Ambientais & Simulação & \\
\hline $\begin{array}{c}\text { Definição do volume } \\
\text { de controlee } \\
\text { determinação das } \\
\text { condições de operação } \\
\text { dos processos }\end{array}$ & $\begin{array}{c}\text { Balanços de massa } \\
\text { e energia }\end{array}$ & $\begin{array}{c}\text { Cálculos da exergia } \\
\text { química }\end{array}$ & $\begin{array}{c}\text { Cálculos usando os } \\
\text { dados } \\
\text { termodinâmicos } \\
\text { obtidos no Aspen Plus }\end{array}$ & $\begin{array}{c}\text { Análise exergética } \\
\text { Desempenho } \\
\text { termodinâmico }\end{array}$ \\
\hline Etapa 1 & Etapa 2 & Etapa 3 & Etapa 4 & Etapa 5 \\
\hline
\end{tabular}

Fonte: Elaborado pelo autor.

Posteriormente, na configuração global desta rota optou-se pelo pré-tratamento de explosão a vapor e a hidrólise enzimática da biomassa lignocelulósica para ponderar a produção de bioetanol por meio da tecnologia de Hidrólise e Fermentação Separadas-SHF. 
Dentre as características da configuração SHF, destaca-se que os processos de hidrólise enzimática e fermentação são executados em dois reatores independentes. Nesta configuração, cada etapa pode ser realizada em condições ótimas de $\mathrm{pH}$ e temperatura. No entanto, a glicose e a acumulação de celobiose na etapa de hidrólise inibem a atividade das enzimas celulolíticas (OJEDA et al., 2011b).

Na Fig. 4.10 apresentou-se um esquema geral da Rota bioquímica 2G implementada no simulador Aspen Plus ${ }^{\circledR}$. Neste modelo, as etapas de moagem, tratamento e concentração do caldo, junto com o processo de fermentação, foram adotadas como blocos de operação Hierarchy. Ainda na simulação desta configuração foram consideradas $140 \mathrm{~kg}$ de palha/tc em base seca como insumo energético destinado à etapa de hidrólise enzimática da biomassa.

Note-se que o diagrama do subsistema envolvendo a concentração do caldo é análogo ao apresentado no sistema de evaporação da rota convencional (Fig. 4.5), adaptado ao respectivo fluxo mássico do caldo. Por outro lado, o esquema da simulação do processo de concentração do hidrolisado (bloco hierárquico-CONC) será apresentado no item 4.4 deste capítulo. 


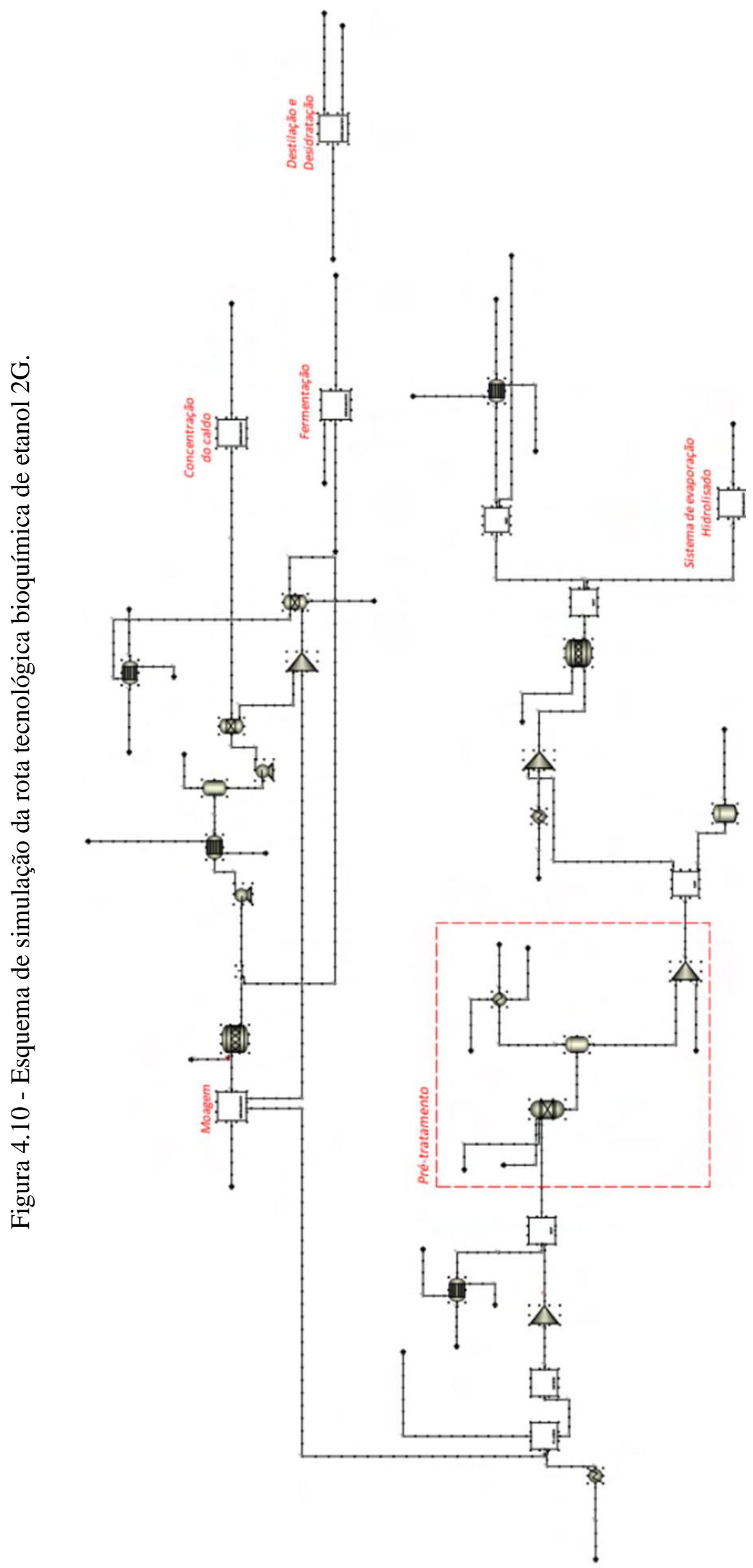

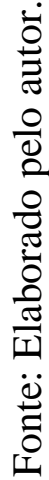




\subsubsection{Rota de conversão termoquímica de etanol $2 \mathrm{G}$}

A Fig. 4.11, mostra uma configuração proposta no simulador Aspen Plus ${ }^{\circledR}$ para a Rota Termoquímica. Neste esquema representado por blocos de hierarquia são consideradas as seguintes áreas de análise: ETANOL representa o processo de produção de bioetanol, PREPARA descreve a etapa de preparação da biomassa, GASIFICA envolve o processo de gaseificação e COGEN o sistema de cogeração. Este bloco engloba a turbina a gás, a turbina a vapor e a caldeira de recuperação de calor. Este último equipamento é constituído pelo economizador, o evaporador e o superaquecedor.

Figura 4.11 - Esquema de simulação da rota tecnológica 3.

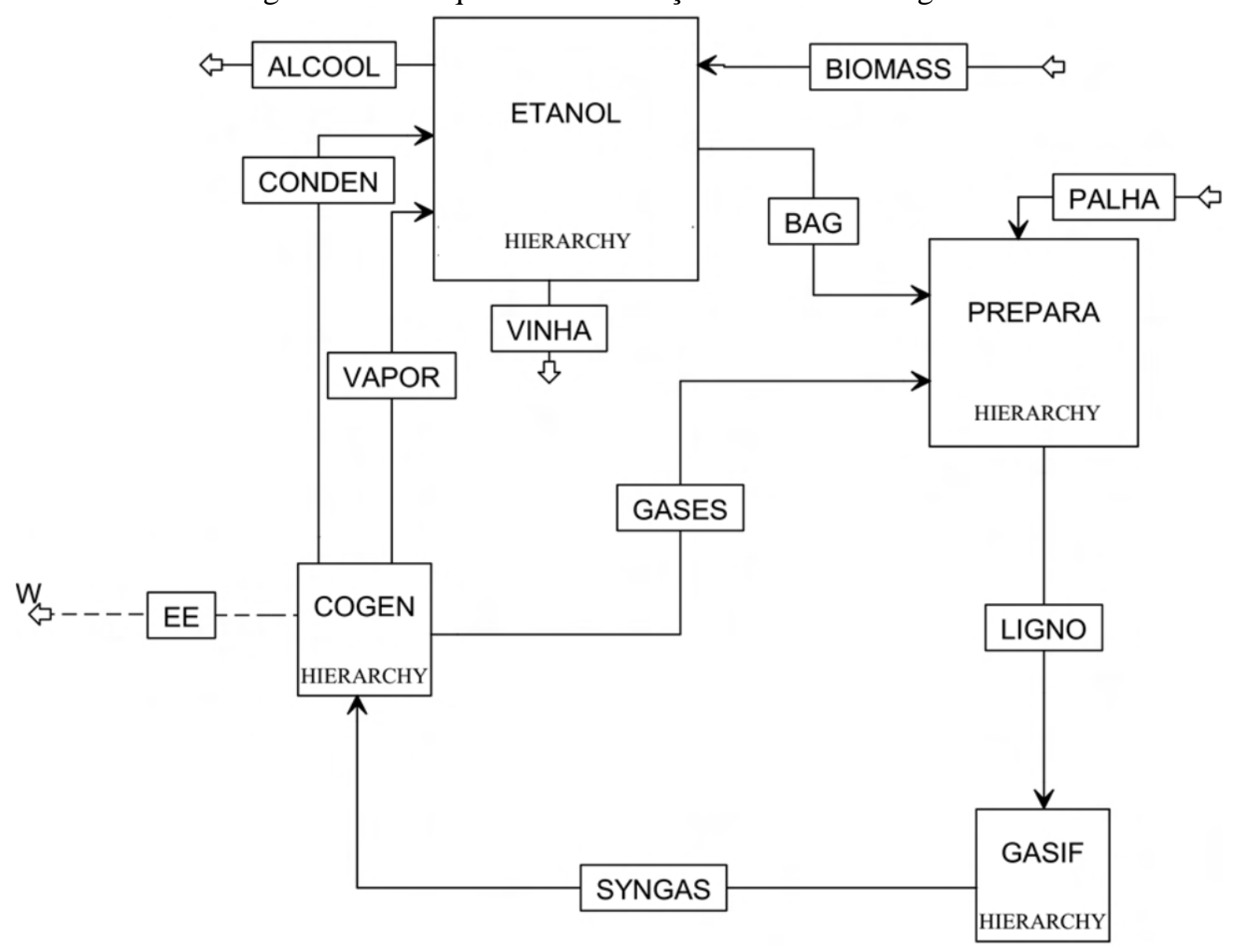

Fonte: Elaborado pelo autor.

Nesta rota são consideradas duas tecnologias de gaseificação, Leito Fluidizado Circulante (CFB) e Leito Arrastado (EF), sendo esses tipos de gaseificadores modelados no Aspen Plus ${ }^{\circledR}$ e Vali ${ }^{\circledR}$, respectivamente. 


\section{GASEIFICADOR DE LEITO FLUIDIZADO CIRCULANTE (CFB)}

O esquema adotado para modelar o gaseificador de tipo CFB é mostrado no Fig. 4.12, baseado no sistema proposto por Camacho-Ardila (2015). As características e uma breve descrição das etapas do projeto são apresentadas a seguir. Além disso, as reações químicas envolvidas no processo de gaseificação são ilustradas na Tab. 4.13 (GÓMEZ-BAREA; LECKNER, 2010).

Figura 4.12 - Esquema de um gaseificador de leito fluidizado circulante.

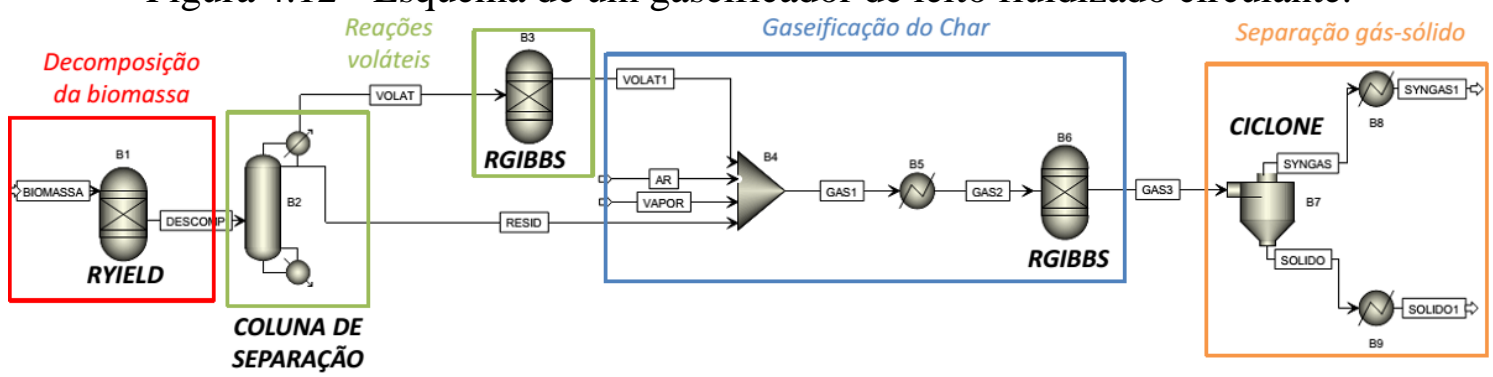

Fonte: Elaborado pelo autor.

Tabela 4.13 - Reações gerais do processo de gaseificação.

\begin{tabular}{|l|c|l|l|c|}
\hline Reações & $\begin{array}{c}\text { Calor de } \\
\text { Reação }\end{array}$ & \multicolumn{2}{c|}{ Nome } & Equação \\
\hline Biomassa $\rightarrow$ Char + Alcatrão $+\mathrm{H}_{2} \mathrm{O}+\mathrm{Gases}$ & $>0$ & Desvolatilização de biomassa & $(4.14)$ \\
\hline Combustão do Char & -111 & Combustão parcial & $(4.15)$ \\
\hline $\mathrm{C}_{2}+1 / 2 \mathrm{O}_{2} \rightarrow \mathrm{CO}$ & -394 & Combustão completa & $(4.16)$ \\
\hline $\mathrm{C}+\mathrm{O}_{2} \rightarrow \mathrm{CO}_{2}$ & +173 & Reação de Boudouard & $(4.17)$ \\
\hline Gaseificação do Char & +131 & Gaseificação de vapor & $(4.18)$ \\
\hline $\mathrm{C}+\mathrm{CO}_{2} \rightarrow 2 \mathrm{CO}$ & -75 & Gaseificação de hidrogênio & $(4.19)$ \\
\hline $\mathrm{C}+\mathrm{H}_{2} \mathrm{O} \rightarrow \mathrm{CO}+\mathrm{H}_{2}$ & & & $(4.20)$ \\
\hline $\mathrm{C}+2 \mathrm{H}_{2} \rightarrow \mathrm{CH}$ & -283 & Oxidação do carbono & $(4.21)$ \\
\hline Oxidação volátil & -242 & Oxidação de hidrogênio & $(4.22)$ \\
\hline $\mathrm{CO}+1 / 2 \mathrm{O}_{2} \rightarrow \mathrm{CO}_{2}$ & -283 & Oxidação do metano & $(4.23)$ \\
\hline $\mathrm{H}_{2}+1 / 2 \mathrm{O}_{2} \rightarrow \mathrm{H}_{2} \mathrm{O}$ & -41 & $\begin{array}{l}\text { Reação de deslocamento } \\
\text { 'shift' água-gás }\end{array}$ \\
\hline $\mathrm{CH}+2 \mathrm{O}_{2} \rightarrow \mathrm{CO}_{2}+2 \mathrm{H}_{2} \mathrm{O}$ & &
\end{tabular}

Fonte: Adaptado de Gómez-Barea e Leckner (2010). 


\section{Decomposição da biomassa}

A biomassa foi especificada a partir da sua análise elementar e análise imediata como um fluxo não convencional, bem como o estado termodinâmico e o fluxo mássico foram introduzidos neste estágio. No simulador, o reator de rendimento, RYIELD, foi usado para descrever a decomposição da biomassa, adotando o rendimento de distribuição de acordo com a análise elementar da biomassa. Nesta etapa, a biomassa é convertida nos seus componentes constitutivos, tais como carbono, hidrogênio, oxigênio, nitrogênio, enxofre, cloro e cinzas.

\section{Reações voláteis}

Nesta fase, ocorre o processo da pirólise. Para simular esta etapa no Aspen Plus ${ }^{\circledR}$ foi utilizado um reator do tipo RGIBBS, introduzindo a temperatura do sistema e os possíveis produtos que podem ser conhecidos neste processo.

Assim, o carbono constituirá parte da fase gasosa, que participa na desvolatização, enquanto o material restante compreende parte da fase sólida (char) e posteriormente resulta na gaseificação. Além disso, uma coluna de separação (B2) foi utilizada antes do reator RGIBBS para dividir os materiais voláteis e sólidos, conforme apresentado na Fig. 4.12.

\section{Gaseificação do Char}

$\mathrm{Na}$ operação deste bloco são fornecidos os agentes de gaseificação (ar-vapor) para converter completamente todo char em produtos gasosos de acordo com o equilíbrio. As partículas resultantes do processo de desvolatilização contém apenas frações de carbono e cinzas.

Do mesmo modo, as correntes, vapor, ar, volatill e resid são misturadas antes de entrar na etapa de gaseificação no reator RGIBBS (B6), de acordo com a Fig. 4.12. O carbono pode reagir com $\mathrm{O}_{2}$ Eq.(4.15) e Eq.(4.16), $\mathrm{CO}_{2}$ Eq.(4.17), $\mathrm{H}_{2} \mathrm{O}$ Eq.(4.18) e $\mathrm{H}_{2}$ Eq.(4.19). Enquanto, os hidrocarbonetos leves $\left(\mathrm{CH}_{4}\right)$ e outros gases combustíveis $\left(\mathrm{CO}, \mathrm{H}_{2}\right)$ podem reagir por meio das reações descritas nas equações (4.20) a (4.22).

\section{Separação gás-sólido}

O ciclone (CYCLONE) é usado para representar a separação gás/sólido. Desta forma, o fluxo de saída superior (SYNGAS) é composto por todos os gases obtidos na etapa de gaseificação (B6). O fluxo inferior (SOLID) descreve os sólidos e cinzas resultantes do processo. 


\section{GASEIFICADOR DE LEITO ARRASTADO (EF)}

O sistema de gaseificação de leito arrastado foi modelado com base nas características indicadas em Peduzzi et al. (2014). Desse modo, com o intuito de garantir o desempenho deste equipamento foi desenvolvida uma regressão linear (Fig. 4.13) considerando as composições químicas do material lignocelulósico apresentadas na Tab. 4.14. Dita regressão permite avaliar os subsistema de preparo e decomposição com relação à porcentagem de perdas de peso (AWL \%) do material nestas etapas.

Tabela 4.14 - Composição da biomassa avaliada no gaseificador EF.

\begin{tabular}{|l|cc|cc|}
\hline \multirow{2}{*}{ Compostos } & \multicolumn{2}{|c|}{ Bagaço da cana } & \multicolumn{2}{c|}{ Palha da cana } \\
\cline { 2 - 6 } & $\begin{array}{c}\text { fração } \\
\text { mássica }\end{array}$ & $\begin{array}{c}\text { percentual } \\
\text { em massa }\end{array}$ & $\begin{array}{c}\text { fração } \\
\text { mássica }\end{array}$ & $\begin{array}{c}\text { percentual } \\
\text { em massa }\end{array}$ \\
\hline Carbono & 0,467 & 46,7 & 0,450 & 45,0 \\
Hidrogênio & 0,058 & 5,8 & 0,063 & 6,3 \\
Oxigênio & 0,465 & 46,5 & 0,443 & 44,3 \\
Cinzas & 0,010 & 1,0 & 0,008 & 0,8 \\
\hline Umidade(\%) & \multicolumn{2}{|c|}{50} & \multicolumn{3}{c}{15} \\
\hline
\end{tabular}

Fonte: Elaborado pelo autor.

Figura 4.13 - Regressões lineares em função da composição da biomassa no gaseificador de leito arrastado.

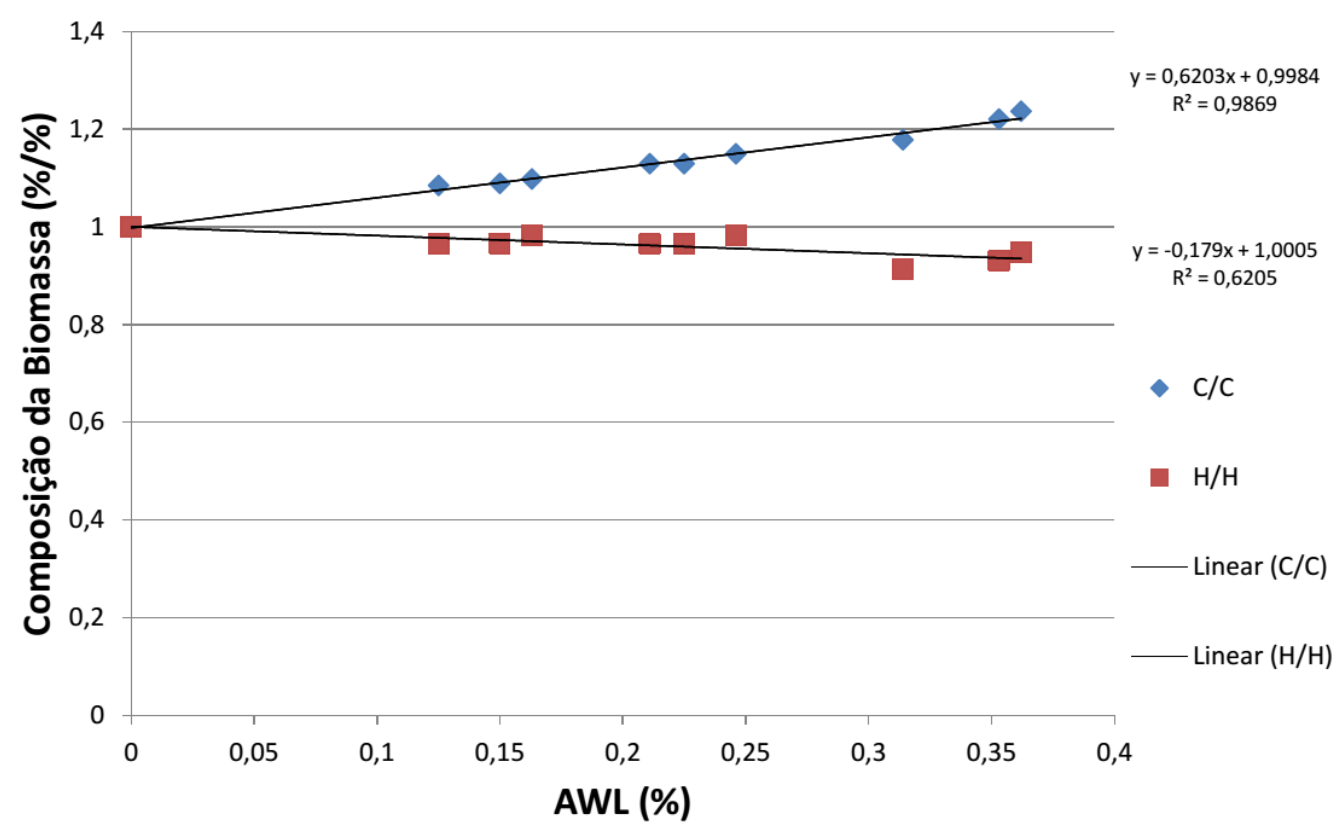

Fonte: Elaborado pelo autor. 
A configuração adotada no programa $\mathrm{Vali}^{\circledR}$ para simular este tipo de gaseificador envolve as etapas de preparo e secagem, seguida da decomposição e gaseificação da biomassa, como ilustrada na Fig. 4.14. As condições de operação das diferentes etapas e os balanços de massa e energia na análise deste sistema são apresentadas no Apêndice C. 


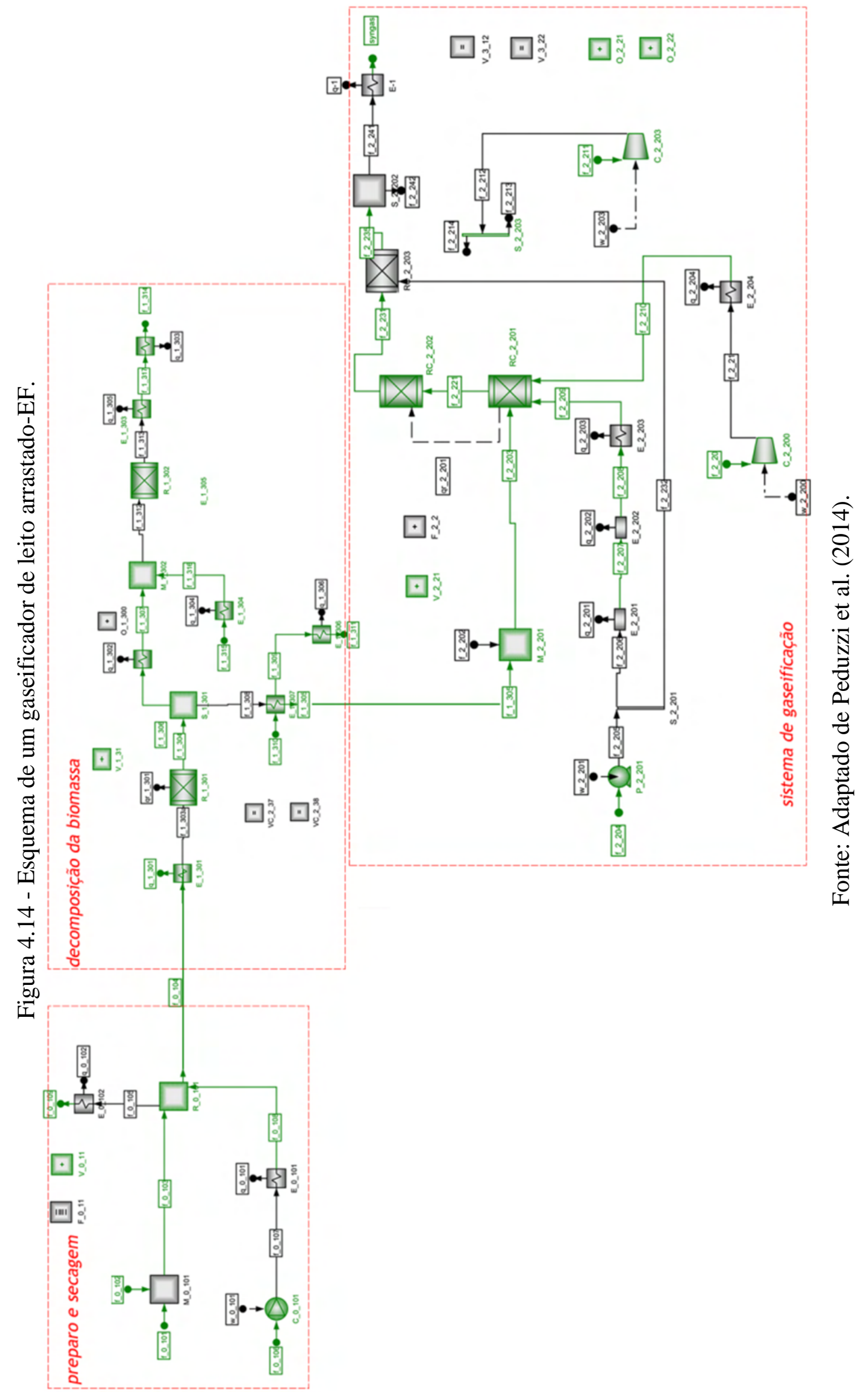




\subsection{FERRAMENTAS DE ANÁLISE UTILIZADAS NA AVALIAÇÃO DAS CONFIGURAÇÕES}

Nesta seção são apresentados os aspectos gerais das ferramentas consideradas na integração térmica, na avaliação do impacto ambiental e na análise econômica das rotas de conversão de biomassa propostas.

\section{Integração Térmica}

Neste estudo, a diferença mínima de temperatura $\left(\Delta \mathrm{T}_{\min }\right)$ foi adotada em $10^{\circ} \mathrm{C}$ para as correntes de processo, exceto para fluxos do sistema de evaporação, os quais adotaram $4{ }^{\circ} \mathrm{C}$ com base na metodologia proposta por Palacios-Bereche et al. (2015). A existência de um evaporador de efeito múltiplo (MEE) no sistema representa um problema conceitual para a construção das curvas compostas CC e GCC, porque o alvo mínimo da utilidade é afetado por suas condições de disposição e funcionamento.

O procedimento da integração térmica foi conduzido aplicando as seguintes etapas, descritas em Palacios-Bereche et al. (2015):

Passo 1. Integração térmica das correntes disponíveis no processo. A Tabela 5 mostra os dados de fluxos quentes e frias disponíveis para a integração térmica.

Passo 2. Avaliação de projeto para implantação do MEE.

Passo 3. Integração do sistema de evaporação e cálculo das metas/alvos de energia (requisitos mínimos de utilidades quentes e frias).

As Tab. 4.15 (Rota 1), Tab. 4.16 (Rota 2) e Tab. 4.17 (Rota 3) apresentam as utilidades consideradas para efetuar a integração energética de cada configuração/cenário base avaliada. 
Tabela 4.15 - Fluxos adotados na integração térmica - ROTA 1.

\section{Fluxos frios e quentes}

Tratamento químico do caldo - trocador de calor

Esterilização do caldo - trocador de calor

Desidratação com monoetilenoglicol (MEG) - trocador de calor

Condensador coluna B-B1

Refervedor coluna A

Refervedor coluna B-B1

Refervedor coluna Extração

Refervedor coluna Recuperação MEG

Condensados dos efeitos do sistema de evaporação do caldo

Flegma

Etanol

Fonte: Elaborado pelo autor.

Tabela 4.16 - Fluxos considerados na integração térmica - ROTA 2.

\section{Fluxos frios e quentes}

Condensados do $1^{\circ}$ efeito do evaporador hidrolisado

Condensados do $2^{\circ}$ efeito do evaporador hidrolisado

Condensados do $3^{\circ}$ efeito do evaporador hidrolisado

Condensados do $4^{\circ}$ efeito do evaporador hidrolisado

Condensados dos efeitos do sistema de evaporação do caldo

Água de pré-lavagem do bagaço anterior ao pré-tratamento

(explosão a vapor)

Vapor de despressurização do pré-tratamento

Aquecimento da água para pré-tratamento

Resfriamento do material pré-tratado

Aquecimento da água para hidrólise

Aquecimento do material para hidrólise - trocador de calor

Condensador coluna B-B1

Refervedor coluna A

Refervedor coluna B-B1

Refervedor coluna Extração

Refervedor coluna Recuperação MEG

Tratamento químico do caldo - trocador de calor

Esterilização do caldo - trocador de calor

Desidratação com monoetilenoglicol (MEG) - trocador de calor

Flegma

Etanol

Fonte: Elaborado pelo autor. 
Tabela 4.17 - Fluxos selecionados na integração térmica - ROTA 3.

\begin{tabular}{|l|}
\hline Fluxos frios e quentes \\
\hline Pré-aquecimento do ar da combustão \\
\hline Preparo e acondicionamento do material lignocelulósico \\
\hline Gases de exaustão \\
\hline Esterilização do caldo - trocador de calor \\
Desidratação com monoetilenoglicol (MEG) - trocador de calor \\
\hline Condensador coluna B-B1 \\
Refervedor coluna A \\
Refervedor coluna B-B1 \\
Refervedor coluna Extração \\
Refervedor coluna Recuperação MEG \\
\hline Condensados dos efeitos do sistema de evaporação do caldo \\
\hline Flegma \\
Etanol
\end{tabular}

Fonte: Elaborado pelo autor.

A simulação da produção de etanol envolve a utilização de sistemas de evaporação de múltiplo efeito para a concentração do caldo. Estes sistemas permitem a redução do consumo de vapor nesta etapa do processo.

A Fig. 4.15 mostra o diagrama do sistema de evaporação de 5 níveis de pressão adotado na rota convencional considerando a rede de trocadores de calor, visando utilizar os condensados dos efeitos do sistema de concentração.

Na rota bioquímica de etanol $2 \mathrm{G}$, o processo de concentração do hidrolisado permite efetuar a integração térmica a partir dos condensados do sistema de múltiplo efeito de 4 níveis de pressão. Assim, a Fig. 4.16 mostra o diagrama do modelo desenvolvido para simular o sistema de concentração do hidrolisado e a rede de trocadores neste processo. 


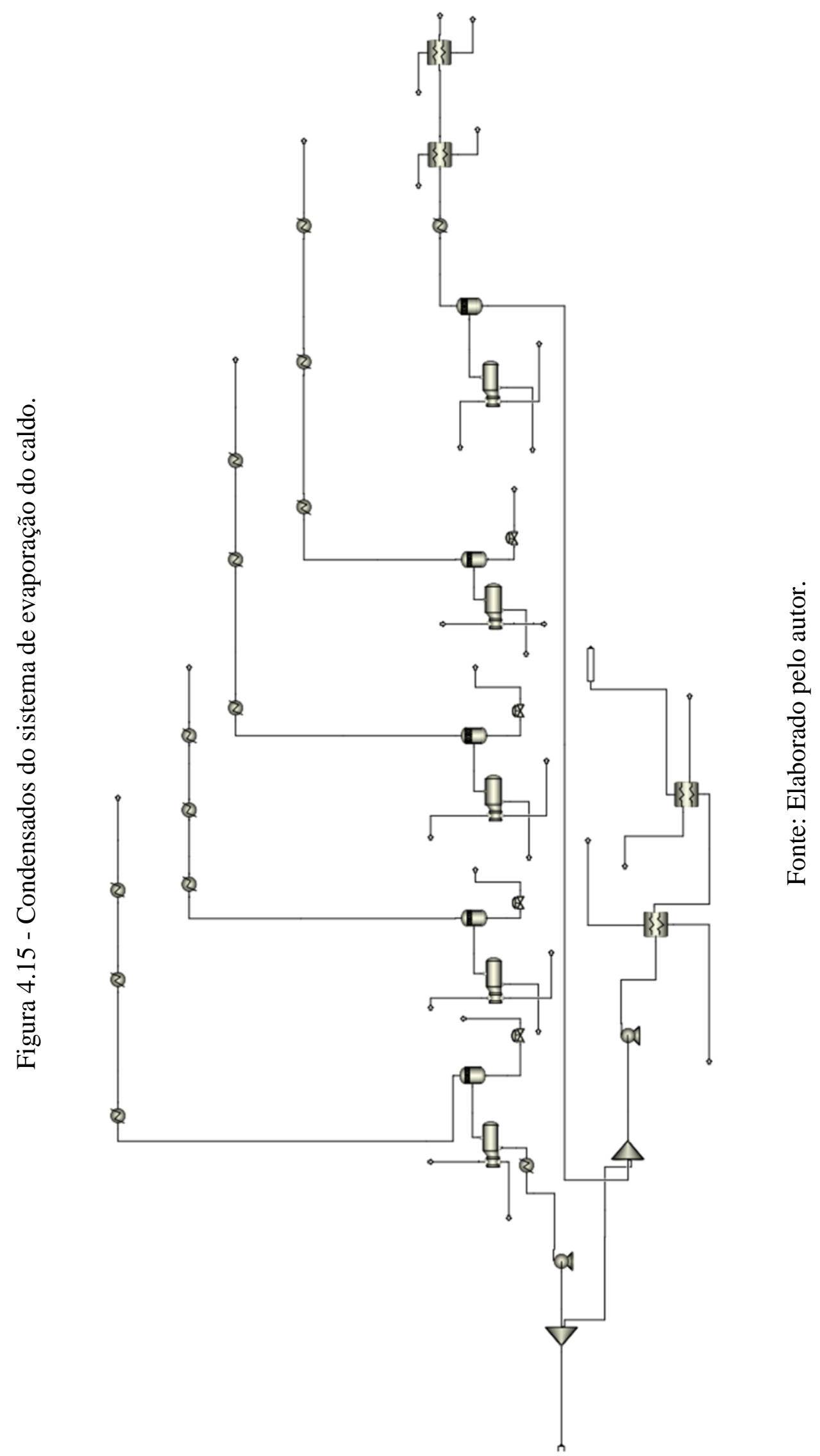




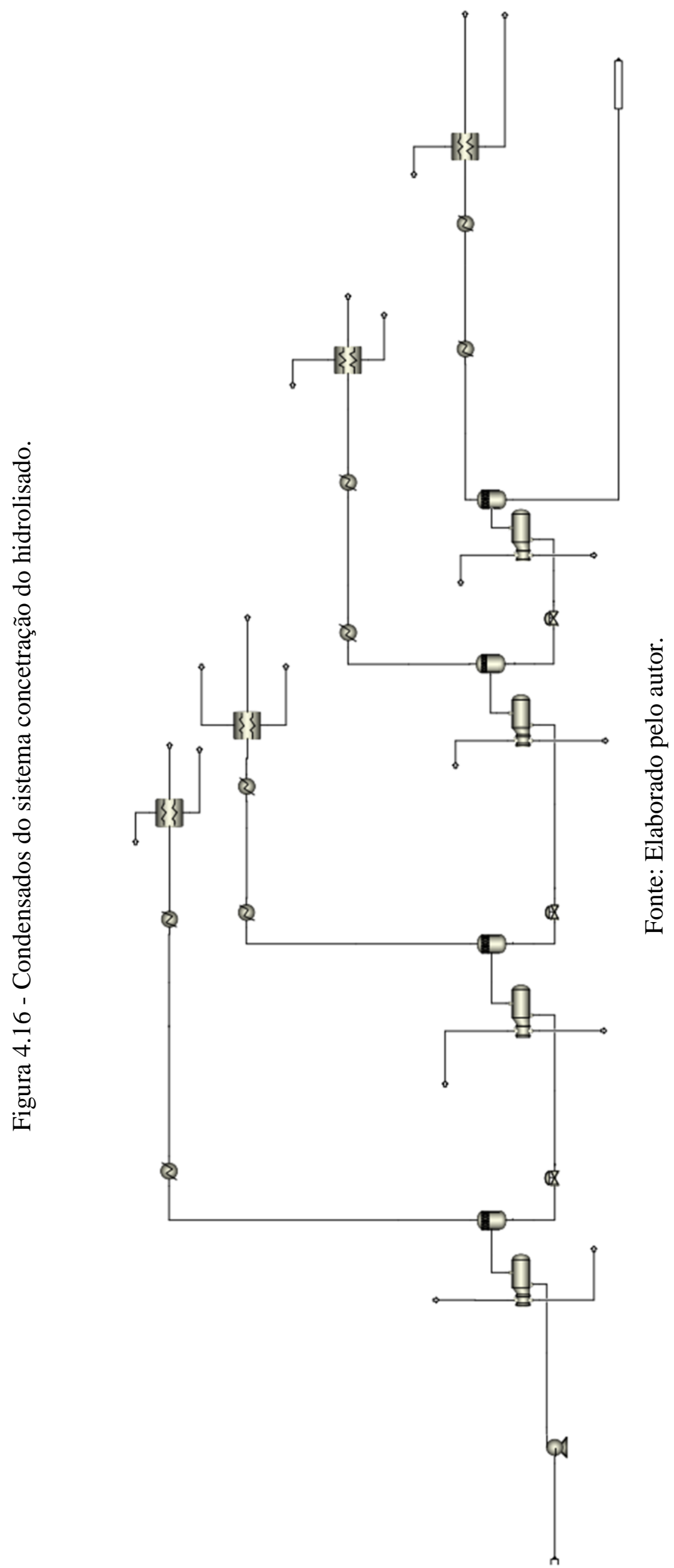




\section{Análise Econômica}

A análise econômica baseou-se na determinação do custo total de investimento dos projetos simulados nos três cenários base: Caso 1, 2 e 3. Nesse contexto, o cálculo do custo total de investimento dos principais equipamentos das configurações avaliadas foi dimensionado utilizando essencialmente as correlações da literatura Turton (2009) e Ulrich; Vasudevan (2003), levando em consideração as variáveis do dimensionamento do processo, como materiais, pressões específicas, fluxos mássicos e volumétricos, potência. Na Tab. 4.18 são sintetizados os principais equipamentos e as variáveis de design selecionadas na simulação das rotas tecnológicas.

Tabela 4.18 - Variáveis de dimensionamento dos equipamentos.

\begin{tabular}{|c|c|c|}
\hline \multicolumn{3}{|c|}{ ROTA 1, ROTA 2} \\
\hline Equipamento & Variável do dimensionamento & Referência \\
\hline \multicolumn{3}{|c|}{ Sistema de limpeza, preparação e extração } \\
\hline Moagem & $\dot{m}$ & Dias et al. 2011 \\
\hline Tanques & $d, h, p$, material & Turton et al. 2009 \\
\hline Tanque de flash & $\dot{V}, p$, material & Ulrich; Vasudevan (2003) \\
\hline \multicolumn{3}{|l|}{ Tratamento de caldo } \\
\hline Clarificador & $d$ & Ulrich; Vasudevan (2003) \\
\hline Filtro rotativo & A, material & Ulrich; Vasudevan (2003) \\
\hline \multicolumn{3}{|l|}{ Fermentação } \\
\hline Fermentador & $v, p$, material & Ulrich; Vasudevan (2003) \\
\hline Centrífuga de fermentação & $\dot{V}$, material & Turton et al. 2009 \\
\hline \multicolumn{3}{|l|}{ Destilação e Desidratação } \\
\hline Torres de bandeja & $\dot{V}, p$, material,$N_{\text {trays }}$ & Ulrich; Vasudevan (2003) \\
\hline \multicolumn{3}{|c|}{ ROTA 3} \\
\hline \multicolumn{3}{|l|}{ Secagem } \\
\hline Secador & $\dot{V}$ & Ulrich; Vasudevan (2003) \\
\hline \multicolumn{3}{|l|}{ Gaseificador CFB } \\
\hline Gaseificador & $\dot{V}, p$, material & Turton et al. 2009 \\
\hline \multicolumn{3}{|l|}{ Gaseificador EF } \\
\hline Gaseificador & $\dot{V}, p, \dot{W}_{\text {pump }}$, material & Turton et al. 2009 \\
\hline \multicolumn{3}{|l|}{ Limpeza a gás } \\
\hline Cyclone & $\dot{V}$ & Ulrich; Vasudevan (2003) \\
\hline Compressor & $\dot{W}_{\text {comp }}$ & Turton et al. 2009 \\
\hline Lavador de gases (Wet scrubber) & $\dot{V}$, material & Ulrich; Vasudevan (2003) \\
\hline \multicolumn{3}{|c|}{ Deslocamento água/gás (Water-gas shift) } \\
\hline Reator WGS & $\dot{V}_{t o t}, \dot{V}_{C O}, \dot{V}_{H 2 O}, p, C O c o n v$ & Ulrich; Vasudevan (2003) \\
\hline \multicolumn{3}{|l|}{ Ciclo Brayton } \\
\hline Turbina a gás & $\dot{W}$, material & Ulrich; Vasudevan (2003) \\
\hline \multicolumn{3}{|c|}{ Equipamentos compartilhados entre as rotas } \\
\hline \multicolumn{3}{|l|}{ Rede trocador de calor } \\
\hline Trocadores & $A, N_{\text {strm }}$ & Dias et al. 2011 \\
\hline \multicolumn{3}{|l|}{ Ciclo Rankine } \\
\hline Turbina a vapor & $\dot{W}_{R K c}$ & Turton et al. 2009 \\
\hline Bomba & $\dot{W}_{\text {pump }}$ & Turton et al. 2009 \\
\hline
\end{tabular}

Fonte: Elaborado pelo autor. 
Onde,

$\dot{m}$ fluxo mássico, $\dot{V}$ fluxo volumétrico, $p$ pressão, $d p$ perda de carga, $\dot{W}$ potencia, $\dot{V}$ fluxo volumetrico, $h$ Altura e $d$ Diâmetro, $Q$ Carga térmica, conv conversão, $N \_t r a y s$ Número de bandejas, $A$ área, $R K c$ Ciclo Rankine.

Note-se que as correlações destes equipamentos encontram-se disponíveis na base de dados na plataforma Osmose. O investimento total foi calculado utilizando fatores de multiplicação das despesas indiretas, como os custos de instalação, contingências e instalações auxiliares. Assim, todos os custos foram atualizados para o ano 2015 por meio do índice Marshall \& Swift ( $M \& S 1536)$ de custos de equipamentos. 


\section{Impacto Ambiental}

O inventário de ciclo de vida (ICV) e a avaliação do impacto do ciclo de vida (LCIA) são indicadores comumente empregados na modelagem de sistemas de energia. No caso particular da plataforma OSMOSE destes já foram integrados por meio do banco de dados do programa ecoinvent V3.1 (YOO et al., 2015). Assim, fluxos de energia como combustível ou consumo de eletricidade são modelados no ecoinvent pela associação com cada fluxo do processo correspondente, na unidade da base de dados dos inventários (GERBER; GASSNER; MARÉCHAL, 2011).

Analogamente, os fluxos de materiais foram modelados dessa maneira com o objetivo de determinar as emissões globais de $\mathrm{CO}_{2}$ de cada rota. Deste modo, as emissões diretas estão associadas com um fluxo elementar da base de dados apresentadas no ecoinvent. Merece destaque, que diferentes métodos de LCA e indicadores podem ser utilizados para a avaliação do impacto ambiental e incluídos na otimização energética (por exemplo, IMPACT 2002+, IPCC 2007).

Neste trabalho, os impactos ambientais são contabilizados nos modelos de LCIA com a abordagem de cradle-to-gate ("do berço-ao-portão"), seguindo a metodologia proposta por GERBER; FAZLOLLAHI; MARÉCHAL, (2013). O método de avaliação de impacto selecionado na análise do cenário de produção de açúcar e etanol da cana (caso de atividade para o Brasil) foi o proposto pelo Painel Intergovernamental sobre Mudanças Climáticas (IPCC). Portanto, o Potencial de Aquecimento Global (em inglês, Global Warming PotentialGWP) com horizonte de 100 anos, foi escolhido como indicador de desempenho ambiental. Os resultados da LCIA foram obtidos pela multiplicação dos fatores de caracterização correspondentes para cada fluxo de inventário no ciclo de vida. 


\section{ANÁliSE EXERGÉTICA DAS ROTAS TECNOLÓGICAS PARA PRODUÇÃO DE BIOETANOL E GERAÇÃO DE ELETRICIDADE}

\subsection{CONCEITUAÇÃO DA ANÁLISE EXERGÉTICA NA PRODUÇÃO DE BIOETANOL E GERAÇÃO DE ELETRICIDADE}

A partir da necessidade de avaliação das exergias dos diferentes fluxos envolvidos nas rotas tecnológicas propostas é necessário realizar o cálculo das propriedades termodinâmicas das substâncias que as compõem. Diversos autores tem trabalhado nesta área, destacando-se Ensinas (2008); Pellegrini (2009), Velásquez (2009) e Ensinas; Nebra (2009), ênfatizando no cálculo de propriedades dos principais fluxos da produção conjunta de açúcar e etanol.

O cálculo da exergia das correntes na produção de etanol se caracteriza por apresentar o comportamento de solução (mistura) ideal, soluções de etanol-água, soluções compostos orgânicos-água e soluções sacarose-água. Deste modo, fluxos como o caldo da cana-deaçúcar, o xarope e o mosto para fermentação são avaliados como uma solução sacarose-água visando determinar suas principais propriedades termodinâmicas. Por outro lado, o etanol hidratado, o álcool de segunda e o etanol anidro são considerados como soluções etanol-água.

Na determinação da exergia de uma solução sacarose-água foi adotado o método proposto por Nebra; Fernandez-Parra (2005). Para a exergia da solução etanol - água, a exergia total é calculada através da soma das componentes física e química, ao passo que a exergia da mistura é obtida junto com a exergia física, considerando a variação dos valores da entalpia, entropia e energia livre de Gibbs devido à mistura (MODESTO; NEBRA; ZEMP, 2005).

A exergia da cana-de-açúcar é determinada pela soma das exergias de suas frações. Já correntes com cargas orgânicas no seu conteúdo, como o vinho, vinhaça, flegmaça e licor de pentoses são consideradas como uma solução ideal na determinação das suas exergias. Enquanto a exergia química destas soluções é calculada através do procedimento estabelecido por Palacios-Bereche et al. (2013). 
Destaca-se que a exergia química padrão dos componentes puros é obtida a partir dos dados apresentados por Szargut et al. (1988). No entanto, para alguns componentes estes valores não se encontram disponíveis, como, o ácido aconítico $\left(\mathrm{C}_{6} \mathrm{H}_{6} \mathrm{O}_{6}\right)$, furfural $\left(\mathrm{C}_{5} \mathrm{H}_{4} \mathrm{O}_{2}\right)$, xilose $\left(\mathrm{C}_{5} \mathrm{H}_{10} \mathrm{O}_{5}\right)$ e glicerol $\left(\mathrm{C}_{3} \mathrm{H}_{8} \mathrm{O}_{3}\right)$. Desta forma, o cálculo da exergía para esses componentes leva em conta o poder calorífico líquido e a composição química (proporções atômicas) de acordo com as correlações definidas em Szargut et al. (1988) para diversos combustíveis.

Na rota tecnológica envolvendo a gaseificação da biomassa, o cálculo da exergia do gás de síntese (syngas) é determinado pela soma das exergias de suas frações, de acordo com a composição obtida na simulação da gaseificador CFB e EF.

De modo geral, a determinação da exergia química $\left(\mathrm{b}_{\mathrm{CH}}\right)$ está baseada em correlações entre uma dada composição elementar do combustível e o seu PCI, conforme apresentado no capítulo 3. Alternativamente, o cálculo $\mathrm{b}_{\mathrm{CH}}$ para cada componente e para todo o fluxo no caso de uma mistura de gases perfeitos ou soluções ideais pode ser avaliado usando a Eq. (5.1).

$$
\mathrm{b}_{\mathrm{CH}}=\sum \mathrm{x}_{\mathrm{i}} \mathrm{b}_{\mathrm{CH}}^{\text {specific }}+\mathrm{RT}_{0} \sum \mathrm{x}_{\mathrm{i}} \ln \mathrm{x}_{\mathrm{i}} \gamma_{\mathrm{i}}
$$

Sendo $\mathrm{b}_{\mathrm{CH}}^{\text {specific }}$ a exergia química padrão da substância $i[\mathrm{~kJ} / \mathrm{kmol}]$ à pressão $\mathrm{P}_{0}$ e temperatura $T_{0}, x_{i}$ a fração molar, $R$ constante universal dos gases e $\gamma$ o coeficiente de atividade. Neste estudo, a influência do $\gamma$ foi avaliada para cada composto observando-se valores próximos de 1. Por esta razão, $\gamma$ foi considerado igual a 1 , solução ideal, nos cálculos de exergia química em misturas.

A exergia física $\left(\mathrm{b}_{\mathrm{PH}}\right)$ foi determinada de acordo com a Eq. (5.2) a fim de calcular entalpia e entropia nas condições avaliadas e de referência.

$$
\mathrm{b}_{\mathrm{PH}}=\left(\mathrm{h}-\mathrm{h}_{0}\right)-\mathrm{T}_{0} \cdot\left(\mathrm{s}-\mathrm{s}_{0}\right)
$$

Por fim, a exergia específica total é calculada como a soma dos componentes físicos e químicos, Eq. (5.3).

$$
\mathrm{b}_{\text {total }}=\mathrm{b}_{\mathrm{CH}}+\mathrm{b}_{\mathrm{PH}}
$$




\subsection{ANÁLISE EXERGÉTICA DA ROTA CONVENCIONAL DE ETANOL $1 \mathrm{G}$}

Na Fig. 5.1 ilustra-se o esquema analisado na avaliação exergética da Rota 1. Destaca-se que no sistema de preparo (bloco limpeza e extração) foram adotados $16 \mathrm{kWh} / \mathrm{tc}$ de energia mecânica consumida para acionamento. As expressões de rendimento exergético serão apresentadas no Apêndice E. 


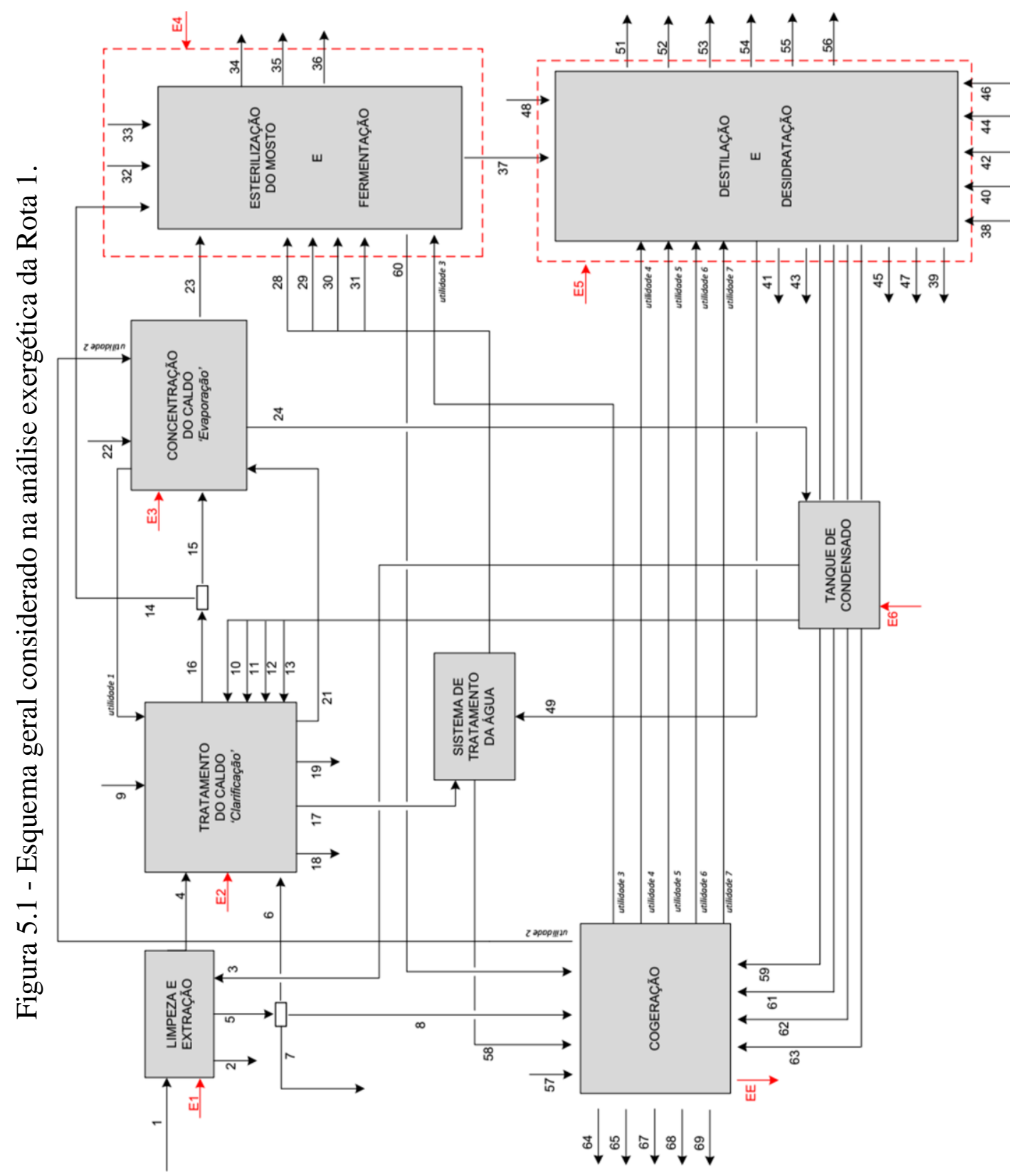

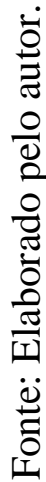




\subsection{RESULTADOS E DISCUSSÕES DA ROTA 1}

Na Tab. 5.1 apresentam-se os resultados dos balanços de massa, energia e exergia para a planta convencional de produção combinada de etanol e eletricidade.

Tabela 5.1 - Resultados da análise global da Rota 1.

\begin{tabular}{|c|c|c|c|c|c|}
\hline Descrição & $\begin{array}{c}\mathbf{T} \\
{\left[{ }^{\circ} \mathbf{C}\right]}\end{array}$ & $\begin{array}{c}\mathbf{P} \\
{[\mathrm{bar}]}\end{array}$ & $\underset{[\mathrm{kg} / \mathrm{s}]}{\mathrm{m}}$ & $\begin{array}{c}\text { btot } \\
{[\mathrm{kJ} / \mathbf{k g}]}\end{array}$ & $\begin{array}{l}\text { Btot } \\
{[k W]}\end{array}$ \\
\hline 1 - Cana-de-açúcar & 25 & 1,013 & 138,9 & 5651 & 784924 \\
\hline $2-$ Terra & 25 & 1,013 & 1,73 & 2209 & 3822 \\
\hline 3 - Água embebição & 50 & 1,013 & 41,67 & 54,11 & 2254 \\
\hline 4 - Caldo & 30,08 & 1,013 & 140,4 & 2520 & 353808 \\
\hline 5 - Bagaço & 30,08 & 1,013 & 38,41 & 10827 & 4158165 \\
\hline 6 - Bagaçilho & 30,08 & 1,013 & 0,69 & 10827 & 7471 \\
\hline 7 - Bagaço excedente & 30,08 & 1,013 & 6,91 & 10827 & 74862 \\
\hline 8 - Bagaço para cogeração & 30,08 & 1,013 & 30,81 & 10827 & 333580 \\
\hline 9 - CAO (óxido de cálcio) & 25 & 1,013 & 0,07 & 1965 & 137,6 \\
\hline 10 - Água -CB-F & 25 & 1,013 & 23,12 & 50 & 1156 \\
\hline 11 - Água para diluição do polímero & 25 & 1,013 & 2,08 & 50 & 104 \\
\hline 12 - Água -LA-FERM & 80 & 1,5 & 4,17 & 59,96 & 250 \\
\hline 13 - Água -CAL & 25 & 1,013 & 1,08 & 50 & 54 \\
\hline 14 - C11-caldo clarificado & 98,03 & 1,013 & 38,56 & 2444 & 94241 \\
\hline 15 - C12-caldo clarificado & 98,03 & 1,013 & 102,9 & 2444 & 251488 \\
\hline 16 - C10-caldo clarificado & 98,03 & 1,013 & 141,5 & 2444 & 345826 \\
\hline 17 - RH2O-FIL & 51,88 & 0,3 & 24,13 & 55,81 & 1347 \\
\hline 18 - Vapor Flash & 99,12 & 0,97 & 1,65 & 50 & 82,5 \\
\hline 19 - TORTA-FIL & 89,04 & 1,1 & 4,39 & 4668 & 20493 \\
\hline Utilidade 1 - 1.69 BAR & 115 & 1,69 & 19,9 & 612,76 & 12194 \\
\hline 21 - Condensado da Utilidade 1 - 1.69 BAR & 115 & 1,69 & 19,9 & 611,7 & 12173 \\
\hline 22 - WC-EVA & 25 & 1,013 & 57,43 & 49,96 & 2869 \\
\hline 23 - Caldo clarificado & 95,65 & 6 & 111,8 & 3201 & 357872 \\
\hline Utilidade 2 - 2.5 BAR - EVAP & 127,4 & 2,5 & 22,81 & 110,2 & 2514 \\
\hline 24 - Condensado da Utilidade 2 - 2.5 BAR & 127,4 & 2,5 & 22,81 & 110,7 & 2525 \\
\hline 26 - CVVT & 83,2 & 0,5385 & 27,13 & 70,86 & 1922 \\
\hline 27 - RWC-EVA & 51,68 & 0,1598 & 59,95 & 54,36 & 3258,9 \\
\hline 28 - Água WTREAT & 29 & 1,013 & 19,91 & 50 & 995,5 \\
\hline 29 - Água WWCENT & 29 & 1,013 & 20,72 & 50 & 1036 \\
\hline 30 - Água WWSG & 25 & 1,013 & 3,83 & 50,00 & 191,5 \\
\hline 31 - Água -FERM & 28 & 6 & 277,8 & 50,52 & 14034 \\
\hline 32 - NUTRIENTES (NH3 - Amoníaco) & 25 & 1,013 & 0,04 & 19841 & 794 \\
\hline 33 - H2SO4 (Ácido sulfúrico) & 29 & 1,013 & 0,06 & 1666 & 100 \\
\hline 34 - OUT (Leveduras) & 29 & 1,013 & 2,29 & 5034 & 11543 \\
\hline
\end{tabular}


Tabela 5.1 - Resultados da análise global da Rota 1 (continuação)

\begin{tabular}{|c|c|c|c|c|c|}
\hline Descrição & $\begin{array}{c}\mathbf{T} \\
{\left[{ }^{\circ} \mathbf{C}\right]}\end{array}$ & $\begin{array}{c}\mathbf{P} \\
{[\mathrm{bar}]}\end{array}$ & $\underset{[\mathrm{kg} / \mathrm{s}]}{\mathrm{m}}$ & $\begin{array}{c}\text { btot } \\
{[\mathrm{kJ} / \mathrm{kg}]}\end{array}$ & $\begin{array}{l}\text { Btot } \\
{[\mathrm{kW}]}\end{array}$ \\
\hline 35 - RH2O - Fermentação & 39 & 6 & 277,8 & 56,96 & 15823 \\
\hline $36-\mathrm{CO} 2$ & 31,66 & 1,013 & 8,88 & 607 & 5390 \\
\hline 37 - Vinho & 31,22 & 1,363 & 145,2 & 2315 & 336138 \\
\hline Utilidade 3 - 6 BAR - FERM (Preparo do mosto) & 158,8 & 6 & 7,6 & 743,28 & 5649 \\
\hline 60 - Condensado da Utilidade 3 - 6 BAR & 158,8 & 6 & 7,6 & 149,4 & 1135 \\
\hline 38 - Água W-CCEX & 30 & 6 & 96,03 & 458,1 & 43991 \\
\hline 39 - Água R-W-CCEX & 50 & 6 & 96,03 & 54,61 & 5244 \\
\hline 40 - W-RSOL & 30 & 6 & 10,91 & 458,1 & 4998 \\
\hline 41 - R-W-RSOL & 50 & 6 & 10,91 & 54,61 & 596 \\
\hline 42 - W-CCRE & 30 & 6 & 15,58 & 458,1 & 7138 \\
\hline 43 - R-W-CCRE & 50 & 6 & 15,58 & 54,61 & 851 \\
\hline $44-\mathrm{W}-\mathrm{CCA}$ & 30 & 6 & 277,8 & 458,1 & 127260 \\
\hline 45 - R-W-CCA & 50 & 6 & 277,8 & 54,61 & 15170 \\
\hline $46-\mathrm{W}-\mathrm{CCB}$ & 30 & 6 & 120,5 & 458,10 & 55201 \\
\hline 47 - R-W-CCB & 50 & 6 & 120,5 & 54,61 & 6580 \\
\hline 48 - MEG (C2H6O2) & 80 & 1,013 & 0,001 & 19463 & 19,5 \\
\hline 49 - Água recuperada da destilação & 60 & 0,2 & 0,54 & 77,63 & 41,9 \\
\hline 50 - GASES & 34,05 & 1,34 & 0,32 & 2779 & 889,3 \\
\hline 51 - Álcool de segunda & 34,05 & 1,34 & 0,18 & 24771 & 4459 \\
\hline 52 - Óleo fúsel (OL-FUS4) & 90 & 1,16 & 0,01 & 5341 & 53,4 \\
\hline 53 - Óleo fúsel (OL-FUS26) & 82,24 & 1,16 & 0,02 & 22613 & 452,3 \\
\hline 54 - Flegmaça & 103,8 & 1,16 & 10,8 & 205,3 & 2217 \\
\hline 55 - Vinhaça & 75,29 & 1,39 & 124,4 & 286,4 & 35628 \\
\hline 56 - Etanol anidro & 35 & 1,013 & 8,96 & 29630 & 265485 \\
\hline Utilidade 4 - 2.5 BAR - Destilação (COL. A) & 127,4 & 2,5 & 20,43 & 668,6 & 13659 \\
\hline 62 - CVE-A Condensado da Utilidade 4 - 2.5 BAR & 127,4 & 2,5 & 20,43 & 110,8 & 2263 \\
\hline Utilidade 5 - 2.5 BAR - Destilação (COL. B) & 127,4 & 2,5 & 9,96 & 668,60 & 6659 \\
\hline 63-CVE-B Condensado da Utilidade 5 - 2.5 BAR & 127,4 & 2,5 & 9,96 & 110,8 & 1103 \\
\hline Utilidade 6 - 6 BAR - Desidratação (Col. Extração) & 158,8 & 6 & 3,44 & 795,70 & 2737 \\
\hline 61 - CVS6-CE Condensado da Utilidade 6 - 6 BAR & 158,8 & 6 & 3,44 & 149,4 & 513,9 \\
\hline Utilidade 7 - 6 BAR - Desidratação (Col. Recuperação) & 158,8 & 6 & 1,19 & 795,70 & 946,9 \\
\hline 59- CVS6-CR Condensado da Utilidade 7 - 6 BAR & 158,8 & 6 & 1,19 & 149,40 & 177,8 \\
\hline 57 - Ar de combustão & 29 & 1,013 & 124,1 & 0 & 0 \\
\hline 58 - Água de reposição & 29 & 1,013 & 2,65 & 50 & 132,4 \\
\hline 64 - Perdas -Vapor 6 BAR & 154 & 6 & 0,48 & 50 & 24,0 \\
\hline 65 - Perdas -Vapor 2.5 BAR & 127,4 & 2,5 & 2,17 & 50 & 108,5 \\
\hline 67 - Gases Exaustão & 197,7 & 1,013 & 154,9 & 158,4 & 24536 \\
\hline 68 - Vapor - PROCESSO 2.5 BAR & 127,4 & 2,5 & 54,27 & 669 & 36306 \\
\hline 69 - Vapor - PROCESSO 6 BAR & 158,8 & 6 & 11,96 & 796 & 9520 \\
\hline
\end{tabular}


Tabela 5.1 - Resultados da análise global da Rota 1 (continuação)

\begin{tabular}{|c|c|}
\hline Descrição & $\begin{array}{c}\text { Btot } \\
{[\mathbf{k W}]}\end{array}$ \\
\hline E1 - Energia Elétrica-Extração & 1500 \\
\hline E2 - Energia Elétrica-Tratamento do Caldo & 1200 \\
\hline E3 - Energia Elétrica-Concentração do Caldo & 1200 \\
\hline E4 - Energia Elétrica-Fermentação & 900 \\
\hline E5 - Energia Elétrica-Destilação & 900 \\
\hline E6 - Energia Elétrica-Tanque de condensados & 300 \\
\hline Consumo de potência mecânica da usina & 8000 \\
\hline ELETRICIDADE EXCEDENTE & 35803 \\
\hline
\end{tabular}

Fonte: Elaborado pelo autor.

Na Fig. 5.2 é ilustrada a eficiência exergética das diversas etapas da Rota 1. Ainda, na Fig. 5.3 apresentam-se os resultados obtidos com relação às irreversibilidades dos processos.

Figura 5.2 - Eficiência exergética por etapa da Rota 1.

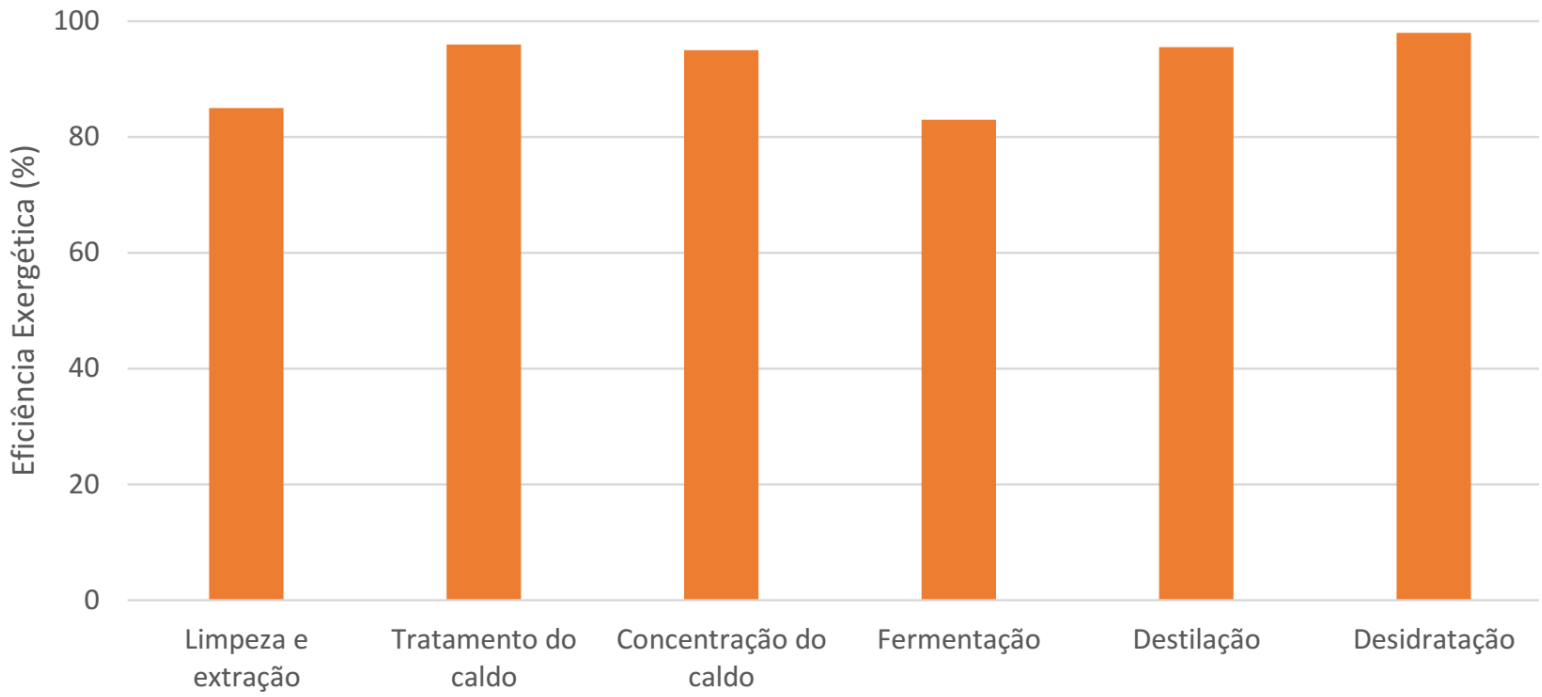

Fonte: Elaborado pelo autor. 
Figura 5.3 - Irreversibilidades dos processos envolvidos na Rota 1.

100000

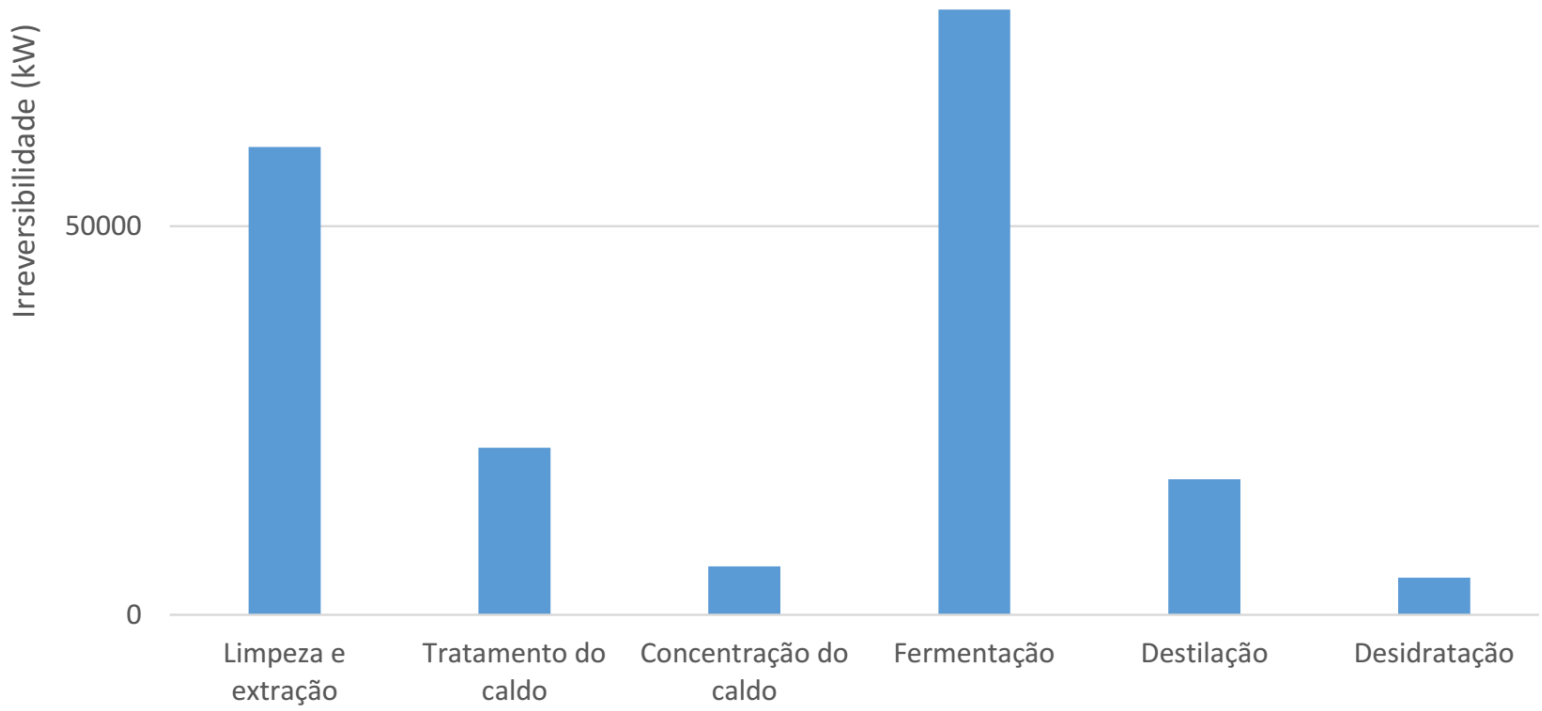

Fonte: Elaborado pelo autor.

Em termos das irreversibilidades gerada por litro de etanol produzido [kWh/l] em cada etapa da rota 1, obtém-se: Limpeza e extração 1,455, Tratamento do caldo 0,520, Concentração do caldo 0,150, Fermentação 1,883, Destilação 0,422 e Desidratação 0,115. 


\subsection{ANÁLISE EXERGÉTICA DA ROTA BIOQUÍMICA DE ETANOL 2G}

A partir deste ponto serão descritos os processos de pré-tratamento da biomassa lignocelulósica avaliados na análise exergética da Rota 2. Ao final serão apresentados os resultados globais do desempenho exergética dessa rota.

\section{Pré-tratamento da biomassa lignocelulósica}

$\mathrm{Na}$ avaliação dos métodos de pré-tratamento da biomassa foram selecionadas as tecnologias mais promissoras na indústria, comumente empregadas quando o insumo utilizado é o bagaço da cana. Desse modo nesta pesquisa foram analisados os métodos de pré-tratamento de explosão a vapor (Caso A), organosolv (Caso B), hidrotérmico (Caso C) e de um modelo combinado (Caso D).

Nas simulações o bagaço da cana-de-açúcar foi considerado como matéria-prima com um conteúdo de umidade fixado em 50\%. Assim, com o intuito de realizar uma análise de sensibilidade em função da composição foram adotadas duas caracterizações químicas desse material lignocelulósico. Para a matéria-prima 1 foi assumida a seguinte composição (p/p): Celulose $47,5 \%$, hemicelulose $20 \%$, lignina $30 \%$, e cinzas $2,5 \%$.

Enquanto que para a matéria-prima 2, foi utilizada uma composição química normalizada (p/p), sendo: Celulose 43,38\%, hemicelulose 25,63\%, lignina 23,24\%, cinzas 2,94\% e extrativos $4,81 \%$. Os extrativos foram representados como ácidos orgânicos, e são inseridos no simulador de acordo com a fórmula molecular de $\mathrm{C}_{6} \mathrm{H}_{6} \mathrm{O}_{6}$. Esta composição média do bagaço é proposta em Rocha et al. (2010), na qual 50 amostras de bagaço foram obtidas de diversas usinas do Brasil e em diferentes momentos de colheita.

Além disso, as propriedades dos componentes que formam este material lignocelulósico são obtidas com base no banco de dados desenvolvido pelo NREL para biocombustíveis (WOOLEY; PUTSCHE, 1996). 
Introduzindo esses métodos de pré-tratamento, as características da tecnologia de explosão a vapor (SE) são ilustradas na Fig. 5.4 e na Tab. 5.3. Os balanços de massa e exergia determinados no método Organosolv (ORG) são descritos na Fig. 5.5 e na Tab. 5.4. Posteriormente, a configuração adotada na tecnologia empregando água quente pressurizada (LHW), processo hidrotérmico, é introduzida na Fig. 5.5 e as propriedades obtidas podem ser vistas na Tab. 5.6. Do mesmo modo, na Tab. 5.7 são apresentados os parâmetros do modelo combinando os métodos de SE e LHW (Fig. 5.6).

Assim, no método de explosão a vapor um reator estequiométrico (RStoic model) é utilizado no simulador para representar as reações envolvidas neste processo. Na Tab. 5.2 são ilustradas as reações e taxas de conversão, as quais foram adotadas no reator de acordo com valores apresentados por Carrasco et al. (2010).

Tabela 5.2 - Reações e taxas de conversão no método de explosão a vapor.

\begin{tabular}{|l|c|c|}
\hline Reações & Rendimento (\%) & Equação \\
\hline $\mathrm{C}_{5} \mathrm{H}_{8} \mathrm{O}_{4}+\mathrm{H}_{2} \mathrm{O} \rightarrow \mathrm{C}_{5} \mathrm{H}_{10} \mathrm{O}_{5}$ & 61,4 & (5.4) \\
\hline $\mathrm{C}_{5} \mathrm{H}_{8} \mathrm{O}_{4}+\mathrm{H}_{2} \mathrm{O} \rightarrow 2.5 \mathrm{C}_{2} \mathrm{H}_{4} \mathrm{O}_{2}$ & 9,2 & $(5.5)$ \\
\hline $\mathrm{C}_{5} \mathrm{H}_{10} \mathrm{O}_{5} \rightarrow \mathrm{C}_{5} \mathrm{H}_{4} \mathrm{O}_{2}+3 \mathrm{H}_{2} \mathrm{O}$ & 5,1 & $(5.6)$ \\
\hline $\mathrm{C}_{6} \mathrm{H}_{10} \mathrm{O}_{5}+\mathrm{H}_{2} \mathrm{O} \rightarrow \mathrm{C}_{6} \mathrm{H}_{12} \mathrm{O}_{6}$ & 4,1 & $(5.7)$ \\
\hline
\end{tabular}

Fonte: Adaptado de Carrasco et al. (2010).

Os principais produtos neste método de pré-tratamento são: Xilose $\left(\mathrm{C}_{5} \mathrm{H}_{10} \mathrm{O}_{5}\right)$, Ácido Acético $\left(\mathrm{C}_{2} \mathrm{H}_{4} \mathrm{O}_{2}\right)$, Furfural $\left(\mathrm{C}_{5} \mathrm{H}_{4} \mathrm{O}_{2}\right)$ e Glicose $\left(\mathrm{C}_{6} \mathrm{H}_{12} \mathrm{O}_{6}\right)$, conforme as equações (5.4) a (5.7). Por fim, o esquema do processo de pré-tratamento de explosão a vapor é ilustrado na Fig. 5.4 e na Tab. 5.3 os parâmetros operacionais adoptados na análise.

Figura 5.4 - Esquema geral do pré-tratamento de explosão a vapor-SE.

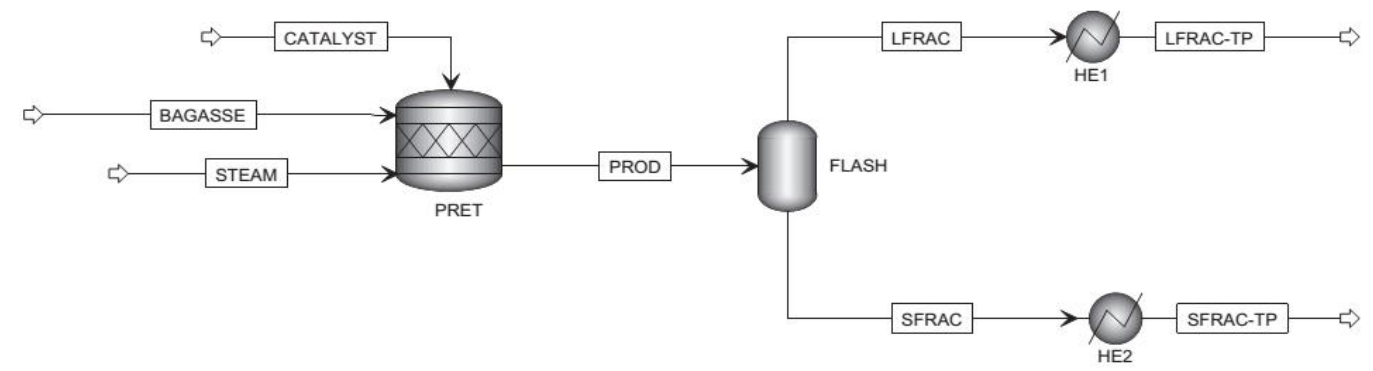

Fonte: Elaborado pelo autor. 
Tabela 5.3 - Parâmetros do pré-tratamento de explosão a vapor-SE.

\begin{tabular}{|c|c|c|c|c|c|c|c|}
\hline Fluxo & $\begin{array}{c}\text { matéria- } \\
\text { prima }\end{array}$ & $m(\mathrm{~kg} / \mathrm{s})$ & $T(K)$ & $P(k P a)$ & $h(k J / k g)$ & $b(k J / k g)$ & $B_{t o t}(k W)$ \\
\hline \multirow{2}{*}{ BAGASSE } & 1 & \multirow{2}{*}{13,89} & \multirow{2}{*}{298,15} & \multirow{2}{*}{101,3} & -23.382 & 9.856 & 136.900 \\
\hline & 2 & & & & -23.561 & 10.570 & 146.817 \\
\hline CATALYST & 1 e 2 & 1,39 & 298,15 & 101,3 & -16.763 & 4.944 & 6.872 \\
\hline STEAM & 1 e 2 & 7,64 & 463,15 & 1250,0 & -13.131 & 900 & 6.876 \\
\hline \multirow{2}{*}{ SFRAC-TP } & 1 & \multirow{2}{*}{5,98} & \multirow{2}{*}{298,15} & \multirow{2}{*}{101,3} & -21.721 & 6.109 & 36.532 \\
\hline & 2 & & & & -21.815 & 6.401 & 38.278 \\
\hline \multirow{2}{*}{ LFRAC-TP } & 1 & \multirow{2}{*}{16,94} & \multirow{2}{*}{298,15} & \multirow{2}{*}{101,3} & -22.540 & 5.938 & 100.590 \\
\hline & 2 & & & & -22.659 & 6.214 & 105.265 \\
\hline
\end{tabular}

Fonte: Elaborado pelo autor.

Na simulação do processo de pré-tratamento Organosolv o solvente escolhido foi uma solução de Etanol 34\% e Água de 66\%, de acordo com Ojeda; Sánchez e Kafarov (2011). Destaca-se que o modelo proposto foi baseado nos parâmetros de pré-tratamento Organosolv de bagaço de cana relatado por Dias (2008). Neste método, são utilizados os separadores SEP1 e SEP2 para representar a separação da fase líquida obtida nestes equipamentos contendo lignina dissolvida no solvente Organosolv, conforme apresentado na Fig. 5.5. Estes fluxos são alimentados na coluna de destilação para a recuperação de solvente. Na simulação adotou-se uma coluna do tipo "RadFrac" operando a pressão de 0,5 MPa.

Figura 5.5 - Esquema geral do pré-tratamento Organosolv-ORG.

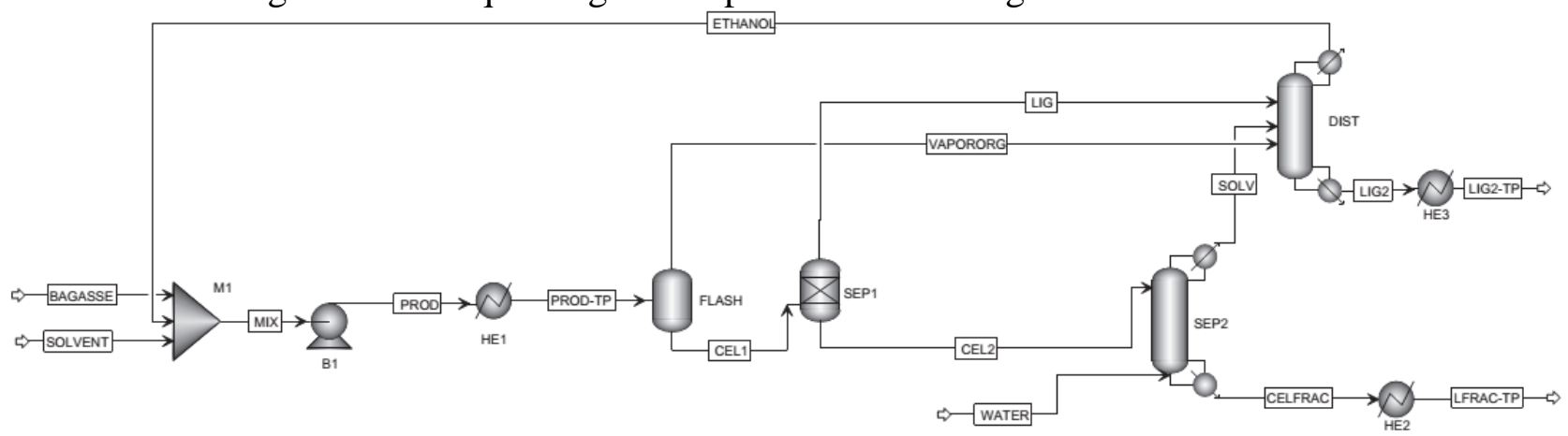

Fonte: Elaborado pelo autor. 
Tabela 5.4 - Parâmetros do pré-tratamento Organosolv-ORG.

\begin{tabular}{|c|c|c|c|c|c|c|c|}
\hline Fluxo & $\begin{array}{c}\text { matéria- } \\
\text { prima }\end{array}$ & $m(\mathrm{~kg} / \mathrm{s})$ & $T(K)$ & $P(k P a)$ & $h(k J / k g)$ & $b(k J / k g)$ & $B_{t o t}(k W)$ \\
\hline \multirow{2}{*}{ BAGASSE } & 1 & \multirow{2}{*}{13,89} & \multirow{2}{*}{298,15} & \multirow{2}{*}{101,3} & -23.382 & 9.856 & 136.900 \\
\hline & 2 & & & & -23.561 & 10.570 & 146.817 \\
\hline \multirow{2}{*}{ SOLVENT } & 1 & \multirow{2}{*}{21,39} & \multirow{2}{*}{298,15} & \multirow{2}{*}{101,3} & -16.305 & 4.719 & 100.939 \\
\hline & 2 & & & & -16.156 & 4.767 & 101.966 \\
\hline WATER & $1 \mathrm{e} 2$ & 19,08 & 298,15 & 101,3 & -15.815 & 50 & 954 \\
\hline \multirow{2}{*}{ LIG2-TP } & 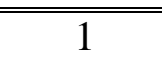 & \multirow{2}{*}{32,39} & \multirow{2}{*}{298,15} & \multirow{2}{*}{101,3} & -20.035 & 3.204 & 103.778 \\
\hline & 2 & & & & -20.117 & 3.567 & 115.535 \\
\hline \multirow{2}{*}{ LFRAC-TP } & 1 & \multirow{2}{*}{21,97} & \multirow{2}{*}{298,15} & \multirow{2}{*}{101,3} & -22.325 & 4.327 & 95.064 \\
\hline & 2 & & & & -22.511 & 4.450 & 97.767 \\
\hline
\end{tabular}

Fonte: Elaborado pelo autor.

Na simulação do método de água quente pressurizada (LHW), também conhecido como prétratamento hidrotérmico, optou-se por um reator de rendimento (RYield). Neste caso, foi avaliada uma taxa de consumo de vapor de 18,000 kg/h baseado em Laser et al., (2002). Além disso, como parâmetros de operação, foram adotados $\mathrm{T}=200^{\circ} \mathrm{C}$, e $\mathrm{P}=5 \mathrm{MPa}$, com um rendimento de recuperação de xilose de 88\% (HAMELINCK; HOOIJDONK; FAAIJ, 2005). O esquema do processo de pré-tratamento de LHW é ilustrado na Fig. 5.6.

Figura 5.6 - Esquema geral do pré-tratamento de água quente pressurizada-LHW.

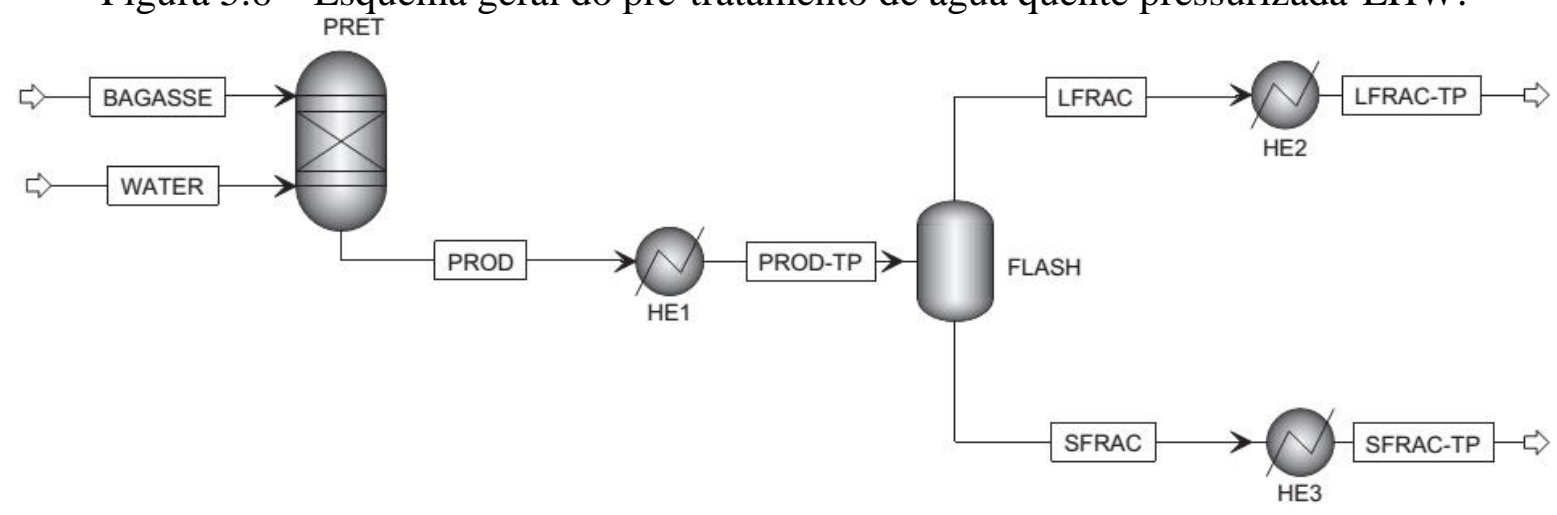

Fonte: Elaborado pelo autor. 
Tabela 5.5 - Parâmetros do pré-tratamento de água quente pressurizada-LHW.

\begin{tabular}{|c|c|c|c|c|c|c|c|}
\hline Fluxo & $\begin{array}{c}\text { matéria- } \\
\text { prima }\end{array}$ & $m(\mathrm{~kg} / \mathrm{s})$ & $T(K)$ & $P(k P a)$ & $h(k J / k g)$ & $b(k J / k g)$ & $B_{t o t}(k W)$ \\
\hline \multirow{2}{*}{ BAGASSE } & 1 & \multirow{2}{*}{13,89} & \multirow{2}{*}{298,15} & \multirow{2}{*}{101,3} & -23.382 & 9.856 & 136.900 \\
\hline & 2 & & & & -23.561 & 10.570 & 146.817 \\
\hline WATER & $1 \mathrm{e} 2$ & 5,00 & 538,15 & 5100,0 & -14.759 & 341 & 1705 \\
\hline \multirow{2}{*}{ SFRAC-TP } & 1 & \multirow{2}{*}{5,98} & \multirow{2}{*}{298,15} & \multirow{2}{*}{101,3} & -21.095 & 6.951 & 41.567 \\
\hline & 2 & & & & -21.520 & 7.598 & 45.436 \\
\hline \multirow{2}{*}{ LFRAC-TP } & 1 & \multirow{2}{*}{12,91} & \multirow{2}{*}{298,15} & \multirow{2}{*}{101,3} & -22.313 & 6.791 & 87.672 \\
\hline & 2 & & & & -22.650 & 7.306 & 94.320 \\
\hline
\end{tabular}

Fonte: Elaborado pelo autor.

Finalmente, tendo em vista a realização de um pré-tratamento mais eficaz, uma configuração é proposta combinando os métodos de SE e LHW, conforme apresentado na Fig. 5.7. A combinação de pré-tratamento físico-químicos pode aumentar a conversão de açúcar a partir de biomassa, melhorando assim o desempenho do método se comparado à implementação de um único pré-tratamento.

Figura 5.7 - Esquema geral combinando pré-tratamentos de SE e LHW.

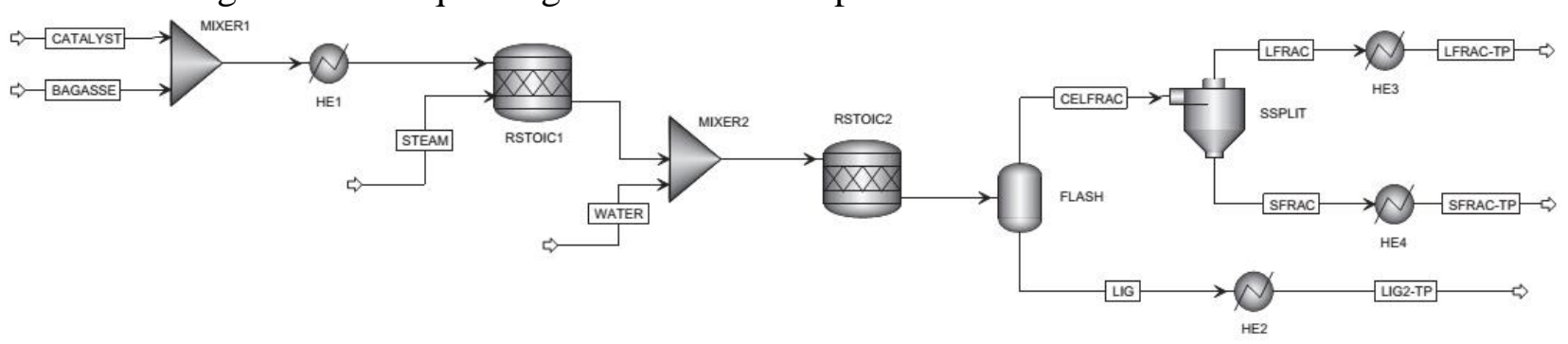

Fonte: Elaborado pelo autor.

Esta configuração aproveita os fluxos de exergia obtidos na saída do processo de SE, adotando-se como insumos no método hidrotérmico. Embora tenham sido obtidos resultados positivos por meio deste arranjo, precisa-se da sua avaliação técnico-econômica e da sua demonstração em escala piloto, para determinar os parâmetros de desempenho visando o escalonamento industrial. 
Tabela 5.6 - Parâmetros do pré-tratamento combinado - SE e LHW.

\begin{tabular}{|c|c|c|c|c|c|c|c|}
\hline Fluxo & $\begin{array}{c}\text { matéria- } \\
\text { prima }\end{array}$ & $m(\mathrm{~kg} / \mathrm{s})$ & $T(K)$ & $P(k P a)$ & $h(k J / k g)$ & $b(k J / k g)$ & $B_{t o t}(k W)$ \\
\hline \multirow{2}{*}{ BAGASSE } & 1 & \multirow{2}{*}{13,89} & \multirow{2}{*}{298,15} & \multirow{2}{*}{101,3} & -23.382 & 9.856 & 136.900 \\
\hline & 2 & & & & -23.561 & 10.570 & 146.817 \\
\hline CATALYST & $1 \mathrm{e} 2$ & 1,39 & 298,15 & 101,3 & -16.763 & 4.944 & 6.872 \\
\hline STEAM & 1 e 2 & 7,64 & 463,15 & 1250,0 & -13.131 & 900 & 6.876 \\
\hline WATER & 1 e 2 & 5,00 & 538,15 & 5100,0 & -15.815 & 341 & 1.705 \\
\hline \multirow{2}{*}{ LIG2-TP } & 1 & \multirow{2}{*}{3,14} & \multirow{2}{*}{298,15} & \multirow{2}{*}{101,3} & -20.873 & 2.788 & 8.754 \\
\hline & 2 & & & & -20.902 & 2.894 & 9.087 \\
\hline \multirow{2}{*}{ SFRAC-TP } & 1 & \multirow{2}{*}{11,82} & \multirow{2}{*}{298,15} & \multirow{2}{*}{101,3} & -21.223 & 5.105 & 60.341 \\
\hline & 2 & & & & -21.466 & 5.502 & 65.034 \\
\hline \multirow{2}{*}{ LFRAC-TP } & 1 & \multirow{2}{*}{12,96} & \multirow{2}{*}{298,15} & \multirow{2}{*}{101,3} & -22.775 & 5.769 & 74.766 \\
\hline & 2 & & & & -22.963 & 6.182 & 80.119 \\
\hline
\end{tabular}

Fonte: Elaborado pelo autor.

Nota-se que o foco destas avaliações foi comparar três processos de pré-tratamento consolidados na indústria; enquanto que a opção de pré-tratamento combinando os métodos $\mathrm{SE}+\mathrm{LHW}$ foi uma proposta alternativa direcionada a otimizar o processo. Desse modo, a rota como um todo foi avaliada por meio do pré-tratamento de explosão a vapor por ser esta tecnologia mais próxima a ser comercializada.

A partir deste ponto serão discutidos os resultados da avaliação dos pré-tratamentos da biomassa apresentados anteriormente, em termos da eficiência exergética e a taxa de exergia destruída para cada método, sendo este último parâmetro uma representação da perda de qualidade de energia. Assim, a comparação da eficiência, em função da exergia total dos produtos/insumos e da taxa de exergia destruída desses pré-tratamentos é ilustrada na Tab. 5.7 . 
Tabela 5.7 - Comparação do rendimento nos processos de pré-tratamento simulados.

\begin{tabular}{|c|c|c|c|c|c|}
\hline \multirow{2}{*}{ Pré-tratamento } & \multirow{2}{*}{$\begin{array}{l}\text { matéria- } \\
\text { prima }\end{array}$} & Caso A & Caso B & Caso $C$ & Caso D \\
\hline & & $S E$ & $O R G$ & $L H W$ & $S E+L H W$ \\
\hline \multirow{2}{*}{$\begin{array}{l}\text { Eficiência Exergética } \\
(\%)\end{array}$} & 1 & 91,0 & 83,3 & 93,3 & 94,4 \\
\hline & 2 & 93,2 & 85,4 & 94,1 & 95,1 \\
\hline \multirow{2}{*}{$\begin{array}{l}\text { Taxa de Exergia Destruída } \\
\text { (MW) }\end{array}$} & 1 & 13,5 & 39,9 & 9,4 & 8,5 \\
\hline & 2 & 10,6 & 36,4 & 8,8 & 8,0 \\
\hline
\end{tabular}

Fonte: Elaborado pelo autor.

Uma elevada eficiência exergética foi obtida para todos os pré-tratamentos. No entanto, observou-se uma eficiência de 83,3\% quando aplicado o processo Organosolv (Caso B) na matéria-prima 1, sendo este valor uma consequência da maior taxa de irreversibilidade envolvida neste processo, devido ao consumo de energia para a recirculação do solvente (solução aquosa de etanol). Em contrapartida, nos métodos de explosão a vapor e hidrotérmico (LHW), foram atingidas eficiências de aproximademente 95\% quando adotadas as duas matérias-primas.

Destaca-se que a utilização de $\mathrm{SO}_{2}$ como catalisador ácido provou ser eficaz no prétratamento de explosão a vapor, devido principalmente ao aumento na recuperação de açúcares da hemicelulose e à diminuição de compostos inibidores produzidos. Adicionalmente, neste método foi empregado vapor saturado de alta pressão no tratamento da biomassa lignocelulósica.

O método hidrotérmico apresentou baixo consumo de exergia dado que na sua operação são adotadas elevadas pressões e temperaturas conforme foi indicado na Tab. 5.5. A água quente pressurizada penetra a matriz da lignocelulose e degrada a hemicelulose em xilose com menor geração de inibidores. Assim, evidenciou-se que neste processo não há necessidade de uma etapa de lavagem final ou neutralização, uma vez que o solvente empregado no prétratamento é a água. 
Com o intuito de comparar o desempenho exergético obtido nos processos de pré-tratamento do Caso A e Caso B, estes foram contrastados com os valores reportados por Ojeda; Sánchez e Kafarov (2011). Observou-se que, a diferença entre os resultados em termos da eficiência exergética e as irreversibilidades não foram superiores de $4 \%$ e $1 \%$ quando considerada a matéria-prima 1. Já adotando a matéria-prima 2, os resultados não excederam de $6 \%$ e $3 \%$, respectivamente.

É importante ressaltar que a porcentagem da exergia destruída obtida na avaliação dos prétratamentos é elevada, quando comparada como a taxa de exergia de bagaço na entrada do processo, de acordo os valores apresentados na Fig. 5.8, sendo $\underline{(\boldsymbol{a}) \text { o cenário considerando a }}$ matéria-prima 1 e $(\boldsymbol{b})$ o cenário optando pela matéria-prima 2. Estes resultados mostram a relevância dos métodos de pré-tratamento da biomassa na eficiência exergética global das rotas de produção de etanol $2 \mathrm{G}$.

Figura 5.8 - Porcentagem da exergia destruída nos processos de pré-tratamento.

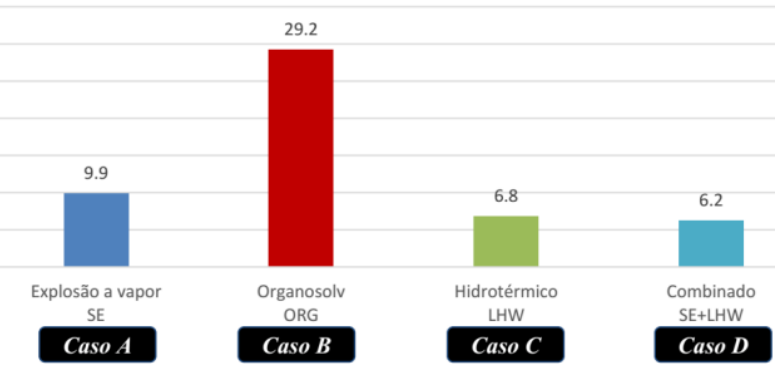

(a) matéria-prima 1

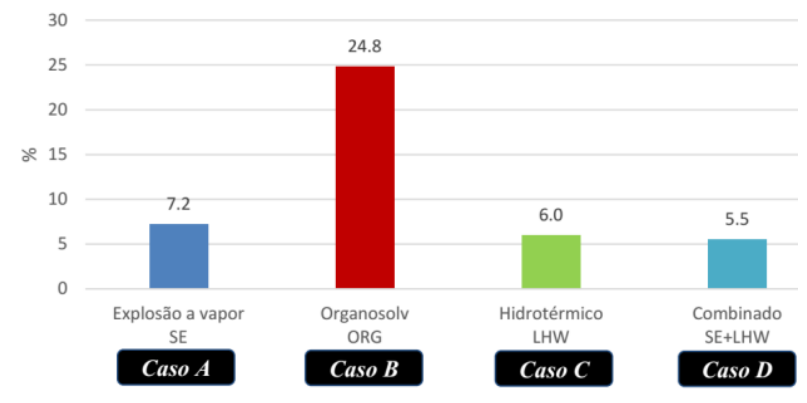

(b) matéria-prima 2

Fonte: Elaborado pelo autor.

De modo geral, é possível afirmar que na escolha de um método de pré-tratamento da biomassa deve ser levada em consideração a eficiência exergética da configuração analisada. Este parâmetro envolve a qualidade de conversão de energia que junto com uma avaliação econômica, do impacto ambiental e do rendimento potencial do método, permitirá determinar o pré-tratamento ótimo em função do processo, uma vez que diferentes produtos são gerados. 


\section{Avaliação global da rota bioquímica de etanol $2 G$}

A Tab. 5.8 resume as informações técnicas adotadas nas simulações do processo de produção de etanol de $2 \mathrm{G}$ via hidrólise enzimática, quando considerado o teor de sólidos de $10 \%$ no reator de hidrólise, com base em dados experimentais reportados pelo NREL (HUMBIRD et al., 2011). Com relação às características do método de pré-tratamento, foram adotadas as reações e rendimentos de conversão, apresentadas no item anterior para o processo de explosão a vapor.

Tabela 5.8 - Principais parâmetros na simulação dos processos de produção de etanol 2G.

\begin{tabular}{|c|c|}
\hline Hidrólise (Reações) & $\begin{array}{c}\text { Taxas de } \\
\text { conversão (\%) }\end{array}$ \\
\hline $\operatorname{CELULOSE}\left(\mathrm{C}_{6} \mathrm{H}_{10} \mathrm{O}_{5}\right)+\operatorname{ÁGUA}\left(\mathrm{H}_{2} \mathrm{O}\right) \rightarrow \operatorname{GLICOSE}\left(\mathrm{C}_{6} \mathrm{H}_{12} \mathrm{O}_{6}\right)$ & 69,2 \\
\hline $\operatorname{HEMICELULOSE}\left(\mathrm{C}_{5} \mathrm{H}_{8} \mathrm{O}_{4}\right)+$ ÁGUA $\left(\mathrm{H}_{2} \mathrm{O}\right) \rightarrow \operatorname{XILOSE}\left(\mathrm{C}_{5} \mathrm{H}_{10} \mathrm{O}_{5}\right)$ & 35,7 \\
\hline \multicolumn{2}{|l|}{ Condições de operação } \\
\hline Concentração de enzimas [Celulase] (FPU/g de biomassa) & 15 \\
\hline Temperatura de operação do reator $\left({ }^{\circ} \mathrm{C}\right)$ & 50 \\
\hline Pressão de operação do reator (bar) & 1,01 \\
\hline Concentração de sólidos no reator (\%) & 10 \\
\hline Tempo de reação $(\mathrm{h})$ & 48 \\
\hline
\end{tabular}

\subsection{RESULTADOS E DISCUSSÕES DA ROTA 2}

Nesta seção, serão tratados os resultados da simulação envolvendo a avaliação global da bioquímica de etanol 2G. Na abordagem proposta, a taxa de exergia destruída e a eficiência exergética são utilizadas como indicadores de desempenho, e visam propor melhorias nos processos com consequente aumento na eficiência das configurações.

Inicialmente, o layout da Rota 2 desta pesquisa é ilustrado na Fig. 5.9. Além disso, a Tab. 5.9 apresenta a descrição dos fluxos envolvidos na análise em função dos balanços de massa, energia e exergia.

Por fim, as Fig. 5.10 e Fig. 5.11 apresentam os resultados globais da Rota 2 em termos da eficiência exergética e das irreversibilidades dos processos. 


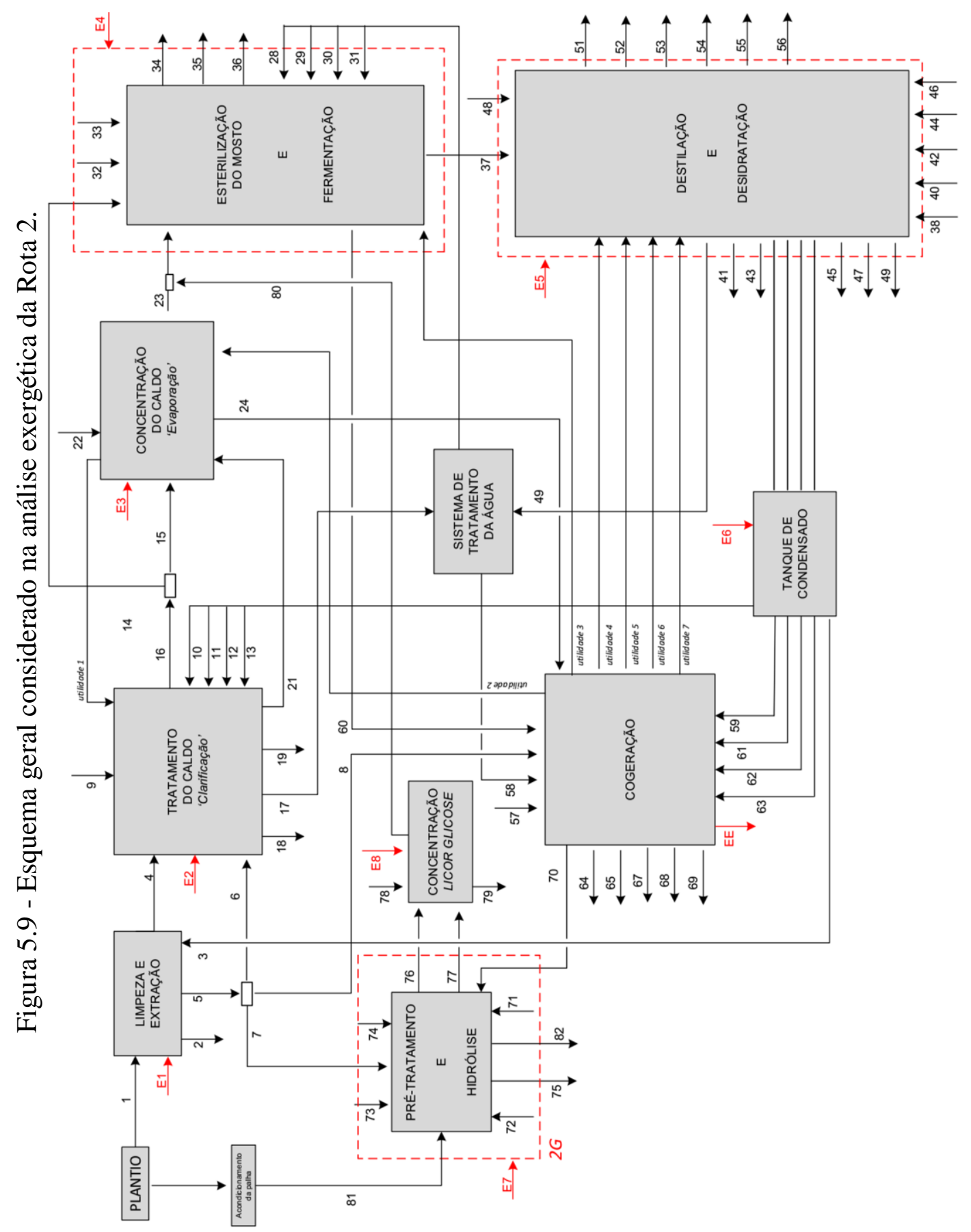

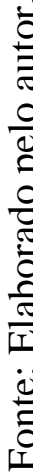


Tabela 5.9 - Resultados da análise global da Rota 2.

\begin{tabular}{|c|c|c|c|c|c|}
\hline Descrição & $\begin{array}{c}\mathbf{T} \\
{\left[{ }^{\circ} \mathbf{C}\right]}\end{array}$ & $\begin{array}{c}\mathbf{P} \\
{[\mathrm{bar}]}\end{array}$ & $\underset{[\mathrm{kg} / \mathrm{s}]}{\mathrm{m}}$ & $\begin{array}{c}\text { btot } \\
{[\mathrm{kJ} / \mathrm{kg}]}\end{array}$ & $\begin{array}{l}\text { Btot } \\
{[\mathrm{kW}]}\end{array}$ \\
\hline 1 - Cana-de-açúcar & 25 & 1,013 & 138,9 & 5651 & 784924 \\
\hline 2 - Terra & 25 & 1,013 & 1,73 & 2209 & 3815 \\
\hline 3 - Água embebição & 50 & 1,013 & 41,67 & 54,11 & 2254 \\
\hline 4 - Caldo & 30,08 & 1,013 & 140,4 & 2520 & 353865 \\
\hline 5 - Bagaço produzido & 30,08 & 1,013 & 38,41 & 10827 & 415914 \\
\hline 6 - Bagaçilho & 30,08 & 1,013 & 0,71 & 10827 & 7687 \\
\hline 7 - Bagaço excedente/para hidrólise & 30,08 & 1,013 & 15,3 & 10827 & 165653 \\
\hline 8 - Bagaço para cogeração & 30,08 & 1,013 & 22,4 & 10827 & 242525 \\
\hline 9 - Óxido de cálcio (CAO) & 25 & 1,013 & 0,07 & 1965 & 137,5 \\
\hline 10 - Água para a diluição do fermento & 25 & 1,013 & 23,12 & 50 & 1155 \\
\hline 11 - Água para diluição do polímero & 25 & 1,013 & 2,08 & 50 & 104,1 \\
\hline 12 - Água para lavagem da torta & 80 & 1,5 & 4,17 & 59,96 & 250,03 \\
\hline 13 - Água - CAL & 25 & 1,013 & 1,08 & 50 & 54,12 \\
\hline 14 - Caldo tratado para concentração & 30 & 1,013 & 38 & 2444 & 92872 \\
\hline 15 - Caldo tratado para preparação do mosto & 30 & 1,013 & 102 & 2444 & 249288 \\
\hline 16 - Caldo misto & 30 & 1,013 & 140 & 2444 & 342160 \\
\hline 17 - RH2O-FIL & 51,88 & 0,3 & 24,13 & 55,81 & 1347 \\
\hline 18 - Vapor Flash & 99,12 & 0,97 & 1,65 & 50 & 82,48 \\
\hline 19 - Torta de filtro & 89,04 & 1,1 & 5,19 & 4668 & 24227 \\
\hline $\begin{array}{l}\text { Utilidade } 1 \text { - Sangria do vapor vegetal para aquecimento } \\
\text { do caldo }\end{array}$ & 115 & 1,69 & 20 & 616 & 12320 \\
\hline $\begin{array}{l}21 \text { - Condensado da Utilidade } 1-1.69 \text { BAR (SVVI } \\
\text { Sangria) }\end{array}$ & 115 & 1,69 & 20 & 98 & 1960 \\
\hline 22 - WC-EVA & 25 & 1,013 & 57,43 & 49,96 & 2869 \\
\hline 23 - Caldo clarificado & 95,65 & 6 & 111,8 & 3201 & 357934 \\
\hline Utilidade 2 - 2.5 BAR - EVAP concentração do caldo & 127,4 & 2,5 & 22,95 & 667 & 15307,65 \\
\hline 24 - Condensado da Utilidade 2 - $2.5 B A R$ & 127,4 & 2,5 & 22,95 & 110 & 2524,5 \\
\hline 26 - CVVT & 83,2 & 0,5385 & 27,13 & 70,86 & 1922 \\
\hline 27 - RWC-EVA & 51,68 & 0,1598 & 59,95 & 54,36 & 3258 \\
\hline 28 - Água WTREAT & 29 & 1,013 & 19,91 & 50 & 995,5 \\
\hline 29 - Água WWCENT & 29 & 1,013 & 20,72 & 50 & 1035 \\
\hline 30 - Água WWSG & 25 & 1,013 & 3,83 & 50 & 191,6 \\
\hline 31 - Água - Fermentação & 28 & 6 & 277,8 & 50 & 13890 \\
\hline 32 - NUTRIENTES (NH3) & 25 & 1,013 & 0,04 & 19841 & 793,64 \\
\hline 33 - H2SO4 (Ácido sulfúrico) & 29 & 1,013 & 0,06 & 1666 & 96,67 \\
\hline 34 - OUT (Leveduras) & 29 & 1,013 & 2,29 & 5034 & 11543 \\
\hline 35 - RH2O - Fermentação & 39 & 6 & 277,8 & 56,96 & 15823 \\
\hline $36-\mathrm{CO} 2$ & 31,66 & 1,013 & 9,26 & 607 & 5621 \\
\hline 37 - Vinho & 31,22 & 1,363 & 158,7 & 2315 & 367390 \\
\hline Utilidade 3 - 6 BAR - FERM (Preparo do mosto) & 158,8 & 6 & 7,9 & 793,29 & 6266,98 \\
\hline 60 - Condensado da Utilidade 3 - 6 BAR & 158,8 & 6 & 7,9 & 149,4 & 1180,26 \\
\hline
\end{tabular}


Tabela 5.9 - Resultados da análise global da Rota 2 (continuação)

\begin{tabular}{|c|c|c|c|c|c|}
\hline Descrição & $\begin{array}{c}\mathbf{T} \\
{\left[{ }^{\circ} \mathbf{C}\right]}\end{array}$ & $\begin{array}{c}\mathbf{P} \\
{[\text { bar] }}\end{array}$ & $\begin{array}{c}\mathrm{m} \\
{[\mathrm{kg} / \mathrm{s}]}\end{array}$ & $\begin{array}{c}\text { btot } \\
{[\mathrm{kJ} / \mathrm{kg}]}\end{array}$ & $\begin{array}{c}\text { Btot } \\
{[\mathrm{kW}]}\end{array}$ \\
\hline 38 - Água W-CCEX & 30 & 6 & 96,03 & 458,1 & 43991 \\
\hline 39 - Água R-W-CCEX & 50 & 6 & 96,03 & 54,61 & 5244 \\
\hline 40 - W-RSOL & 30 & 6 & 10,91 & 458,1 & 4998 \\
\hline 41 - R-W-RSOL & 50 & 6 & 10,91 & 54,61 & 596 \\
\hline 42 - W-CCRE & 30 & 6 & 15,58 & 458,1 & 7138 \\
\hline 43 - R-W-CCRE & 50 & 6 & 15,58 & 54,61 & 851 \\
\hline 44 - W-CCA & 30 & 6 & 277,8 & 458,1 & 127260 \\
\hline 45 - R-W-CCA & 50 & 6 & 277,8 & 54,61 & 15170 \\
\hline $46-\mathrm{W}-\mathrm{CCB}$ & 30 & 6 & 120,5 & 458,10 & 55201 \\
\hline 47 - R-W-CCB & 50 & 6 & 120,5 & 54,61 & 6580 \\
\hline 48 - MEG (C2H6O2) & 80 & 1,013 & 0,001 & 19463 & 58,4 \\
\hline 49 - Água recuperada da destilação & 60 & 0,2 & 0,54 & 77,63 & 41,9 \\
\hline 50 - GASES & 34,05 & 1,34 & 0,46 & 2779 & 1278 \\
\hline 51 - Álcool de segunda & 34,05 & 1,34 & 0,31 & 24771 & 7679 \\
\hline 52 - Óleo fúsel (OL-FUS4) & 90 & 1,16 & 0,02 & 5341 & 106,8 \\
\hline 53 - Óleo fúsel (OL-FUS26) & 82,24 & 1,16 & 0,03 & 22613 & 678 \\
\hline 54 - Flegmaça & 104 & 1,2 & 11,8 & 105,3 & 1242 \\
\hline 55 - Vinhaça & 75 & 1,4 & 135,4 & 286,4 & 38779 \\
\hline 56 - Etanol anidro & 35 & 1,013 & 11,52 & 29630 & 341338 \\
\hline Utilidade 4 - 2.5 BAR - Destilação (COL. A) & 127,4 & 2,5 & 21,63 & 668,6 & 14462 \\
\hline 62-CVE-A Condensado da Utilidade 4-2.5 BAR & 127,4 & 2,5 & 21,63 & 110,8 & 2397 \\
\hline Utilidade 5 - 2.5 BAR - Destilação (COL. B) & 127,4 & 2,5 & 12,86 & 668,60 & 8598 \\
\hline 63-CVE-B Condensado da Utilidade 5 - 2.5 BAR & 127,4 & 2,5 & 12,86 & 110,8 & 1425 \\
\hline Utilidade 6 - 6 BAR - Desidratação (Col. Extração) & 158,8 & 6 & 3,5 & 796 & 2786 \\
\hline 61-CVS6-CE Condensado da Utilidade 6 - 6 BAR & 158,8 & 6 & 3,5 & 149 & 521 \\
\hline Utilidade 7 - 6 BAR - Desidratação (Col. Recuperação) & 158,8 & 6 & 1,25 & 795,70 & 995 \\
\hline 59- CVS6-CR Condensado da Utilidade 7 - 6 BAR & 158,8 & 6 & 1,25 & 149,40 & 187 \\
\hline 57 - Ar de combustão & 29 & 1,013 & 124,1 & 0 & 0 \\
\hline 58 - Água de reposição & 29 & 1,013 & 2,65 & 50 & 132,4 \\
\hline 64 - Perdas -Vapor 6 BAR & 154 & 6 & 0,48 & 50 & 24,0 \\
\hline 65 - Perdas -Vapor 2.5 BAR & 127,4 & 2,5 & 2,17 & 50 & 108,5 \\
\hline 67 - Gases Exaustão & 197,7 & 1,013 & 164,9 & 158,4 & 26120 \\
\hline 68 - Vapor - PROCESSO 2.5 BAR & 127,4 & 2,5 & 81,4 & 669 & 54457 \\
\hline 69 - Vapor - PROCESSO 6 BAR & 158,8 & 6 & 13,8 & 796 & 10985 \\
\hline 70 - Vapor para o pré-tratamento do bagaço & 280 & 12,5 & 7,64 & 989 & 7556 \\
\hline 71 - Água para lavagem do bagaço pré-tratado & 30 & 1,013 & 123,4 & 50 & 6170 \\
\hline 72 - Água para hidrólise enzimática & 50 & 2,5 & 103 & 50 & 5150 \\
\hline 73 - Enzima & 29 & 1,013 & 0,6 & 23730 & 14238 \\
\hline 74 - Dióxido de enxofre (SO2) & 25 & 1,013 & 0,3 & 4892 & 1468 \\
\hline 75 - Torta de lignina & 50 & 1,013 & 6,4 & 10802 & 69133 \\
\hline
\end{tabular}


Tabela 5.9 - Resultados da análise global da Rota 2 (continuação)

\begin{tabular}{|c|c|c|c|c|c|}
\hline Descrição & $\begin{array}{c}\mathbf{T} \\
{\left[{ }^{\circ} \mathbf{C}\right]}\end{array}$ & $\begin{array}{c}\mathbf{P} \\
{[\mathrm{bar}]}\end{array}$ & $\begin{array}{c}\mathrm{m} \\
{[\mathrm{kg} / \mathrm{s}]}\end{array}$ & $\begin{array}{c}\text { btot } \\
{[\mathrm{kJ} / \mathrm{kg}]}\end{array}$ & $\begin{array}{l}\text { Btot } \\
{[\mathrm{kW}]}\end{array}$ \\
\hline 76 - Vapor flash do pré-tratamento do bagaço & 101 & 1,013 & 3,6 & 822 & 2959,2 \\
\hline 77 - Licor de glicose diluído & 50 & 1,013 & 105,7 & 480 & 50736 \\
\hline $\begin{array}{l}78 \text { - Vapor de escape para concentração do licor de } \\
\text { glicose }\end{array}$ & 127 & 2,5 & 26 & 665 & 17290 \\
\hline $\begin{array}{l}79 \text { - Condensado do vapor de escape concentração } \\
\text { glicose }\end{array}$ & 127 & 2,5 & 26 & 110 & 2860 \\
\hline 80 - Licor de glicose concentrado & 56 & 0,2 & 13,8 & 3265 & 45057 \\
\hline 81 - Palha & 25 & 1,013 & 19,44 & 15750 & 306180 \\
\hline 82 - Licor de Pentoses & 37 & 1,013 & 98,63 & 537,6 & 53023 \\
\hline E1 - Energia Elétrica-Extração & & & & & 1500 \\
\hline E2 - Energia Elétrica-Tratamento Caldo & & & & & 1200 \\
\hline E3 - Energia Elétrica-Concentração Caldo & & & & & 1200 \\
\hline E4 - Energia Elétrica-Fermentação & & & & & 900 \\
\hline E5 - Energia Elétrica-Destilação & & & & & 900 \\
\hline E6 - Energia Elétrica-Tanque de Condensados & & & & & 300 \\
\hline E7 - Energia Elétrica-Hidrólise Enzimática & & & & & 9840 \\
\hline E8 - Energia Elétrica-Concentração do licor de glicose & & & & & 1215 \\
\hline Consumo de potência mecânica da usina & & & & & 8000 \\
\hline ELETRICIDADE EXCEDENTE & & & & & 26072 \\
\hline
\end{tabular}

Fonte: Elaborado pelo autor.

Figura 5.10 - Eficiência exergética da Rota 2.

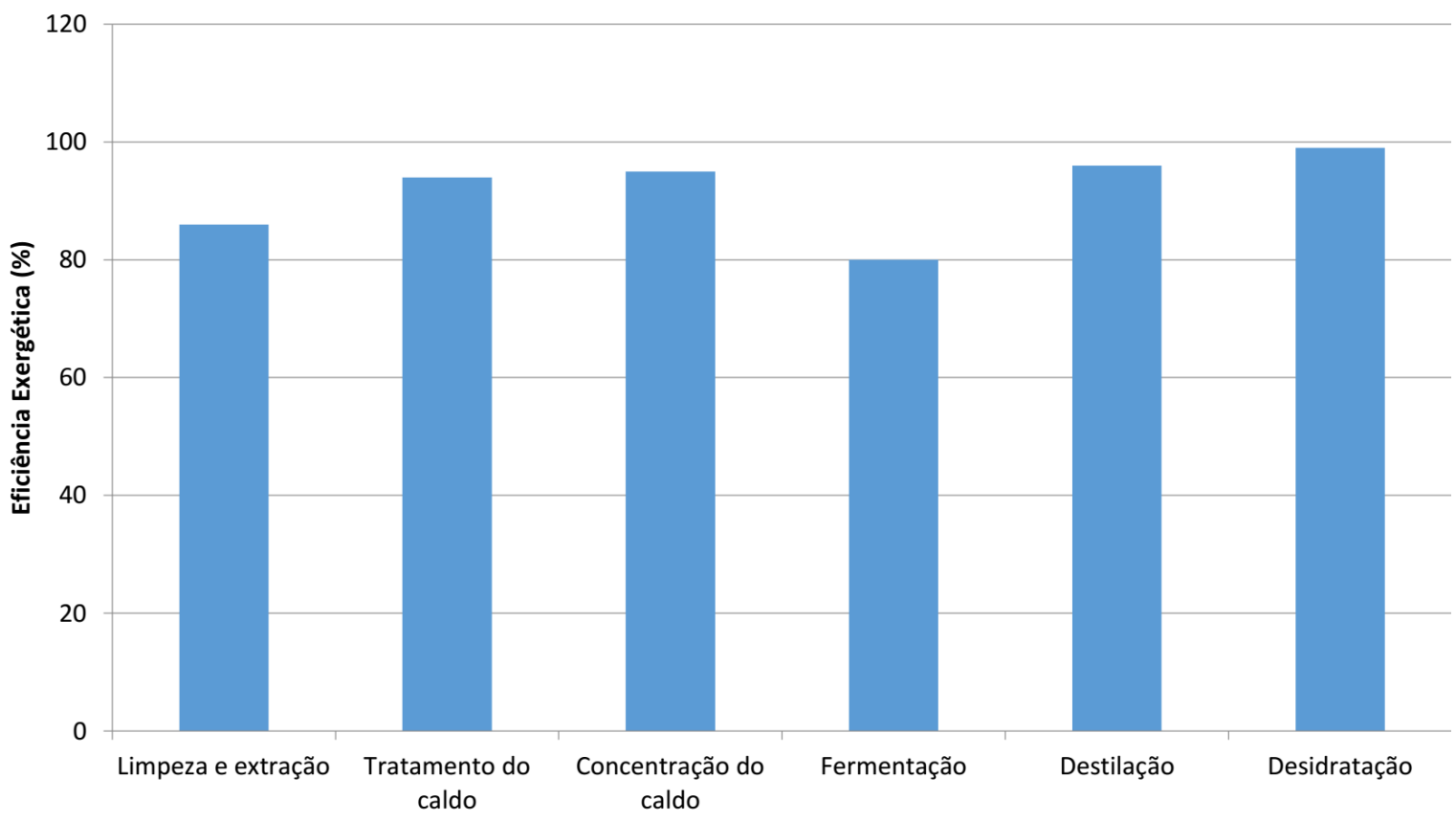

Fonte: Elaborado pelo autor. 
Figura 5.11 - Taxa de irreversibilidade da Rota 2.

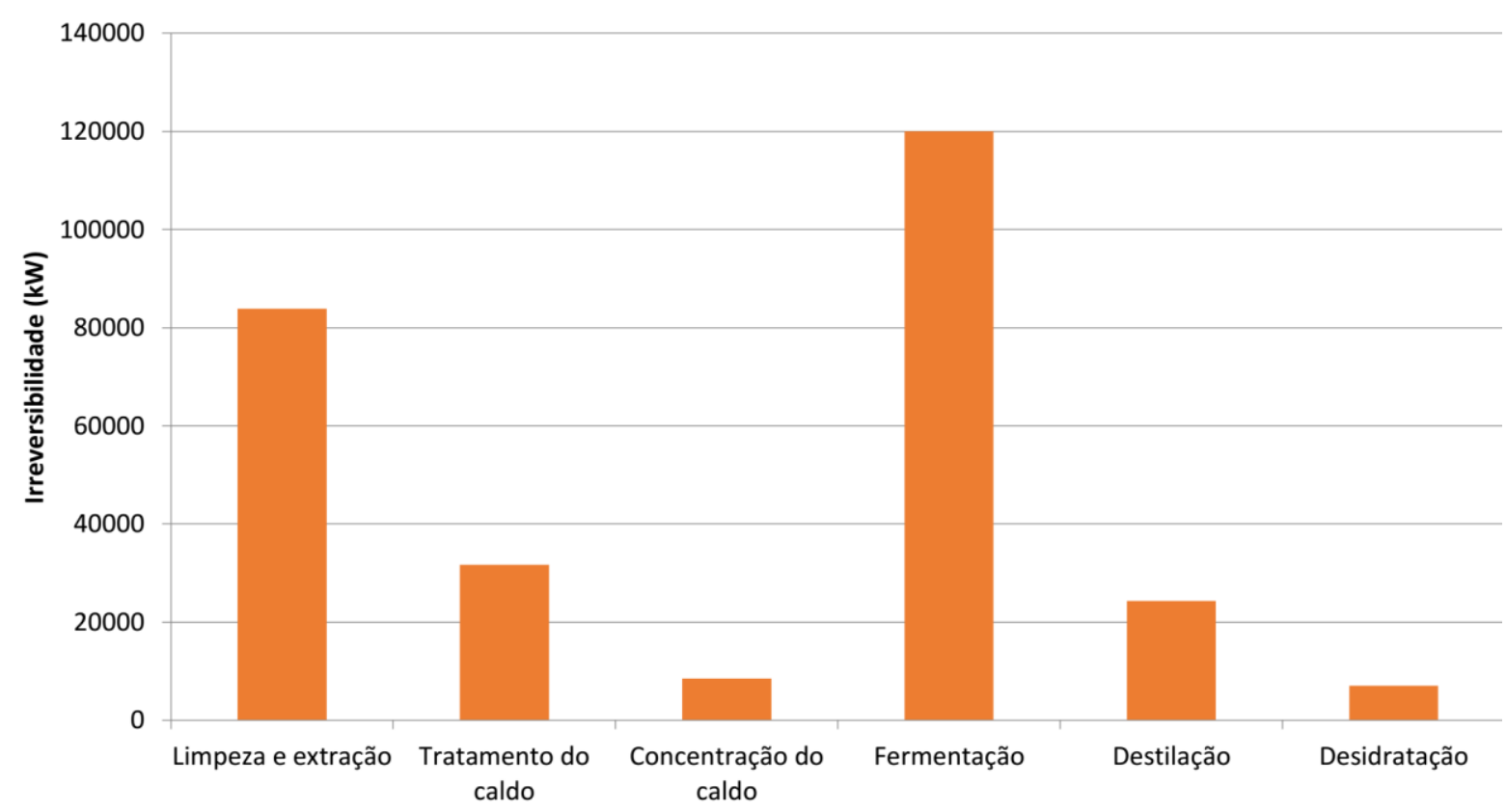

Fonte: Elaborado pelo autor.

Com relação às irreversibilidades gerada por litro de etanol produzido $[\mathrm{kWh} / \mathrm{l}] \mathrm{em}$ cada subsistema da rota 2, tém-se: Limpeza e extração 1,384, Tratamento do caldo 0,523, Concentração do caldo 0,140, Fermentação 1,980, Destilação 0,401 e Desidratação 0,116. Nota-se que a capacidade de moagem na planta quando considerado o uso da palha atinge 570 toneladas de biomassa por hora. 


\subsection{ANÁLISE EXERGÉTICA DA ROTA TERMOQUÍMICA DE ETANOL 2G}

Nesta seção são apresentados os aspectos relevantes e as considerações técnicas da modelagem do processo de gaseificação da biomassa envolvendo a rota termoquímica de etanol 2G (Rota 3) desta pesquisa. Para tal, são ilustradas as características desta rota para produção de bioetanol e geração de eletricidade por meio da gaseificação do bagaço e palha da cana-de-açúcar.

Deste modo, na Fig. 5.12 é mostrado um esquema simplificado para a simulação da rota de co-produção de etanol e eletricidade a partir da tecnologia de gaseificação do material lignocelulósico.

Figura 5.12 - Esquema geral da simulação para a rota tecnológica de 2G termoquímica.

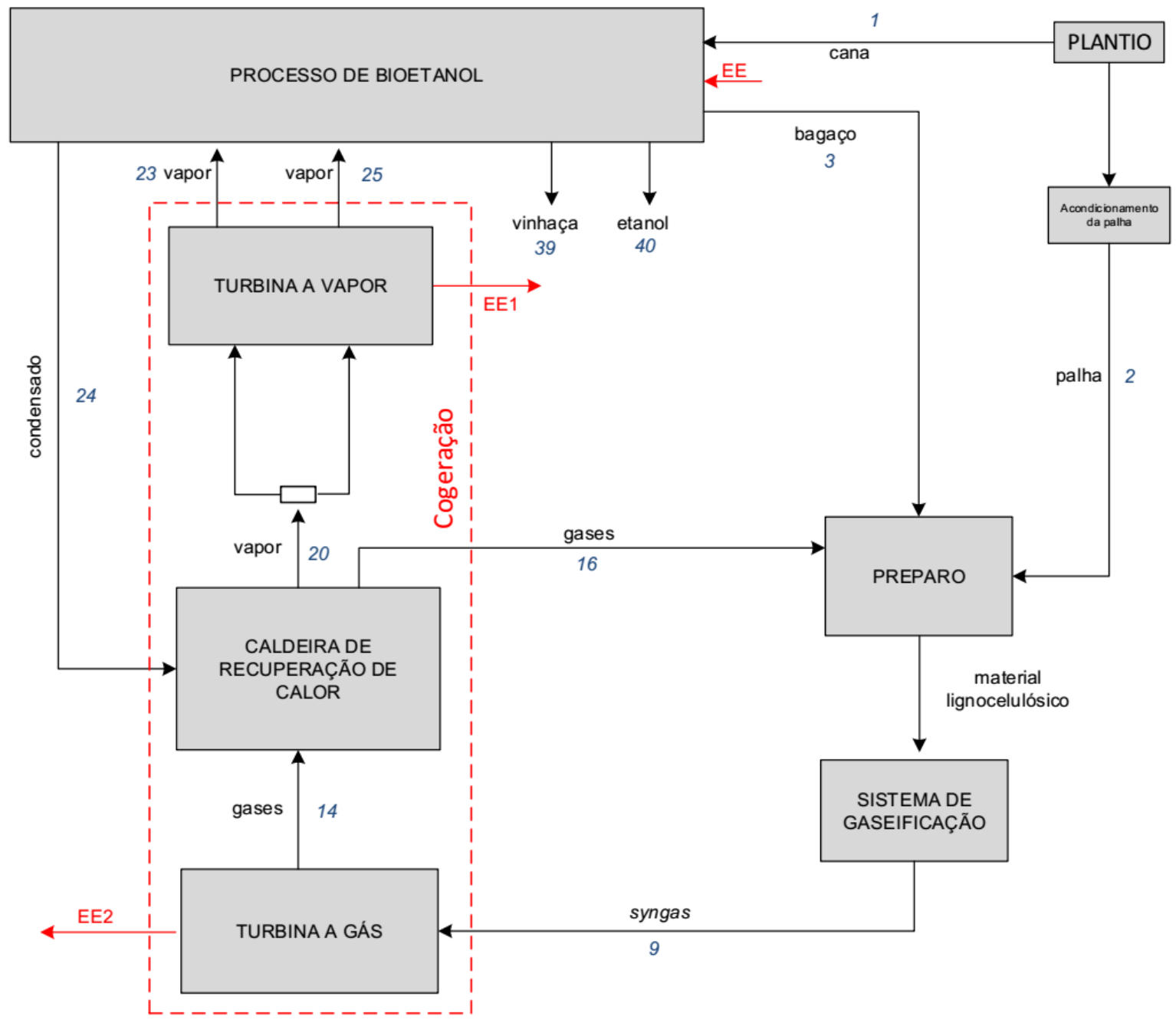

Fonte: Elaborado pelo autor. 
Com base nas considerações expostas no capítulo 4 referentes às etapas e reações químicas das tecnologias CFB e EF, foi construído o esquema geral visando integrar o sistema de gaseificação, a unidade de cogeração e o processo de produção de etanol.

Nesta seção serão apresentadas as principais características do ciclo combinado implementado e o sistema de limpeza do syngas da configuração proposta no simulador Aspen Plus ${ }^{\circledR}$ para avaliar a Rota 3.

Primeiramente, o material lignocelulósico foi preparado para atingir os requerimentos do processo da gaseificação. Merece destaque a incorporação da etapa de secagem adotada na análise quando empregada a mistura bagaço e palha na configuração CFB. Assim, a Fig. 5.13 apresenta o diagrama do sistema de secagem e limpeza deste sistema.

Figura 5.13 - Preparo da mistura bagaço e palha da cana-CFB.

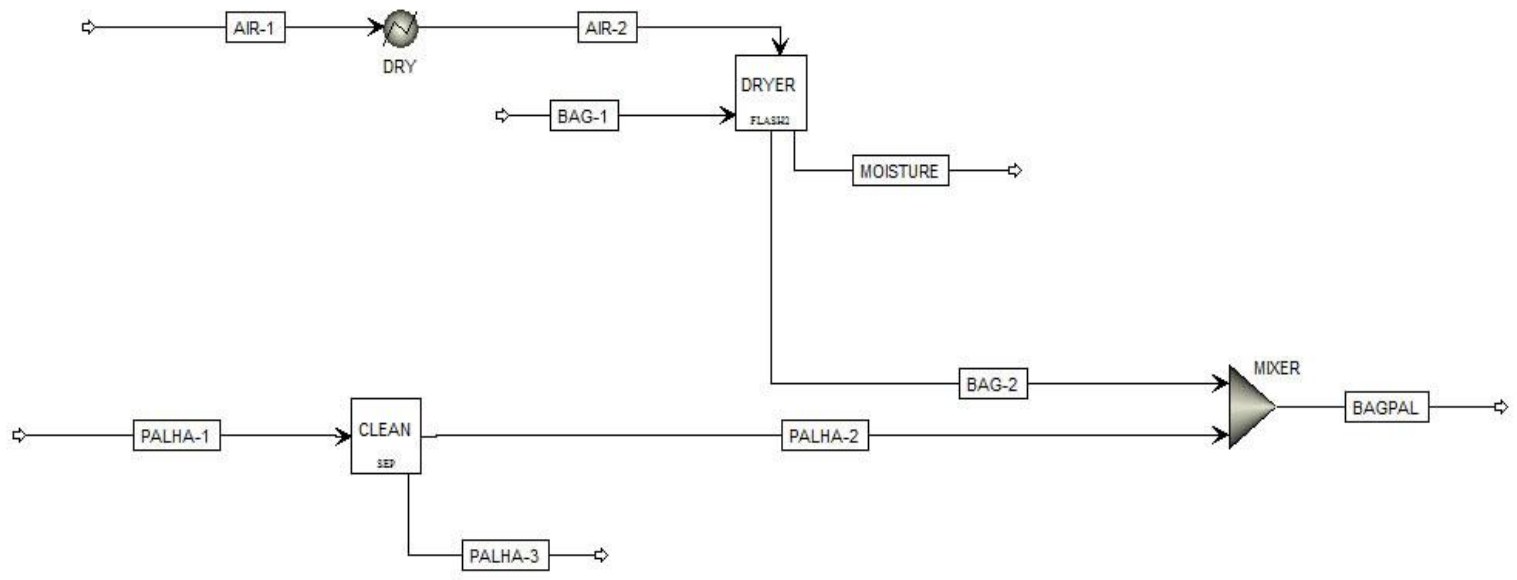

Fonte: Elaborado pelo autor.

O bloco separador "CLEAN" representa a limpeza e a diminuição de tamanho de partícula da palha, enquanto o bloco "MIXER" considera a mistura da palha e do bagaço. Na simulação considerou a palha contendo $15 \%$ de umidade e o bagaço com $50 \%$ de umidade. 
Na Fig. 5.14 apresenta-se o esquema simplificado do ciclo combinado (correspondente do bloco da planta de utilidades-cogeração). A análise foi conduzida sob as hipóteses de regime permanente; compressão isentrópica e sem considerar perdas na câmara de combustão. Além disso, como o objetivo de avaliar o impacto na geração de eletricidade foram adotados três diferentes estados de vapor vivo na entrada da turbina a vapor, sendo, $300{ }^{\circ} \mathrm{C}$ a $21 \mathrm{bar}, 480$ ${ }^{\circ} \mathrm{C}$ a 67 bar, e $510{ }^{\circ} \mathrm{C}$ a 81 bar, com eficiência isentrópica de 76\%, 83\% e 83\%; respectivamente.

Deste modo no ciclo Brayton, foi considerada uma razão de pressão de 16, temperatura de $550{ }^{\circ} \mathrm{C}$ e pressão de 1 bar na saída da turbina a gás. Já a pressão de condensação no ciclo a vapor foi estabelecida como sendo 0,1 bar e uma diferença mínima de temperatura de transferência de calor de $10{ }^{\circ} \mathrm{C}$, baseado na configuração proposta por Medeiros et al. (2014).

Figura 5.14 - Esquema geral do ciclo combinado.

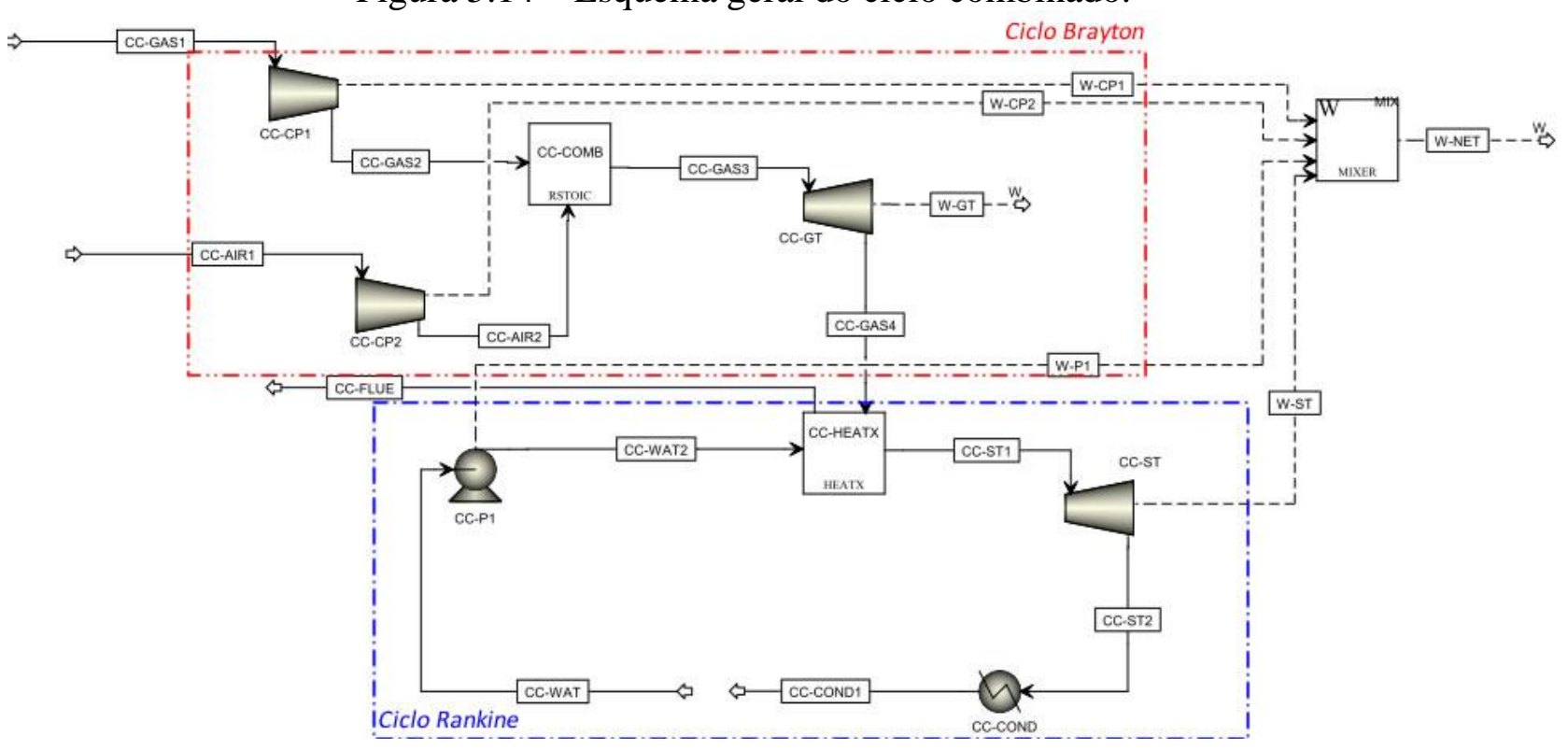

Fonte: Elaborado pelo autor.

Na Fig. 5.15 apresenta-se o diagrama simplificado do sistema de limpeza do syngas adotado no simulador Aspen Plus ${ }^{\circledR}$. A limpeza do gás obtido no gaseificador (CFB) envolve a separação de sólidos e alcatrão. Desta forma, o bloco SEP (separador) simula o ciclone que está sendo usado na separação de partículas sólidas dispersas de fase gasosa. Já o fluxo SOLIDS inclui os sólidos, sendo assim separados o char e as cinzas da corrente do gás produzido no processo de gaseificação (GAS). Por último, os blocos CON1 e CON2 representam a condensação do alcatrão. 
Figura 5.15 - Esquema geral do sistema de limpeza do gás de síntese.

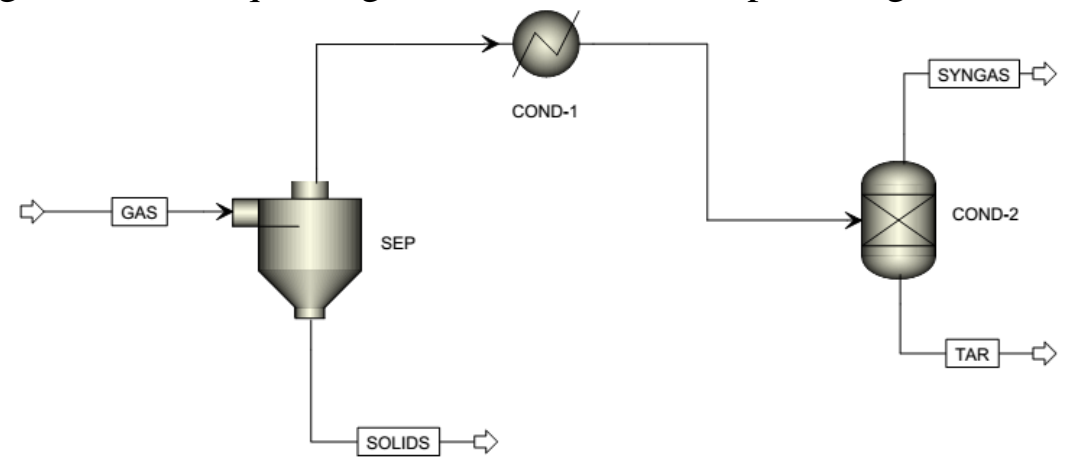

Fonte: Elaborado pelo autor. 


\subsection{RESULTADOS E DISCUSSÕES DA ROTA 3}

Inicialmente, são apresentados os resultados da simulação do gaseificador de leito fluidizado circulante (CFB). Na análise foram consideradas diferentes temperaturas de gaseificação e razões de equivalência (ER).

A composição do gás de síntese (\% vol. base seca) quando adotado o ar como agente oxidante foi $\mathrm{H}_{2}$ 15,7\%; $\mathrm{CO} 17,3 \%$; $\mathrm{CO}_{2} 13,9 \%$; $\mathrm{N}_{2} 49,6 \%$ e $\mathrm{CH}_{4}$ 2,3\%, conduzindo o processo à temperatura da gaseificação de $850^{\circ} \mathrm{C}$ e pressão de $101,325 \mathrm{kPa}$, como ilustrado na Fig. 5.16. O poder calorífico inferior (PCI) obtido nesta análise foi 7,10 MJ/kg.

Figura 5.16 - Composição do syngas em termos da temperatura de operação-CBF.
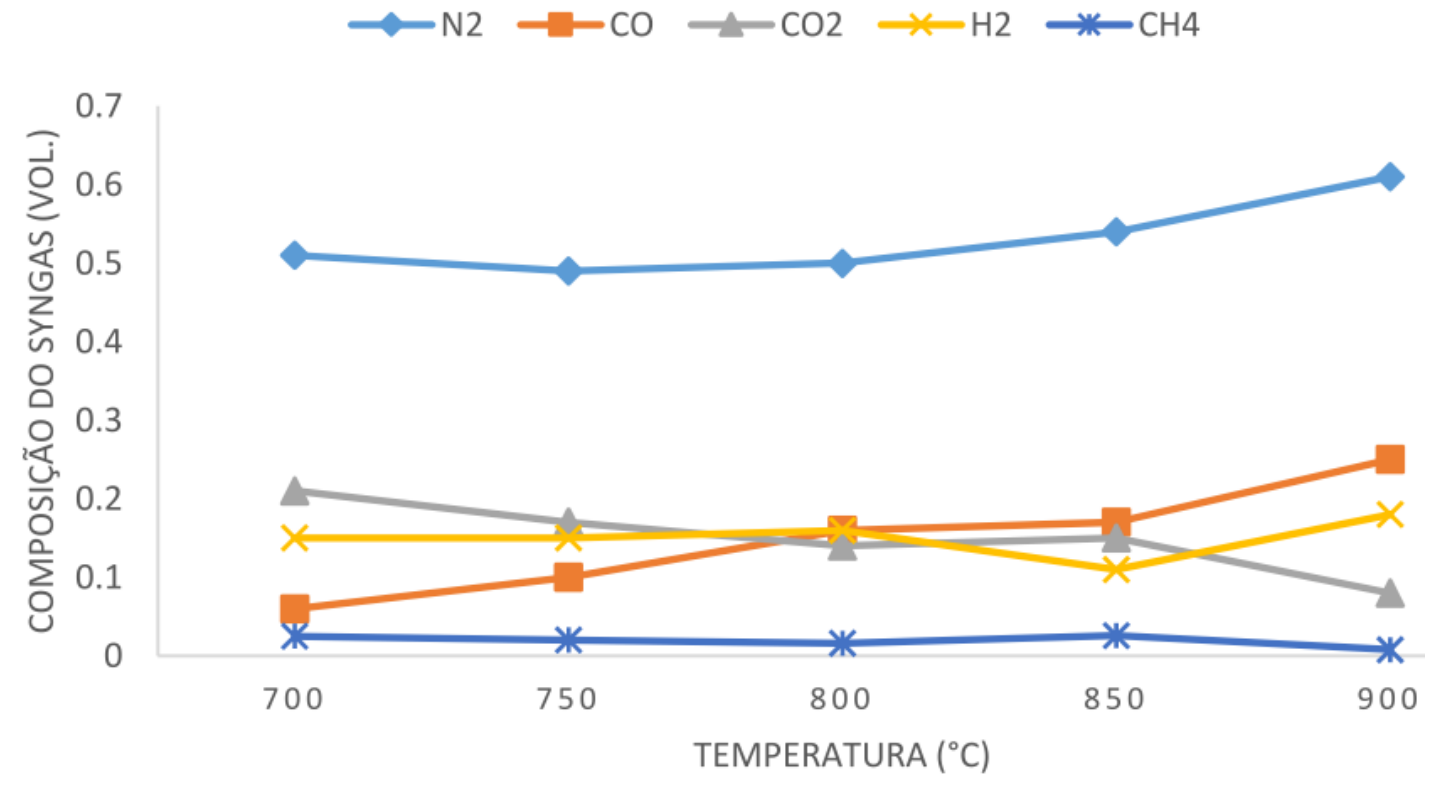

Fonte: Elaborado pelo autor.

Na Fig. 5.17 apresentam-se os efeitos da ER para alguns elementos envolvidos na composição do syngas. Destaca-se que o comportamento da temperatura de gaseificação varia proporcionalmente à razão de equivalência. 
Figura 5.17 - Composição do syngas em função da razão de equivalência -CFB.

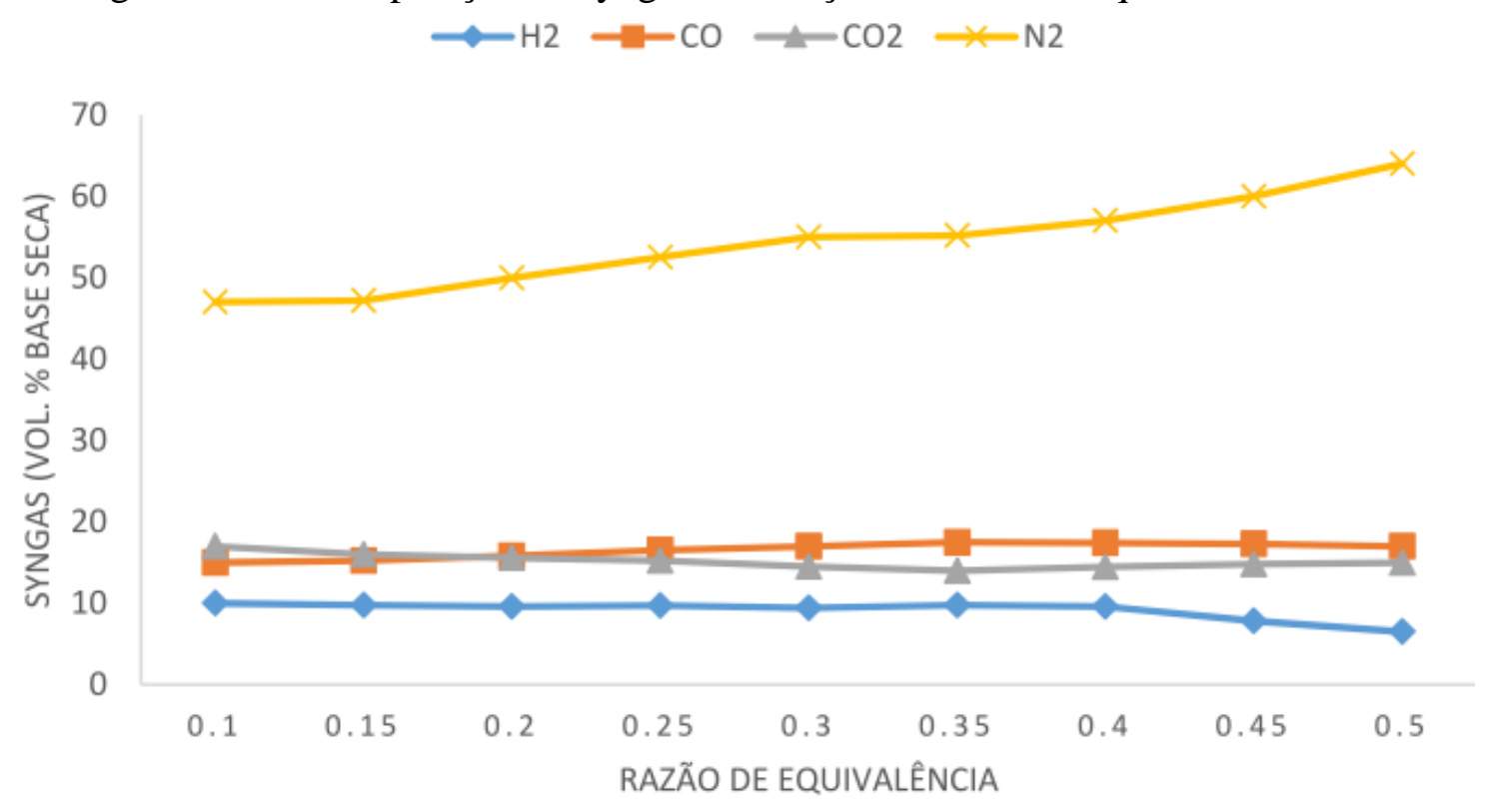

Fonte: Elaborado pelo autor.

Na Tab. 5.10 é ilustrada a composição em base seca do syngas obtido na gaseificação do bagaço da cana-de-açúcar configuração-CFB, adotando uma mistura de ar e vapor como agente gasificante.

Tabela 5.10 - Composição do gás sintético no processo CFB-Bagaço.

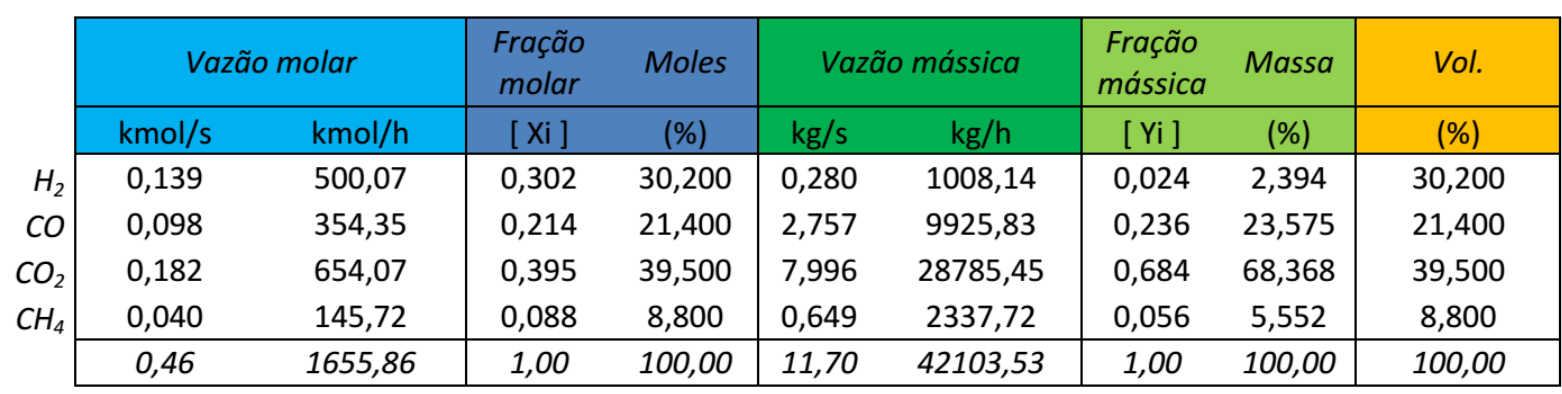

Fonte: Elaborado pelo autor.

Os resultados da simulação do sistema CFB foram validados com os modelos experimentais apresentados por Li et al. (2004) e Meng et al. (2011), os quais utilizaram biomassas lignocelulósicas como insumo energético. Assim, os valores obtidos usando misturas de ar e vapor são análogos aos dados reportados experimentalmente, em referência aos diferentes gases produzidos como $\mathrm{CO}, \mathrm{CO}_{2}$ e $\mathrm{H}_{2}$. 
Além disso, na Tab. 5.11 apresenta-se a composição em base seca do gás de sintése obtido na gaseificação da mistura bagaço/palha de cana na configuração-CFB, adotando SB de 0.8 e empregando ar e vapor como agentes oxidantes.

Tabela 5.11 - Composição do gás sintético no processo CFB-Mistura.

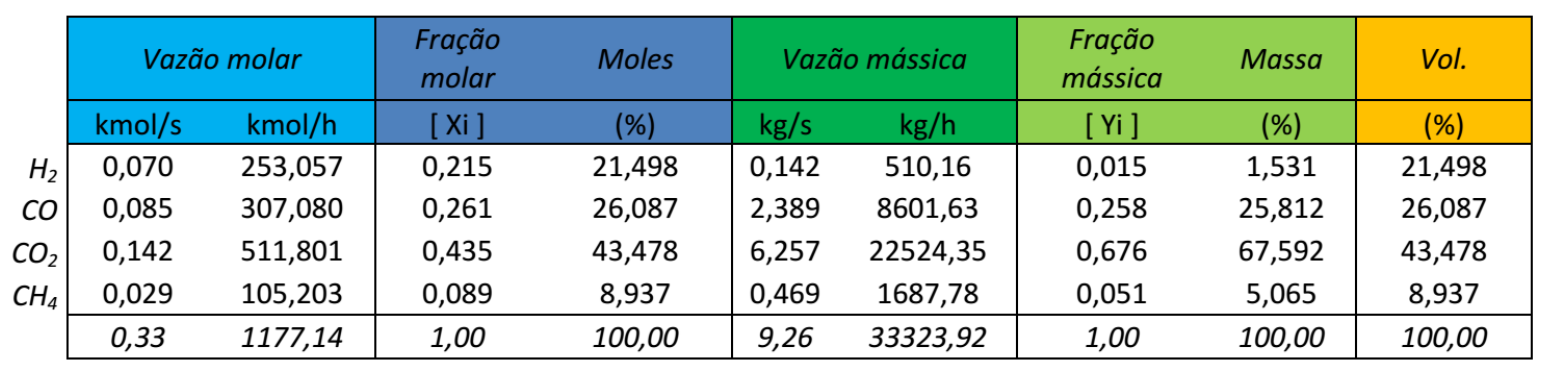

Fonte: Elaborado pelo autor.

A partir deste ponto, os resultados da simulação do gaseificador de tipo leito arrastado-EF modelados no programa Vali $^{\circledR}$ são apresentados. Inicialmente, na Fig. 5.18 ilustra-se a composição do syngas (base seca) em decorrência ao indicador SB quando considerado bagaço da cana como insumo.

Figura 5.18 - Composição do syngas no gaseificador EF-Bagaço.

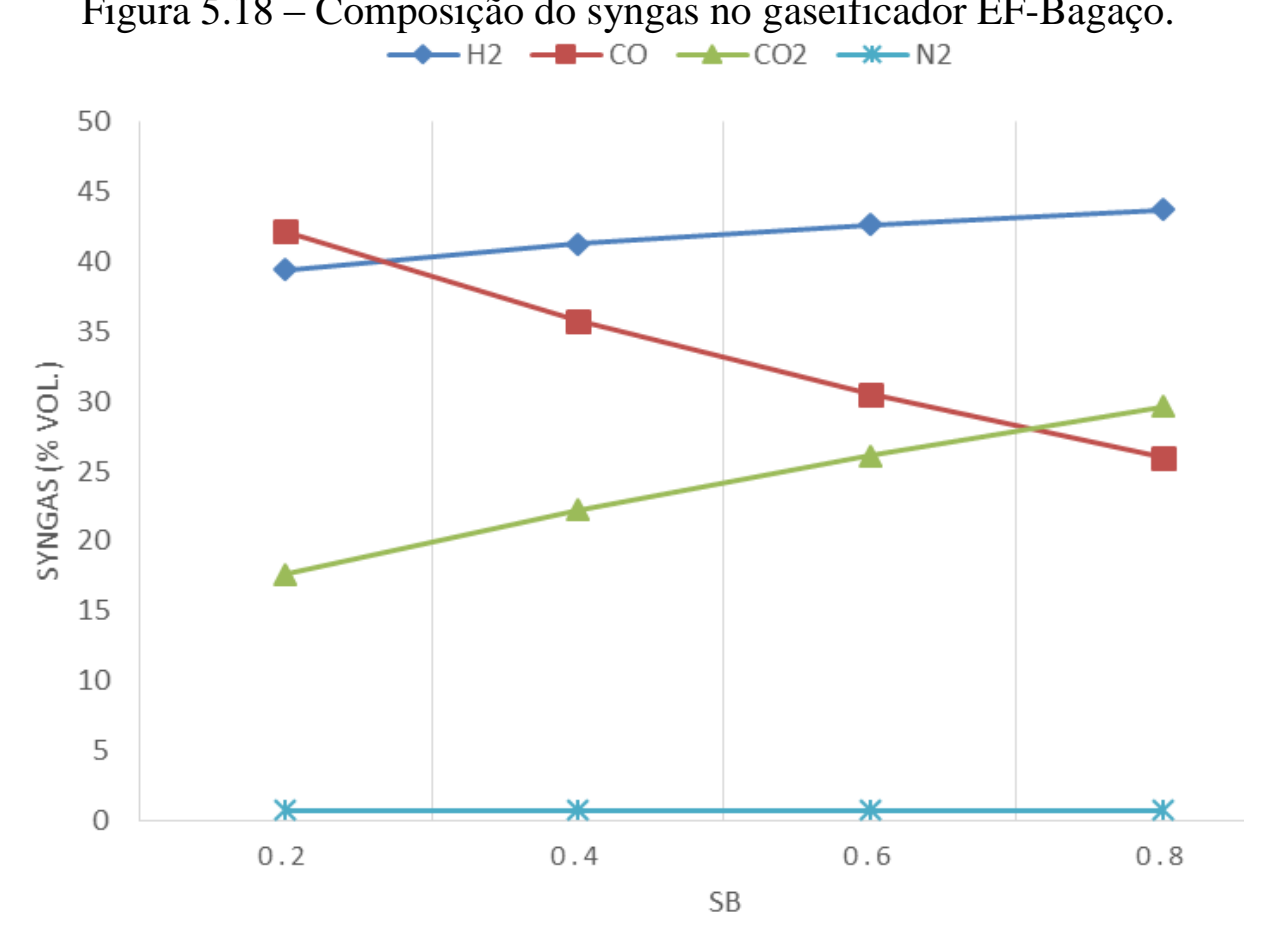

Fonte: Elaborado pelo autor. 
Desse modo, na Tab. 5.12 é apresentada a composição do gás sintético obtida na gaseificação da cana no processo de leito arrastado-EF, adotando SB de 0.8. Já o PCI obtido nesta análise foi $8,39 \mathrm{MJ} / \mathrm{kg}$.

Tabela 5.12 - Composição do gás sintético no processo EF-Bagaço.

\begin{tabular}{|c|c|c|c|c|c|c|c|c|c|}
\hline \multicolumn{2}{|c|}{ Vazão molar } & \multirow{2}{*}{$\begin{array}{c}\begin{array}{c}\text { Fração } \\
\text { molar }\end{array} \\
\mathrm{Xi}] \\
\end{array}$} & \multirow{2}{*}{$\begin{array}{c}\text { Moles } \\
(\%)\end{array}$} & \multicolumn{2}{|c|}{ Vazão mássica } & \multirow{2}{*}{$\begin{array}{c}\begin{array}{c}\text { Fração } \\
\text { mássica }\end{array} \\
{[\mathrm{Yi}]}\end{array}$} & \multirow{2}{*}{$\frac{\text { Massa }}{(\%)}$} & \multirow{2}{*}{$\begin{array}{c}\begin{array}{c}\text { Vazão } \\
\text { Volumétrica }\end{array} \\
\mathrm{m}^{3} / \mathrm{h}\end{array}$} & \multirow{2}{*}{$\begin{array}{l}\text { Vol. } \\
(\%)\end{array}$} \\
\hline $\mathrm{kmol} / \mathrm{s}$ & $\mathrm{kmol} / \mathrm{h}$ & & & $\mathrm{kg} / \mathrm{s}$ & $\mathrm{kg} / \mathrm{h}$ & & & & \\
\hline 0,442 & 1592,568 & 0,437 & 43,716 & 0,892 & 3210,617 & 0,041 & 4,121 & 37728,598 & 43,716 \\
\hline 0,263 & 946,019 & 0,260 & 25,968 & 7,361 & 26498,365 & 0,340 & 34,010 & 22411,579 & 25,968 \\
\hline 0,300 & 1079,485 & 0,296 & 29,632 & 13,197 & 47507,922 & 0,610 & 60,974 & 25573,453 & 29,632 \\
\hline 0,007 & 24,905 & 0,007 & 0,684 & 0,194 & 697,673 & 0,009 & 0,895 & 590,005 & 0,684 \\
\hline 1,01 & 3642,98 & 1,00 & 100,00 & 21,64 & 77914,58 & 1,00 & 100,00 & 86303,63 & 100,00 \\
\hline
\end{tabular}

Fonte: Elaborado pelo autor.

Posteriormente, na Fig. 5.19 apresenta-se a composição do syngas (base seca) em decorrência ao indicador SB para a mistura de bagaço e palha da cana considerada como insumo.

Figura 5.19 - Composição do syngas no gaseificador EF-Mistura.

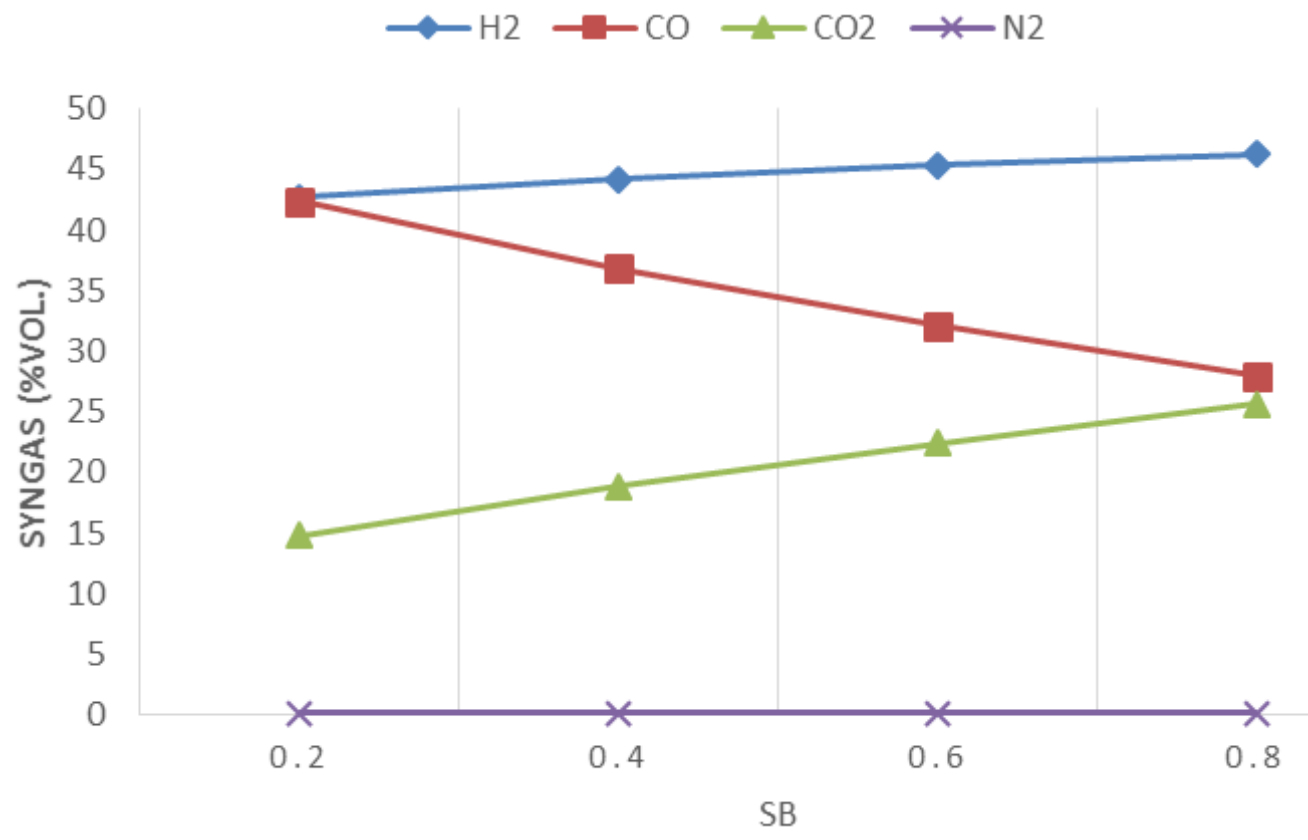

Fonte: Elaborado pelo autor.

Além disso, a composição do syngas obtido na gaseificação da mistura cana e palha no processo de leito arrastado-EF, adotando SB de 0.8 é reportada na Tab. 5.13. O PCI obtido nesta análise foi $9,52 \mathrm{MJ} / \mathrm{kg}$. 
Tabela 5.13 - Composição do gás sintético no processo EF-Mistura.

\begin{tabular}{|c|c|c|c|c|c|c|c|c|c|}
\hline \multicolumn{2}{|c|}{ Vazão molar } & \multirow{2}{*}{$\begin{array}{c}\begin{array}{c}\text { Fração } \\
\text { molar }\end{array} \\
\text { Xi ] }\end{array}$} & \multirow{2}{*}{$\begin{array}{c}\text { Moles } \\
(\%)\end{array}$} & \multicolumn{2}{|c|}{ Vazão mássica } & \multirow{2}{*}{$\begin{array}{c}\begin{array}{c}\text { Fração } \\
\text { mássica }\end{array} \\
{\left[\mathrm{Yi}_{\mathrm{i}}\right]} \\
\end{array}$} & \multirow{2}{*}{$\begin{array}{c}\text { Massa } \\
(\%)\end{array}$} & \multirow{2}{*}{$\begin{array}{c}\begin{array}{c}\text { Vazão } \\
\text { Volumétrica }\end{array} \\
\mathrm{m}^{3} / \mathrm{h} \\
\end{array}$} & \multirow{2}{*}{$\begin{array}{l}\text { Vol. } \\
(\%) \\
\end{array}$} \\
\hline $\mathrm{kmol} / \mathrm{s}$ & $\mathrm{kmol} / \mathrm{h}$ & & & $\mathrm{kg} / \mathrm{s}$ & $\mathrm{kg} / \mathrm{h}$ & & & & \\
\hline 0,531 & 1910,498 & 0,463 & 46,289 & 1,070 & 3851,564 & 0,046 & 4,648 & 45260,501 & 46,289 \\
\hline 0,321 & 1154,984 & 0,280 & 27,984 & 8,987 & 32351,573 & 0,390 & 39,045 & 27362,061 & 27,984 \\
\hline 0,294 & 1056,989 & 0,256 & 25,610 & 12,922 & 46517,861 & 0,561 & 56,142 & 25040,504 & 25,610 \\
\hline 0,001 & 4,856 & 0,001 & 0,118 & 0,038 & 136,069 & 0,002 & 0,164 & 115,050 & 0,118 \\
\hline 1,15 & 4127,33 & 1,00 & 100,00 & 23,02 & 82857,07 & 1,00 & 100,00 & 97778,12 & 100,00 \\
\hline
\end{tabular}

Fonte: Elaborado pelo autor.

As Fig. 5.20 e Fig. 5.21 apresentam os resultados obtidos na gaseificação do bagaço da cana em termos da eficiência exergética e as irreversibilidades do processo gaseificação de leito arrastado, respectivamente. Conclui-se que as maiores perdas de exergia ocorrem no sistema de gaseificação da biomassa.

Figura 5.20 - Eficiência exergética do gaseificador EF-Bagaço.

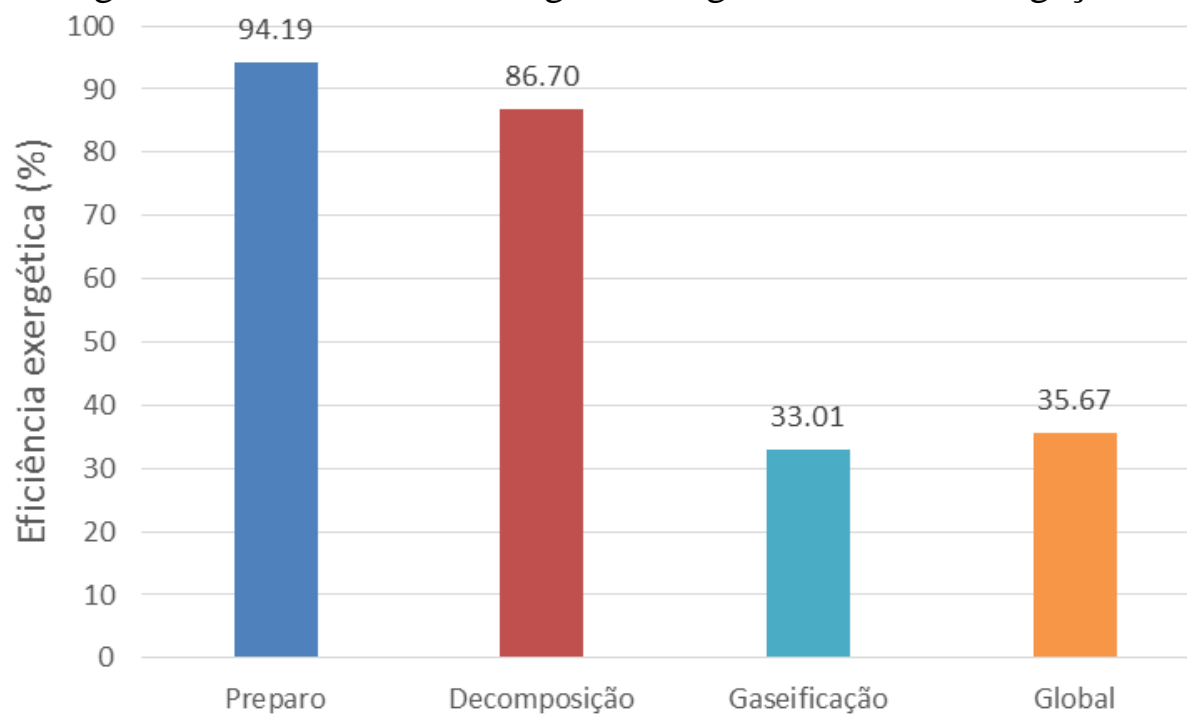

Fonte: Elaborado pelo autor. 
Figura 5.21 - Irreversibilidades do processo de gaseificação EF-Bagaço.

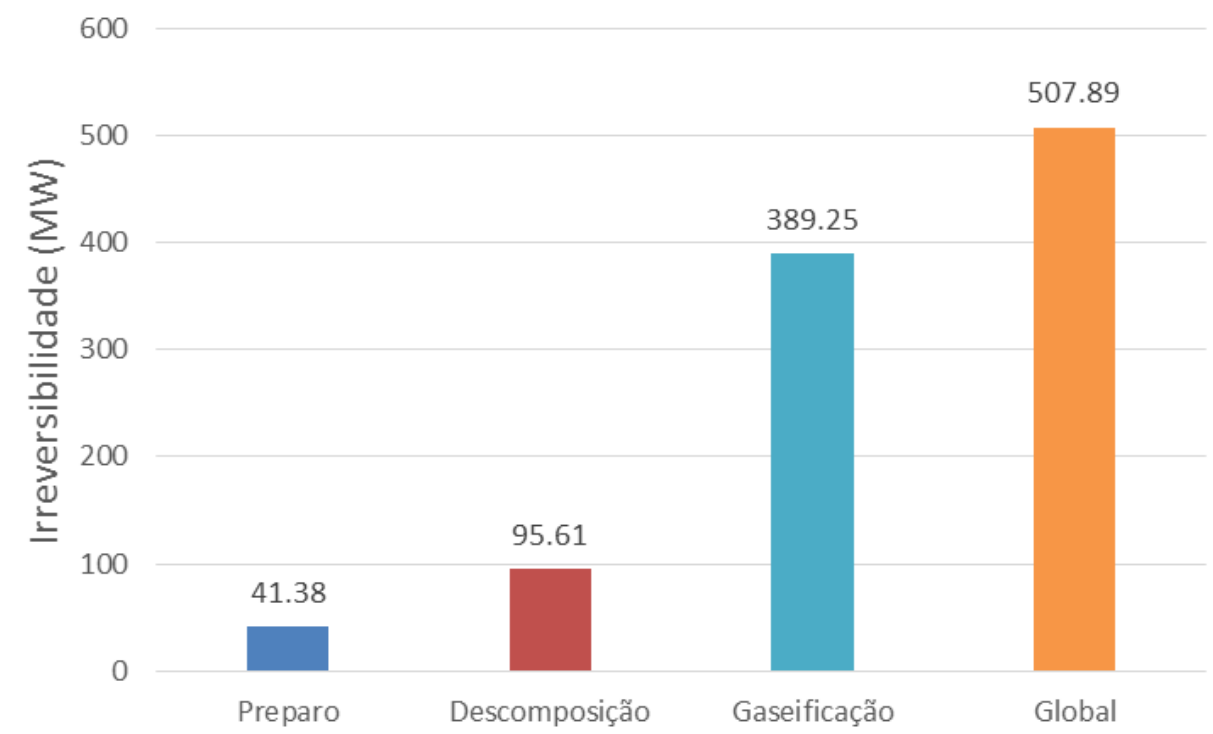

Fonte: Elaborado pelo autor.

As Fig. 5.22 e Fig. 5.23 apresentam os resultados obtidos em termos da eficiência exergética e as irreversibilidades do processo gaseificação de leito arrastado, quando empregada a palha da cana como combustível.

Figura 5.22 - Eficiência exergética do gaseificador EF-Palha.

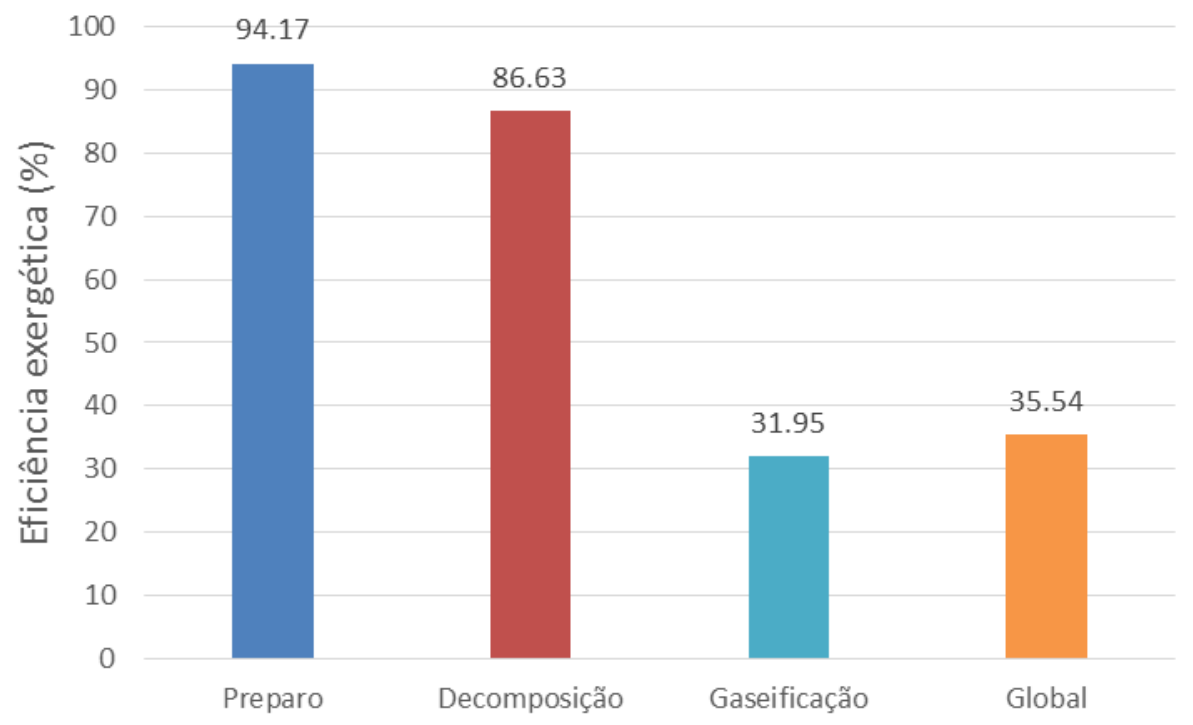

Fonte: Elaborado pelo autor. 
Figura 5.23 - Irreversibilidades do processo de gaseificação EF-Palha.

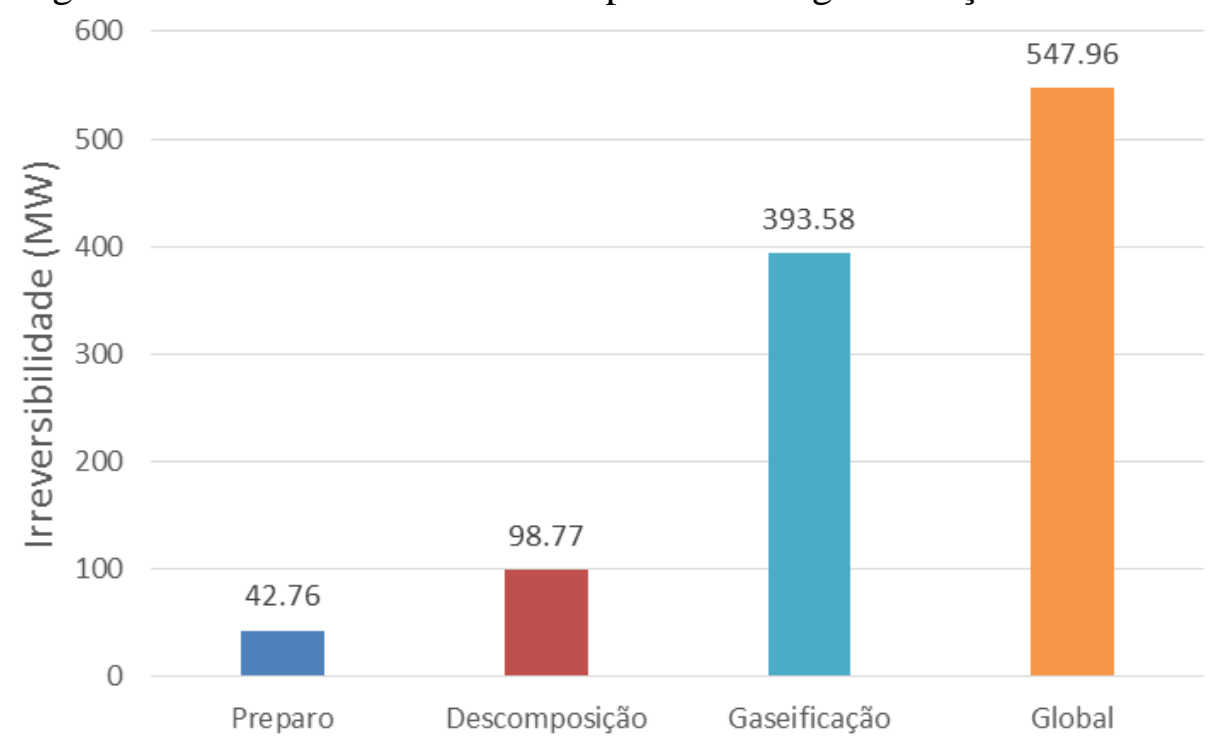

Fonte: Elaborado pelo autor.

Deste ponto em diante, os resultados da simulação do ciclo combinado são apresentados. Cabe salientar que uma análise de sensibilidade foi conduzida adotando diferentes condições de vapor vivo na entrada da turbina a vapor, $300{ }^{\circ} \mathrm{C} \mathrm{a} 21 \mathrm{bar}, 480^{\circ} \mathrm{C}$ a $67 \mathrm{bar}$, e $510^{\circ} \mathrm{C} \mathrm{a} 81$ bar. O combustível considerado neste sistema foi o gás de síntese obtido nos processos de gaseificação CFB e EF da biomassa (bagaço e palha da cana).

Na Tab. 5.14 e Tab. 5.15 ilustram-se os resultados em termos da eficiência exergética e rendimento térmico do ciclo combinado para as diferentes condições de vapor avaliadas.

Tabela 5.14 - Análise do ciclo combinado operando com syngas-Processo CFB.

\begin{tabular}{|c|c|c|c|c|c|}
\hline Vapor vivo & $\begin{array}{l}\text { Temperatura [C] } \\
\text { Pressão [bar] }\end{array}$ & $\begin{array}{l}510 \\
81 \\
\end{array}$ & & $\begin{array}{l}480 \\
67 \\
\end{array}$ & $\begin{array}{l}300 \\
21 \\
\end{array}$ \\
\hline \multirow{3}{*}{ BAGAÇO } & \multirow[t]{2}{*}{ Rendimento [\%] } & \begin{tabular}{|l} 
Brayton \\
Rankine
\end{tabular} & $\begin{array}{l}33.91 \\
31.26 \\
\end{array}$ & $\begin{array}{l}33.91 \\
30.37 \\
\end{array}$ & $\begin{array}{l}33.91 \\
24.78 \\
\end{array}$ \\
\hline & & Planta & 50.71 & 50.23 & 47.22 \\
\hline & Eficiência Exergética [\%] & & 49.78 & 49.31 & 46.36 \\
\hline \multirow{4}{*}{$\begin{array}{c}\text { BAGAÇO } \\
+ \\
\text { PALHA }\end{array}$} & \multirow{4}{*}{ Rendimento [\%] } & Brayton & 33.81 & 33.81 & 33.81 \\
\hline & & \begin{tabular}{|l} 
Rankıne \\
Planta
\end{tabular} & 50.68 & 50.50 & $\begin{array}{l}24.18 \\
47.18\end{array}$ \\
\hline & & & & & \\
\hline & & & 49.47 & 49.00 & 46.05 \\
\hline
\end{tabular}

Fonte: Elaborado pelo autor. 
Tabela 5.15 -Análise do ciclo combinado operando com syngas-Processo EF.

\begin{tabular}{|c|c|c|c|c|c|}
\hline Vapor vivo & $\begin{array}{l}\text { Temperatura [C] } \\
\text { Pressäo [bar] }\end{array}$ & $\begin{array}{l}510 \\
81\end{array}$ & & $\begin{array}{l}480 \\
67 \\
\end{array}$ & $\begin{array}{l}300 \\
21\end{array}$ \\
\hline \multirow{3}{*}{ BAGAÇO } & \multirow[t]{2}{*}{ Rendimento [\%] } & $\begin{array}{l}\text { Brayton } \\
\text { Rankine }\end{array}$ & $\begin{array}{l}33.50 \\
31.28 \\
\end{array}$ & $\begin{array}{l}33.50 \\
30.39 \\
\end{array}$ & $\begin{array}{l}33.50 \\
24.78 \\
\end{array}$ \\
\hline & & Planta & 50.38 & 49.87 & 46.83 \\
\hline & Eficiência Exergética [\%] & & 50.78 & 50.27 & 47.20 \\
\hline \multirow{4}{*}{$\begin{array}{c}\text { BAGAÇO } \\
+ \\
\text { PALHA }\end{array}$} & \multirow[t]{3}{*}{ Rendimento [\%] } & $\begin{array}{l}\text { Brayton } \\
\text { Rankine }\end{array}$ & $\begin{array}{l}33.59 \\
31.29\end{array}$ & $\begin{array}{l}33.59 \\
30.39\end{array}$ & $\begin{array}{l}33.59 \\
24.78\end{array}$ \\
\hline & & Planta & 50.43 & 49.90 & 40.94 \\
\hline & & & & & \\
\hline & Eficiência Exergética [\%] & & 51.08 & 50.54 & 47.52 \\
\hline
\end{tabular}

Fonte: Elaborado pelo autor.

Nota-se que a partir dos resultados para as condições de $480{ }^{\circ} \mathrm{C}$ a 67 bar e $510^{\circ} \mathrm{C}$ a 81 bar, o rendimento global da planta e a eficiência exergética apresentaram comportamentos similares, sendo por esta razão adotada na análise do sistema de cogeração o conjunto de $480{ }^{\circ} \mathrm{C}$ a 67 bar como parâmetro de avaliação do vapor vivo, conforme foi ilustrado no cap. 4 .

Por fim, na Tab. 5.17 são ilustrados os parâmetros de operação considerados na análise exergética global da Rota Termoquímica. Destaca-se que o modelo desenvolvido no simulador Aspen Plus ${ }^{\circledR}$ foi apresentado na Fig. 4.11, enquanto o layout da planta considerada nesta análise foi ilustrado na Fig. 5.12. 
Tabela 5.16 -Resultados da análise exergética da Rota 3.

\begin{tabular}{|c|c|c|c|c|c|c|c|c|c|}
\hline Fluxo & $m(k g / s)$ & $P($ bar $)$ & $T\left({ }^{\circ} \mathrm{C}\right)$ & $\begin{array}{l}\text { Btot } \\
(k W)\end{array}$ & Fluxo & $m(\mathrm{~kg} / \mathrm{s})$ & $P($ bar $)$ & $T\left({ }^{\circ} \mathrm{C}\right)$ & $\begin{array}{c}\text { Btot } \\
(k W)\end{array}$ \\
\hline 1 & 138,9 & 1,013 & 25 & 784924 & 21 & 51,8 & 0,1 & 45,8 & 2957 \\
\hline 2 & 19,44 & 1,013 & 25 & 306180 & 22 & 51,8 & 2,45 & 45,8 & 2974 \\
\hline 3 & 43,2 & 1,013 & 30 & 446072 & 23 & 48,1 & 2,5 & 140 & 59092 \\
\hline 4 & 140,4 & 1,013 & 30 & 353808 & 24 & 45,8 & 2,5 & 125 & 74158 \\
\hline 5 & 73,2 & 2 & 850 & 393605 & 25 & 2,1 & 1,2 & 140 & 62775 \\
\hline 6 & 73,2 & 2 & 350 & 281014 & 26 & 27,9 & 0,07 & 39 & 4163 \\
\hline 7 & 73,2 & 2 & 50 & 243357 & 27 & 27,9 & 0,07 & 34 & 1412 \\
\hline 8 & 110,4 & 1,013 & 35 & 5542 & 28 & 27,9 & 2,45 & 34 & 1420 \\
\hline 9 & 110,4 & 15,7 & 450 & 5840 & 29 & 50 & 2,45 & 160 & 34335 \\
\hline 10 & 73,2 & 15 & 431 & 315346 & 30 & 35,9 & 2,45 & 160 & 246523 \\
\hline 11 & 433,4 & 1,013 & 25 & 2384 & 31 & 128 & 2,45 & 154 & 87424 \\
\hline 12 & 433,4 & 15,7 & 376 & 147832 & 32 & 130 & 2,45 & 135 & 87282 \\
\hline 13 & 502,6 & 15,4 & 945 & 412271 & 33 & 130 & 2,45 & 122 & 13650 \\
\hline 14 & 502,6 & 1,2 & 442 & 128778 & 34 & 25,9 & 2,45 & 34 & 1319 \\
\hline 15 & 502,6 & 1,2 & 270 & 57955 & 35 & 155,9 & 2,45 & 107 & 14187 \\
\hline 16 & 502,6 & 1,1 & 190 & 45036 & 36 & 211,6 & 2,45 & 91,2 & 16378 \\
\hline 17 & 51,8 & 45,3 & 250 & 17309 & 37 & 14,1 & 2,45 & 160 & 9683 \\
\hline 18 & 120 & 45,3 & 258 & 39024 & 38 & 41,2 & 1,013 & 50 & 2229 \\
\hline 19 & 51,8 & 45,3 & 258 & 59092 & 39 & 110,6 & 1,013 & 89 & 31677 \\
\hline 20 & 51,8 & 67 & 480 & 74158 & 40 & 6,30 & 1,013 & 35 & 186669 \\
\hline \multicolumn{9}{|c|}{ Eletricidade Excedente } & 122539 \\
\hline
\end{tabular}

Fonte: Elaborado pelo autor. 


\section{HIERARQUIZAÇÃO DAS ROTAS TECNOLÓGICAS AVALIADAS}

Inicialmente, são apresentadas as metas de consumo mínimo de utilidades ou máxima recuperação de energia (MER), adotadas na integração energética de cada rota tecnológica. Posteriormente, os resultados obtidos na integração dos processos e a avaliação global das configurações de biorrefinaria serão discutidos em termos da produção de etanol, geração de eletricidade, impacto ambiental e eficiência exergética a fim de obter a sua hierarquização utilizando a exergia como indicador de qualidade de conversão dos processos.

\subsection{INTEGRAÇÃO DOS PROCESSOS NAS CONFIGURAÇÕES DE BIORREFINARIA}

A integração de processos das configurações propostas para produção de etanol e geração de energia elétrica a partir da cana-de-açúcar é apresentada a seguir. Desse modo, a integração energética da rota convencional utilizando o método Pinch depende fortemente dos parâmetros adotados no processo de simulação e fluxos considerados na análise. Por exemplo, a redução do consumo de vapor após a integração varia consideravelmente em termos dessas hipóteses. Nota-se por exemplo, que usando tecnologias semelhantes para produzir etanol em uma destilaria autônoma, Dias et al. (2009) encontrou uma redução no consumo de vapor de $31 \%$ maior do que a encontrada no presente estudo.

Fig. 6.1 (a) e (b) ilustra a análise Pinch na produção de etanol e eletricidade da Rota 1 a partir dos diagramas da Curva Composta e da Grande Curva Composta. Destaca-se que a faixa de temperatura entre $80^{\circ} \mathrm{C}$ e $105^{\circ} \mathrm{C}$ (zona do ponto pinch) compreende fluxos considerados no evaporador de efeito simples usado para concentrar o mosto na etapa da fermentação. 
Figura 6.1 - MER - Rota 1.

Composite Curve for Periode 1 and Time 1

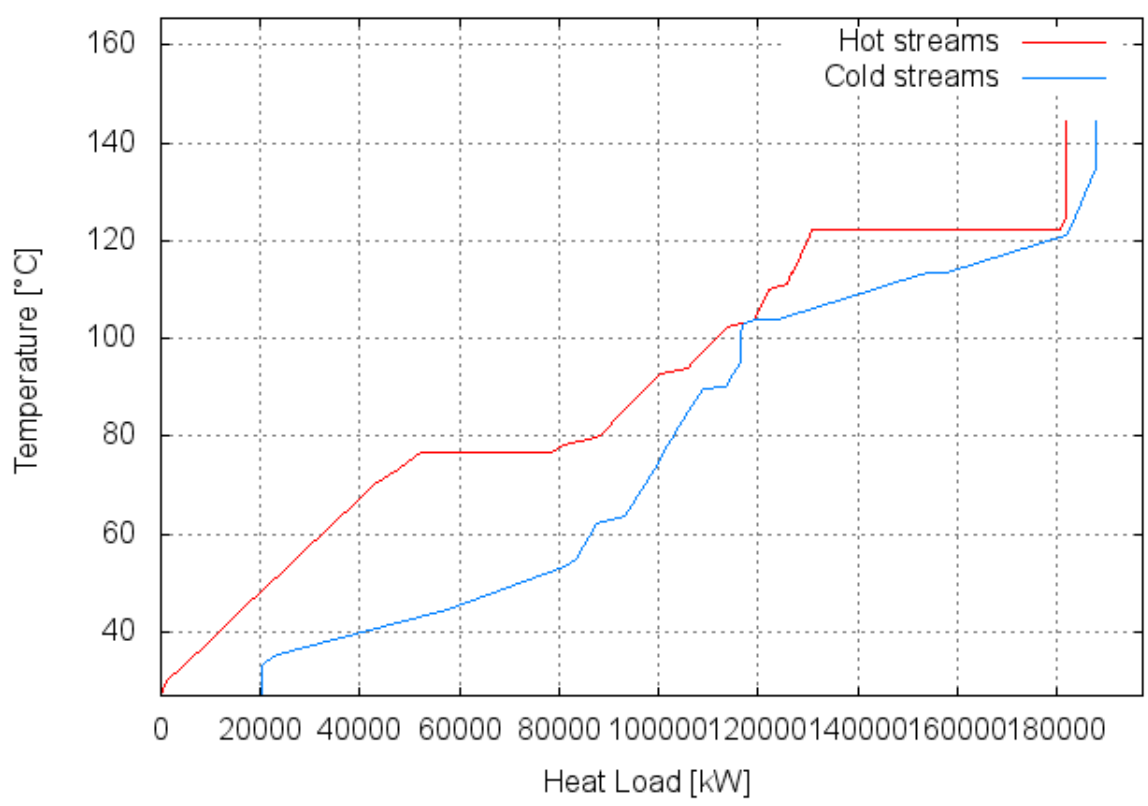

(a) Curva Composta

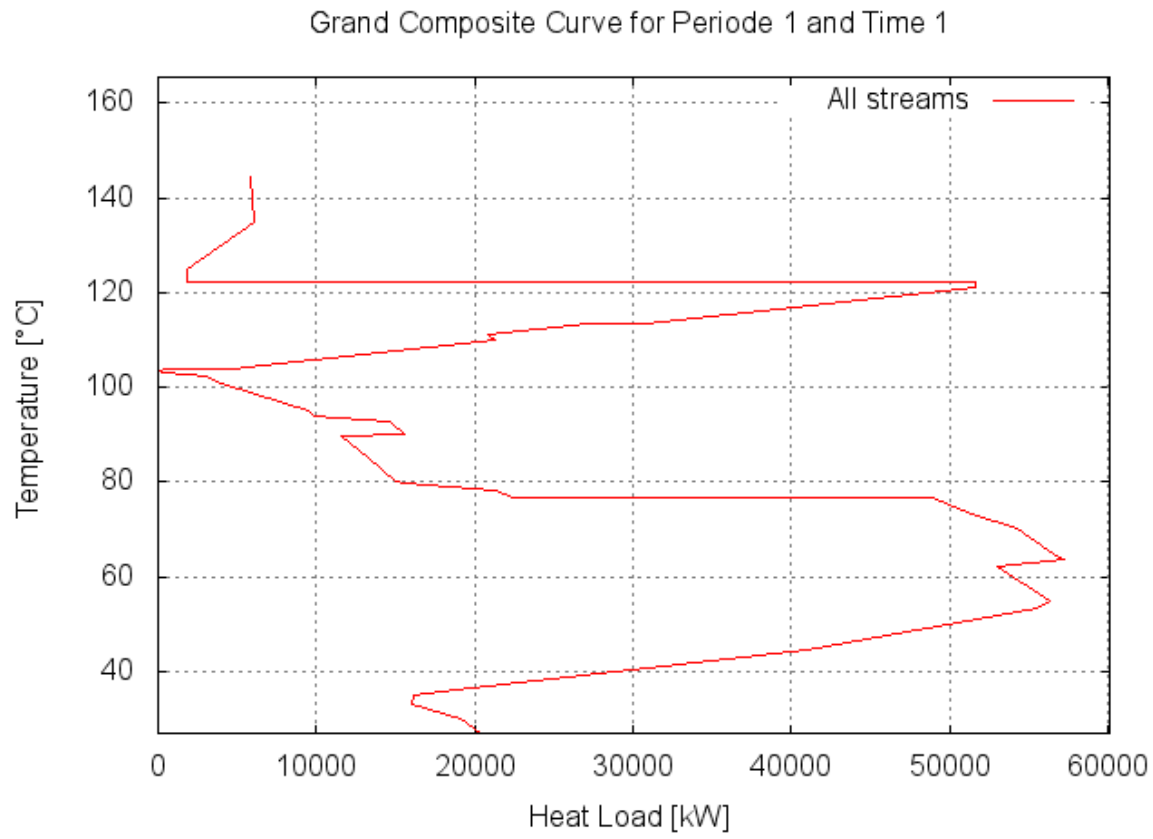

(b) Grande Curva Composta

Fonte: Elaborado pelo autor. 
Na plataforma bioquímica, a produção de etanol $2 \mathrm{G}$ a partir do bagaço da cana é integrada à destilaria autônoma, considerando o pré-tratamento de explosão a vapor e hidrólise enzimática, usando o bagaço excedente disponível após a integração térmica do processo. Nesse contexto, os diagramas da Curva Composta e da Grande Curva Composta para a Rota 2 são apresentados na Fig. 6.2 (a) e (b), respectivamente.

Figura 6.2 - MER - Rota 2.

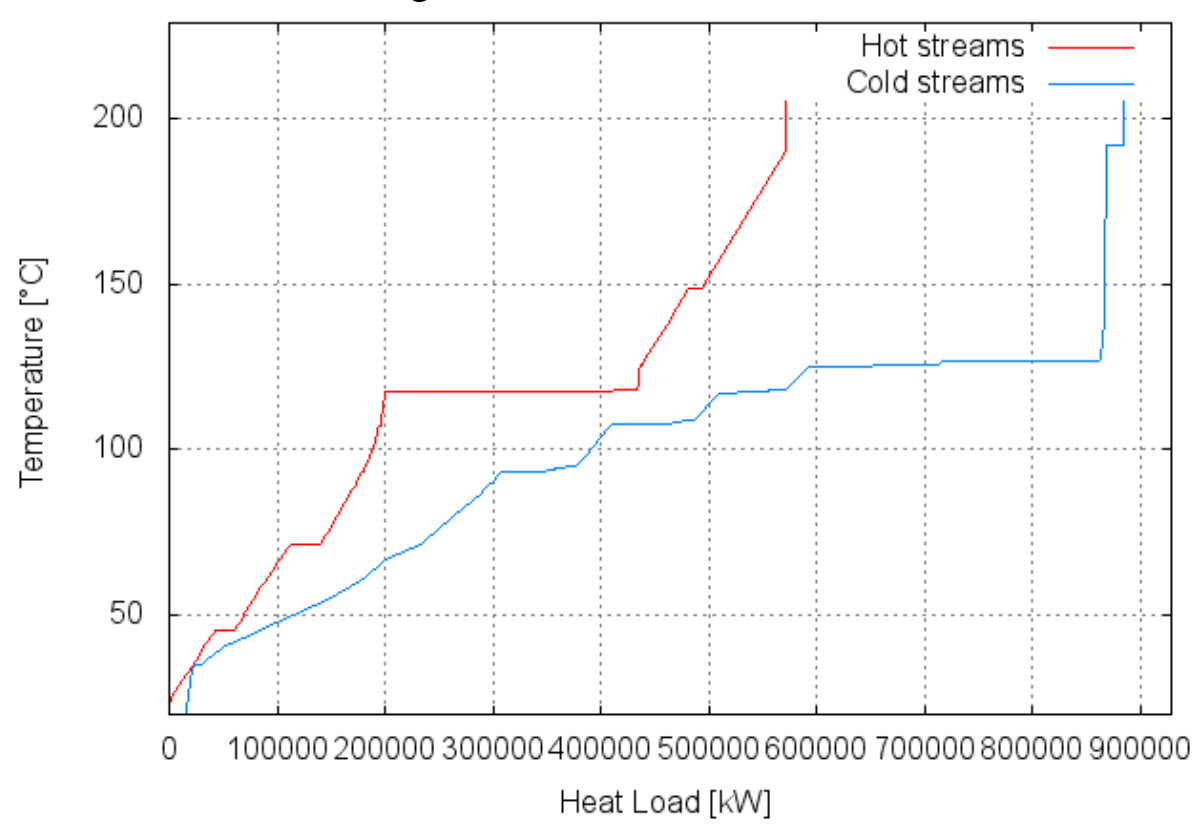

(a) Curva Composta

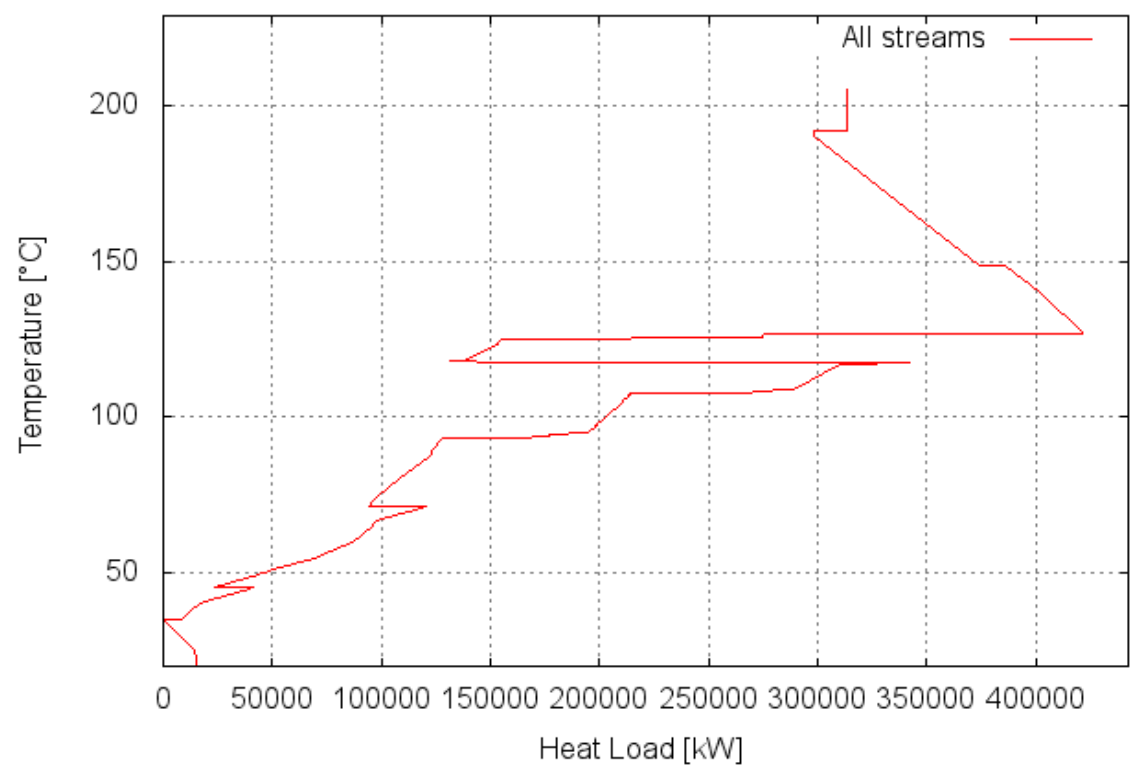

(b) Grande Curva Composta

Fonte: Elaborado pelo autor. 
Nota-se que a produção de etanol é função do consumo de energia do processo, uma vez que a quantidade de bagaço enviada para o processo de $2 \mathrm{G}$ é função dos requerimentos energéticos da unidade de cogeração. Um maior requerimento de energia implica em uma maior quantidade de bagaço enviada à caldeira e, consequentemente, em uma menor quantidade de bagaço disponível para a produção de etanol de $2 \mathrm{G}$. Assim, a produção de etanol pode ser aumentada reduzindo-se ainda mais a demanda de calor do processo.

Na Rota 3, o material lignocelulósico seco é gaseificado em um reator de CFB e o gás produzido é queimado em uma turbina a gás, cujos gases de exaustão são a entrada de um ciclo de vapor. A Fig. 6.3 (a) e (b) mostra a Curva Composta e a Grande Curva Composta Curva para esta configuração.

Figura 6.3 - MER - Rota 3.

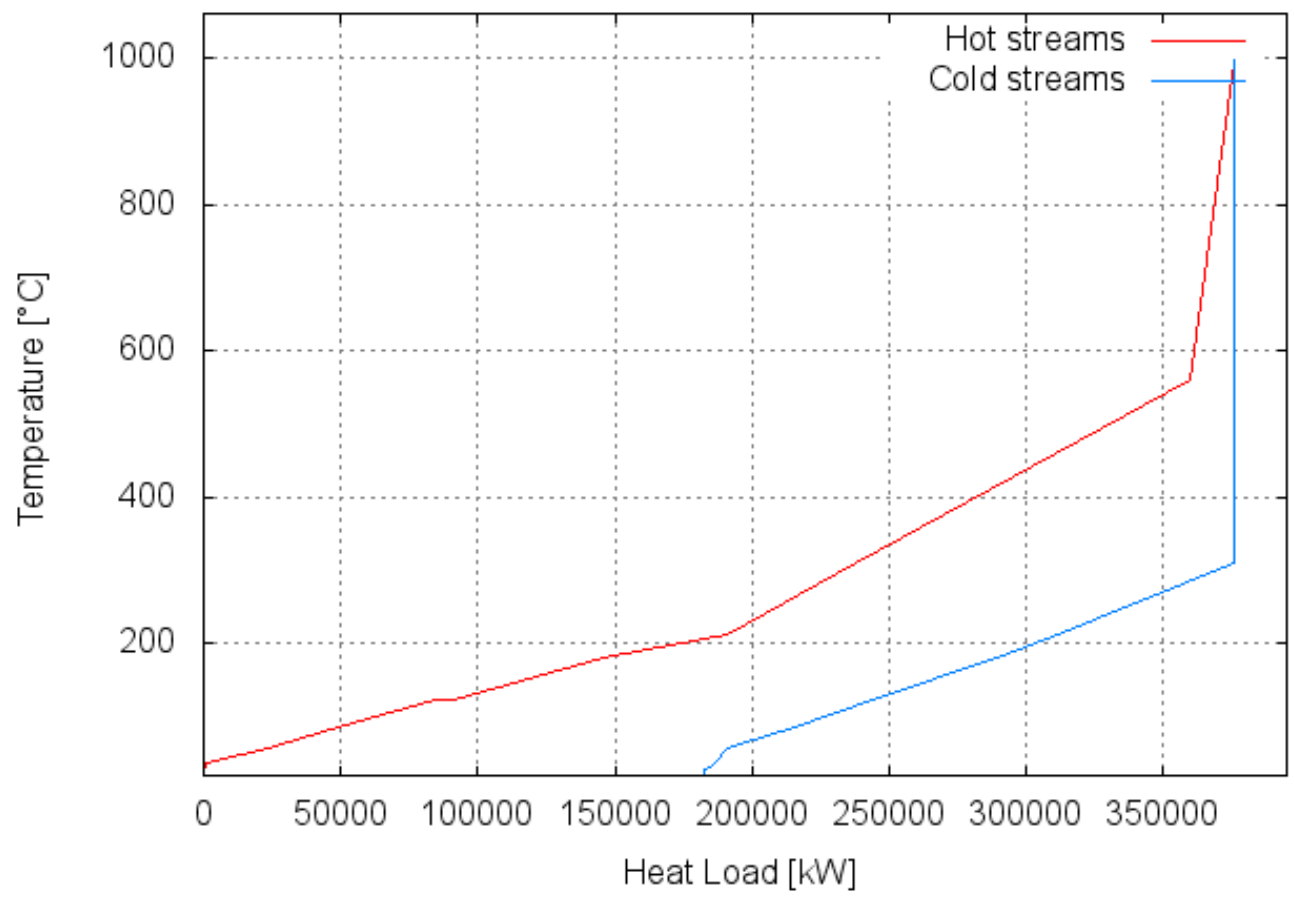

(a) Curva Composta 


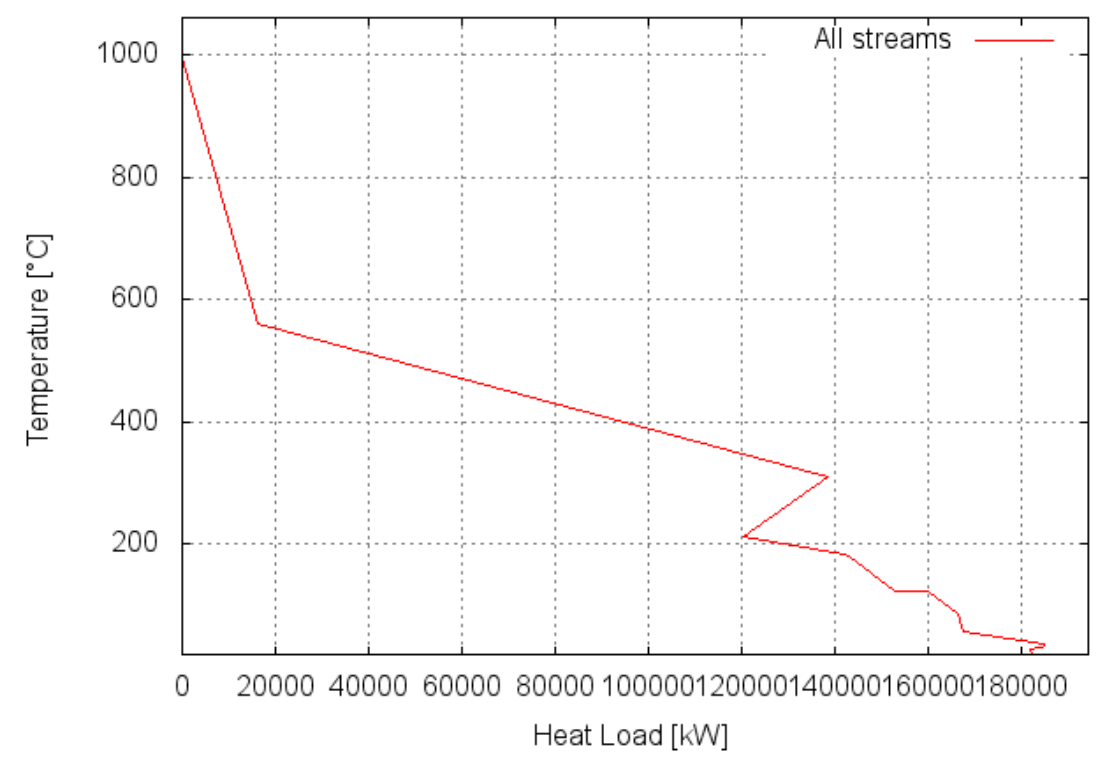

(b) Grande Curva Composta

Fonte: Elaborado pelo autor.

\subsection{AVALIAÇÃO GLOBAL DAS CONFIGURAÇÕES ESTUDADAS}

Para a análise global das rotas de produção de etanol e eletricidade, primeiramente, avaliou-se as emissões de $\mathrm{CO}_{2}$ equivalente, por meio da relação entre a estimativa global líquida de $\mathrm{CO}_{2}$ emitida na atmosfera devida a sua operação e a exergia dos produtos para cada configuração, sendo esta denominada índice de $\mathrm{CO}_{2}$ equivalente em base exergética.

Posteriormente, analisou-se a eletricidade excedente e/ou disponível para venda à rede e finalmente ponderou-se a produção de etanol destes sistemas. Nesse sentido, mostram-se os resultados da simulação obtidos para as rotas avaliadas na Fig. 6.4. 
Figura 6.4 - Análise global das rotas tecnológicas.

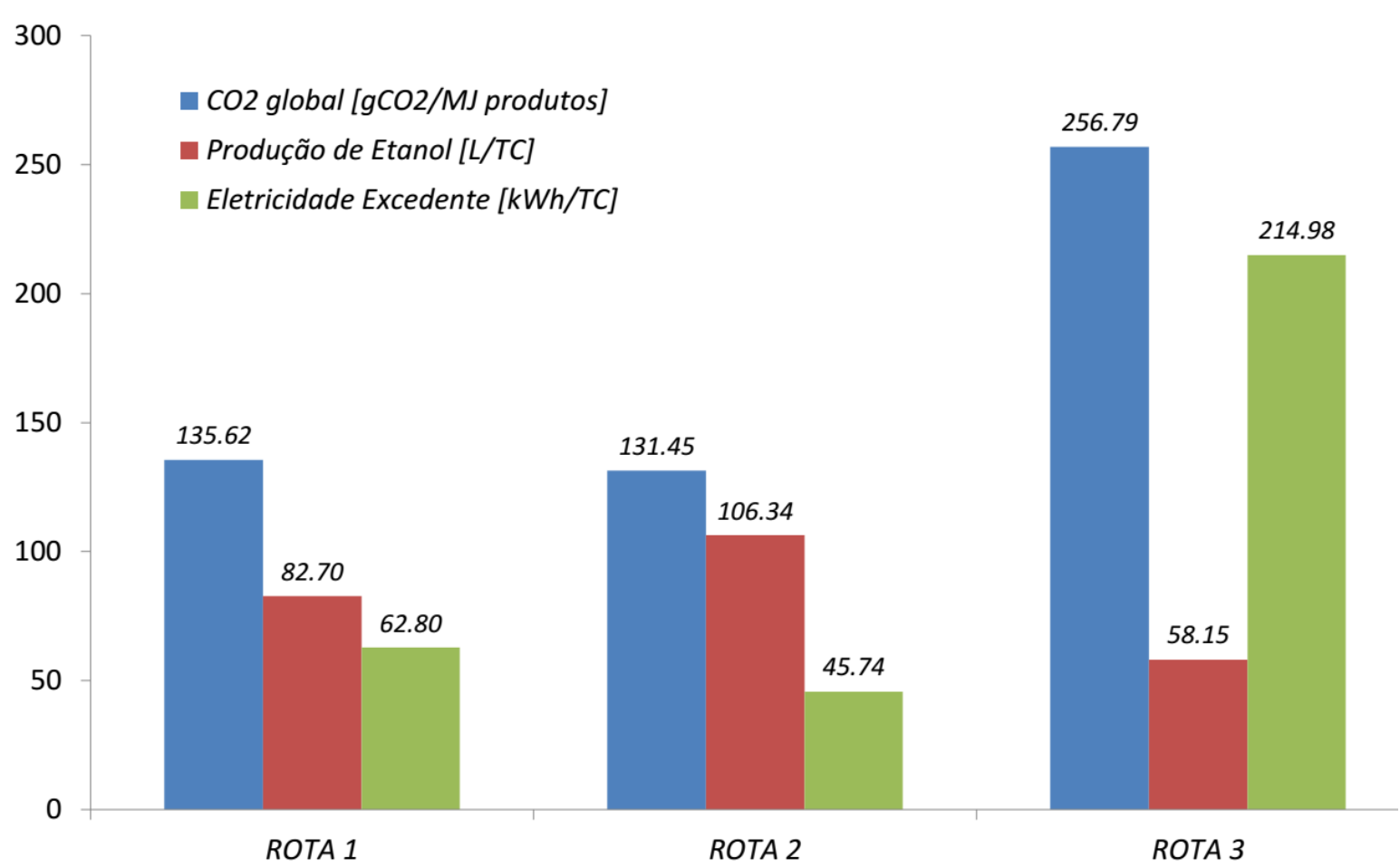

Fonte: Elaborado pelo autor.

À luz destes resultados observa-se que a maior geração de eletricidade foi obtida na Rota 3, envolvendo o processo de conversão termoquímica da gaseificação da biomassa. Entretanto, nesta configuração, uma maior taxa de emissões de $\mathrm{CO}_{2}$ é observada em relação às rotas estudadas.

Por outro lado, a Rota 2 merece destaque no quesito da produção de etanol sendo que nesta foi atingida a maior produtividade, bem como a menor taxa de emissões de $\mathrm{CO}_{2}$ equivalentes $\left(\mathrm{CO}_{2} \mathrm{e}\right)$ dentre todas as configurações.

Cabe salientar que as emissões de $\mathrm{CO}_{2}$ contabilizam as emissões referentes à produção de etanol e geração de eletricidade como produtos. Com a finalidade de comparar os resultados com outros autores, o índice de $\mathrm{CO}_{2}$ equivalente foi aplicado considerando somente o etanol como produto, obtendo-se 148,26 $\mathrm{gCO}_{2} \mathrm{e} / \mathrm{MJ}$ (rota 1), 154,48 $\mathrm{gCO}_{2} \mathrm{e} / \mathrm{MJ}$ (rota 2) e 333,19 $\mathrm{gCO}_{2} \mathrm{e} / \mathrm{MJ}$ (rota 3 ). 
Em termos da produção de etanol ao comparar com os cenários avaliados por Milanez et al. (2015), envolvendo configurações de $1 G$ e $1 G-2 G$ integrados, nesses sistemas foram reportados 84,9 1/tc e 108 1/tc respectivamente.

Albarelli (2013) apresenta resultados para o processo convencional de produção de etanol (destilaria autônoma) e para a configuração de etanol 2G-bioquímico, envolvendo prétratamento de explosão a vapor e hidrólise enzimática, em termos de produção de etanol. Seus resultados também foram similares aos obtidos neste trabalho, sendo de 81,9 1/tc e 93.6 1/tc, respectivamente, conforme apresentado no capítulo 1.

\section{Índice Exergético de Renovabilidade}

Com o intuito de complementar as informações em relação ao impacto ambiental das configurações, a discussão sobre a renovabilidade dos processos foi conduzida empregando o índice exergético de renovabilidade, introduzido no capítulo 3.

Para tal, o índice de renovabilidade das configurações foi aplicado com duas variações. Primeiramente, considerando por separado a exergia dos produtos (etanol e eletricidade) e subprodutos que poderiam ser obtidos através do processamento dos resíduos, denominado de índice 1. Estes subprodutos variam em função da rota avaliada (Tab. 6.1). Após, adotando na análise a exergia dos produtos e subprodutos conjuntamente no numerador, definido como índice 2, conforme apresentado na Fig. 6.5.

Além disso, com o intuito de visualizar os aportes das diferentes parcelas neste indicador, na Tab. 6.1 é sumarizada a sua contribuição por componente. Note-se que a parcela das irreversibilidades introduzida para cada rota nesta tabela se refere à exergia destruída global, envolvem os aportes do processo de cogeração, ainda merece ser destacado que quando empregada esta abordagem dois valores de rendimento exergético surgem para cada rota tecnológica, constatando a relação entre a renovabilidade e o rendimento exergético.

Neste sentido, o índice 1 e índice 2 ilustrados na figura abaixo, empregam os valores de rendimento exergético obtidos por meio das Eqs. (7) e (8), respectivamente, de acordo com as expressões definidas no Apêndice E. 
Figura 6.5 - Índice de renovabilidade das rotas.

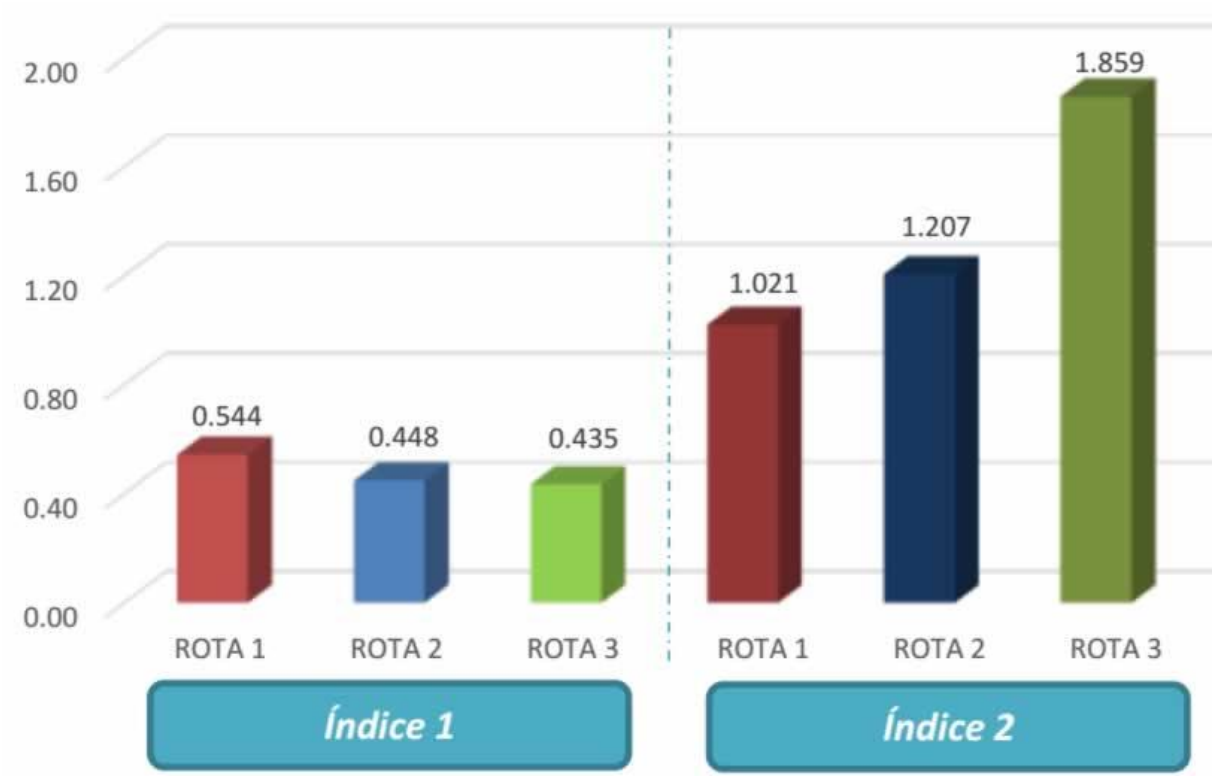

Fonte: Elaborado pelo autor.

Observa-se que o índice exergético de renovabilidade para as rotas avaliadas foi ambientalmente desfavorável, no índice 1 , denotando que a exergia dos produtos não poderia ser usada para restaurar o meio ambiente às condições anteriores à ocorrência do processo, devido principalmente às irreversibilidades totais constatadas nos processos de produção de etanol e eletricidade. Enquanto que aplicado o índice 2, ao considerar a valorização exergética dos resíduos e o seu potencial com subprodutos, o indicador foi ambientalmente favorável. 
Tabela 6.1 - Parcelas da exergia associada ao índice de renovabilidade.

\begin{tabular}{lccc} 
& ROTA 1 & ROTA 2 & ROTA 3 \\
\cline { 2 - 4 } & \multicolumn{3}{c}{ B [kW] } \\
\hline B Insumos químicos (Fóssil) & 138 & 138 & 138 \\
Óxido de cálcio (CaO) & 20 & 58 & 20 \\
MEG (C2H6O2) & 794 & 794 & 794 \\
Nutrientes (NH3) & 100 & 97 & 100 \\
Ácido sulfúrico (H2SO4) & 0 & 1468 & 0 \\
Dióxido de enxofre (SO2) & 1051 & 2554 & 1051
\end{tabular}

\begin{tabular}{lccc} 
B produtos & & & \\
B etanol & 265485 & 341338 & 186669 \\
B eletricidade excedente & 35803 & 26072 & 122539 \\
\hline B produtos & 301288 & 367410 & 309208
\end{tabular}

\begin{tabular}{lccc} 
B subprodutos e/ou resíduos & & & \\
Bagaço excedente ou hidrólise & 74815 & 165653 & 306072 \\
Torta de Filtro & 20492 & 24227 & 16306 \\
Vinhaça & 35628 & 38779 & 31677 \\
Licor de Pentoses & 0 & 53023 & 0 \\
\hline B Subprodutos/Resíduos & 130935 & 281682 & 354055
\end{tabular}

\begin{tabular}{lccc} 
B emissões & 5390 & 5621 & 5120 \\
CO2 (subsistema fermentação) & 889 & 1278 & 759 \\
Gases (subsistema Destilação e Desidratação) & 24536 & 26120 & 45036 \\
\hline Gases Exaustão (subsistema Cogeração) & 29926 & 33020 & 50915 \\
\hline B emissões & & & \\
Irreversibilidades & & & \\
B destruída & 392288 & 502140 & 304892 \\
\hline
\end{tabular}

Fonte: Elaborado pelo autor.

Os dados obtidos para o índice $(\lambda)$ foram confrontados com os resultados reportados por Pellegrini (2009) e Velásquez (2009), introduzidos no capítulo 3. Portanto, quando comparada a simulação da rota tecnológica 1 com a usina tradicional analisada por Pellegrini (2009) e com a configuração para esta rota adotada por Velásquez (2009), obtêm-se um valor mais baixo deste indicador. Isto se deve, provavelmente, a diferenças na definição dos insumos químicos ( $\left.\mathrm{B}_{\text {fóssil }}\right)$, emissões ( $\left.\mathrm{B}_{\text {emissões }}\right)$ e exergia dos produtos/subprodutos ( $\mathrm{B}_{\text {produtos/subprodutos }}$ ).

Já os valores envolvendo a rota 2 desta pesquisa exibem resultados similares na análise da conversão do material lignocelulósico (polpa + fruta) avaliado por Velásquez (2009) no estudo da produção de biocombustíveis. 
Ao passo que os valores da Rota 3 apresentam para o índice 1, resultados divergentes quando comparado com a métrica obtida na análise do sistema BIGCC conduzida por Pellegrini (2009). Isto se deve principalmente as diferenças na capacidade de moagem e a implantação do processo de gaseificação utilizando simultaneamente o bagaço e a palha da cana-de-açúcar como fontes energéticas.

Deste modo, por meio da aplicação destes indicadores, índice de $\mathrm{CO}_{2}$ equivalente em base exergética e índice exergético de renovabilidade, observa-se que a exergia é utilizada como um indicador ambiental para quantificar as irreversibilidades dos processos e determinar os vestígios deixados no meio ambiente (impacto ambiental). Um paralelo entre o índice de renovabilidade (índice 1 e índice 2) e a eficiência exergética global das rotas tecnológicas apresenta-se na Fig. 6.6 e Fig. 6.7.

Figura 6.6 - Comparação entre o índice 1 e a eficiência exergética global.

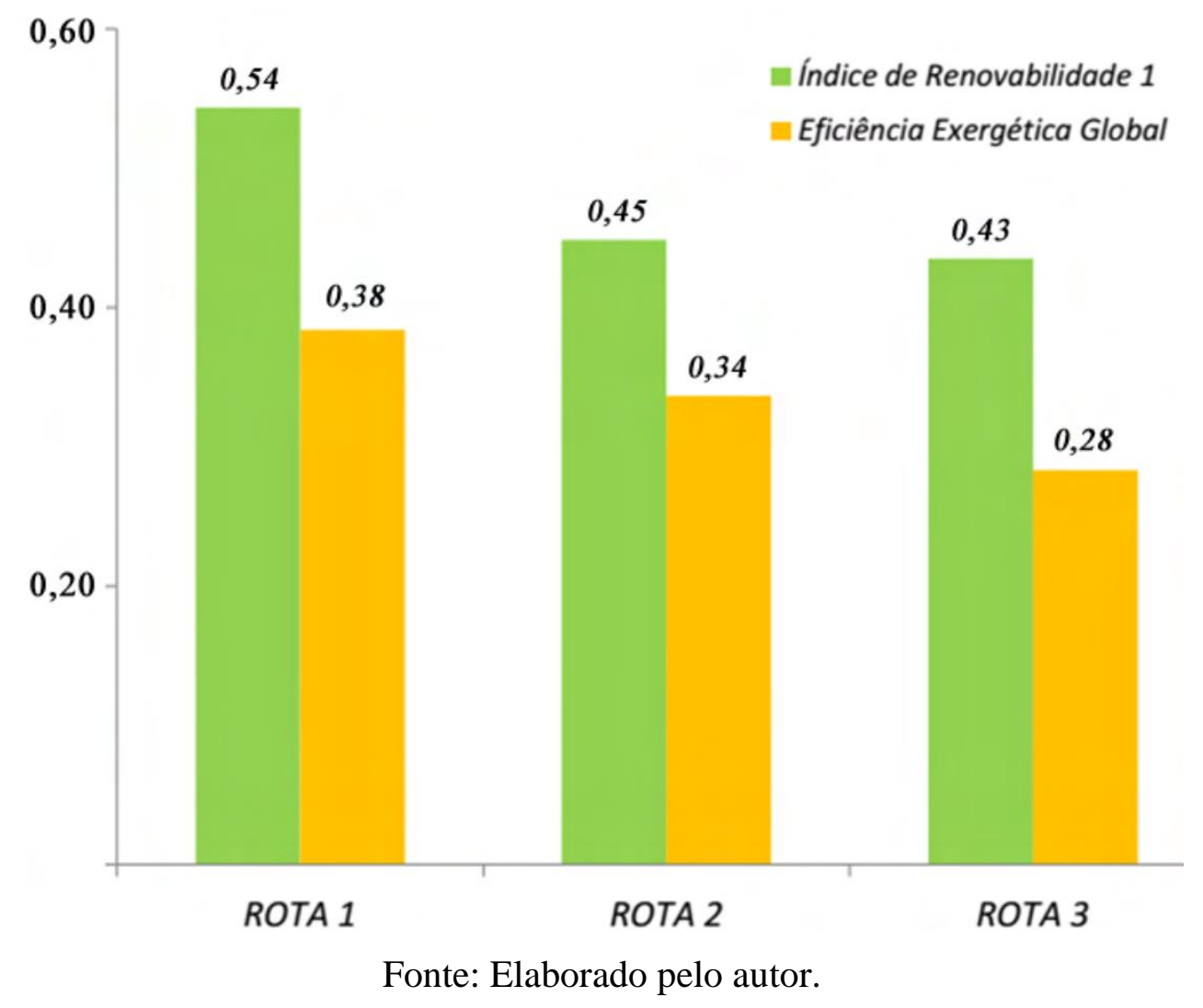


Figura 6.7 - Comparação entre o índice 2 e a eficiência exergética global.

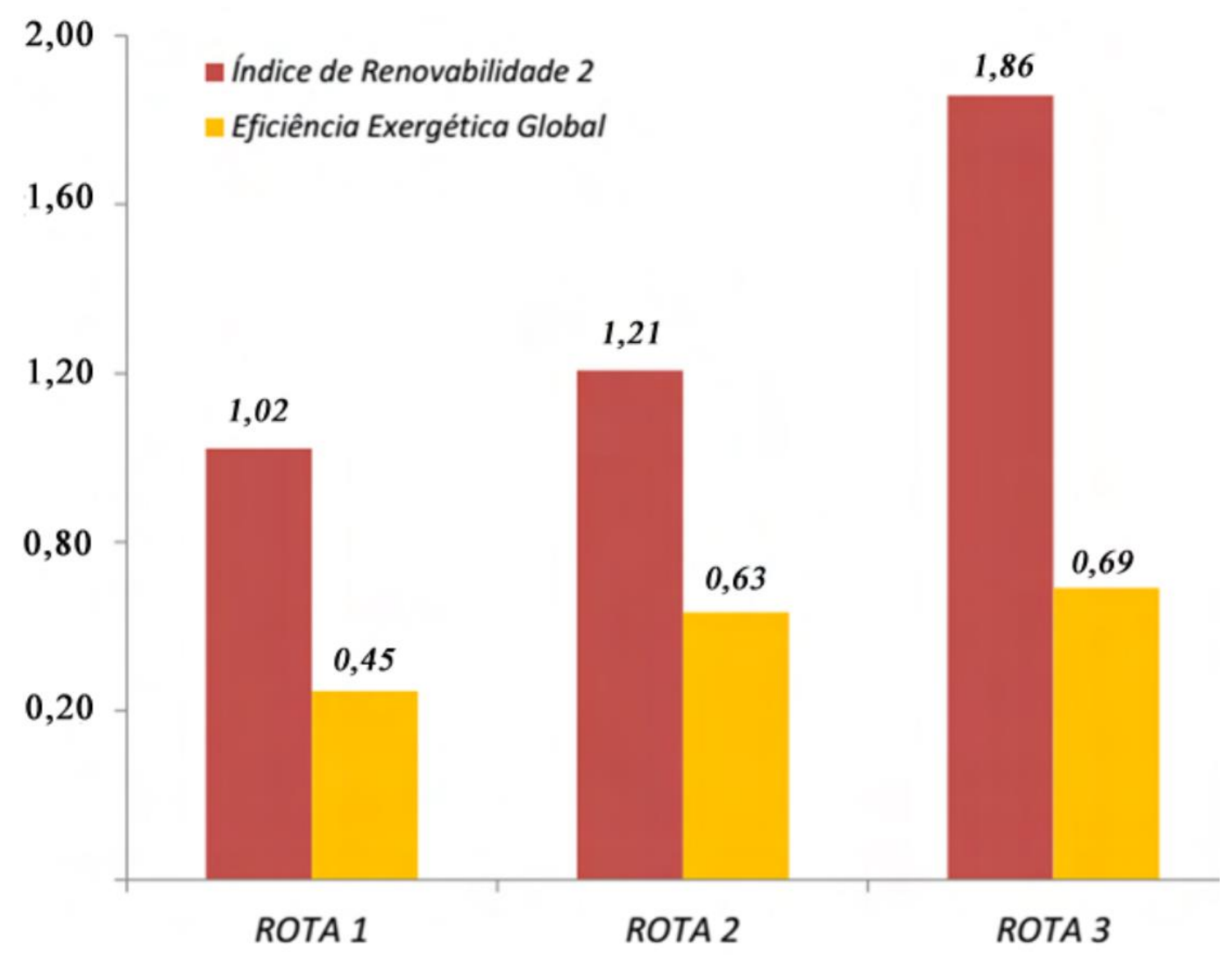

Fonte: Elaborado pelo autor. 


\subsection{ANÁLISE E DISCUSSÃO DOS RESULTADOS DAS ROTAS OTIMIZADAS}

Após a análise de integração energética implementada na formulação MILP, determinou-se o mínimo de energia requerida e a integração dos processos ótima nas rotas de conversão avaliadas. A partir dos balanços de massa e energia (entradas e saídas de cada unidade) e dos modelos termodinâmicos adotados na simulação, os processos foram completamente definidos. Assim, estas informações são usadas para avaliar o desempenho das configurações de acordo com critérios técnicos, ambientais e econômicos, previamente estabelecidos.

A Tab. 6.2 apresenta os resultados da otimização das rotas convencional, bioquímica e termoquímica analisadas. Vale a pena notar que os valores do custo total do investimento incluem o custo operacional (OPEX) e as despesas de capital (CAPEX) de cada configuração.

Tabela 6.2 - Resultados de otimização das rotas tecnológicas avaliadas.

\begin{tabular}{|c|c|c|c|c|c|}
\hline & & & $\begin{array}{l}\text { Custo } \\
\text { total }\end{array}$ & $\begin{array}{c}\text { Custo do capital } \\
\text { anualizado }\end{array}$ & Impacto \\
\hline \multicolumn{3}{|c|}{ ESTUDO DE CASO } & $\begin{array}{c}\text { Milhões de US\$ } \\
\text { (MUS\$) }\end{array}$ & MUS\$̦/ano & $\mathrm{kgCO} 2 \mathrm{eq} / \mathrm{TC}$ \\
\hline ROTA 1 & $\begin{array}{l}\text { Cenário base } \\
\text { Aspen Plus }\end{array}$ & 1G-CONV & 239,1 & 28,0 & 276,12 \\
\hline ROTA 2 & $\begin{array}{l}\text { Cenário base } \\
\text { Aspen Plus }\end{array}$ & 2G-BIO-SHF-SE & 343,3 & 40,3 & 258,09 \\
\hline ROTA 3 & $\begin{array}{l}\text { Cenário base } \\
\text { Aspen Plus }\end{array}$ & 2G-TERMO-ELE-CFB & 334,2 & 39,2 & 414,13 \\
\hline
\end{tabular}

Fonte: Elaborado pelo autor.

De acordo com esta tabela, a Rota 2 (plataforma bioquímica) representa o melhor sistema em termos do impacto ambiental. Porém, um maior custo total de investimento quando comparada com a plataforma termoquímica e convencional. Vale destacar neste ponto, que avaliação econômica considerou-se uma taxa de juros anual de 10 \% e um período de vida do projeto de 20 anos. 
Em contrapartida, continuando a análise em relação ao impacto ambiental das configurações conduzida neste capítulo, nota-se que foram consideradas diversas categorias de impacto sendo, GWP-climate change, HTP-human toxicity, ALO-agricultural land occupation, FDPfossil depletion.

Nesse sentido, a Fig. 6.8 mostra os indicadores de impacto ambiental relativos ao ciclo de vida da produção de etanol nos diversos cenários avaliados, incluindo os processos integrados para a produção de biomassa, transporte e conversão nas biorrefinarias.

Em geral, nota-se que os processos de produção de etanol $2 \mathrm{G}$ pela via bioquímica e termoquímica apresentam melhores indicadores ambientais, quando comparados com a tecnologia de etanol $1 \mathrm{G}$ para todas as categorias de impacto ambiental que foram selecionadas.

Figura 6.8 - Indicadores de impacto ambiental.

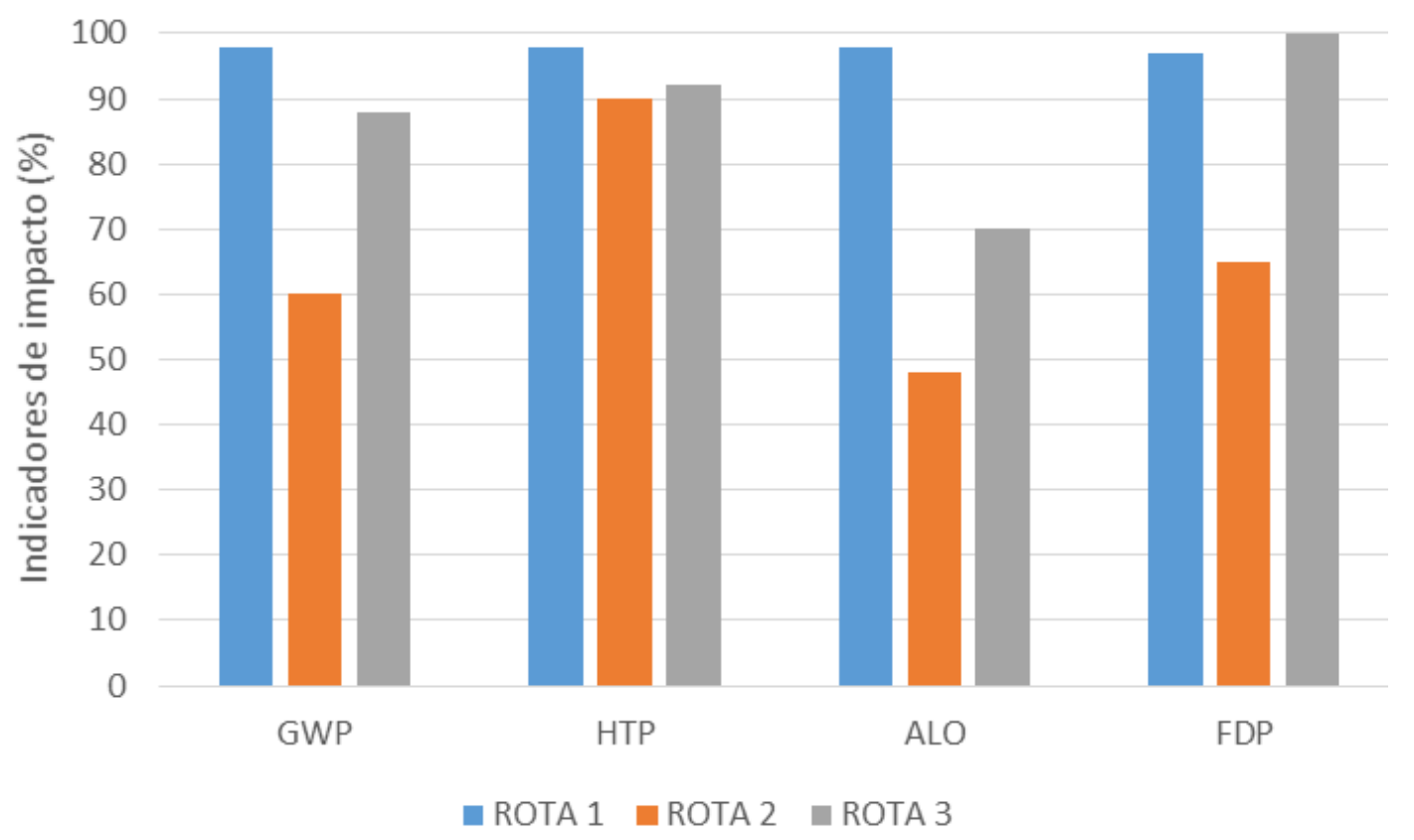

Fonte: Elaborado pelo autor.

Com o intuito de sintetizar os principais resultados desta pesquisa e conduzir a hierarquização das configurações, na Tab. 6.3 são ilustrados os parâmetros considerados na avaliação destas tecnologias de conversão de biomassa. 
Para fins da avaliação global destas tecnologias, nota-se que a expressão da eficiência exergética do índice 1 foi adotada na análise, uma vez que as simulações propostas visam com produtos o etanol e a eletricidade. Por essa razão, os indicadores de $\mathrm{CO}_{2}$ emitidos, a produção de etanol e eletricidade apresentados abaixo se referem aos resultados obtidos por meio da aplicação deste índice.

O paralelo com o índice 2 tem com objetivo comparar as variações da renovabilidade e a eficiência exergética ao adotar os resíduos intrínsecos na conversão destas rotas, e confrontálos como subprodutos, visando o seu processamento e em consequência sua valorização.

Tabela 6.3 - Resultados da hierarquização das rotas tecnológicas.

\begin{tabular}{|l|c|c|c|}
\hline PARÂMETROS & ROTA 1 & ROTA 2 & ROTA 3 \\
\hline Eficiência exergética 1 [\%] & 38,38 & 33,67 & 28,34 \\
\hline Índice de renovabilidade 1 & 0,54 & 0,45 & 0,43 \\
\hline Custo exergético unitário médio 1 & 2,60 & 2,97 & 3,52 \\
\hline $\mathrm{CO}_{2}$ global [gCO $/ \mathrm{MJ}$ produtos] & 135,6 & 131,4 & 256,8 \\
\hline Produção de etanol [L/TC] & 82,7 & 106,3 & 58,1 \\
\hline Eletricidade excedente [kWh/TC] & 62,8 & 45,7 & 214,9 \\
\hline Eficiência exergética 2 [\%] & 44,67 & 63,29 & 69,15 \\
\hline Índice de renovabilidade 2 & 1,02 & 1,20 & 1,86 \\
\hline Custo exergético unitário médio 2 & 2,24 & 1,58 & 1,45 \\
\hline
\end{tabular}

Fonte: Elaborado pelo autor.

Quando adotada a definição de rendimento exergético associada ao índice 1, observa-se que a rota convencional otimizada apresentou o melhor indicador em termos da eficiência exergética dos processos, por conseguinte o seu custo unitário médio em base exergética foi o menor dentre as plataformas avaliadas.

Ao passo que a rota bioquímica foi o sistema mais importante na produção de etanol, devido à integração de rota de produção de etanol $1 \mathrm{G}$ com a unidade de $2 \mathrm{G}$, ainda nota-se que esta tecnologia possui as menores taxas de emissões globais de $\mathrm{CO}_{2}$, sendo a configuração com melhor desempenho no tocante ao impacto ambiental. 
Além disso, a rota termoquímica apresentou a configuração mais relevante quando a geração de eletricidade foi o objeto de análise, à custa de atingir o maior impacto ambiental das rotas tecnológicas.

Observa-se um comportamento oposto quando empregada a expressão exergética integrada ao índice 2. Nota-se da Tab. 6.3, que a partir dessa definição do rendimento a Rota 3 seria a configuração mais relevante no tocante da eficiência exergética e o custo exergético unitário, dentre os sistemas estudos. Ainda esta tabela sintetiza os resultados do Índice Exergético de Renovabilidade para as duas variantes discutidas neste item. 


\section{CONCLUSÕES E PERSPECTIVAS}

De acordo com os resultados relativos à eficiência exergética dos processos, verifica-se que as reações químicas envolvidas nas etapas de hidrólise, fermentação e combustão representam as principais causas de irreversibilidades, destruição de exergia, na produção de etanol e geração de eletricidade utilizando o bagaço e a palha da cana-de-açúcar como insumo energético.

$\mathrm{Na}$ avaliação global das tecnologias estudas, a rota convencional otimizada (Rota 1) apresentou a máxima eficiência exergética dos processos, por conseguinte o menor custo exergético unitário médio como consequência de uma redução do consumo de vapor e ao procedimento de integração energética, permitindo que uma maior quantidade de bagaço fosse destinada para outros fins de conversão.

Em termos da análise envolvendo a integração dos processos constatou-se que a produção de etanol de segunda geração (Rota 2) via hidrólise enzimática, vinculada ao processo convencional permitiu atingir a maior taxa de produção de etanol sobre as outras configurações. No entanto, a análise econômica mostrou que este processo de $2 \mathrm{G}$ (plataforma bioquímica) tem o maior custo de capital em comparação com as rotas tecnológicas estudas e ainda situou-se como a configuração mais sustentável apresentando as menores taxas de emissões globais de $\mathrm{CO}_{2}\left(131,45 \mathrm{gCO}_{2} / \mathrm{MJ}\right.$ produtos).

Em relação aos resultados obtidos nas etapas do sistema de gaseificação (Rota 3), foi realizada a comparação de duas tecnologias de gaseificação, EF e CFB, indicando ao processo de gaseificação do tipo leito arrastado (EF) como a opção mais relevante em função da eficiência exergética dos processos. De fato, utilizando o gaseificador EF e via integração de processos é possível reduzir a necessidade de energia térmica da biorrefinaria. Merece ser destacado que na avaliação global da rota termoquímica apresentou-se a maior taxa de geração de energia elétrica excedente $214,98 \mathrm{kWh} / \mathrm{TC}$, à custa de atingir o maior impacto ambiental das rotas tecnológicas. 


\section{Sugestões para trabalhos futuros}

Para uma possível continuidade desta tese, algumas propostas para trabalhos futuros podem ser recomendadas:

- Modelagem do processo convencional de produção de etanol $1 \mathrm{G}$ e integrado ao processo de hidrólise, avaliando a introdução de possíveis melhorias no processo de fermentação e destilação (fermentação extrativa a vácuo ou desidratação por membranas) que visem diminuir o consumo energético e maximizar a produção de etanol.

- Análise da diversificação de produtos oferecidos pelas usinas sucroalcooleiras (Rota Alcoolquímica de uma biorrefinaria de cana-de-açúcar), em função da eficiência de conversão em base exergética, e o impacto na viabilidade econômica do processo de produção de etanol e/ou subprodutos.

- Implementação da tecnologia de hidrólise-sacarificação e fermentação simultâneas como uma variável na avaliação da rota 2 .

- Análise exergo-econômica das rotas tecnológicas adotadas visando obter os custos exergéticos unitários dos fluxos envolvidos.

- Aplicação de ferramentas de otimização multi-objetivo a fim de avaliar técnica econômica e ambientalmente todos os processos estudados nesta pesquisa.

- Avaliar o recolhimento da palha de cana em todas as configurações para viabilizar a produção de etanol e a geração de eletricidade no período da safra e entressafra.

- Análise detalhada do consumo da água e proposição de circuitos que permitam o reúso deste recurso nas diversas configurações. 


\section{REFERÊNCIAS BIBLIOGRÁFICAS}

ABDOLLAHI-NEISIANI, M. et al. Pretreatment Techniques for Biofuels and Biorefineries. In: FANG, Z. (Ed.). Berlin, Heidelberg: Springer Berlin Heidelberg, 2013. p. 197-227.

AL-MAYYAHI, M. A.; HOADLEY, A. F. A.; RANGAIAH, G. P. CO2 Emissions Targeting for Petroleum Refinery Optimization. In: Multi-Objective Optimization in Chemical Engineering. John Wiley \& Sons Ltd, 2013. p. 293-333.

Albarelli, J. Q. Produção de açúcar e etanol de primeira e segunda geração: simulação, integração energética e análise econômica. UNIVERSIDADE ESTADUAL DE CAMPINAS - Campinas, SP, 2013.

ALBARELLI, J. Q. et al. Valorization of sugarcane biorefinery residues using supercritical water gasification: A case study and perspectives. The Journal of Supercritical Fluids, v. 96, p. 133-143, 2015a.

ALBARELLI, J. Q. et al. Multi-objective optimization of a sugarcane biorefinery for integrated ethanol and methanol production. Energy, $2015 \mathrm{~b}$.

ALBARELli, J. Q.; ENSINAS, A. V.; SILVA, M. A. A New Proposal of Cellulosic Ethanol to Boost Sugarcane Biorefineries: Techno-Economic Evaluation. International Journal of Chemical Engineering, v. 2014, 2014.

ASPENTECH. Aspen Plus V8.6. Disponível em: <http://www.aspentech.com/>. Acesso em: 5 dez. 2013.

ASPENTECH. Aspen physical property system, Physical property models, V8.6.

BAIN COMPANY E GAS ENERGY. Potencial de diversificação da indústria química: Químicos com base em fontes renováveis. Disponível em: <http://www.bndes.gov.br/SiteBNDES/export/sites/default/bndes_pt/Galerias/Arquivos/produ tos/download/chamada_publica_FEPprospec0311_Quimicos_Relat4_Quimicos_de_renovavei s.pdf>. Acesso em: 15 dez. 2014. 
BALAT, M.; BALAT, H.; OZ, C. Progress in bioethanol processing. Progress in Energy and Combustion Science, v. 34, n. 5, p. 551-573, 2008.

BASU, P. Biomass Gasification, Pyrolysis and Torrefaction. Elsevier, 2013.

BEJAN, A.; TSATSARONIS, G.; MORAN, M. Thermal Design and Optimization. N.Y: John Wiley \& Sons Inc., 1996.

BELGIORNO, V. et al. Energy from gasification of solid wastes. Waste management (New York, N.Y.), v. 23, n. 1, p. 1-15, 2003.

BELSIM. Vali V4.7. Disponível em: <http://www.belsim.com/>. Acesso em: 7 fev. 2014.

BIOSEV. Setor Sucroalcooleiro. Disponível em: <http://www.mzweb.com.br/biosev/>. Acesso em: 1 out. 2016.

BLANCO, L.; VELÁSQUEZ, H.; CHEJNE, F. Energetic, exergetic and thermoeconomic analysis of a biomass gasification processProceedings of the $26 \mathrm{TH}$ International Conference on Efficiency, Costs, Optimization, Simulation and Environmental Impact of Energy Systems - ECOS. Anais. Guilin, China: 2013.

BOLLIGER, R. Méthodologie de la synthèse des systèmes énergétiques industrielsBolliger. École Polytechnique Fédérale de Lausanne (EPFL), 2010.

BONOMI, A. et al. Techno-economic and Environmental Assessment of Second Generation Ethanol: Short and Long Term Prospects. Chemical engineering transactions, v. 50, 2016. BONOMI, A. (COORD. . et al. The Virtual Sugarcane Biorefinery (VSB). Campinas: Disponível em: <http://ctbe.cnpem.br/pesquisa/avaliacao-integrada biorefinaria〉.

CAMACHO-ARDILA, Y. et al. Syngas production from sugar cane bagasse in a circulating fluidized bed gasifier using Aspen PlusProceedings 22nd European Symposium on Computer Aided Process Engineering. Anais. London-UK: Elsevier, 2012. 
CAMACHO-ARDILA, Y. et al. Simulation of ethanol production via fermentation of the synthesis gas using Aspen Plus. Chemical engineering transactions, 2014.

CAMARGO, A. C. (COORD). Conservação de Energia na Indústria do Açúcar e do Álcool. São Paulo: Instituto de Pesquisas Tecnológicas (IPT), 1990.

CANAONLINE. Preço do bagaço de cana começa a reagir. Disponível em: <http://www.canaonline.com.br/conteudo/preco-do-bagaco-de-cana-comeca-a-reagir.html>. Acesso em: 1 out. 2016.

CARDONA, C. A.; QUINTERO, J. A.; PAZ, I. C. Production of bioethanol from sugarcane bagasse: Status and perspectives. Bioresource technology, v. 101, n. 13, p. 4754-66, 2010. CARRASCO, C. et al. SO2-catalyzed steam pretreatment and fermentation of enzymatically hydrolyzed sugarcane bagasse. Enzyme and Microbial Technology, v. 46, n. 2, p. 64-73, 2010.

CHACARTEGUI, R. et al. SPHERA project: Assessing the use of syngas fuels in gas turbines and combined cycles from a global perspective. Fuel Processing Technology, v. 103, p. 134-145, 2012.

CHAVEZ-RODRIGUEZ, M. F. et al. Water reuse and recycling according to stream qualities in sugar-ethanol plants. Energy for Sustainable Development, v. 17, n. 5, p. 546-554, 2013. CHEN, J. Cane sugar handbook, a manual for cane sugar manufacturers and their chemists. New York: John Wiley \& Sons, Inc., 1993.

CORTEZ, L.; LORA, E.; GÓMEZ, E. Biomassa para Energia.

DAMARTZIS, T.; MICHAILOS, S.; ZABANIOTOU, A. Energetic assessment of a combined heat and power integrated biomass gasification-internal combustion engine system by using Aspen Plus®. Fuel Processing Technology, v. 95, p. 37-44, 2012.

DAMARTZIS, T.; ZABANIOTOU, A. Thermochemical conversion of biomass to second generation biofuels through integrated process design-A review. Renewable and Sustainable Energy Reviews, v. 15, n. 1, p. 366-378, 2011. 
DE OLIVEIRA JUNIOR, S. Exergy: Production, Cost and Renewability. São Paulo: Springer, 2013.

DE SOUZA-SANTOS, M. L.; BENINCA, W. DE A. New Strategy of Fuel-Slurry Integrated Gasifier/Gas Turbine (FSIG/GT) Alternative for Power Generation Applied to Biomass. Energy \& Fuels, v. 28, n. 4, p. 2697-2707, 2014.

DE SOUZA-SANTOS, M. L.; BERNAL, A. F. B.; RODRIGUEZ-TORRES, A. F. New Developments on Fuel-Slurry Integrated Gasifier/Gas Turbine (FSIG/GT) Alternative for Power Generation Applied to Biomass; Configuration Requiring No Steam for Gasification. Energy \& Fuels, v. 29, n. 6, p. 3879-3889, 2015.

DEVI, L.; PTASINSKI, K. J.; JANSSEN, F. J . A review of the primary measures for tar elimination in biomass gasification processes. Biomass and Bioenergy, v. 24, n. 2, p. 125$140,2003$.

DIAS, M. Simulação do processo de produção de etanol a partir do açúcar e do bagaço visando a integração do processo e a maximização da produção de energia excedentes de bagaço. Universidade Estadual de Campinas, Campinas-SP, 2008.

DIAS, M. Desenvolvimento e otimização de processos de produção de etanol de 1G e 2G geração e eletricidade a partir da cana-de-açúcar. Universidade Estadual de Campinas, Campinas-SP, 2011.

DIAS, M. O. S. et al. Improving bioethanol production from sugarcane: evaluation of distillation, thermal integration and cogeneration systems. Energy, v. 36, n. 6, p. 3691-3703, 2011.

DIAS, M. O. S. et al. Integrated versus stand-alone second generation ethanol production from sugarcane bagasse and trash. Bioresource technology, v. 103, n. 1, p. 152-61, 2012.

DIAS, M. O. S. et al. Evaluation of process configurations for second generation integrated with first generation bioethanol production from sugarcane. Fuel Processing Technology, v. 109, p. 84-89, 2013a. 
DIAS, M. O. S. et al. Biorefineries for the production of first and second generation ethanol and electricity from sugarcane. Applied Energy, v. 109, p. 72-78, 2013 b.

DUTTA, A. et al. Techno-economics for conversion of lignocellulosic biomass to ethanol by indirect gasification and mixed alcohol synthesis. Environmental Progress \& Sustainable Energy, v. 31, n. 2, p. 182-190, 2012.

EISJBERG, R. The design and economic analysis of a modern bioethanol factory located in Brazil. Delft University of Technology, Delft, 2006.

EliA NETO, A. (COORDENADOR). Manual de Conservação e Reúso de Água na Agroindústria Sucroenergética. Brasília, DF.

ENSINAS, A.; NEBRA, S. Exergy analysis as a tool for sugar and ethanol process improvement. In: Handbook of exergy, hydrogen energy, and hydropower research. New York: Nova Science Publishers, 2009.

ENSINAS, A. V. Integração térmica e otimização termoeconômica aplicadas ao processo industrial de produção de açúcar e etanol. Universidade Estadual de Campinas, CampinasSP., 2008.

ENSINAS, A. V; ARNAO, J. H. S.; NEBRA, S. A. INCREASING ENERGETIC EFFICIENCY IN SUGAR, ETHANOL, AND ELECTRICITY PRODUCING PLANTS. In: LUÍS AUGUSTO BARBOSA CORTEZ - COORDENADOR; FAPESP (Eds.). Sugarcane bioethanol — R\&D for Productivity and Sustainability. Blucher, 2010.

ESCOBAR, P. J. Análise termoeconômica integrada das plantas de cogeração e etanol em uma destilaria autônoma. [s.1.] Universidade Federal de Itajubá. Minas Gerais, 2010.

FERNANDES, M. C. Investigação experimental de gaseificação de biomassa em leito fluidizado. [s.1.] Universidade Estadual de Campinas, Campinas-SP, 2014. 
GASSNER, M.; MARÉCHAL, F. Methodology for the optimal thermo-economic, multiobjective design of thermochemical fuel production from biomass. Computers \& Chemical Engineering, v. 33, n. 3, p. 769-781, 2009.

GASSNER, M.; MARÉCHAL, F. Increasing Efficiency of Fuel Ethanol Production from Lignocellulosic Biomass by Process Integration. Energy \& Fuels, v. 27, n. 4, p. 2107-2115, 2013.

GERBER, L.; FAZLOLLAHI, S.; MARÉCHAL, F. A systematic methodology for the environomic design and synthesis of energy systems combining process integration, Life Cycle Assessment and industrial ecology. Computers \& Chemical Engineering, v. 59, p. 2$16,2013$.

GERBER, L.; GASSNER, M.; MARÉCHAL, F. Systematic integration of LCA in process systems design: Application to combined fuel and electricity production from lignocellulosic biomass. Computers \& Chemical Engineering, v. 35, n. 7, p. 1265-1280, 2011.

GLAZER, A. N. .; NIKAIDO, H. Microbial Biotechnology: Fundamentals of Applied Microbiology. Cambridge: Cambridge University Press, 2007.

GÓMEZ-BAREA, A.; LECKNER, B. Modeling of biomass gasification in fluidized bed. Progress in Energy and Combustion Science, v. 36, n. 4, p. 444-509, 2010.

GUPTA, K. K.; REHMAN, A.; SARVIYA, R. M. Bio-fuels for the gas turbine: A review. Renewable and Sustainable Energy Reviews, v. 14, n. 9, p. 2946-2955, 2010.

HAMELINCK, C. N.; HOOIJDONK, G. VAN; FAAIJ, A. P. Ethanol from lignocellulosic biomass: techno-economic performance in short-, middle- and long-term. Biomass and Bioenergy, v. 28, n. 4, p. 384-410, 2005.

HASSUANI, S. J.; LEAL, M. R. L. V. MACEDO, I. C. (ED). . Biomass Power Generation: Sugarcane Bagasse and Trash. Piracicaba. 
HENDRIKS, A. T. W. M.; ZEEMAN, G. Pretreatments to enhance the digestibility of lignocellulosic biomass. Bioresource Technology, v. 100, n. 1, p. 10-18, 2009.

HUMBIRD, D. et al. Process Design and Economics for Biochemical Conversion of Lignocellulosic Biomass to Ethanol Process Design and Economics for Biochemical Conversion of Lignocellulosic Biomass to Ethanol.

IBRAHEEM, O.; NDIMBA, B. K. Molecular Adaptation Mechanisms Employed by Ethanologenic Bacteria in Response to Lignocellulose-derived Inhibitory Compounds. International Journal of Biological Sciences, v. 9, n. 6, p. 598-612, 2013.

JIN, H.; LARSON, E. D.; CELIK, F. E. Performance and cost analysis of future, commercially mature gasification-based electric power generation from switchgrass. Biofuels, Bioproducts and Biorefining, v. 3, n. 2, p. 142-173, 2009.

JORGENSEN, S.; NORSNIELSEN, S. Application of exergy as thermodynamic indicator in ecology. Energy, v. 32, n. 5, p. 673-685, 2007.

KAM, M. J. DE; MOREY, R. V; TIFFANY, D. G. Integrating Biomass to Produce Heat and Power at Ethanol Plants. v. 25, n. 2, 2009.

KAMATE, S. C.; GANGAVATI, P. B. Exergy analysis of cogeneration power plants in sugar industries. Applied Thermal Engineering, v. 29, n. 5-6, p. 1187-1194, 2009.

KANOGLU, M.; DINCER, I.; ROSEN, M. A. Understanding energy and exergy efficiencies for improved energy management in power plants. Energy Policy, v. 35, n. 7, p. 3967-3978, 2007.

KASEMBE, E. D.; JOHN, G. R.; MHILU, C. F. Exergy analysis of high temperature biomass gasification. International Journal of Sustainable Development-OIDA, 2012.

KEMP, I. C. Pinch Analysis and Process Integration. Elsevier, 2007. 
KIRUBAKARAN, V. et al. A review on gasification of biomass. Renewable and Sustainable Energy Reviews, v. 13, n. 1, p. 179-186, 2009.

KLEIN, S. A. Engineering Equation Solver Software User's Guide. Wisconsin, Madison, USA.

KOTAS, T. J. The Exergy Method of Thermal Plant Design. London-UK: Butterworths, 1985.

KRAHL, M. Desenvolvimento sustentável, sustentabilidade e exergia: Identificação de relações pertinentes e de indicadores baseados em exergia. Universidade Federal Fluminense, 2009.

KUMAR, A.; SHARMA, A.; BHANDARI, P. Biomass Gasification and Syngas Utilization. In: Sustainable Bioenergy Production. CRC Press, 2014. p. 341-360.

KUMAR, P. et al. Methods for Pretreatment of Lignocellulosic Biomass for Ef cient Hydrolysis and Biofuel Production. Industrial and Engineering Chemistry (Analytical Edition), p. 3713-3729, 2009.

LASER, M. et al. A comparison of liquid hot water and steam pretreatments of sugar cane bagasse for bioconversion to ethanol. Bioresource Technology, v. 81, n. 1, p. 33-44, 2002.

LI, X. T. et al. Biomass gasification in a circulating fluidized bed. Biomass and Bioenergy, v. 26, n. 2, p. 171-193, 2004.

LORA, E. S.; VENTURINI, O. J. Biocombustíveis. Rio de Janeiro: Editora Interciência Ltda., 2012.

LUQUE, R.; SPEIGHT, J. G. Gasification for Synthetic Fuel Production. [s.l.] Elsevier, 2015.

MACEDO, H. III Workshop Tecnológico sobre: Hidrólise para Produção de Etanol. Disponível em: <www.apta.sp.gov.br/cana>. Acesso em: 9 fev. 2012. 
MARECHAL, F.; KALITVENTZEFF, B. Targeting the minimum cost of energy requirements: A new graphical technique for evaluating the integration of utility systems. Computers \& Chemical Engineering, v. 20, p. S225-S230, 1996.

MARTÍN, C. et al. Comparison of the fermentability of enzymatic hydrolyzates of sugarcane bagasse pretreated by steam explosion using different impregnating agents. Applied biochemistry and biotechnology, v. 98-100, p. 699-716, 2002.

MARTÍN, C. et al. A study of three strategies for improving the fermentability of sugarcane bagasse hydrolysates for fuel ethanol production. International Sugar Journal, v. 109, n. 1297, p. 33-35-39, 2007.

MARTINS, F. D.; FONTES, D. C.; GOMES, M. A. Process and system for producing alcohol by split-feed distillation.United States, 2009. Disponível em: <http://www.freepatentsonline.com/y2009/0324796.html>

MEDEIROS, E. et al. Preliminary assessment by the virtual sugarcane biorefinery framework of syngas production and power generation from a first-generation sugarcane plant lignocellulosic biomass5th International Conference on Engineering for Waste and Biomass Valorisation. Anais, Rio de Janeiro: 2014.

MEIRELLES, A. Expansão da produção de bioetanol e melhoria tecnológica da destilação alcoólicaFAPESP, Workshop do projeto diretrizes de políticas públicas para a agroindústria canavieira do estado de São Paulo. Anais...Lorena: 2006Disponível em: <http://bizuando.com/material-apoio/processos-qi2/Workshop_Etanol_Sessao 4_Antonio_Meir.pdf>

MELGAR, A. et al. Thermochemical equilibrium modelling of a gasifying process. Energy Conversion and Management, v. 48, n. 1, p. 59-67, 2007.

MENG, X. et al. Biomass gasification in a $100 \mathrm{kWth}$ steam-oxygen blown circulating fluidized bed gasifier: Effects of operational conditions on product gas distribution and tar formation. Biomass and Bioenergy, v. 35, n. 7, p. 2910-2924, 2011. 
MENON, V.; RAO, M. Trends in bioconversion of lignocellulose: Biofuels, platform chemicals \& biorefinery concept. Progress in Energy and Combustion Science, v. 38, n. 4, p. 522-550, 2012.

MIAN, A.; ENSINAS, A. V.; MARECHAL, F. Multi-objective optimization of SNG production from microalgae through hydrothermal gasification. Computers \& Chemical Engineering, v. 76, p. 170-183, 2015.

MIKULANDRIC, R., LONCAR, D.; BOHNING, D.; BOHME, R. Biomass gasification process modelling approachesProceedings of the $8^{\mathrm{TH}}$ Conference on Sustainable Development of Energy, Water and Environment Systems - SDEWES. Anais...Dubrovnik, Croatia: 2013

MILANEZ, A. Y. et al. De promessa a realidade : como o etanol celulósico pode revolucionar a indústria da cana-de-açúcar - uma avaliação do potencial competitivo e sugestões de política pública. Biocombustíveis BNDES setorial, v. 41, p. 237-294, 2015.

MME, M. DE M. E E.-. Balanço Energético Nacional 2016, ano base 2015. Rio de Janeiro. Disponível em: <https://ben.epe.gov.br/>.

MODESTO, M.; NEBRA, S.; ZEMP, R. J. A proposal to calculate the exergy of non ideal mixtures ethanol-water using properties of excess.Proceedings of 14th European Biomass Conference \& Exhibition. Biomass for Energy, Industry and Climate Protection. Anais...Paris: ETA-Florence, Italy. WIP-Munich, Germany, 2005.

MODESTO, M.; ZEMP, R. J.; NEBRA, S. A. Ethanol Production from Sugar Cane: Assessing the Possibilities of Improving Energy Efficiency through Exergetic Cost Analysis. Heat Transfer Engineering, v. 30, n. 4, p. 272-281, 2009.

MOLYNEAUX, A. A practical evolutionary method for the multi-objective optimization of complex integrated energy systems including vehicle drive trains. École Polytechnique Fédérale de Lausanne (EPFL), 2002. 
MOSIER, N. et al. Features of promising technologies for pretreatment of lignocellulosic biomass. Bioresource Technology, v. 96, n. 6, p. 673-686, 2005.

MOSQUEIRA-SALAZAR, K. J. et al. Reduction of water consumption in an integrated firstand second-generation ethanol plant. Energy for Sustainable Development, v. 17, n. 5, p. $531-535,2013$.

NEBRA, S. ; FERNANDEZ-PARRA, M. . The exergy of sucrose-water solutions: proposal of a calculation method.Proceeding of 18th International Conference on Efficiency, Cost, Optimization, Simulation and Environmental Impact of Energy Systems. Anais...Trondheim, Noruega: 2005.

NIKOO, M. B.; MAHINPEY, N. Simulation of biomass gasification in fluidized bed reactor using ASPEN PLUS. Biomass and Bioenergy, v. 32, n. 12, p. 1245-1254, 2008.

OJEDA, K.; EL-HALWAGI, M.; KAFAROV, V. Design of a lignocellulosic feedstock biorefinery. In: STUART, P.; EL-HALWAGI, M. (Eds.). . Integrated Biorefineries: Design, Analysis, and Optimization. CRC Press Book, 2012.

OJEDA, K. et al. Evaluation of technological alternatives for process integration of sugarcane bagasse for sustainable biofuels production-Part 1. Chemical Engineering Research and Design, v. 89, n. 3, p. 270-279, 2011a.

OJEDA, K. et al. Exergy analysis and process integration of bioethanol production from acid pre-treated biomass: Comparison of SHF, SSF and SSCF pathways. Chemical Engineering Journal, v. 176-177, p. 195-201, 2011b.

OJEDA, K.; KAFAROV, V. Exergy analysis of enzymatic hydrolysis reactors for transformation of lignocellulosic biomass to bioethanol. Chemical Engineering Journal, v. 154, n. 1-3, p. 390-395, 2009.

OJEDA, K.; SÁNCHEZ, E.; KAFAROV, V. Sustainable ethanol production from lignocellulosic biomass - Application of exergy analysis. Energy, v. 36, n. 4, p. 2119-2128, 2011. 
OLOFSSON, I.; NORDIN, A.; SÖDERLIND, U. Initial review and evaluation of process technologies and systems suitable for cost efficient medium scale gasification for biomass to liquid fuels. Umeå: Disponível em: 〈http://www.biofuelregion.se/dokument/5_95.pdf>.

PALACIOS-BERECHE, R. Modelagem e integração energética do processo de produção de etanol a partir da biomassa de cana-de-açúcar. [s.l.] Universidade Estadual de Campinas, Campinas-SP, 2011.

PALACIOS-BERECHE, R. et al. Exergetic analysis of the integrated first- and secondgeneration ethanol production from sugarcane. Energy, v. 62, p. 46-61, 2013.

PALACIOS-BERECHE, R. et al. Double-effect distillation and thermal integration applied to the ethanol production process. Energy, v. 82, p. 512-523, 2015.

PANDEY, A. et al. Pretreatment of biomass : processes and technologies.

PAVIET, F.; CHAZARENC, F.; TAZEROUT, M. Thermo Chemical Equilibrium Modelling of a Biomass Gasifying Process Using Thermo Chemical Equilibrium Modelling of a Biomass Gasifying Process Using ASPEN PLUS. INTERNATIONAL JOURNAL OF CHEMICAL, v. 7, 2009.

PEDUZZI, E. et al. Torrefaction modelling for lignocellulosic biomass conversion processes. Energy, v. 70, p. 58-67, 2014.

PELLEGRINI, L. et al. Modern concept for ethanol distilleries: maximization of the electricity surplusENCIT. Anais. 2008.

PELLEGRINI, L.; DE OLIVEIRA JR, S. Exergy analysis of sugarcane bagasse gasification. Energy, v. 32, n. 4, p. 314-327, 2007.

PELLEGRINI, L. F. Análise e otimização termo-econômica-ambiental aplicada à produção combinada de açúcar, álcool e eletricidade. [s.1.] Universidade de São Paulo, São Paulo, 2009. 
PELLEGRINI, L. F.; DE OLIVEIRA JUNIOR, S. Combined production of sugar, ethanol and electricity: Thermoeconomic and environmental analysis and optimization. Energy, v. 36, n. 6, p. 3704-3715, 2011.

PETERS, M.; TIMMERHAUS, K. Plant Design and Economics for Chemical Engineers. 4TH. ed. Boston, USA: McGrawHil, 2001.

PIEKARCZYK, W. et al. Thermodynamic evaluation of biomass-to-biofuels production systems. Energy, v. 62, p. 95-104, 2013.

PRASAD, S.; SINGH, A.; JOSHI, H. C. Ethanol as an alternative fuel from agricultural, industrial and urban residues. Resources, Conservation and Recycling, v. 50, n. 1, p. 1-39, 2007.

PRINS, M. J.; PTASINSKI, K. J.; JANSSEN, F. J. J. G. Exergetic optimisation of a production process of Fischer-Tropsch fuels from biomass. Fuel Processing Technology, v. 86, n. 4, p. 375-389, 2004.

PTASINSKI, K. J.; PRINS, M. J.; PIERIK, A. Exergetic evaluation of biomass gasification. Energy, v. 32, n. 4, p. 568-574, 2007.

PUIG-ARNAVAT, M.; BRUNO, J. C.; CORONAS, A. Review and analysis of biomass gasification models. Renewable and Sustainable Energy Reviews, v. 14, n. 9, p. 28412851, 2010.

RABELO, S. C. Avaliação e otimização de pré-tratamentos e hidrólise enzimática do bagaço de cana-de-açúcar para a produção de etanol de segunda geração. [s.l.] Universidade Estadual de Campinas, Campinas-SP, 2010.

RABELO, S. C. et al. Production of bioethanol, methane and heat from sugarcane bagasse in a biorefinery concept. Bioresource Technology, v. 102, n. 17, p. 7887-7895, 2011.

REIN, P. Cane sugar engineering. Berlin: Verlag, 2007. 
RENEWABLE FUELS ASSOCIATION. Ethanol industry outlook, World Fuel Ethanol

Production. Disponível em: <http://www.ethanolrfa.org/resources/publications/outlook/>. Acesso em: $20 \mathrm{dez} .2015$.

ROCHA, G. et al. Compositional variability of raw, steam-exploded and delignificated sugarcane bagasseProceedings of the 8th International Congress on Distributed Generation and Energy in Rural Areas-AGRENER GD. Anais. 2010.

RUIZ, J. A. et al. Biomass gasification for electricity generation: Review of current technology barriers. Renewable and Sustainable Energy Reviews, v. 18, p. 174-183, 2013.

SAIDUR, R. et al. A review on exergy analysis of biomass based fuels. Renewable and Sustainable Energy Reviews, v. 16, n. 2, p. 1217-1222, 2012.

SANTOS, F. et al. Potencial da palha de cana-de-açúcar para produção de etanol. Quim. Nova, v. 35, n. 5, p. 1004-1010, 2012.

SATYANARAYANA, K. G.; GUIMARÃES, J. L.; WYPYCH, F. Studies on lignocellulosic fibers of Brazil. Part I: Source, production, morphology, properties and applications. Composites Part A: Applied Science and Manufacturing, v. 38, n. 7, p. 1694-1709, 2007.

SEABRA, J. E. A.; MACEDO, I. C. TECHNOLOGY OPTIONS FOR THE FUTURE SUGARCANE BIOREFINERIES. In: COORDENADOR, L. A. B. C.-; FAPESP (Eds.). Sugarcane bioethanol — R\&D for Productivity and Sustainability. Blucher, 2010.

SECCHI, A. R. Otimização de Processos. Disponível em: <http://www2.peq.coppe.ufrj.br/Pessoal/Professores/Arge/>.

SIENIUTYCZ, S. A Synthesis of Thermodynamic Models Unifying Traditional and WorkDriven Operations with Heat and Mass Exchange. Open Systems \& Information Dynamics, v. 10, n. 1, p. 31-49, 2003.

SILVA, P.; FLÓREZ-ORREGO, D. EXERGIA: Conceituação e Aplicação. São Paulo: Disponível em: <http://www.academia.edu/3315176/Exergia_Conceituacao_e_Aplicacao>. 
SONG, G. et al. Exergy evaluation of biomass steam gasification via interconnected fluidized beds. International Journal of Energy Research, v. 37, n. 14, p. 1743-1751, 2013.

SRINIVAS, S.; FIELD, R. P.; HERZOG, H. J. Modeling Tar Handling Options in Biomass Gasification. Energy \& Fuels, v. 27, n. 6, p. 2859-2873, 2013.

STEVEnS, D. J. Hot Gas Conditioning: Recent Progress with Larger-Scale Biomass Gasification Systems, Update and Summary of recent Progress.

SUES, A.; JURAŠČÍK, M.; PTASINSKI, K. Exergetic evaluation of 5 biowastes-to-biofuels routes via gasification. Energy, v. 35, n. 2, p. 996-1007, 2010.

SUN, Y.; CHENG, J. Hydrolysis of lignocellulosic materials for ethanol production: A review. Bioresource Technology, v. 83, n. 1, p. 1-11, 2002.

SZARGUT, J.; MORRIS, D.; STEWARD, F. Exergy analysis of thermal, chemical, and metallurgical processes. New York: Hemisphere Publishing Corporation, 1988.

TAILLON, J.; BLANCHARD, R. Exergy analysis of biomass cogeneration systems based on gasification and combustionProceedings 3rd International Exergy, Life Cycle Assessment, and Sustainability Workshop \& Symposium (ELCAS). Anais. Nisyros - Greece: 2013.

TSATSARONIS, G. Thermoeconomic analysis and optimization of energy systems. Progress in Energy and Combustion Science, v. 19, n. 3, p. 227-257, 1993.

TURTON, R. Analysis, synthesis, and design of chemical processes. 3rd. ed. Prentice Hall, 2009.

U.S. DEPARTMENT OF ENERGY. The Technology Roadmap for Plant/Crop-Based Renewable Resources 2020. Research Priorities for Fulfilling A Vision To Enhance U.S. Economic Security. Disponível em: 〈http://energy.gov/〉. 
ULRICH, G.; VASUDEVAN, P. A guide to chemical engineering process design and economics. 2nd. ed. CRC, 2003.

UNICA. Produção brasileira de etanol. Disponível em: <http://www.unica.com.br/unica/> . Acesso em: 1 out. 2015.

VAN DER HEIJDEN, H.; PTASINSKI, K. J. Exergy analysis of thermochemical ethanol production via biomass gasification and catalytic synthesis. Energy, v. 46, n. 1, p. 200-210, 2012.

VAZ JÚNIOR, S. Biomassa para química verde. Brasília, DF: Embrapa Agroenergia, 2013.

VELÁSQUEZ, H. I. Avaliação exergética e exergo-ambiental da produção de biocombustíveis. Universidade de São Paulo, São Paulo., 2009.

VELÁSQUEZ, H. I. et al. Exergo-environmental evaluation of liquid biofuel production processes. Energy, v. 54, p. 97-103, 2013.

WOOLEY, R. J.; PUTSCHE, V. Development of an Aspen Plus physical property database for biofuels components. Golden, Colorado, USA. Disponível em: <http://www.nrel.gov/docs/legosti/old/20685.pdf>.

YOO, M.-J. et al. 12th International Symposium on Process Systems Engineering and 25th European Symposium on Computer Aided Process Engineering. Elsevier, 2015. v. 37

ZHENG, Y.; PAN, Z.; ZHANG, R. Overview of biomass pretreatment for cellulosic ethanol production. International Journal of Agricultural and Biological Engineering, v. 2, n. 3, p. 51-68, 2009. 


\section{APÊNDICE A. MÁXIMA RECUPERAÇÃo DE ENERGIA PARA PROCESSOS DE PRÉ-TRATAMENTO DA BIOMASSA.}

Nesta seção, são apresentados os resultados da integração de processos para os métodos de pré-tratamento da biomassa visando determinar o mínimo de energia requerida (MER) nas configurações. Este parâmetro representa o melhor aproveitamento da energia (recuperação máxima possível) em uma rede de trocador de calor para um determinado valor de $\Delta$ Tmim. As especificações utilizadas para a simulação dos métodos de pré-tratamento são encontradas em Silva e Oliveira Jr. (2014).

A princípio, os fluxos quentes e frios dos processos junto à entalpia correspondente e perfis de temperatura são identificados. As correntes quentes são por definição fluxos que requerem resfriamento enquanto correntes frias são fluxos que requerem aquecimento.

Posteriormente, os fluxos são utilizados para construir a cascata de calor, que pode ser representada graficamente pela Curva Composta e Grande Curva Composta do processo, em termos do perfil de temperatura e entalpia, como ilustrado na análise dos métodos de prétratamento da Fig. A.1 à Fig. A.3.

A curva composta "quente" é obtida agregando o calor dos diferentes fluxos quentes no mesmo intervalo de temperatura e, por conseguinte, representa o calor disponível do processo. Equivalentemente, a curva composta "fria" é composta por todos os fluxos frios e, por conseguinte, representa a necessidade de calor.

A transferência de calor pode ocorrer somente se a diferença de temperatura entre as curvas compostas é maior que o conjunto $\Delta$ Tmin. A grande curva composta mostra o calor líquido trocado por intervalo de temperatura e é obtida pela subtração entre a curva composta quente e a curva composta fria. Esta representação gráfica é especialmente útil para exibir a integração de certas unidades, em particular, para uma rede de vapor com o resto do processo. 
Fig. A.1 e Fig. A.3 mostraram a curva composta e a grande curva composta para os prétratamentos estudados de LHW e SE, respectivamente. Observa-se que ambas as curvas têm ponto de pinch semelhante à temperatura em torno de $94{ }^{\circ} \mathrm{C}$. Por último, a abordagem MER da configuração envolvendo o pré-tratamento combinado dos métodos LHW e SE foi de 115 ${ }^{\circ} \mathrm{C}$ (ponto de pinch), tal como apresentado na Fig. A.1. Adicionalmente, os parâmetros adoptados na determinação do MER para cada pré-tratamento será apresentada da Tab. A.1 à Tab. A.3. Destaca-se que o método Organosolv não foi considerado na análise devido ao seu baixo potencial de integração térmica.

Figura A.1 - MER - Explosão a vapor (SE).
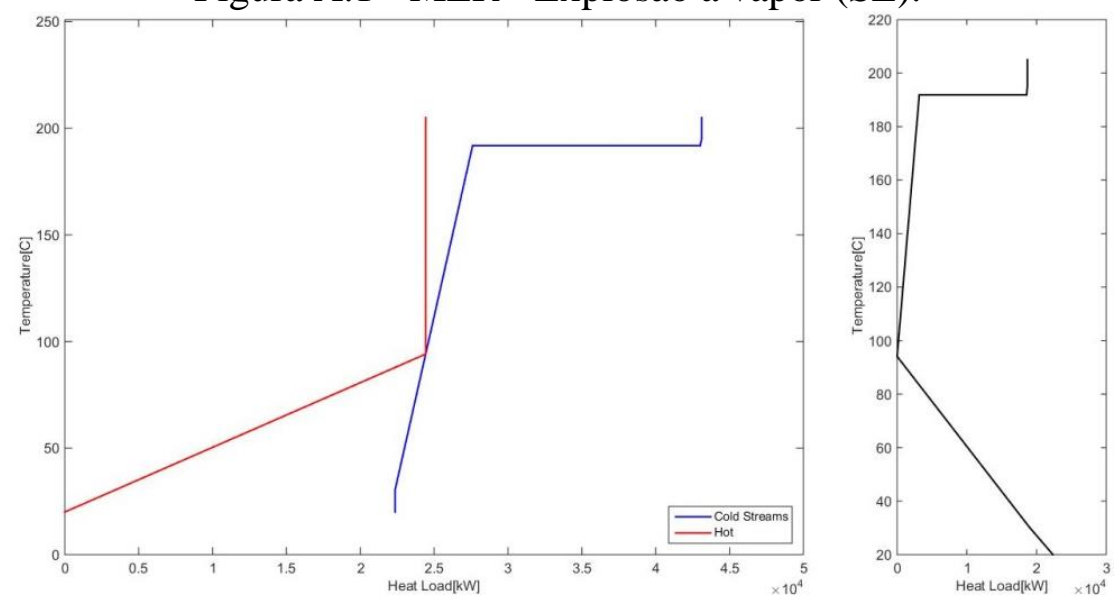

\section{Curva Composta}

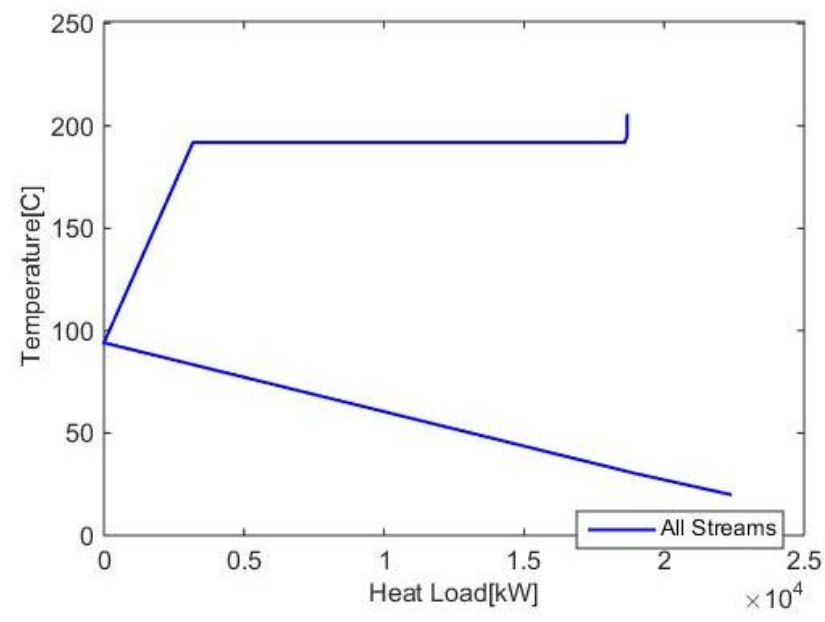

Grande Curva Composta

Fonte: Elaborado pelo autor. 
Tabela A.1 - Parâmetros MER - Explosão a vapor (SE).

\begin{tabular}{cccccc}
\hline Unit & $\begin{array}{c}\text { Stream } \\
\text { Name }\end{array}$ & Tin & Tout & Q & Stream \\
& & {$\left[{ }^{\circ} \mathrm{C}\right]$} & {$\left[{ }^{\circ} \mathrm{C}\right]$} & {$[\mathrm{kW}]$} & \\
\hline PRET-SE & HE1 & 25,3 & 189,9 & 5348.76 & cold \\
PRET-SE & HE2 & 189,9 & 189,9 & 15405.11 & cold \\
PRET-SE & HE3 & 189,9 & 190 & 1.405 & cold \\
PRET-SE & HE4 & 99,1 & 25 & 18406.65 & hot \\
PRET-SE & HE5 & 99,1 & 25 & 6019.52 & hot \\
\hline
\end{tabular}

Fonte: Elaborado pelo autor.

Figura A.2 - MER - LHW.

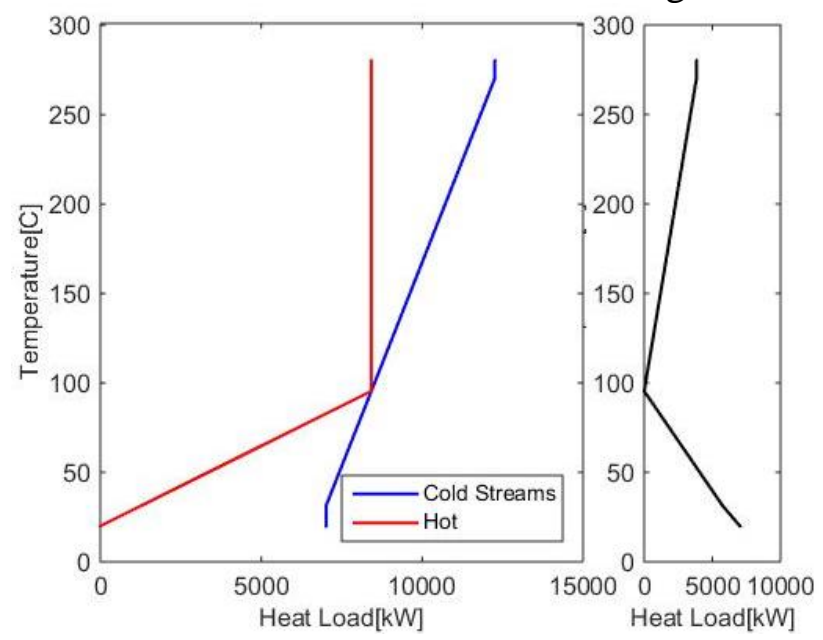

Composite Curve

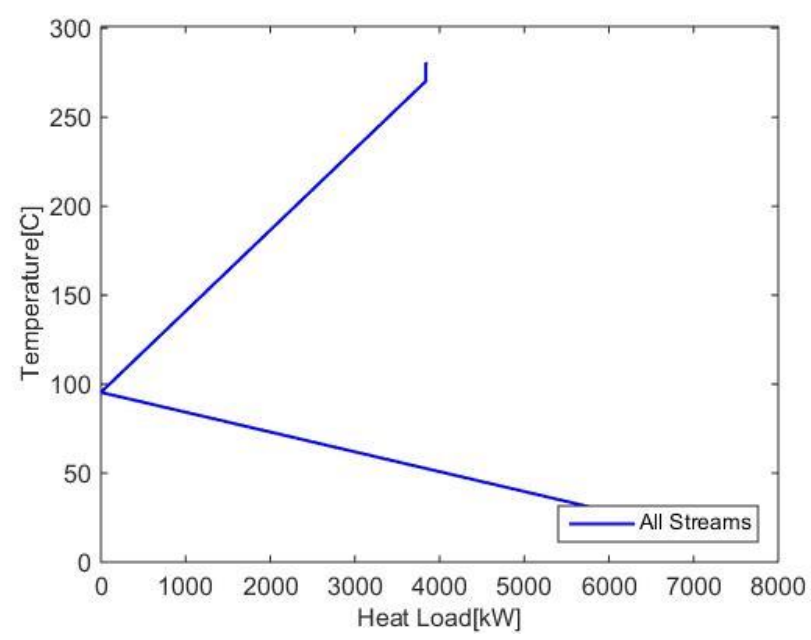

Grand Composite Curve

Fonte: Elaborado pelo autor.

Tabela A.2 - Parâmetros MER - Água quente pressurizada (LHW).

\begin{tabular}{cccccc}
\hline Unit & $\begin{array}{c}\text { Stream } \\
\text { Name }\end{array}$ & Tin & Tout & Q & Stream \\
& & {$\left[{ }^{\circ} \mathrm{C}\right]$} & {$\left[{ }^{\circ} \mathrm{C}\right]$} & {$[\mathrm{kW}]$} & \\
\hline PRET-SE & HE1 & 25,3 & 189,9 & 5348.76 & cold \\
PRET-SE & HE2 & 189,9 & 189,9 & 15405.11 & cold \\
PRET-SE & HE3 & 189,9 & 190 & 1.405 & cold \\
PRET-SE & HE4 & 99,1 & 25 & 18406.65 & hot \\
PRET-SE & HE5 & 99,1 & 25 & 6019.52 & hot \\
\hline
\end{tabular}

Fonte: Elaborado pelo autor. 
Figura A.3 - MER - Pré-tratamento combinado entre SE e LHW.
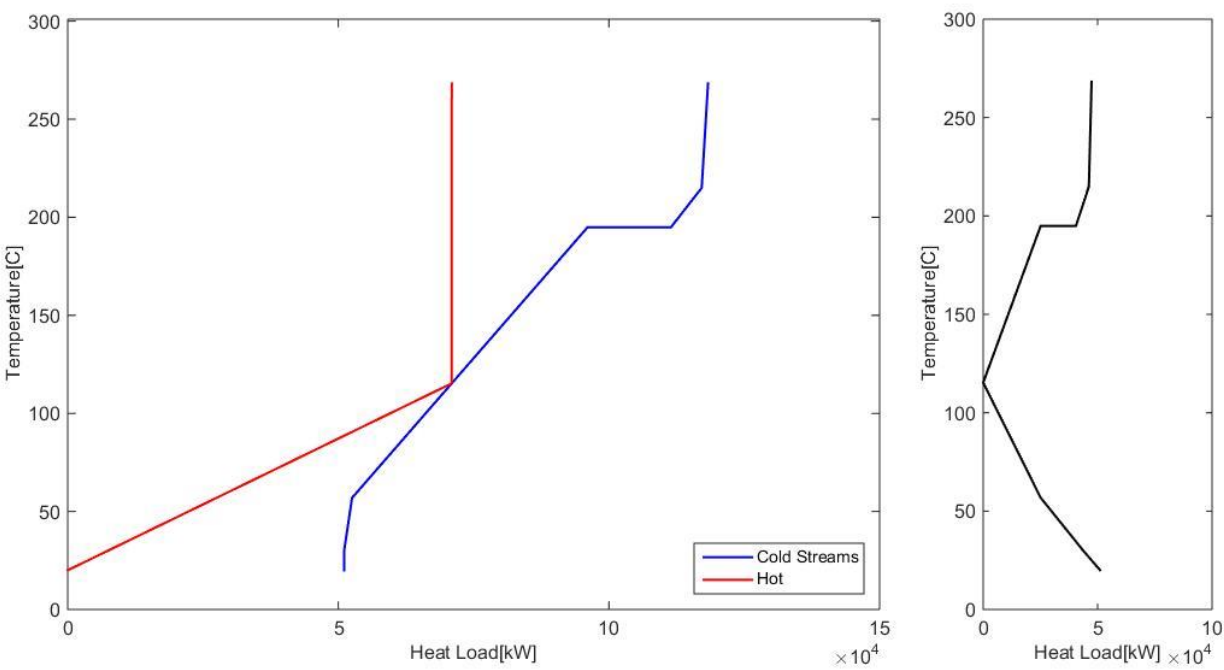

Curva composta

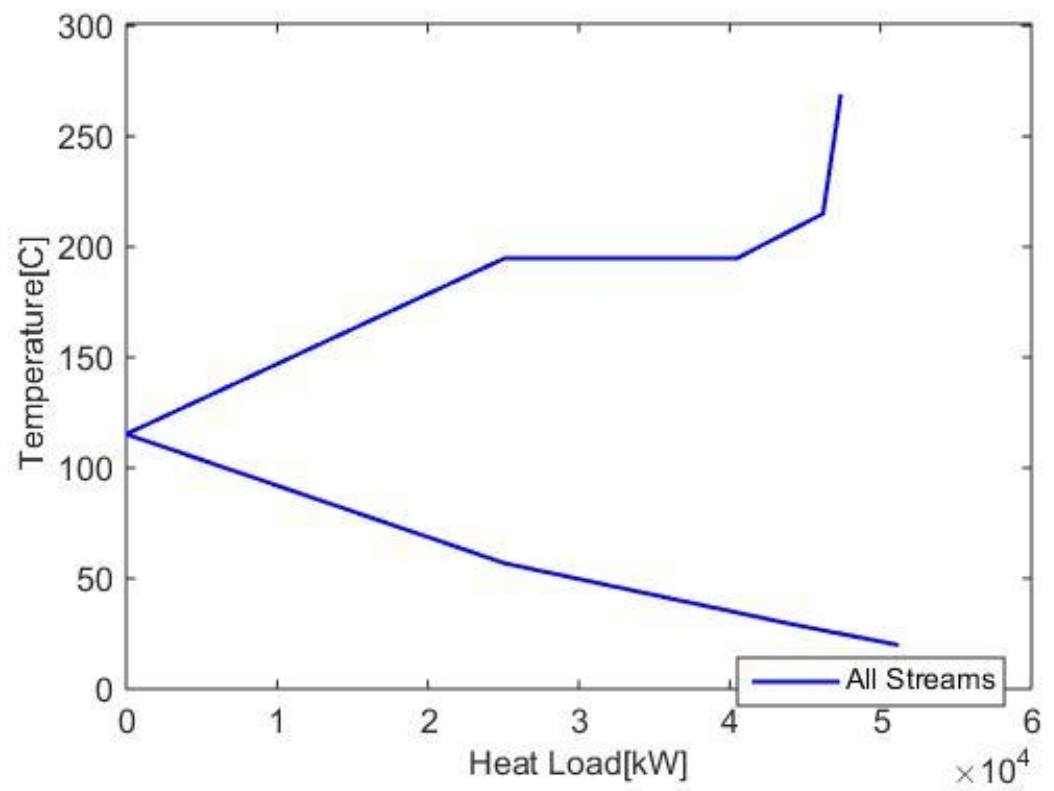

Grande curva composta

Fonte: Elaborado pelo autor. 
Tabela A.3 - Parâmetros MER - Pré-tratamento combinado entre SE e LHW.

\begin{tabular}{cccccc}
\hline Unit & Stream Name & $\begin{array}{c}\text { Tin } \\
{\left[{ }^{\circ} \mathrm{C}\right]}\end{array}$ & $\begin{array}{c}\text { Tout } \\
{\left[{ }^{\circ} \mathrm{C}\right]}\end{array}$ & $\begin{array}{c}\mathrm{Q} \\
{[\mathrm{kW}]}\end{array}$ & \begin{tabular}{c} 
Stream \\
\hline PRET-SE_LHW
\end{tabular} \\
PRET-SE_LHW & HE1 & 25,3 & 189,9 & 5348.76 & cold \\
PRET-SE_LHW & HE3 & 189,9 & 190 & 1.40 & cold \\
PRET-SE_LHW & HE4 & 120,3 & 25 & 68858.93 & hot \\
PRET-SE_LHW & HE5 & 120,3 & 25 & 2088.02 & hot \\
PRET-SE_LHW & HE6 & 31,9 & 190 & 41235.51 & cold \\
PRET-SE_LHW & HE7 & 26,4 & 265,2 & 5240.46 & cold \\
PRET-SE_LHW & HE8 & 265,2 & 265 & 5.4175 & hot \\
\hline
\end{tabular}

Fonte: Elaborado pelo autor. 


\section{APÊNDICE B. DETERMINAÇÃO DO MÍNIMO DE ENERGIA REQUERIDA NAS ROTAS TECNOLÓGICAS.}

Tabela B.1 - Parâmetros MER - Rota 1.

\begin{tabular}{|c|c|c|c|c|c|c|c|c|c|}
\hline & & Tin & Tin & Tout & Tout & $Q$ & Stream & Tin & Tout \\
\hline Unit & Stream Name & {$\left[{ }^{\circ} \mathrm{C}\right]$} & {$[K]$} & {$\left[{ }^{\circ} \mathrm{C}\right]$} & {$[K]$} & {$[k W]$} & & $1-T o / T$ & $1-\mathrm{TO} / \mathrm{T}$ \\
\hline TRATCAL & HE1 & 34,2 & 307,35 & 105 & 378,15 & 44104,44 & cold & 0,111 & 0,278 \\
\hline TRATCAL & HE2 & 115,8 & 388,95 & 115 & 388,15 & 44302,47 & hot & 0,298 & 0,296 \\
\hline COGERA & HE3 & 127,4 & 400,55 & 102 & 375,15 & 6762,39 & hot & 0,318 & 0,272 \\
\hline COGERA & ECO1 & 275,69 & 548,84 & 197,78 & 470,93 & 14432,66 & hot & 0,502 & 0,42 \\
\hline COGERA & $\mathrm{ECO} 2$ & 24 & 297,15 & 25 & 298,15 & 14432,66 & cold & 0,081 & 0,084 \\
\hline COGERA & PRE1 & 356,45 & 629,6 & 275,69 & 548,84 & 15285,65 & hot & 0,566 & 0,502 \\
\hline COGERA & PRE2 & 29 & 302,15 & 150 & 423,15 & 15285,65 & cold & 0,096 & 0,354 \\
\hline COGERA & EVA1 & 994,9 & 1268,05 & 356,45 & 629,6 & 132953,8 & hot & 0,785 & 0,566 \\
\hline COGERA & EVA2 & 25 & 298,15 & 26 & 299,15 & 132953,8 & cold & 0,084 & 0,087 \\
\hline COGERA & SUP1 & 1164,96 & 1438,11 & 994,9 & 1268,05 & 38289,55 & hot & 0,81 & 0,785 \\
\hline COGERA & SUP2 & 285,81 & 558,96 & 480 & 753,15 & 38289,55 & cold & 0,511 & 0,637 \\
\hline EVAP & EVAH1h & 127,42 & 400,57 & 127,42 & 400,57 & 49746,93 & hot & 0,318 & 0,318 \\
\hline EVAP & EVAH1c & 98,05 & 371,2 & 116,06 & 389,21 & 49746,93 & cold & 0,264 & 0,298 \\
\hline EVAP & $\mathrm{EVAH} 2 \mathrm{~h}$ & 116,069 & 389,219 & 115,02 & 388,17 & 3265,95 & hot & 0,298 & 0,296 \\
\hline EVAP & EVAH2c & 108,33 & 381,48 & 108,5 & 381,65 & 3265,95 & cold & 0,284 & 0,284 \\
\hline EVAP & EVAH3h & 108,5 & 381,65 & 107,31 & 380,46 & 3742,11 & hot & 0,284 & 0,282 \\
\hline EVAP & EVAH3c & 98,76 & 371,91 & 99,05 & 372,2 & 3742,11 & cold & 0,266 & 0,266 \\
\hline EVAP & EVAH4h & 99,05 & 372,2 & 97,61 & 370,76 & 4268,03 & hot & 0,266 & 0,263 \\
\hline EVAP & EVAH4c & 84,57 & 357,72 & 85,13 & 358,28 & 4268,03 & cold & 0,236 & 0,238 \\
\hline EVAP & EVAH5h & 85,13 & 358,28 & 83,2 & 356,35 & 4925,37 & hot & 0,238 & 0,233 \\
\hline EVAP & EVAH5c & 57,05 & 330,2 & 58,56 & 331,71 & 4925,37 & cold & 0,173 & 0,177 \\
\hline EVAP & AQEST & 95,7 & 368,85 & 130 & 403,15 & 14815,79 & cold & 0,259 & 0,322 \\
\hline EVAP & REEST & 130 & 403,15 & 32 & 305,15 & 41783,98 & hot & 0,322 & 0,105 \\
\hline FERM & TCFER & 28 & 301,15 & 39,5 & 312,65 & 12416,57 & cold & 0,093 & 0,126 \\
\hline DEST & HE4h & 84,93 & 358,08 & 35 & 308,15 & 20189,11 & hot & 0,237 & 0,114 \\
\hline DEST & HE4c & 30 & 303,15 & 48,45 & 321,6 & 20189,11 & cold & 0,099 & 0,151 \\
\hline DEST & HE5h & 81,64 & 354,79 & 81,63 & 354,78 & 16345,1 & hot & 0,23 & 0,23 \\
\hline DEST & HE5C & 31,22 & 304,37 & 60 & 333,15 & 16345,1 & cold & 0,103 & 0,18 \\
\hline DEST & HE6h & 81,63 & 354,78 & 81,62 & 354,77 & 10050,87 & hot & 0,23 & 0,23 \\
\hline DEST & HE6C & 30 & 303,15 & 49,99 & 323,14 & 10050,87 & cold & 0,099 & 0,155 \\
\hline DEST & HE7h & 109,32 & 382,47 & 75,29 & 348,44 & 17981,63 & hot & 0,286 & 0,216 \\
\hline DEST & HE7C & 60 & 333,15 & 90 & 363,15 & 17981,63 & cold & 0,18 & 0,248 \\
\hline DESID & CCEX & 30 & 303,15 & 50 & 323,15 & 7575,46 & cold & 0,099 & 0,155 \\
\hline DESID & RAEAC & 78,3 & 351,45 & 35 & 308,15 & 8800,78 & hot & 0,223 & 0,114 \\
\hline DESID & CCRE & 30 & 303,15 & 50 & 323,15 & 1229,23 & cold & 0,099 & 0,155 \\
\hline DESID & RESFh & 149,59 & 422,74 & 90 & 363,15 & 910,53 & hot & 0,354 & 0,248 \\
\hline DESID & RESFc & 30 & 303,15 & 50 & 323,15 & 910,53 & cold & 0,099 & 0,155 \\
\hline
\end{tabular}

Fonte: Elaborado pelo autor. 
Tabela B.2 - Parâmetros MER - Rota 2.

\begin{tabular}{|c|c|c|c|c|c|c|c|c|c|}
\hline & & Tin & Tin & Tout & Tout & $Q$ & Stream & Tin & Tout \\
\hline Unit & Stream Name & {$\left[{ }^{\circ} \mathrm{C}\right]$} & {$[K]$} & {$\left[{ }^{\circ} \mathrm{C}\right]$} & {$[K]$} & {$[k W]$} & & $1-T o / T$ & $1-\mathrm{To} / \mathrm{T}$ \\
\hline TRATCAL & HE1 & 34,2 & 307,35 & 105 & 378,15 & 44104,44 & cold & 0,111 & 0,278 \\
\hline TRATCAL & HE2 & 115,8 & 388,95 & 115 & 388,15 & 44302,47 & hot & 0,298 & 0,296 \\
\hline COGERA & HE3 & 127,4 & 400,55 & 102 & 375,15 & 6762,39 & hot & 0,318 & 0,272 \\
\hline COGERA & ECO1 & 275,69 & 548,84 & 197,78 & 470,93 & 14432,66 & hot & 0,502 & 0,42 \\
\hline COGERA & $\mathrm{ECO} 2$ & 24 & 297,15 & 25 & 298,15 & 14432,66 & cold & 0,081 & 0,084 \\
\hline COGERA & PRE1 & 356,45 & 629,6 & 275,69 & 548,84 & 15285,65 & hot & 0,566 & 0,502 \\
\hline COGERA & PRE2 & 29 & 302,15 & 150 & 423,15 & 15285,65 & cold & 0,096 & 0,354 \\
\hline COGERA & EVA1 & 994,9 & 1268,05 & 356,45 & 629,6 & 132953,8 & hot & 0,785 & 0,566 \\
\hline COGERA & EVA2 & 25 & 298,15 & 26 & 299,15 & 132953,8 & cold & 0,084 & 0,087 \\
\hline COGERA & SUP1 & 1164,96 & 1438,11 & 994,9 & 1268,05 & 38289,55 & hot & 0,81 & 0,785 \\
\hline COGERA & SUP2 & 285,81 & 558,96 & 480 & 753,15 & 38289,55 & cold & 0,511 & 0,637 \\
\hline FERM & TCFER & 28 & 301,15 & 39,5 & 312,65 & 12416,57 & cold & 0,093 & 0,126 \\
\hline DEST & HE4h & 84,93 & 358,08 & 35 & 308,15 & 20189,11 & hot & 0,237 & 0,114 \\
\hline DEST & $\mathrm{HE} 4 \mathrm{C}$ & 30 & 303,15 & 48,45 & 321,6 & 20189,11 & cold & 0,099 & 0,151 \\
\hline DEST & HE5h & 81,64 & 354,79 & 81,63 & 354,78 & 16345,1 & hot & 0,23 & 0,23 \\
\hline DEST & HE5C & 31,22 & 304,37 & 60 & 333,15 & 16345,1 & cold & 0,103 & 0,18 \\
\hline DEST & HE6h & 81,63 & 354,78 & 81,62 & 354,77 & 10050,87 & hot & 0,23 & 0,23 \\
\hline DEST & HE6C & 30 & 303,15 & 49,99 & 323,14 & 10050,87 & cold & 0,099 & 0,155 \\
\hline DEST & HE7h & 109,32 & 382,47 & 75,29 & 348,44 & 17981,63 & hot & 0,286 & 0,216 \\
\hline DEST & HE7c & 60 & 333,15 & 90 & 363,15 & 17981,63 & cold & 0,18 & 0,248 \\
\hline DESID & CCEX & 30 & 303,15 & 50 & 323,15 & 7575,46 & cold & 0,099 & 0,155 \\
\hline DESID & RAEAC & 78,3 & 351,45 & 35 & 308,15 & 8800,78 & hot & 0,223 & 0,114 \\
\hline DESID & CCRE & 30 & 303,15 & 50 & 323,15 & 1229,23 & cold & 0,099 & 0,155 \\
\hline DESID & RESFh & 149,59 & 422,74 & 90 & 363,15 & 910,53 & hot & 0,354 & 0,248 \\
\hline DESID & RESFc & 30 & 303,15 & 50 & 323,15 & 910,53 & cold & 0,099 & 0,155 \\
\hline EVAPCALD & HE10 & 115 & 388,15 & 35 & 308,15 & 9025,06 & hot & 0,296 & 0,114 \\
\hline EVAPCALD & HE11 & 115 & 388,15 & 115 & 388,15 & 59081,15 & cold & 0,296 & 0,296 \\
\hline EVAPCALD & HE12 & 116 & 389,15 & 115 & 388,15 & 642,37 & hot & 0,298 & 0,296 \\
\hline EVAPCALD & HE20 & 107 & 380,15 & 35 & 308,15 & 2265,02 & hot & 0,281 & 0,114 \\
\hline EVAPCALD & HE21 & 107 & 380,15 & 107 & 380,15 & 16580,62 & cold & 0,281 & 0,281 \\
\hline EVAPCALD & HE22 & 108 & 381,15 & 107 & 380,15 & 166,52 & hot & 0,283 & 0,281 \\
\hline EVAPCALD & HE30 & 98 & 371,15 & 35 & 308,15 & 2107,83 & hot & 0,264 & 0,114 \\
\hline EVAPCALD & HE31 & 98 & 371,15 & 98 & 371,15 & 16764,75 & cold & 0,264 & 0,264 \\
\hline EVAPCALD & HE32 & 99 & 372,15 & 98 & 371,15 & 1449,04 & hot & 0,266 & 0,264 \\
\hline EVAPCALD & HE40 & 83 & 356,15 & 35 & 308,15 & 1539,43 & hot & 0,233 & 0,114 \\
\hline EVAPCALD & HE41 & 83 & 356,15 & 83 & 356,15 & 17428,26 & cold & 0,233 & 0,233 \\
\hline EVAPCALD & HE42 & 85 & 358,15 & 83 & 356,15 & 148,815 & hot & 0,237 & 0,233 \\
\hline EVAPCALD & HE50h & 55,29 & 328,44 & 35 & 308,15 & 639,27 & hot & 0,168 & 0,114 \\
\hline EVAPCALD & HE50c & 25 & 298,15 & 25,55 & 298,7 & 639,27 & cold & 0,084 & 0,086 \\
\hline EVAPCALD & HE51h & 55,3 & 328,45 & 55,29 & 328,44 & 17738,66 & hot & 0,168 & 0,168 \\
\hline EVAPCALD & HE51c & 25 & 298,15 & 40,27 & 313,42 & 17738,66 & cold & 0,084 & 0,128 \\
\hline EVAPCALD & HE52 & 61 & 334,15 & 55 & 328,15 & 172,17 & hot & 0,183 & 0,168 \\
\hline EVAPCALD & HE60h & 158,83 & 431,98 & 158,82 & 431,97 & 11573,36 & hot & 0,368 & 0,368 \\
\hline EVAPCALD & HE60c & 95,82 & 368,97 & 130 & 403,15 & 11573,36 & cold & 0,26 & 0,322 \\
\hline
\end{tabular}




\begin{tabular}{|c|c|c|c|c|c|c|c|c|c|}
\hline EVAPCALD & HE7Oh & 130 & 403,15 & 32 & 305,15 & 32652,85 & hot & 0,322 & 0,105 \\
\hline EVAPCALD & HE70c & 12 & 285,15 & 77,16 & 350,31 & 32652,85 & cold & 0,042 & 0,22 \\
\hline EVAPCALD & HE80 & 99 & 372,15 & 115 & 388,15 & 4470,18 & cold & 0,266 & 0,296 \\
\hline EVAPCALD & EVAH1h & 200 & 473,15 & 133,52 & 406,67 & 59726,97 & hot & 0,423 & 0,328 \\
\hline EVAPCALD & EVAH1C & 115,36 & 388,51 & 115,63 & 388,78 & 59726,97 & cold & 0,297 & 0,297 \\
\hline EVAPCALD & EVAH $2 \mathrm{~h}$ & 200 & 473,15 & 133,59 & 406,74 & 15495,77 & hot & 0,423 & 0,328 \\
\hline EVAPCALD & EVAH2c & 107,9 & 381,05 & 108,06 & 381,21 & 15495,77 & cold & 0,283 & 0,283 \\
\hline EVAPCALD & EVAH3h & 200 & 473,15 & 133,59 & 406,74 & 16956,99 & hot & 0,423 & 0,328 \\
\hline EVAPCALD & EVAH3c & 98,33 & 371,48 & 98,64 & 371,79 & 16956,99 & cold & 0,265 & 0,265 \\
\hline EVAPCALD & EVAH4h & 200 & 473,15 & 133,59 & 406,74 & 16219,33 & hot & 0,423 & 0,328 \\
\hline EVAPCALD & EVAH4c & 84,16 & 357,31 & 84,89 & 358,04 & 16219,33 & cold & 0,236 & 0,237 \\
\hline EVAPCALD & EVAH5h & 200 & 473,15 & 133,59 & 406,74 & 16247,26 & hot & 0,423 & 0,328 \\
\hline EVAPCALD & EVAH5c & 56,83 & 329,98 & 60,55 & 333,7 & 16247,26 & cold & 0,172 & 0,181 \\
\hline EVAPHYD & HE101h & & 390,1 & 35 & 308,15 & 22826,43 & hot & 0,3 & 0,114 \\
\hline EVAPHYD & HE101c & 25 & 298,15 & 44,66 & 317,81 & 22826,43 & cold & 0,084 & 0,141 \\
\hline EVAPHYD & HE111 & 116,94 & 390,09 & 116,95 & 390,1 & 145509 & cold & 0,3 & 0,3 \\
\hline EVAPHYD & HE121 & 117,22 & 390,37 & 116,94 & 390,09 & 1573,38 & hot & 0,3 & 0,3 \\
\hline EVAPHYD & HE202h & 107,31 & 380,46 & 35 & 308,15 & 1941,15 & hot & 0,282 & 0,114 \\
\hline EVAPHYD & & 25 & & & & & cold & & 0,084 \\
\hline EVAPHYD & HE212 & 107,29 & 380,44 & 107,32 & 380,47 & 14208,83 & cold & 0,282 & 0,282 \\
\hline EVAPHYD & HE222 & 107,6 & 380,75 & 107,29 & 380,44 & 137,07 & hot & 0,283 & 0,282 \\
\hline EVAPHYD & HE303h & 97,61 & 370,76 & 35 & 308,15 & 2290,12 & hot & 0,263 & 0,114 \\
\hline EVAPHYD & HE303c & 25 & 298,15 & 25,19 & 298,34 & 2290,12 & cold & 0,084 & 0,084 \\
\hline EVAPHYD & HE313 & 97,6 & 370,75 & 97,62 & 370,77 & 19605,31 & cold & 0,263 & 0,263 \\
\hline EVAPHYD & HE323 & 98 & 371,15 & 97,6 & 370,75 & 170,62 & hot & 0,264 & 0,263 \\
\hline EVAPHYD & HE404h & 83,2 & 356,35 & 35 & 308,15 & 1356,83 & hot & 0,233 & 0,114 \\
\hline EVAPHYD & HE404c & 25 & 298,15 & 25,97 & 299,12 & 1356,83 & cold & 0,084 & 0,087 \\
\hline EVAPHYD & HE414 & 83,2 & 356,35 & 83,2 & 356,35 & 15358,45 & cold & 0,233 & 0,233 \\
\hline EVAPHYD & HE424 & 83,72 & 356,87 & 83,2 & 356,35 & 116,28 & hot & 0,235 & 0,233 \\
\hline EVAPHYD & EVAH11h & 127,44 & 400,59 & 127,42 & 400,57 & 178614,8 & hot & 0,318 & 0,318 \\
\hline EVAPHYD & EVAH11c & 40,02 & 313,17 & 117,21 & 390,36 & 178614,8 & cold & 0,128 & 0,3 \\
\hline EVAPHYD & EVAH21h & 128 & 401,15 & 127,48 & 400,63 & 13065,73 & hot & 0,319 & 0,318 \\
\hline EVAPHYD & EVAH21c & 107,55 & 380,7 & 107,6 & 380,75 & 13065,73 & cold & 0,283 & 0,283 \\
\hline EVAPHYD & EVAH31h & 128 & 401,15 & 127,48 & 400,63 & 18755,42 & hot & 0,319 & 0,318 \\
\hline EVAPHYD & EVAH31c & 97,88 & 371,03 & 98 & 371,15 & 18755,42 & cold & 0,264 & 0,264 \\
\hline EVAPHYD & EVAH41h & 128 & 401,15 & 127,48 & 400,63 & 14495,67 & hot & 0,319 & 0,318 \\
\hline EVAPHYD & EVAH41c & 83,56 & 356,71 & 83,72 & 356,87 & 14495,67 & cold & 0,234 & 0,235 \\
\hline
\end{tabular}

Fonte: Elaborado pelo autor. 
Tabela B.3 - Parâmetros MER - Rota 3.

\begin{tabular}{|llcccccccc|}
\hline Unit & Stream Name & $\begin{array}{c}\text { Tin } \\
{\left[{ }^{\circ} \mathrm{C}\right]}\end{array}$ & $\begin{array}{c}\text { Tin } \\
{[\mathrm{K}]}\end{array}$ & $\begin{array}{c}\text { Tout } \\
{\left[{ }^{\circ} \mathrm{C}\right]}\end{array}$ & $\begin{array}{c}\text { Tout } \\
{[\mathrm{K}]}\end{array}$ & $\begin{array}{c}Q \\
{[\mathrm{~kW}]}\end{array}$ & Stream & $\begin{array}{c}\text { Tin } \\
1-\mathrm{To} / \mathrm{T}\end{array}$ & $\begin{array}{c}\text { Tout } \\
1-\mathrm{To} / \mathrm{T}\end{array}$ \\
\hline dryer & PRLAh & 127,41 & 400,56 & 127,41 & 400,56 & 7392,61 & hot & 0,31808 & 0,31808 \\
dryer & PRLAC & 25 & 298,15 & 80 & 353,15 & 7392,61 & cold & 0,08385 & 0,226533 \\
dryer & HX4h & 68,22 & 341,37 & 35 & 308,15 & 2193,29 & hot & 0,199842 & 0,113581 \\
dryer & HX4c & 25 & 298,15 & 25,188 & 298,338 & 2193,29 & cold & 0,08385 & 0,084428 \\
gasifier & HE1 & 25 & 298,15 & 175 & 448,15 & 15101,43 & cold & 0,08385 & 0,390494 \\
gasifier & HE2 & 1000 & 1273,15 & 25 & 298,15 & 347,25 & hot & 0,785453 & 0,08385 \\
gasifier & COND & 1000 & 1273,15 & 37 & 310,15 & 35761,91 & hot & 0,785453 & 0,119297 \\
gasifier & HE3 & 37 & 310,15 & 25 & 298,15 & 248,16 & hot & 0,119297 & 0,08385 \\
gasifier & HE4 & 37 & 310,15 & 25 & 298,15 & 183,39 & hot & 0,119297 & 0,08385 \\
CC & B4h & 571,88 & 845,03 & 193,72 & 466,87 & 169042,8 & hot & 0,676757 & 0,414933 \\
CC & B4c & 48,49 & 321,64 & 300 & 573,15 & 169042,8 & cold & 0,150759 & 0,523423 \\
CC & B6h & 224 & 497,15 & 46 & 319,15 & 160928,5 & hot & 0,450568 & 0,144133 \\
CC2 & BOILER & 46 & 319,15 & 215 & 488,15 & 2602,37 & cold & 0,144133 & 0,440438 \\
CC2 & CONDNSR & 46 & 319,15 & 46 & 319,15 & 1807,61 & cold & 0,144133 & 0,144133 \\
\hline
\end{tabular}

Fonte: Elaborado pelo autor. 


\section{APÊNDICE C. FLUXOS CONSIDERADOS NA ANÁLISE EXERGÉTICA DO GASEIFICADOR LEITO ARRASTADO}

Neste apêndice são apresentados os resultados envolvendo o projeto do gaseificador leito arrastado-EF utilizando o bagaço e a palha da cana como insumo energético, caso 7 e caso 8 , respectivamente. Na simulação destes estudos de caso da Rota Termoquímica $2 \mathrm{G}$ foi empregado o programa computacional (Vali®).

Nesse contexto, a Tab. C.1 ilustra a caracterização dos fluxos considerados na análise exergética do gaseificador EF quando empregado o bagaço da cana como combustível. Enquanto que na Tab. C.2 apresentam-se os fluxos envolvidos na análise exergética deste tipo de gaseificador, quando considerado a palha da cana como fonte energética. 


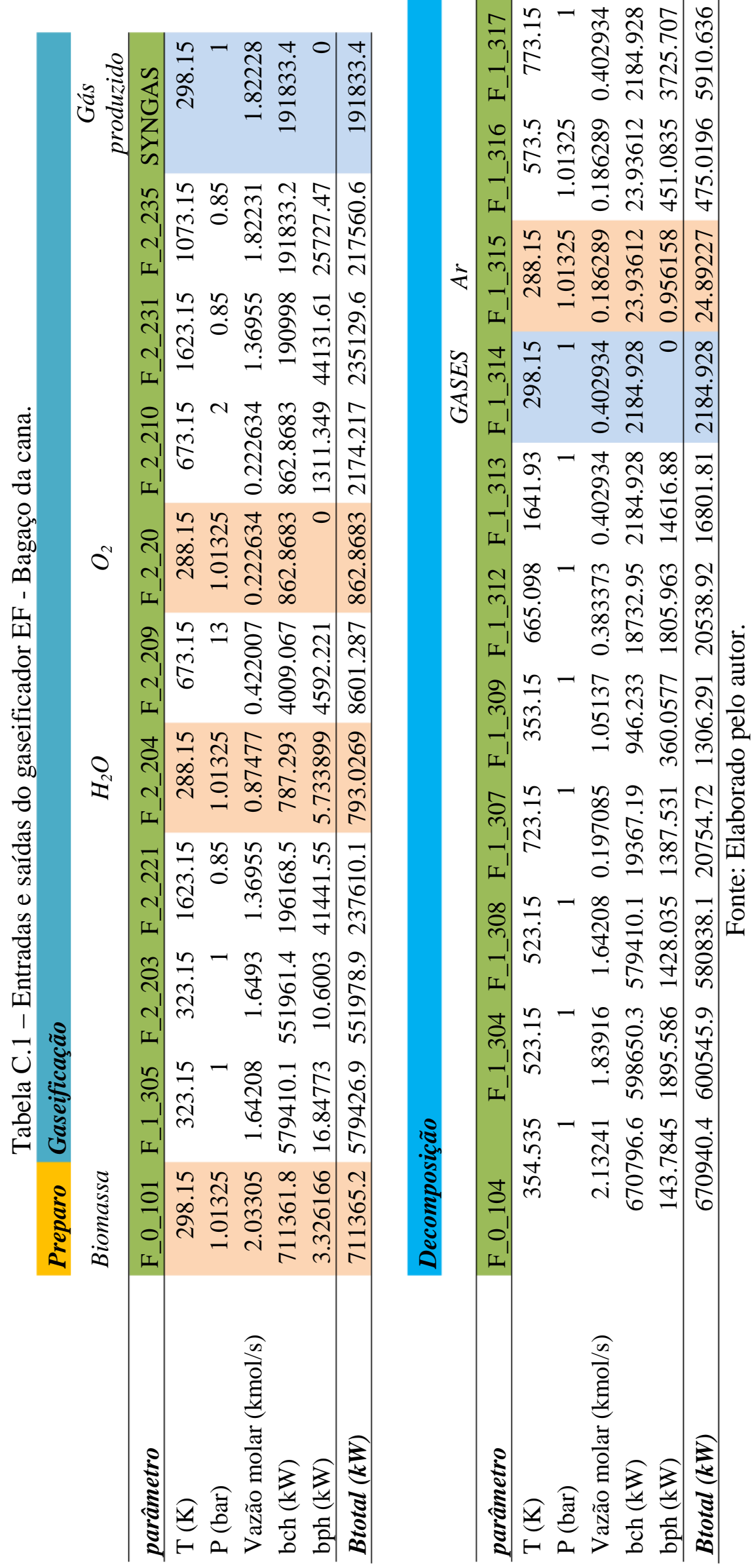



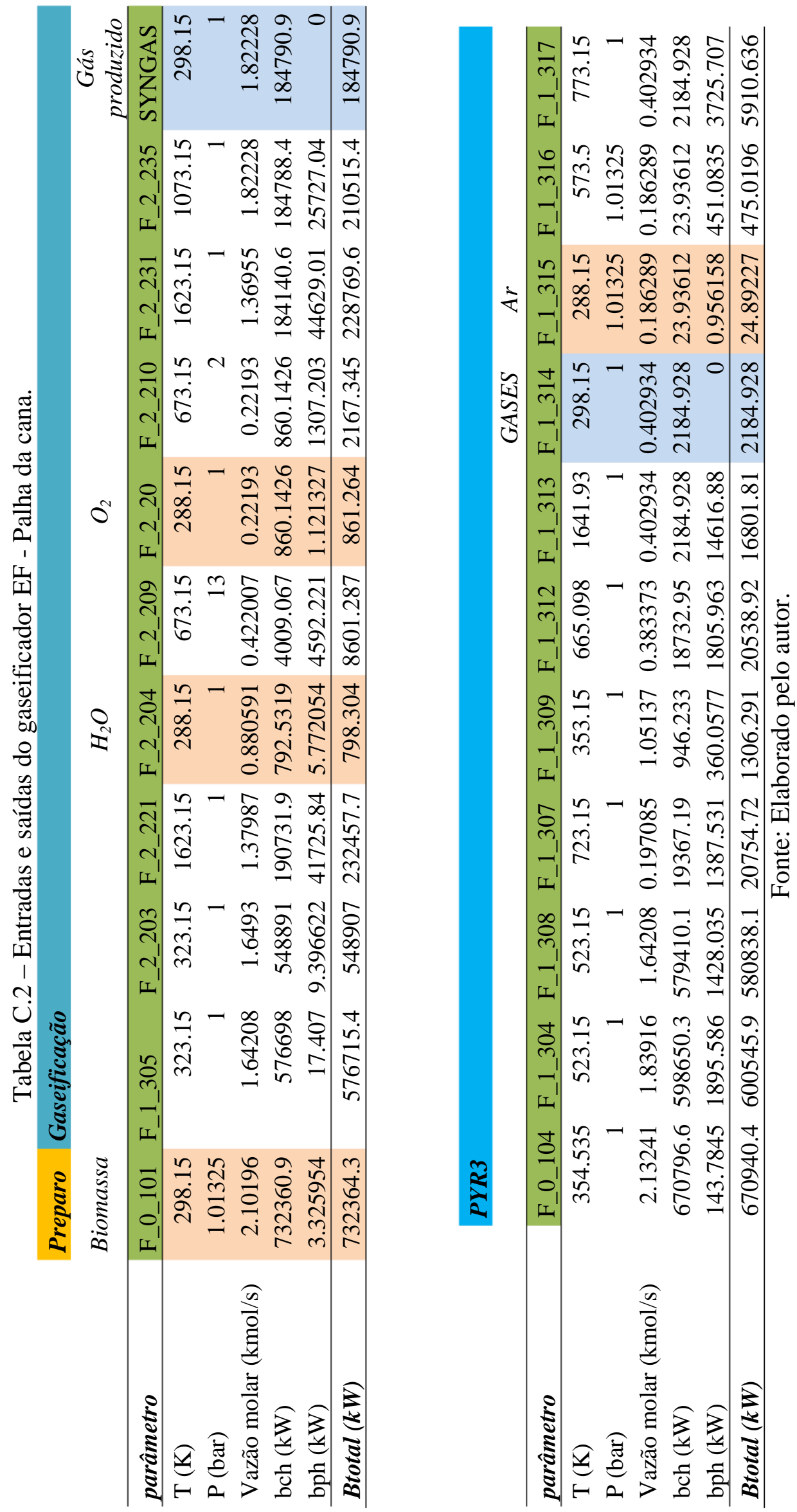


\section{APÊNDICE D. OTIMIZAÇÃO MULTI-OBJETIVO: PLATAFORMA OSMOSE.}

Com o objetivo de definir as configurações ótimas das rotas tecnológicas propostas a plataforma Osmose foi considerada na análise destes sistemas, adotando a metodologia de otimização apresentada na Cap. 4. Nota-se que para a aplicação da otimização multi-objetivo (MOO) foi utilizada como ferramenta matemática Matlab, permitindo a solução do algoritmo evolutivo na versão desta plataforma desenvolvida na linguagem de programação Lua.

Neste apêndice são ilustrados os resultados da avaliação da rota termoquímica envolvendo a sua avaliação global por meio das tecnologias de gaseificação Leito Fluidizado CirculanteCFB e Leito Arrastado-EF (Caso 3 e Caso 4), utilizado o bagaço da cana como insumo.

$\mathrm{Na}$ otimização multi-objetivo da rota termoquímica nestas configurações, uma população inicial de 100 casos foi adotada com um número máximo de 1000 iterações. Assim, a população final representada nas curvas de Pareto compõe-se de cerca de 70 pontos para ambas as funções objetivo, eficiência exergética e custo de investimento.

Ainda, com o intuito de determinar os parâmetros ótimos destas configurações avaliadas foram definidas variáveis as decisão para cada tecnologia. Nesse sentido, na Tab. C.1 serão apresentados ditos parâmetros. Descata-se que na determinação dos custos de investimento dos equipamentos das rotas foram adotadas as premissas apresentadas na Tab. C.2

Tabela C.1 -Parâmetros de análise adotados na avaliação da Rota 2G-Termoquímica.

\begin{tabular}{|c|c|c|}
\hline Variáveis de estado & Faixas & leradas \\
\hline & $C F B$ & $E F$ \\
\hline SB & \multicolumn{2}{|c|}{$0,2-0,8$} \\
\hline ER & \multicolumn{2}{|c|}{$0,1-0,5$} \\
\hline Temperatura de gaseificação ( C ) & \multicolumn{2}{|c|}{$700-900$} \\
\hline Pressão do vapor vivo (MPa) & \multicolumn{2}{|c|}{$6,5-10$} \\
\hline
\end{tabular}

Fonte: Elaborado pelo autor. 
Tabela C.2 -Principais parâmetros utilizados na determinação dos custos de investimento.

\begin{tabular}{|l|c|l|}
\hline Dados & Valor & Unidades \\
\hline Tempo de vida do projeto & 20 & anos \\
\hline Construção e início & 2 & anos \\
\hline Taxa de juros & 10 & $\%$ ano \\
\hline Operação do processo (safra) & 200 & dias/ano \\
\hline
\end{tabular}

Fonte: Adaptado de Albarelli et al. (2015b).

\section{Rota termoquímica - Gaseificador de Leito Fluidizado Circulante}

Na Fig. D.1 é apresentada a otimização multi-objetivo da rota termoquímica global utilizando o gaseficador CFB no sistema de gaseificação. Esta figura representa a fronteira de Pareto, indicando o conjunto de soluções Pareto-ótimo dos objetivos definidos.

Figura D.1 - Otimização multi-objetivo da rota 3-gaseificador CFB.

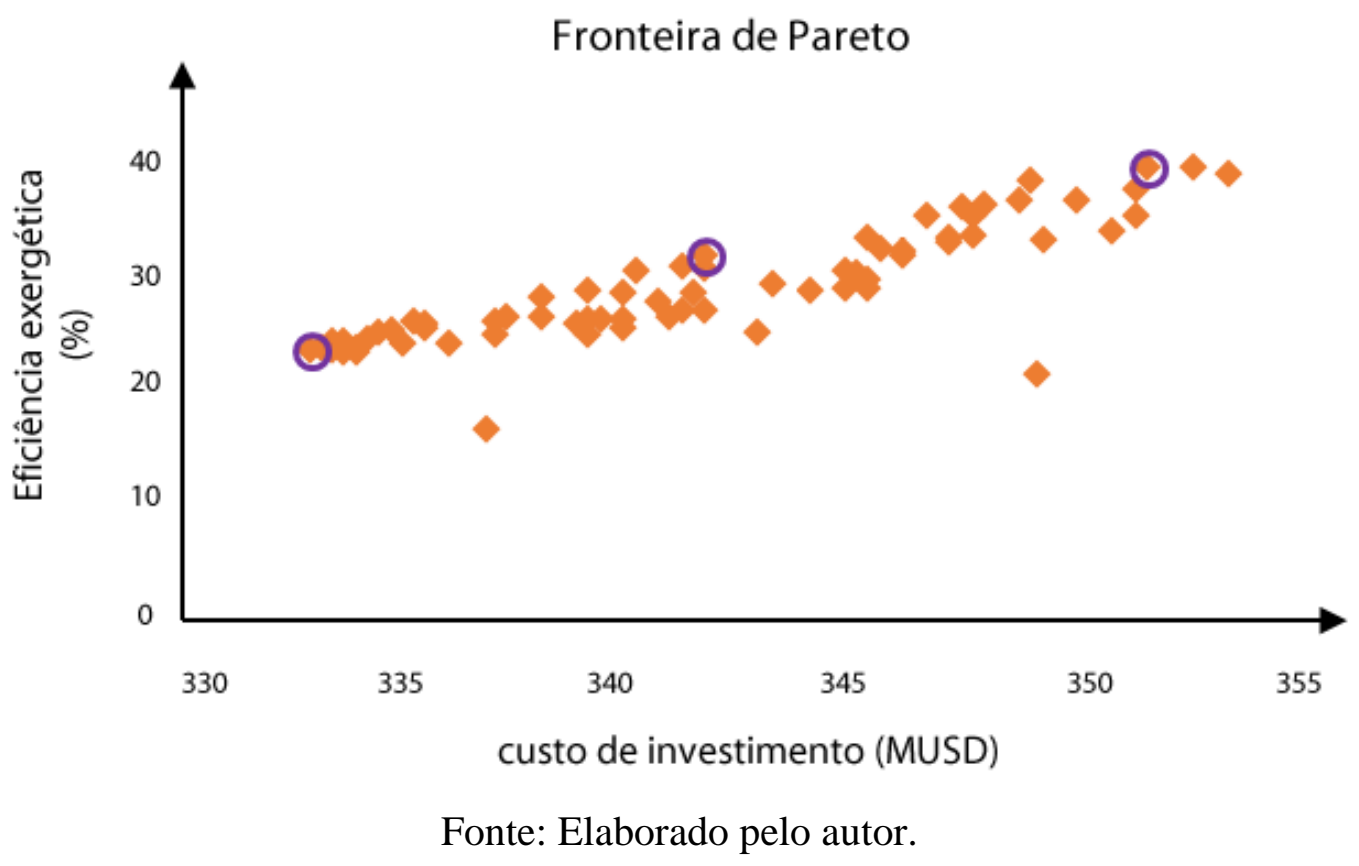




\section{Rota termoquímica - Gaseificador de Leito Arrastado}

Analogamente à anterior análise, na Fig. D.2 apresentam-se os resultados da otimização multi-objetivo desta rota adotando o sistema de gaseificação EF na avaliação global. Note-se a partir desta figura o mapeamento do conjunto ótimo de Pareto no espaço das funções objetivo definidas para o problema em questão.

Figura D.2 - Otimização multi-objetivo da rota 3-gaseificador EF..

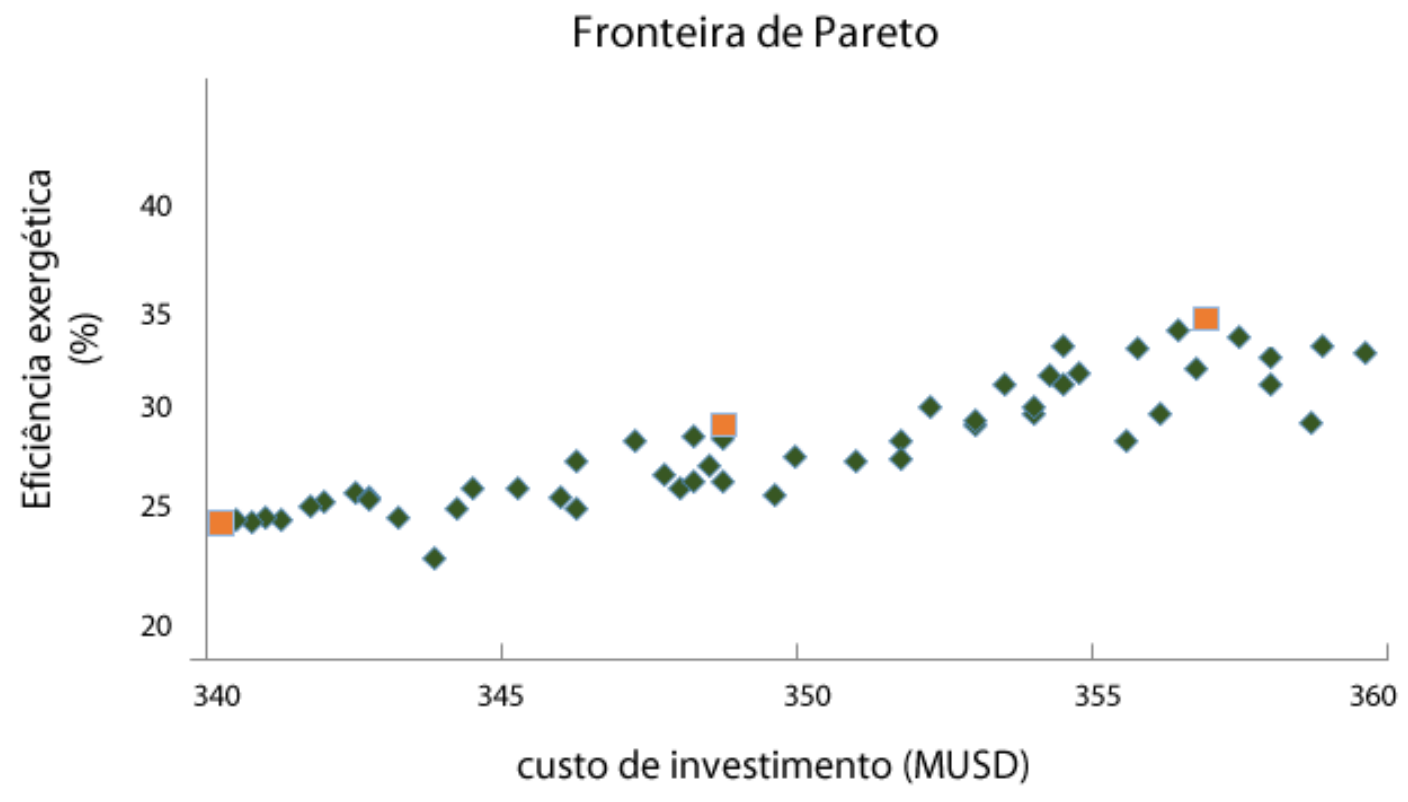

Fonte: Elaborado pelo autor. 


\section{APÊNDICE E. EXPRESSÕES DE RENDIMENTO EXERGÉTICO.}

Unidade de limpeza, extração e preparo (moagem):

$$
\eta=\frac{B_{\text {caldo }}+B_{\text {bagaço }}}{B_{\text {cana }}+B_{H 2 O-e m b}+B_{e-\text { prepext }}+B_{\text {e-moagem }}}
$$

Sendo $B_{\text {e-moagem }}$ e $B_{\text {e-prepex }}$, a energia mecânica consumida para acionamento e a eletricidade consumida nesta etapa.

$\underline{\text { Unidade do tratamento do caldo (clarificação): }}$

$$
\eta=\frac{B_{c 10}}{B_{\text {caldo }}+B_{\text {bagaşiho }}+B_{H 2 O}+B_{C a O}+B_{e-\text { trat }}}
$$

Unidade da concentração do caldo (evaporação):

$$
\eta=\frac{B_{X 30}+B_{\text {condensado }}}{B_{C 10}+B_{\text {utilidade } 2.5}+B_{\text {cond } 1.69}+B_{\text {e-evap }}}
$$

$B_{X 30}$ representa o fluxo exergético da corrente X30, brix do mosto final para fermentação e $\mathrm{B}_{\mathrm{C} 10}$ caldo clarificado. $B_{\text {e-evap }}$ denota a eletricidade consumida nesta etapa, $B_{\text {utilidade2.5 }}$ a utilidade a 2,5 bar, e $B_{\text {cond1.69 }}$ o condensado a 1,69 bar da sangria de vapor vegetal.

Unidade de preparo do mosto e fermentação:

$$
\eta=\frac{B_{\text {vinho }}}{B_{\mathrm{X} 30}+B_{H 2 O}+B_{\text {utilidade } 6}+B_{N H 3}+B_{\mathrm{H} 2 \mathrm{SO} 4}+B_{e-\text { ferm }}}
$$

A exergia da amônia $\left(\mathrm{B}_{\mathrm{NH} 3}\right)$ simula os nutrientes requeridos nesta etapa. Ainda $\mathrm{B}_{\mathrm{H} 2 \mathrm{SO} 4}$, representa a exergia do ácido sulfúrico. 
Unidade de destilação e desidratação:

$$
\eta=\frac{B_{\text {ETANOL }}}{B_{\text {vinho }}+B_{H 2 O}+B_{\text {utilidades }}+B_{M E G}+B_{e-\text { ferm }}}
$$

Sendo $B_{\text {ETANOL }}$ a exergia do etanol anidro e $B_{M E G}$ a exergia do $\mathrm{C}_{2} \mathrm{H}_{6} \mathrm{O}_{2}$ (monoetileno glicol).

Unidade de cogeração:

$$
\eta=\frac{B_{\text {ELETRICIDADE }}+B_{V A P O R}-B_{\text {CONSUMO }}}{B_{\text {bagaço }}+B_{H 2 O}+B_{\text {condensados }}}
$$

$B_{\text {CONSUMo }}$ denota a eletricidade consumida nas etapas do processo.

Por fim, as expressões consideradas na avaliação da eficiência exergética global das rotas tecnológicas são:

$$
\begin{gathered}
\eta_{1}=\frac{B_{\text {ETANOL }}+B_{\text {Eletricidade }}}{B_{\text {CANA }}+B_{\text {PALHA }}} \\
\eta_{2}=\frac{B_{\text {ETANOL }}+B_{\text {Eletricidade }}+B_{\text {subprodutos }}}{B_{C A N A}+B_{\text {PALHA }}-B_{\text {Bagaço }}}
\end{gathered}
$$

Onde $B_{\text {eletricidade }}$ e $B_{\text {bagaço }}$ correspondem às suas parcelas excedentes. 